\title{
MANAGING A MATURE COASTAL TOURISM DESTINATION: \\ THE CASE OF PATTAYA, THAILAND
}

By

\section{Chootima Longjit}

\author{
A thesis \\ submitted to the Victoria University of Wellington \\ in fulfilment of the requirements for the degree of \\ Doctor of Philosophy \\ in Tourism Management
}

Victoria University of Wellington

2010 


\begin{abstract}
This thesis develops the concept of destination management with a particular focus on the management of a local destination. It concentrates on seeking to understand what constitutes the general concept of destination management, exploring management practices, and clarifying the overall management of the local destination. In the absence of previous literature, a conceptual framework is developed from the bodies of literature in tourism, management, inter-organizational relationships, and integrated coastal management. This framework illustrates aspects, issues, and dimensions that are relevant to destination management and provides a structure for the analysis of destination management in Pattaya, Thailand.
\end{abstract}

Given the exploratory nature of the study, a multi-phase case study is used. A mix of holistic and embedded cases is used to obtain broad and in-depth data relevant to the concept and practice of destination management. Pattaya, as one of the major coastal resorts in Thailand, is selected as the case study as tourism has been developed there for several decades and its diverse problems provide a range of management challenges. Its major tourism attractions - beaches, nightlife, Pattaya Music Festival - are examined as embedded cases. In addition to secondary data, semi-structured interviews and observation are used to collect primary data. The broad concept of destination management is developed first and then used as a basis to examine the nature and extent of destination management in Pattaya. The conceptual framework provides a structure to analyze the individual embedded cases and to compare commonalities and differences between their management processes and structures and their implications for the practice of destination management.

The research reveals that there is a relationship between the practitioners' perspectives on a tourism destination and on destination management, and that there is a relationship between their initial perspectives on destination management and their management practices that occur at the destination. Destination management is defined as "the collaboration of relevant agencies responsible for providing multiple tourism products at the destination in a way to achieve common goals or destination goals." The research also highlights that destination management requires the integration of management agencies, of management purposes, and of management 
activities at the destination scale. In Pattaya, varying levels of integration occur and relevant agencies are commonly involved with managing aspects of tourism rather than the destination as a whole. The embedded cases reveal that two main forms of management occur in Pattaya: daily operations and project management. Daily management is practised by single agencies to achieve individual organizational goals and is evident in most aspects of beach management and the management of dispersed nightlife activities. Project-based management involves the pursuit of project goals and is carried out by committees, for example, Walking Street Committee and the Pattaya Music Festival Committees. A lack of common goals and low levels of integration are factors which lead to an absence of destination management. The formulation of destination goals and a scaled-up project management structure is suggested as one means of fostering destination management. 


\section{ACKNOWLEDGEMENTS}

My deepest appreciation and thanks to my principal supervisor, Prof. Douglas G. Pearce, who provided me the opportunity to start this journey. With his guidance and valuable suggestions, patience, and understanding, I successfully completed my study. Big thanks to my second supervisor, Dr. Adam Weaver, for his advice, encouragement, and support throughout my study. A special thanks to Prof. Jafar Jafari, the first person to introduce the key to my success when I decided to start this PhD journey - 'Endurance’ was the key.

I would like to thank all my family members for their moral support. Thank to my wonderful parents for their unconditional love, support, and belief in my ability. I decided to take this journey not only for myself but also for them, especially for my mother since she loves learning and always wants to have a higher education. Thanks to both of my brothers for taking good care of our parents when I was away.

Thank you to my boss and the scholarship committee members at the Faculty of Management Sciences, Kasetsart University Sri Racha Campus for financial support. Without the four years of funds, my life here in New Zealand would have been a struggle and my journey would be difficult to finish.

Thanks to all my friends in New Zealand. Without your friendship, my journey would have been lonely and less enjoyable. I would like to thank P'Garoon, Tam, Aor, Pa, Tarn, Palm, Moa, Bowl, Fa, and Bew for being wonderful brothers and sisters while I was in New Zealand. Thank you to my PhD colleagues: Wayne Pihema (NZ), Marian Evans (NZ), Jorge Velez (Columbia), Karthik Peedikappurath (India), Rebecca Bednarek (NZ), Zanele Ndaba (South Africa), Lois Parkes (Jamaica), Heike Schänzel (Germany), Huong Nguyen (Vietnam), Cesar Guala (Chile), and Saurabh Jain (India) for the laughs and tears that we shared. It was a great experience to have known you.

Last but not the least, I would like to thank all my research participants for their cooperation and valuable input of empirical materials. Thank you all for being a part of this research. Without you, this thesis would not have been possible. 


\section{TABLE OF CONTENTS}

\section{CHAPTER 1 INTRODUCTION: DESTINATIONS AND DESTINATION

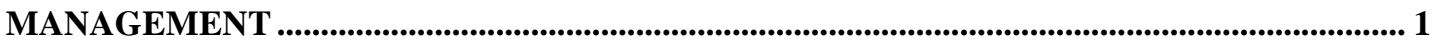

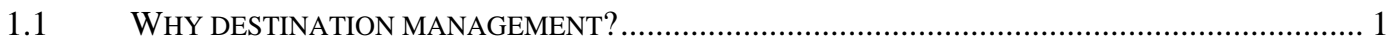

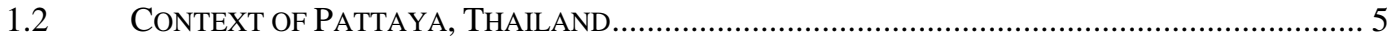

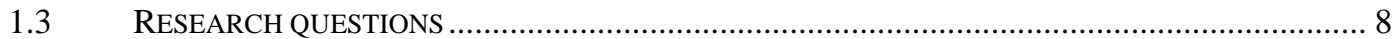

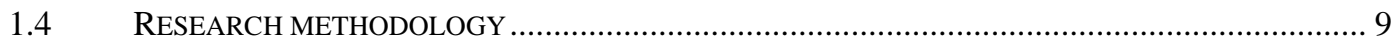

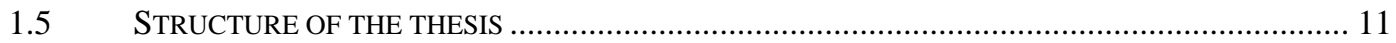

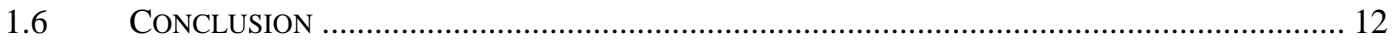

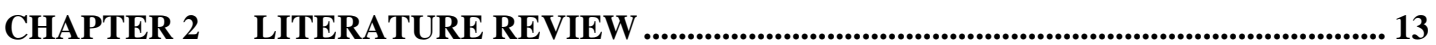

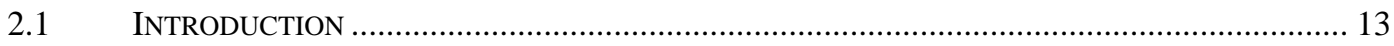

2.2 TOURISM DESTINATIONS AND THEIR DEVELOPMENT ………………….......................... 13

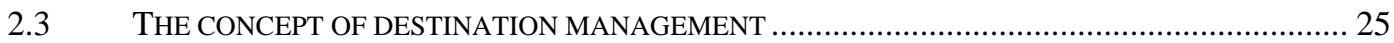

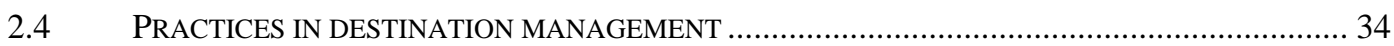

2.5 A CONCEPTUAL FRAMEWORK FOR DESTINATION MANAGEMENT …...................................... 45

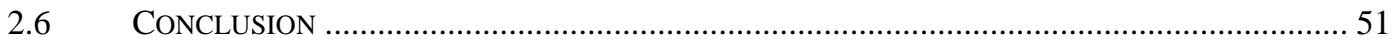

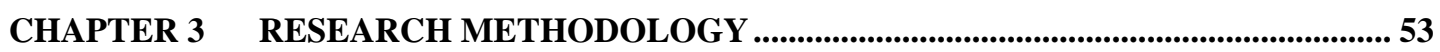

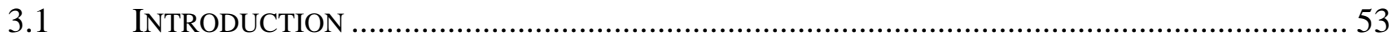

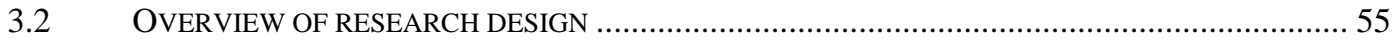

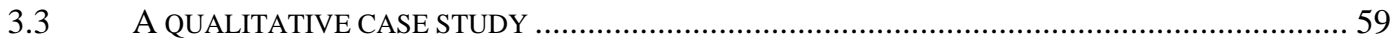

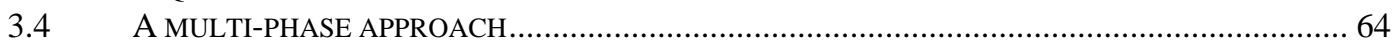

3.5 LIMITATIONS OF THE RESEARCH METHODOLOGY …............................................................ 87

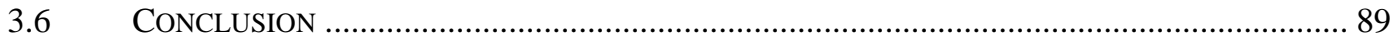

CHAPTER 4 THE RESEARCH CONTEXT: THAILAND AND PATTAYA ......................... 92

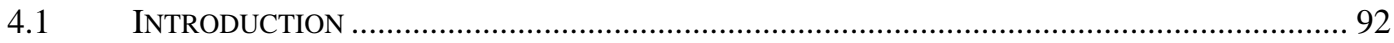

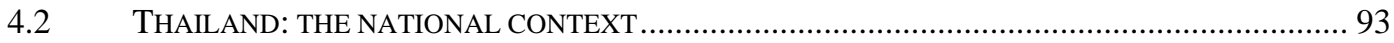

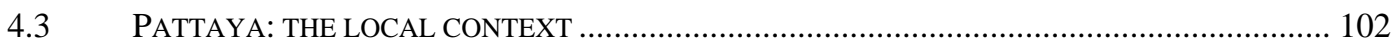

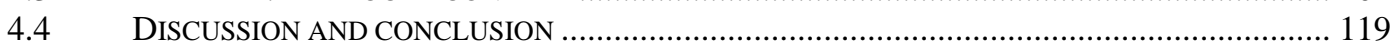

CHAPTER 5 CONCEPTS OF A TOURISM DESTINATION AND DESTINATION

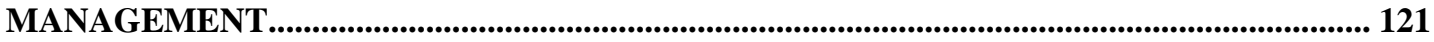

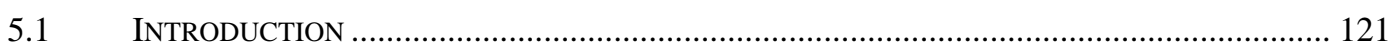

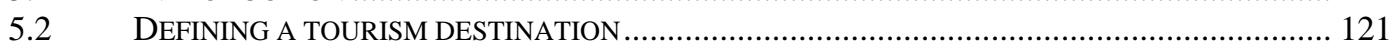

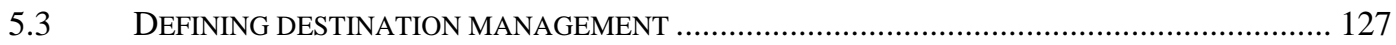

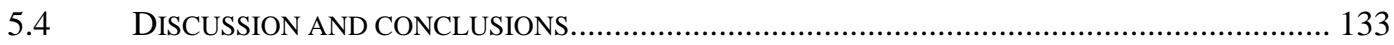

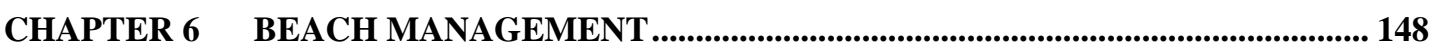

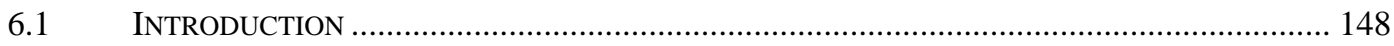

6.2 THE CHARACTERISTICS OF THE BEACH ZONE ……………………….......................... 149

6.3 MANAGEMENT AGENCIES AND THEIR PURPOSES ............................................................ 154

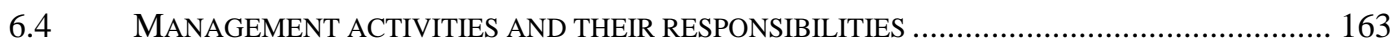

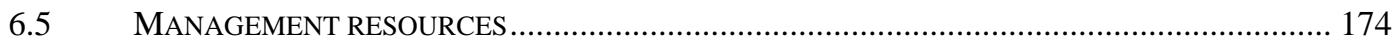

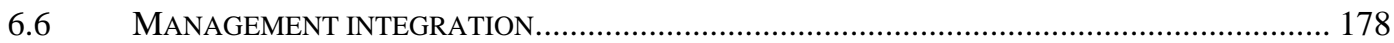

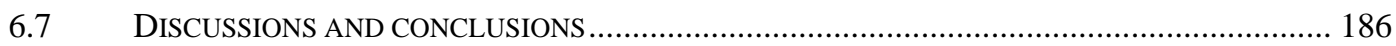

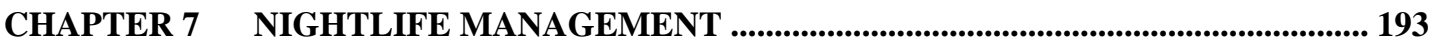

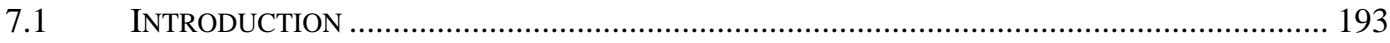

7.2 THE CHARACTERISTICS OF NIGHTLIFE ATTRACTIONS ............................................................ 193

7.3 MANAGEMENT AGENCIES AND THEIR PURPOSES .............................................................. 199

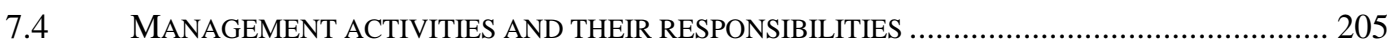

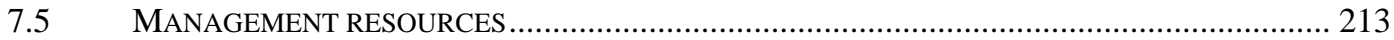

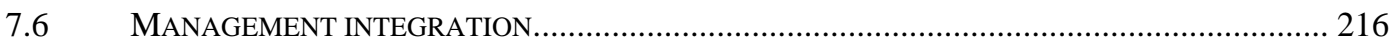

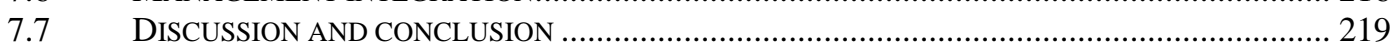


CHAPTER 8 FESTIVAL MANAGEMENT: THE PATTAYA MUSIC FESTIVAL ........... 225

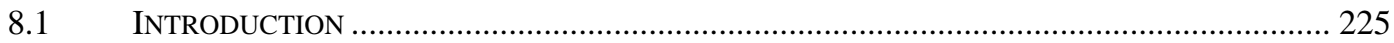

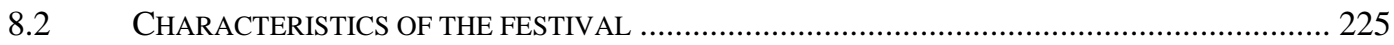

8.3 MANAGEMENT AGENCIES AND THEIR PURPOSES ……............................................... 230

8.4 MANAGEMENT ACTIVITIES AND THEIR RESPONSIBILITIES …………………................. 234

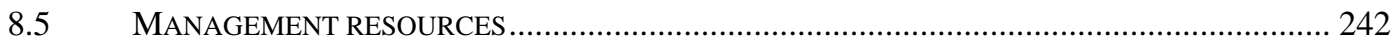

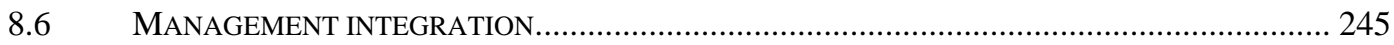

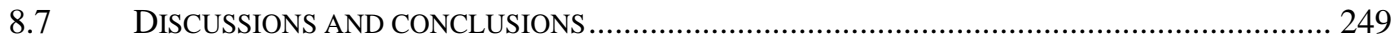

CHAPTER 9 DESTINATION MANAGEMENT IN PATTAYA................................................. 254

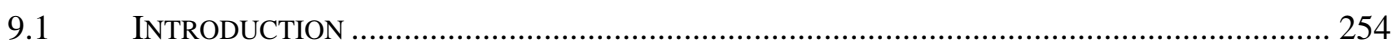

9.2 THE CONCEPTS OF DESTINATION MANAGEMENT ………….............................................. 254

9.3 PRACTICES OF DESTINATION MANAGEMENT IN PATTAYA ……………………................... 259

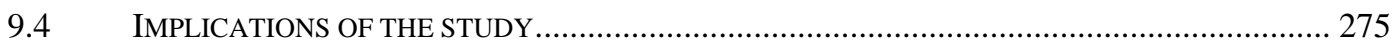

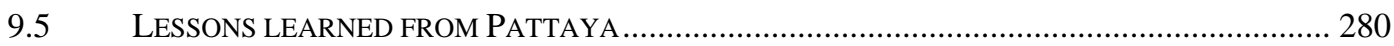

9.6 RECOMMENDATIONS FOR THE MANAGEMENT AGENCIES................................................ 286

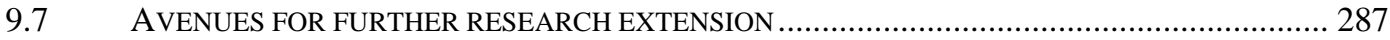

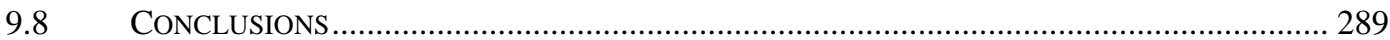

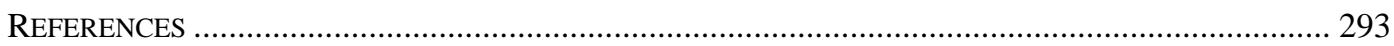

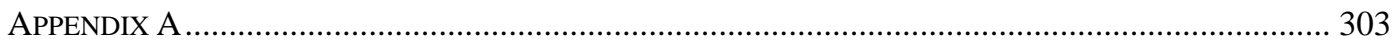

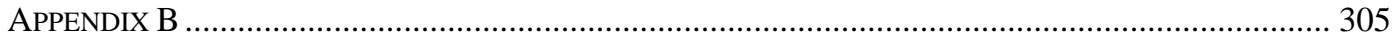

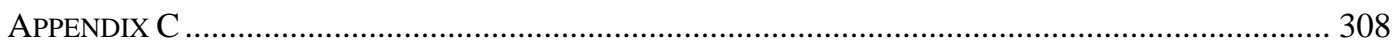




\section{List of Tables}

Table 2.1: Changing characteristics within the Butler sequence. ............................ 19

Table 2.2: Parallels between managing a firm and a tourism destination.................. 30

Table 2.3: Features and levels of management integration...................................... 50

Table 3.1: Names and scales of databases used for data collection..........................68

Table 3.2: A framework for Phase I analysis...........................................................6 68

Table 3.3: Phase II interview respondents from different sectors and administrative

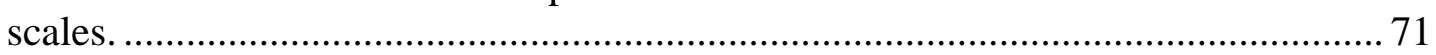

Table 3.4: Examples of documents collected in Phase II......................................... 73

Table 3.5: A framework for Phase II analysis............................................................ 74

Table 3.6: Pattaya's characteristics perceived by nineteen respondents. ................... 76

Table 3.7: Pattaya's characteristics perceived by different organizational levels of

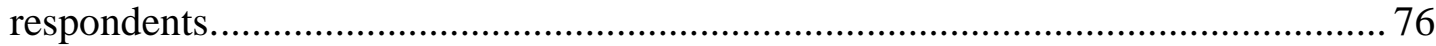

Table 3.8: Pattaya's characteristics perceived by different types of respondents'

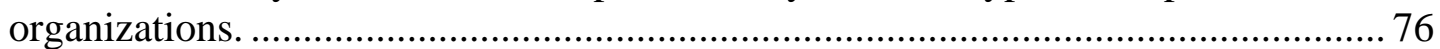

Table 3.9: Key themes identified during Phase II of the study................................. 77

Table 3.10: Phase III interview respondents from different sectors and administrative

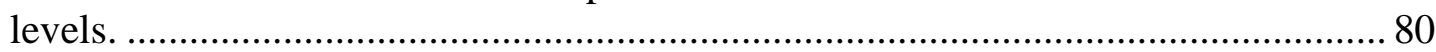

Table 3.11: Additional interview respondents from the private sector....................... 81

Table 3.12: Examples of contextual data collected in Phase III. ................................ 83

Table 3.13: Analytical framework for attraction management process...................... 84

Table 3.14: Analytical framework for the practice of destination management........ 87

Table 4.1: Thailand tourist arrivals and tourism revenue from 1996 to 2006............ 98

Table 4.2: Pattaya tourists' arrivals and tourism revenues in 1996 to 2006 ............. 107

Table 5.1: A summary of key aspects of a tourism destination defined by the practitioners

Table 5.2: A summary of key aspects of destination management defined by the

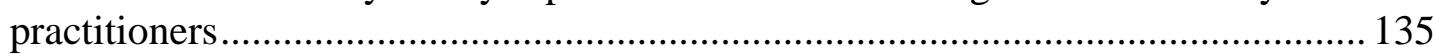

Table 5.3: A summary of the practitioners' perspectives of TD and DM................ 138

Table 5.4: Key aspects of TD and DM from the practitioners and the literature..... 140

Table 5.5: Broad concepts of TD and DM used in the study................................... 145

Table 6.1: Examples of regulations for the beach umbrella services on Pattaya Beach.

158

Table 6.2: Key agencies and their management purposes. ..................................... 159

Table 6.3: Examples of organisational goals of key agencies. ................................ 160

Table 6.4: Management agencies and their responsible activities. ..............................165

Table 6.5: A summary of beach management practice........................................... 187

Table 7.1: Examples of nightlife businesses in Pattaya ........................................... 194

Table 7.2: Management agencies and their management purposes.......................... 202

Table 7.3: Visions of key public agencies involved in managing Pattaya's nightlife.

Table 7.4: Management activities undertaken by particular agencies. .................... 206

Table 7.5: Resource management in managing Pattaya's nightlife.......................... 214

Table 7.6: A summary of nightlife management in Pattaya...................................... 220

Table 8.1: Thailand Grand Festivals organized by Tourism Authority of Thailand.

226

Table 8.2: A summary of management agencies involved in the different committees.

Table 8.3: Management activities and responsible agencies. ............................... 237 
Table 8.4: A summary of management practices for Pattaya Music Festival.......... 250

Table 9.1: A summary of key finding of destination management in Pattaya......... 260

Table 9.2: Public and private agencies involved in managing Pattaya's attractions.269

Table 9.3: Management activities undertaken in Pattaya........................................ 272 


\section{List of Figures}

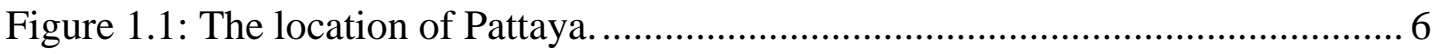

Figure 2.1: Structure and hierarchy of command of a tourism firm. ........................ 31

Figure 2.2: The broad management structure of the tourism destination. .................. 33

Figure 2.3: Horizontal and vertical differentiation of destination management

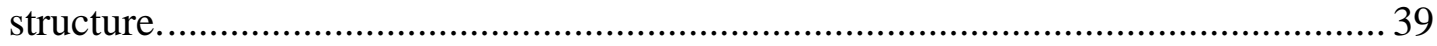

Figure 2.4: Forms of organizational interactions.................................................... 40

Figure 2.5: A conceptual framework for destination management analysis............. 46

Figure 3.1: A flowchart of research methodology..................................................... 56

Figure 3.2: A summary of four phases of data collection and analysis. ..................... 65

Figure 3.3: Analytical framework for the general concept of destination management.

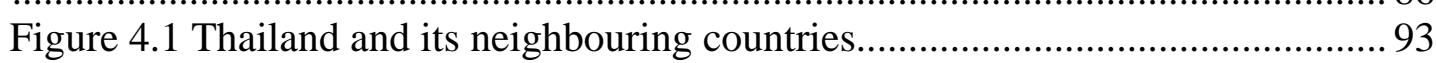

Figure 4.2 Structure of Thai Public Administrative System.................................... 95

Figure 4.3: An organizational chart of the Ministry of Tourism and Sports of

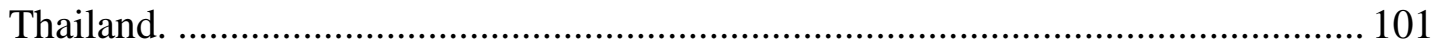

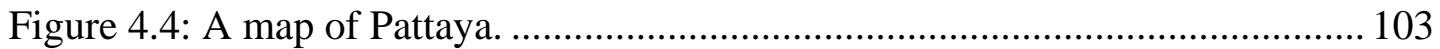

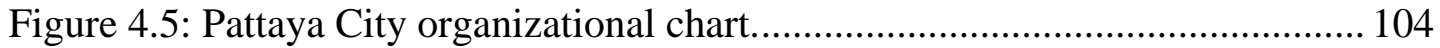

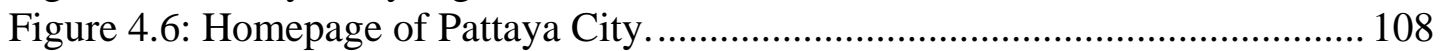

Figure 4.7: Marketing activities to promote Pattaya's tourism................................ 109

Figure 4.8: Beaches in Pattaya and Larn Island.................................................... 110

Figure 4.9: Pattaya's Nightlife, Walking Street, and other entertainment attractions.

Figure 4.10: Cultural events and Pattaya Music Festival in Pattaya........................ 112

Figure 6.1: Geographical and physical characteristics of Pattaya Beach................. 150

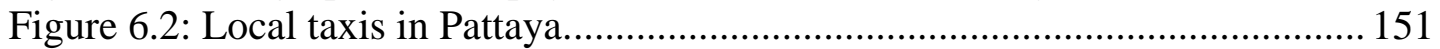

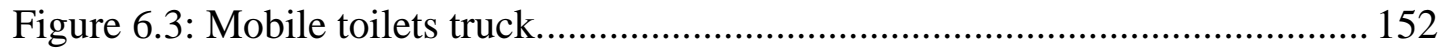

Figure 6.4: Key agencies involved in beach management..................................... 155

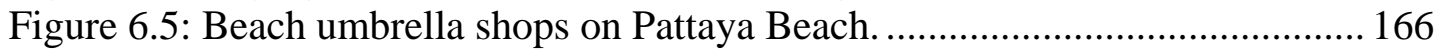

Figure 6.6: The organization of the beach and marine resources. .......................... 167

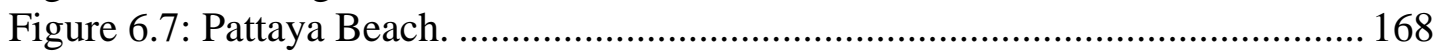

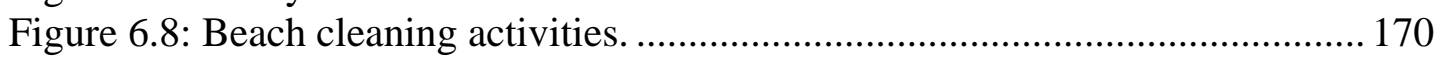

Figure 6.9: Activities to improve natural resources.............................................. 171

Figure 6.10: Public notices of star rating system for beach quality identification... 172

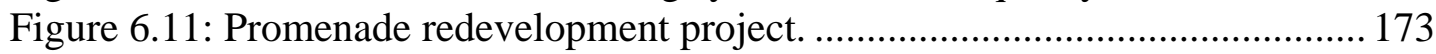

Figure 6.12: The dyadic relationship between Pattaya City and other public agencies.

Figure 6.13: The dyadic relationship between the public agencies and the private agencies.

Figure 6.14: The dyadic relationship between other public agencies and the beach vendors

Figure 6.15: A mix of dyadic relationships between Pattaya City and other public agencies and between Pattaya City and the private agencies.

Figure 6.16: The set relationship between Pattaya City and other public agencies. 183

Figure 6.17: Areas of jurisdiction in the safety project on Pattaya Beach............... 185

Figure 7.1: Nightlife businesses in Walking Street and those dispersed elsewhere

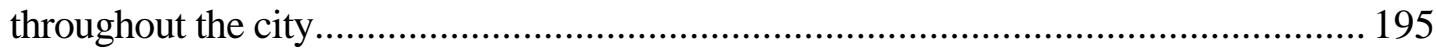

Figure 7.2: Pictures of Walking Street............................................................ 197

Figure 7.3: Examples of nightlife businesses located outside Walking Street. ....... 198 
Figure 7.4: Key agencies involved in managing Pattaya's nightlife. ...................... 200

Figure 7.5: The entrance to Walking Street at night (A and B)............................. 208

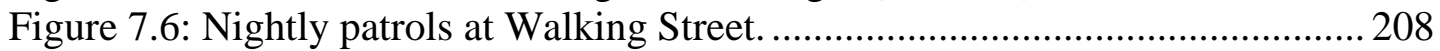

Figure 7.7: Festivals and events held in Walking Street...................................... 212

Figure 7.8: The network relationship of the Walking Street Committee................. 218

Figure 8.1: An example of a brochure that provides information regarding the festival

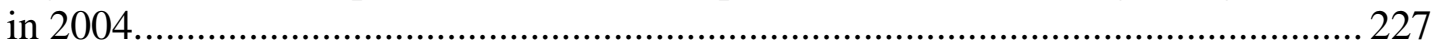

Figure 8.2: Locations of the stages in A, 2003 and B, 2004 .................................. 229

Figure 8.3: Management structure for Pattaya Music Festival. ............................... 230

Figure 8.4: The project information for Pattaya Music Festival (2002)................. 233

Figure 8.5: Brochures and stickers provided to the public. ................................... 238

Figure 8.6: Security at Pattaya Music Festival. ...................................................... 239

Figure 8.7: Hundreds of stalls crowded along Beach Road at the festival. ............. 240

Figure 8.8: First aid and medical treatment at the festival..................................... 241

Figure 8.9: A set relationship between Pattaya City and other agencies in broad

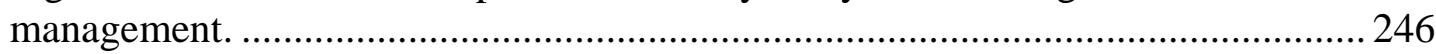

Figure 8.10: A network relationship of relevant agencies in a particular committee.

Figure 9.1: Maximizing management integration at the local destination. 


\section{Chapter 1 Introduction: Destinations and Destination}

\section{Management}

\subsection{Why destination management?}

Tourism has become one of the largest and fastest growing economic sectors in the world since 1950 and many countries have invested in tourism development (WTO, 2008). Today more than seventy countries receive at least 100,000 international tourist arrivals per year (WTO, 2009). Various types of tourism have been developed in these destinations. Mass tourism, nature-based tourism, cultural tourism, educational tourism, and medical tourism are examples. To attract tourists, these destinations need to compete with each other and with emerging destinations.

In order to compete with other destinations, a destination must provide quality tourism products and related services to tourists. The concept of sustainability becomes vital for the destination since it is believed to create destination competitiveness in the tourism market (Ritchie \& Crouch, 2003). In turn, a competitive destination results in sustainability for the local economy, environment, and society. The virtuous cycle of these two concepts can benefit all stakeholders at the destination. This indicates a necessity to move beyond tourism development and draws more attention to destination management - the practices that might foster the sustainability and competitiveness of destinations.

Theoretically, a destination needs to be managed to sustain its tourism resources, to provide quality tourism products and related services, and to be competitive in the tourism market. This is a challenging task. Moreover, tourism-related issues that emerge through the destination's development life cycle may bring more challenges to its management. As destinations reach more advanced stages of development, more complex issues and more negative tourism impacts seem to occur. The final stage of destination development, consolidation/stagnation (Weaver \& Lawton, 2002), seems to be the most challenging for destination management. This can be clearly seen in many mature destinations, particularly coastal resorts. Pattaya, for example, has been developed as a major coastal resort in Thailand for more than four 
decades. At present, Pattaya faces many problems related to its natural environment, economy, and society (Pattaya City, 2005), which seems to bring difficulties and challenges to its management. How a mature destination, such Pattaya, is managed to solve problems, to attract tourists, to sustain tourism resources, and to compete with other destinations underlies the researchers' interest in studying destination management.

However, the concept of destination management has appeared quite recently in the tourism literature and there are few studies from a management perspective (e.g., Carlsen, 1999; Flagestad \& Hope, 2001; Sainaghi, 2003; Welford \& Ytterhus, 2004; Westermann, Pohle, \& Sehl, 2005). A lack of clarity about this notion still exists. Therefore, this thesis seeks to fill that gap and broaden our understanding regarding destination management. It intends to clarify this view by developing the general concept and identifying its key aspects with respect to the management of a local destination. The thesis examines the management of a mature coastal tourism destination, Pattaya, with a particular focus on the management of major tourism attractions: beaches, nightlife attractions, and the Pattaya Music Festival that had been identified by practitioners as crucial to the resort's continued success. Emphasis is given to management structure and process. The general concept of destination management developed in this study is used to reflect on the practice of destination management in Pattaya, thereby allowing key aspects of destination management to be identified.

In the review of the tourism literature, various issues relevant to tourism destinations and destination management can be found, and they are briefly discussed in the following sub-sections. These issues provide the focus for in-depth research on the topic. They will be discussed in more detail in Chapter 2. In other sections of this chapter, the research context, the research questions and thesis objectives, and the thesis structure are presented.

\subsubsection{What is a tourism destination?}

Before discussing destination management, it is necessary to understand what a tourism destination is. In the tourism literature, the term 'tourism destination' seems 
to be defined differently depending on the views that tourism scholars have. The definition of a tourism destination in terms of its geographical location, the content of a destination, and cooperation in terms of tourism production (Framke, 2002) is an example. Agreement on a definition of a destination seems to be lacking (Laws, 1995). Several factors account for this.

First, a destination is perceived at various geographical scales, ranging from a small attraction, a self-contained resort, a village or a town or a city, a province or a state, to a region or a country (Cho, 2000; Ritchie \& Crouch, 2003; Weaver \& Lawton, 2002). Among various geographical scales of the destination, a village or a town or a city seems to be a scale at which most tourism activities occur (Leiper, 1997). This scale is also a focus of this study and is referred throughout the thesis using the terms 'the local destination' and 'the destination scale'.

Second, at the local scale, various tourism products and services are required at the destination to provide for tourists. They include natural and cultural attractions, accessibility, suitable amenities, and security (Cho, 2000; Leiper, 1997) and can be categorized differently. For example, they are categorized into primary and secondary tourism elements (Laws, 1995; Ritchie \& Crouch, 2003) or they are categorized through various service sectors such as attractions, accommodation, food service, and transportation (Pizam, 2000). This in turn usually means that multiple tourism stakeholders are involved at the destination. These tourism stakeholders can refer to the public sector: government agencies and tourism organizations; non-profit organizations and associations; the private sector: businesses, investors and operators; local residents; and the tourists themselves (Bramwell, Henry, Jackson, \& Stradten, 1996; Hardy \& Beeton, 2001; Liu, 2003; Sautter \& Leisen, 1999).

These factors seem to lead to various definitions of a tourism destination being employed by tourism scholars. From a management point of view, it is necessary to understand how the destination managers perceive and define this term. A general concept of a tourism destination, drawn from tourism scholars and destination managers, needs to be developed to understand the notion of destination 
management. Thus, the practitioners' views regarding a tourism destination may bring about an understanding of their views regarding destination management.

\subsubsection{What is destination management?}

In the tourism management literature, the term 'destination management' seems to be defined differently depending on how the destination is perceived. As a consequence, agreement on a definition of destination management does not seem to exist. Several issues in relation to destination management are present in the literature.

First, multiple agencies from different operational sectors and administrative scales appear to be involved in destination management. These agencies can come from public or private sectors or community representatives (Ritchie \& Crouch, 2003; Sheehan \& Ritchie, 2005; UNEP, 2005). They can exist at various administrative scales such as the national, provincial, and municipal (Page, 2003; Ritchie \& Crouch, 2003). Their responsibilities may vary. Marketing management, operation management, and human resource management are examples (Page, 2003). Coordination and cooperation between all agencies to carry out these tasks, to produce quality tourism products and services, and to enhance destination identity appear to be crucial.

Second, given the multiple agencies and various responsibilities, a lack of clarity in management structure is generally present. Although the perspective of coordination and cooperation is suggested in many tourism studies, such as stakeholder interactions (e.g., Caffyn \& Jobbins, 2003; Sheehan \& Ritchie, 2005) and collaboration and partnerships (e.g., Bramwell \& Lane, 2000), many of these studies relate to planning and policy making in tourism development (e.g., Dredge, 2006a; Medeiros de Araujo \& Bramwell, 2000; Sautter \& Leisen, 1999). Few of them relate to the ongoing management of destinations (e.g., Augustyn \& Knowles, 2000; Plummer, Kulczycki, \& Stacey, 2006). A form of partnership developed by public sector, private sector, and communities is suggested as an example of collaboration between relevant agencies for destination management (Jamieson, 2006; Ritchie \& Crouch, 2003). How these practices occur at the local destination is still unclear. Apart from the partnership, a form of hierarchy seems to exist between some 
agencies, particularly in the public sector. As stated by Page (2003), hierarchical management, which is characterized by different levels of power, authority, and status, can exist in management organizations. These highlight a necessity for an indepth study to explore the involvement and management structure of relevant agencies in managing the local destination.

The issues of multiple managers, unclear roles and responsibilities, and unclear management structures represent key dimensions relevant to the notion of destination management. They also address the main thrust of this thesis. From a management point of view, it is also necessary to understand how management agencies define and perceive destination management and how their views can reflect their current management practices. Thus, the concept of destination management needs to be developed and used to examine the management that is practised at the destination.

To pursue this research, Pattaya is selected as a case study as diverse and complex issues and problems existing there make it a very appropriate place to examine destination management. The study of destination management in Pattaya can bring insight into how a tourism destination is managed and bring about a better understanding of the notion of destination management.

\subsection{Context of Pattaya, Thailand}

Tourism has been used as an economic development tool by the Thai government since 1979. In 1995, five major destinations: Bangkok, Chonburi - Pattaya, Chiangmai, Songkla - Had Yai, and Phuket earned more than US\$400 million from tourism (Anon., 2001). At present, these five destinations still play an important role in attracting tourists into the country. Excluding Bangkok, Pattaya has an advantage over the other four destinations in its location (approximately 80 kilometres from Bangkok; see Figure 1.1) and in the provision of various tourism activities to various types of tourists. Furthermore, the 2005 Thailand Tourism Marketing Plan included Pattaya in the cluster of beach and seaside products as one of the main tourism products for overseas markets (TAT, 2005) 
Figure 1.1: The location of Pattaya.

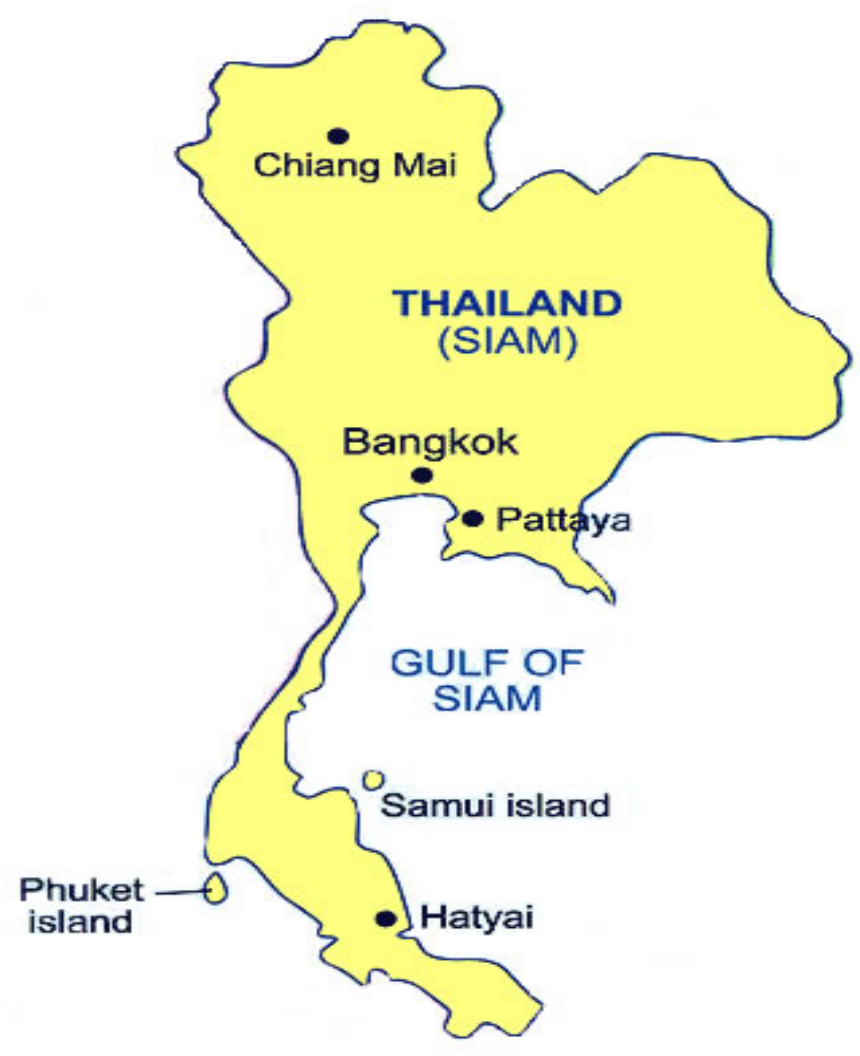

Source: modified from google.com (2005)

Over four decades of tourism development, Pattaya has played an important part in generating revenue for the regional and national economy. It was officially developed as a tourism destination to cater for American soldiers in the Vietnam War period. Since 1959, major developments in infrastructure, services, and entertainment businesses have been established (Pattaya City, 2004). At present, diverse tourism products and services draw large numbers of tourists and inject a large amount of money into the city and the country. For example, in 2003, tourist numbers in Pattaya exceeded 4.2 million and tourism injected more than US\$800 million (approximately NZ\$1,000 million) into the Thai economy (Pattaya City, 2004).

Given its economic importance, Pattaya should be managed in a way to provide quality tourism and to maintain its tourist numbers. However, after more than forty years of development, this resort city has now reached the stage of maturity. Overdevelopment and intensive usage of its natural resources has degraded the marine ecosystem and seawater quality and caused environmental problems for Pattaya. 
Major physical, environmental, economic, social, and political problems are present (Pattaya City, 2004; Smith, 1992). Examples include congestion and insufficient water supply in the summer season, garbage, water pollution, poor drainage, degradation of natural resources, cultural conflict, prostitution, drugs, and crime. These problems in Pattaya raise a question about who is responsible for managing Pattaya and solving these problems.

In the management of the city and to address the problems, various agencies, particularly from the public sector, seem to be involved, such as Pattaya City, the provincial government, the local police, and the local tourism organization. Various agencies seem to be involved in managing Pattaya but their roles and responsibilities are unclear or overlap. For example, a Central Region 3 office of the Tourism Authority of Thailand is responsible for Pattaya's tourism marketing and promotion, but Pattaya City also works on marketing and promotion. Some cooperation between public and private agencies appears to occur in Pattaya. For instance, a meeting in March 2005 for the planning of a tourism marketing promotion for Pattaya and Chonburi province involved representatives from the public sector (i.e., Pattaya's Mayor, an officer from TAT Central Region 3 office), private sector (i.e., Thai Hotels Association: Eastern office, association of Pattaya Hotel Business), and community (i.e., an academic institution) (Chonburi108, 2005a). Another example is financial cooperation for public relations and an advertising campaign to promote tourism in Pattaya by the public and private sectors (Chonburi108, 2005b). How and to what extent cooperation occurs is unclear.

Pattaya's physical characteristics and managerial issues, which will be discussed in more detail in Chapter 4, underline the need to explore the management practices there. In short, Pattaya represents a very appropriate focus for examining the management of a mature coastal tourism destination because:

- It is one of the main coastal tourism destinations in Thailand, which makes a major contribution to the country's economy.

- Its tourism industry has been developed for more than 40 years, and is still focused on more development. 
- The problems in Pattaya are diverse and complex, which requires good management practice to solve all those problems.

- Although Pattaya has a local self-government system and is managed independently, there seems to be some cooperation between public and private sectors, and between different scales of public organizations such as Pattaya City Council, TAT Central Region 3 office, and the provincial government.

- It provides an opportunity to study diverse agencies, activities, and functions in managing Pattaya as a tourism destination.

\subsection{Research questions}

This thesis addresses the issue of destination management, clarifies what it is, and examines whether it is practised in Pattaya. The two main research questions addressed are:

- What is destination management?

- Is destination management practised in Pattaya?

Regarding the concept of destination management, the study will focus on what constitutes destination management, drawing from the practitioners' perspectives and from the tourism literature. Since the practitioners are directly involved in destination management, their views can provide insights into the notion from a management point of view. Moreover, their views may reflect management practices at the destination scale.

The concept of destination management that is developed will then be used as the basis to examine whether destination management is practised in Pattaya. This involves consideration of such questions as which agencies manage aspects of tourism in Pattaya, what are their responsibilities, and how are they involved at the local destination. Management structures, activities, processes, and levels of integration will also be considered. Since this study aims to clarify the processes and practices of managing a destination as a whole, research methods that enable the researcher to systematically define and clarify relevant issues are taken into account. 


\subsection{Research methodology}

Given the breadth of issues to be covered in this exploratory research, a qualitative multi-phase case study is adopted to study destination management in Pattaya. A mix of holistic and embedded case studies is intentionally used to access broad and indepth information that is relevant to destination management. This research focuses on current management practices and does not attempt to analyze past management practices, but its findings might influence what may happen in the future.

A conceptual framework of destination management is developed from related sets of literature: tourism management (Page, 2003), principles of management (Sisk, 1969), and principles of integrated coastal management (Turner, Adgar, Crooks, Lorenzoni, \& Ledoux, 2001). In the tourism management literature, tourism supply and tourist demand are two fundamental areas that require management at the destinations. The tourism supply must be provided at the destination. At the same time, tourist demand is important and needs to be understood by the supply side. Then, tourism suppliers can respond to different types of demand. In the principles of management literature, the management process is viewed by using a systems approach. Regarding this concept, various dimensions of management structure and management process can be identified. In the integrated coastal management literature, multiple dimensions of integration are identified. Although this literature focuses solely on coastal management, the principles seem to apply to all types of tourism destinations. Examples are the integration of programmes and plans for economic development, environmental quality management and coastal management, and integration of responsibilities across different levels of government - local, provincial, regional, national and international - and between public and private sectors. This conceptual framework is used to provide a structure for analysing the practice of destination management

Four phases of data collection and analysis are undertaken in the study: conceptualization of the broad subject area and development of interview questions, development of preliminary insights into the management structure in Pattaya, background information on the tourism management process in Pattaya, and a final analysis for a holistic view of destination management (see Figure 3.1). The first 
phase provides broad information about tourism issues and tourism management in Pattaya. The second phase provides preliminary insights into management structures in Pattaya. The third phase provides descriptive information on management structures and processes in managing Pattaya's tourism. The fourth phase is the final analysis of the concept and practice of destination management. The information regarding management agencies, their responsibilities, purposes, and management resources are collected and analyzed using the conceptual framework. The concept of destination management is also developed in the study.

The first phase was undertaken in January and February 2006. Since this phase was intentionally selected to conceptualize the framework without visiting the study site, on-line documents were reviewed to develop general information regarding current tourism conditions and issues in Pattaya. The interview questions were developed and the primary interview respondents were also identified in this phase. The second phase was carried out from March to mid May 2006. The data collected in this phase identified information related to tourism characteristics, management agencies, activities, and functions in managing tourism in Pattaya. The broad concept of destination management was also developed in this phase. The methods to access information in this phase were document analysis, semi-structured interviews, and informal site observation. In the field, contextual data were also compiled. Preliminary analysis was taken to identify major issues to be selected as the subcases for in-depth study in the next phase. Other issues rarely identified by the analysis such as social and cultural issues were largely excluded by the study. In the third phase of research, interview questions were developed and the respondents were identified. This phase of study was undertaken from September to December 2006. Semi-structured interviews, document analysis, and formal and informal site observation were used to access in-depth information regarding the management of the beaches, nightlife attractions, and Pattaya Music Festival: the selected sub-cases. The broad concept of destination management developed in the previous phase was cross-checked with the respondents in this phase. The interviews in the second and the third phases were conducted in the Thai language with key informants associated with agencies involved in managing tourism-related activities in Pattaya. They were audio recorded and transcribed by the researcher. The data obtained from the first 
three phases were synthesized and analyzed for the final analysis in the fourth phase. In this way, the broad concept of destination management was refined and the question of whether or not destination management is practised in Pattaya is addressed.

\subsection{Structure of the thesis}

Nine chapters are presented in this thesis. Chapter One has provided an overview of the thesis. The context of Pattaya was briefly introduced. A summary of destination issues in relation to destination management has been presented. Two main research questions were then outlined. Finally, the research methodology was summarized.

Chapter Two reviews the literature. The chapter starts with issues commonly found in tourism destinations, particularly in mature coastal tourism destinations. Existing definitions of the terms 'a tourism destination' and 'destination management' are presented. Three sets of existing literature are described and discussed: the literature on tourism management, the literature on management (principles of management, organization theory, and inter-organization theory), and the literature on integrated coastal management. The conceptual framework developed from these related literatures is presented.

In Chapter Three, the methodology used in the study is discussed. Four phases of data collection and analysis are outlined, explained, and discussed. A process of coding and analyzing collected data is explained. The analytical framework for the final results is introduced and described.

Chapter Four provides general information about Pattaya and Thailand, its culture, society, economy, and politics. The government's administrative system in the country is presented. This chapter also provides information on tourism development, both nationally and in Pattaya.

In Chapter Five, findings from the research in relation to the concept of 'destination management' are presented. The chapter provides definitions of 'a tourism 
destination' and 'destination management' in the context of Pattaya. The management point of view regarding these two terms is also discussed

Chapters Six to Eight present the findings from the research in relation to the management of beaches, nightlife, and the music festival in Pattaya. The management of beaches in Pattaya is described in Chapter Six, nightlife in Chapter Seven, and the Pattaya Music Festival in Chapter Eight. The findings of each of these three chapters are presented and discussed in five sections: characteristics of the attraction, management agencies and their purposes, management activities and their responsibilities, management resources, and management integration. Management agencies and their purposes in managing particular attractions are clarified. Their responsibilities are described in terms of how they are differentiated and integrated at the scale of Pattaya. Management resources needed to carry out relevant activities are also discussed.

In Chapter Nine, the key findings are summarized in terms of the concept of destination management in Pattaya. The chapter then assesses whether extent destination management is practised in the resort. Factors that shape management in Pattaya are also broadly discussed. Recommendations for Pattaya and similar destinations are made and suggestions for further research are outlined.

\subsection{Conclusion}

This chapter has provided an introduction and overview of the thesis. It has emphasized a need to pay more attention to the notion of destination management: the practices that might enable the destination to be sustainable and competitive. It has raised issues related to tourism destinations as a starting point to highlight the necessity for in-depth research on destination management. To better understand the notion of destination management, the study suggests identifying issues that arise in tourist destinations, refining the concept of destination management, and using it to examine practices at the local destination. The focus of this study is to clarify what constitutes destination management and to assess whether destination management is practised in Pattaya, a mature coastal destination. 


\section{Chapter 2 Literature Review}

\subsection{Introduction}

This chapter presents existing concepts regarding a tourism destination and destination management, and subsequently proposes broad concepts of these two terms drawing on the literature. It raises issues relevant to tourism destinations and their development, and discusses these with regard to mature coastal destinations. This chapter also discusses the structure and process of destination management at the local level. A conceptual framework for tourism destination management analysis is developed and introduced at the end of the chapter. This chapter is developed to provide general understanding of how the knowledge of management can be applied in managing coastal destinations. Some environmental and social issues commonly found at the coastal resorts are briefly mentioned as examples in relevant discussion.

\subsection{Tourism destinations and their development}

This section provides a review of the tourism literature regarding the term 'tourism destination'. The concepts related to this term are presented and synthesized. Then, issues related to destination development are stressed particularly in the context of mature coastal destinations, the focus of this study. Concepts and practices to move forward to destination management are presented at the end of this section.

\subsubsection{Existing definitions and concepts of tourism destinations}

The term 'tourism destination' has been widely used and defined differently (Framke, 2002). Agreement on the meaning of this term does not seem to exist (Framke, 2002; Laws, 1995). In the review of the tourism literature, a tourism destination is seen to have four main characteristics: it is a particular geographical area; it must be selected and visited by tourists; it needs to provide some kinds of tourism products and services; and it involves multiple stakeholders

First, the destination is a particular geographical area to which the tourist goes, in contrast to an origin, a place from where the tourist comes (Leiper, 1990). The destination area can be perceived at diverse geographical scales (Carter \& Fabricius, 
2006; Cho, 2000; Laws, 1995; Papatheodorou, 2006; Pearce, 1989; Ritchie \& Crouch, 2003). When taking a trip, the tourist may perceive the destination at the scale of a purpose-built attraction, a town or a city, a tourism district, a province, a tourism region within one country, or a whole country. Moreover, on a trip, the tourist may visit a single or multiple tourism destinations (Cho, 2000), and destinations within destinations (Carter \& Fabricius, 2006). Excluding a purposebuilt attraction, the town or resort city seems to be the smallest level at which the tourist visits and all tourism services exist (Carter \& Fabricius, 2006). Many resort destinations exist at this local scale (Laws, 1995). This study, which aims to explore the management of a coastal resort destination, also focuses on this local scale of the destination. The terms 'the local destination', 'the destination scale', and 'the local scale', will be used to refer to this geographical scale of the destination throughout this thesis. This first characteristic of a tourism destination leads to the question of what makes the tourist choose to visit particular destinations instead of others. This underlines the tourist's behaviour in the process of destination selection and visitation.

Without selection and visitation, a tourism place does not become a tourism destination. This second characteristic of a tourism destination highlights tourist demand. Tourist demand can be considered in two different locations: at the origin, and at the destination. At the origin, tourist demand is likely to occur through a process of destination selection before taking a trip. In this sense, tourist demand is expressed as a function of a relationship between tourists' motivation and their ability to travel (Pearce, 1995). Tourism motivation is driven by factors within individual tourists (Leiper, 1990), and in their personal and interpersonal environments at the origin (Pearce, 1989). Tourists may want to travel because they want to respond to their motivational factors such as relaxation, play, shopping, social interaction, sexual opportunity, educational opportunity, and self-fulfilment (C. Ryan, 2003). The fundamental psychological motivation underlying these factors is the individual needs of tourists (Leiper, 1990; Pearce, 1995) "to escape, to break from routine and change of place” (Pearce, 1995, p. 22). In order to satisfy their needs, the tourists are required to meet some conditions (Pearce, 1995). In general, the tourists must have enough time and money to travel. In addition, tourists' physical health, age, and knowledge regarding the destination are particular 
conditions that enable the tourists to travel. Tourist demand at the origin appears to have a major role in a process of destination selection. It functions as a push factor for the tourists (Cho, 2000) to choose some particular destinations that enable them to satisfy their needs. However, when the tourists visit the destination, their demands may be expressed in different ways.

At the tourism destination, tourist demand is expressed in various dimensions. In general, it can be expressed in total numbers of people who actually visit the destination (Paajanen, 2000; Page, Brunt, Busby, \& Connell, 2001; Pearce, 1995). In particular, it can be expressed in numbers of people participating in particular tourism products and services, and in the amount of money spent on those products and services (Paajanen, 2000; Pearce, 1995). It is usually presented in statistics and numbers (Paajanen, 2000; Page, et al., 2001), which can reflect tourist numbers, their characteristics, and amount of money spent at the destination.

Tourist demand can change over time in volume and quality (Pearce, 1995). According to the increase in discretionary time and money that people have (Pearce, 1995), the number of tourists appears to increase gradually. Thus, tourists, nowadays, seem to have more travelling experiences, to be more specific in their desire, and to have more expectations regarding a destination's quality (Cabrini, 2004). At the same time, when at the destination, their demands must be met (Laws, 1995) by tourism service providers. This makes the provision of tourism products and services necessary and comes into play when the tourists actually visit the destination. Moreover, it may influence the tourists' destination choices (Cho, 2000; Leiper, 2000).

This leads to the third characteristic of a tourism destination, the provision of tourism products and services, or tourism supply (Sainaghi, 2003), which comprises attractions, amenities, and accessibility. Examples of tourism attractions are natural and cultural resources, tourism activities, festivals, events, and entertainment. They can be categorized into primary and secondary attractions (Laws, 1995; Ritchie \& Crouch, 2003). Primary attractions, what Leiper (2000) refers to as the 'primary nucleus', are the main tourism resources that appeal to tourists. They are "an attribute 
of a place... which is influential in a traveller's decision about where to go" (Leiper, 1990, p. 374). Secondary attractions are also an attribute of a place but do not significantly influence the tourists' decisions in selecting the destination (Leiper, 1990). Amenities can refer to necessary facilities and services provided by the private and public sectors for the convenience and comfort of the tourists when at the destination. They can include tourism services such as accommodation, restaurants, and retailers; and basic infrastructure or public facilities such as water supply, electricity supply, roads and transportation systems, communication systems, and sanitation systems. Accessibility refers to the ease of access to the destination. Destinations with easily accessible routes are generally able to draw more tourists to the area than a less accessible destination. These tourism products and services contribute to the destination's identity (Framke, 2002) and may function as pull factors of the destination (Cho, 2000).

A combination of these tourism products creates physical features of the destination that the tourist can experience (Leiper, 1997). These features can be categorized into three main types of destinations, urban, rural, and resort (Anderson, 2000a), on the basis of their natural resources and the extent of physical development at the destination. As implied by their names, urban destinations provide city lifestyle and activities as their tourism resources (Jansen-Verbeke, 2000) while rural destinations provide countryside and outdoor recreational activities as their tourism resources (Momsen, 2000). Resort destinations, the focus of this study, seem to combine characteristics of both urban and rural tourism resources (Aramberri, 2000) since they can provide natural resources and city recreational activities to the tourists. In addition, most of the population at resort destinations are tourists, and this makes the resorts' economies highly dependent on tourism (Aramberri, 2000). These characteristics distinguish resort destinations from other types of destinations. Characteristics of resort destinations, particularly in mature coastal tourism destinations, will be described in more detail in section 2.2.3.

Finally, the diversity of demand and supply often results in the involvement of multiple stakeholders, the fourth distinguishing aspect of tourism destination. In the tourism literature, Freeman's stakeholder definition and theory have been used to identify stakeholder groups and their roles in relation to tourism planners (e.g., 
Sautter \& Leisen, 1999) and the operations of destination management organizations (e.g., Sheehan \& Ritchie, 2005). In Freeman's definition, “a stakeholder is any group or individual which can affect or is affected by an organization” (Freeman, 2005, p. 496). With regard to this definition, tourism stakeholders are anyone who can affect and is affected by tourism. These stakeholders include tourists, public and private sectors that provide tourism services, NGOs, and local residents (Sautter \& Leisen, 1999). Their involvement and expectations may be different and be in conflict. Basically, tourists expect to experience quality tourism products and services from the destination (Yu \& Goulden, 2006). Various individuals, firms, and organizations provide these tourism products and services in order to satisfy the tourists. These tourism providers can be from the public or private sectors (Pearce, 1989). The public sector may expect economic and social benefits for local communities at the destination, while the private sector may expect to achieve its basic goal, making a profit (Pearce, 1989). NGOs are involved directly and indirectly in tourism by serving the interests of particular groups (Pearce, 1989). Residents are indirectly involved in tourism through their daily life, or directly interact with the tourists. They may expect to have a better quality of life regarding economic and social environments (Brunt \& Courtney, 1999). The involvement and contrasting expectations of these stakeholders bring complexity to tourism development and management at the destination. Furthermore, some of these stakeholders, such as private and public services and NGOs, may come from broader geographical scales, such as provincial, regional, and national scales. This indicates diversity amongst tourism stakeholders at the local destination.

Drawing from these four major characteristics - the destination's geography, its demand, its supply, and its stakeholders - the concept of the 'tourism destination' can be broadly described as a local geographical area that is selected and visited by tourists. This place needs to provide a variety of tourism products and services that create the destination's identity, satisfy the tourists, and bring benefits to all related tourism stakeholders.

At the destination scale, the extent of tourist demand, tourism supply and the tourism stakeholder mix appears to be different at each stage of development. To understand 
their relationships, attention needs to turn to destination development and the tourist area life cycle, described in the following section.

\subsubsection{Destination development and its life cycle}

Destination development can be seen in terms of tourist demand, tourism supply, and tourism stakeholders (Butler, 1980; Pearce, 1989; Prideaux, 2000). The relationships of these three factors create different phases of destination development.

In tourism development literature, Butler's life cycle model is the most popular and useful for creating an understanding of the destination development process (Agarwal, 1997; Pearce, 1995; Prosser, 1995; Weaver \& Lawton, 2002). Although this model has been criticised by many scholars in terms of its generalisibility to other types of destinations (Prideaux, 2000) and its limitation as an analytical tool (Agarwal, 1997), it simply pictures a development path of a tourism destination when a whole destination is perceived as a single tourism product. It provides an understanding as to how a tourism product is developed and which characteristics are relevant at different development stages. It illustrates that different management practices are required at different stages of destination development. It also indicates that some management practices are significant in delaying the destination's progress through the life cycle.

Table 2.1 presents various characteristics in different stages of a destination's life cycle (Weaver \& Lawton, 2002). Incremental development of tourist demand, tourism supply, and tourism stakeholders occurs in the first three stages. The tourism stakeholders in these three stages are tourists, tourism service providers both from the public and private sectors, and local residents. When the destination becomes more important and attracts more tourists, it becomes more institutionalised by local agencies. Regional and national institutions from public and private sectors are likely to be involved. In the later stages of development, the quantity and characteristics of tourist demand and tourism supply change. For example, tourism attractions change from authentic to generic, privately owned tourism businesses from local to international and the demographics of tourist demand change. Besides tourists, tourism service providers, and local residents, the tourism stakeholders involved in 
these later stages of development become more diverse. Local, regional, and national NGOs are included. Thus, the involvement of all stakeholders in these later stages seems to be crucial to minimize negative tourism impacts and to maintain the quality of a destination.

Table 2.1: Changing characteristics within the Butler sequence.

\begin{tabular}{|c|c|c|c|c|}
\hline Variable & Exploration & Involvement & Development & $\begin{array}{l}\text { Consolidation/ } \\
\text { stagnation }\end{array}$ \\
\hline $\begin{array}{l}\text { Status of the destination } \\
\text { within the tourism system }\end{array}$ & Peripheral & Gradual incorporation & Full integration & Full integration \\
\hline Rate of growth in visitation & $\begin{array}{l}\text { None (low level } \\
\text { equilibrium) }\end{array}$ & Low growth & Rapid growth & None (high level equilibrium) \\
\hline $\begin{array}{l}\text { Spatial pattern of tourism } \\
\text { activity }\end{array}$ & Dispersed & $\begin{array}{l}\text { Nodes of concentration } \\
\text { appear }\end{array}$ & Concentrated & Highly concentrated \\
\hline Attractions & $\begin{array}{l}\text { Cultural/natural, unique to } \\
\text { destination }\end{array}$ & Mainly cultural/natural & $\begin{array}{l}\text { Mainly specialised tourist } \\
\text { orientation }\end{array}$ & $\begin{array}{l}\text { Specialized and contrived } \\
\text { tourist orientation; generic }\end{array}$ \\
\hline Ownership of operations & Local & Local, some non-local & Mainly non-local & Non-local \\
\hline Accommodation & $\begin{array}{l}\text { No specialized } \\
\text { accommodation }\end{array}$ & Small-scale, unobtrusive & Mainly large-scale & $\begin{array}{l}\text { Large-scale 'international' } \\
\text { style }\end{array}$ \\
\hline Market origins & Diverse & Less diverse & $\begin{array}{l}\text { Dominant markets } \\
\text { emerge }\end{array}$ & Dominant markets \\
\hline Psychographics of market & Allocentric & Allocentric-midcentric & Midcentric-psychocentric & Psychocentric \\
\hline Seasonality & None & Emergent & Seasonal & Highly seasonal \\
\hline Length of stay & Extended & Relatively long & Relatively short & Brief \\
\hline Economic status of tourism & Insignificant & Minor, supplementary & Dominant & Overwhelming dependency \\
\hline Tourism-derived revenue & Insignificant and stable & Small and growing & Large and growing & Large and stable \\
\hline Multiplier effect & Extremely high & High & Declining & Low \\
\hline Linkages & Local & Mainly local & Mainly non-local & Non-local \\
\hline Leakages & None & Minor & Major & Very high \\
\hline $\begin{array}{l}\text { Commodification of } \\
\text { attractions }\end{array}$ & $\begin{array}{l}\text { Non-commercial, } \\
\text { 'authentic' }\end{array}$ & $\begin{array}{l}\text { Somewhat commercial, } \\
\text { mainly authentic }\end{array}$ & $\begin{array}{l}\text { Commercial, increasingly } \\
\text { contrived }\end{array}$ & Highly commercial, contrived \\
\hline Irridex & Pre-euphoria & Euphoria & $\begin{array}{l}\text { Apathy (early), } \\
\text { annoyance (later) }\end{array}$ & Antagonism, then resignation \\
\hline Environmental stress & Very low & Low but increasing & High & Very high \\
\hline
\end{tabular}

Source: Weaver \& Lawton (2002, p. 311)

In Table 2.1, negative tourism impacts in relation to economic, environmental, and social characteristics of the destination are presented. These negative tourism impacts can emerge in the early stage of development. They appear more clearly in the consolidation stage, particularly of coastal tourism destinations (Knowles \& Curtis, 1999). If destinations cannot change their conditions, they may reach the stagnation 
stage. The destinations that enter the consolidation or stagnation stage are likely to be confronted with a range of management-related challenges. In the following section, the complex characteristics and negative impacts of mature destinations, particularly at coastal tourism destinations, are described.

\subsubsection{Mature coastal tourism destinations}

Coastal resort destinations have two primary characteristics: they feature a range of tourism resources and they often experience a rapid rate of development. Firstly, like other resort destinations, a coastal tourism destination involves the use both of natural and urban tourism resources. The natural tourism resources commonly mentioned in the coastal tourism literature comprise sandy beaches, sea, tropical climate, vegetation, and marine species (e.g., C. M. Hall, 2001; Kumar, 1995). The urban tourism resources can include hotels, retail shops, restaurants, pubs, bars, shows, and entertainments (mentioned as recreational businesses in Kumar, 1995; Pearce, 1995). These mixed tourism resources create the distinctive and complex characteristics of the coastal resort destination.

Secondly, many coastal destinations seem to follow a similar pattern of rapid development (Page, et al., 2001; Smith, 1992). The development of coastal destinations usually starts with natural tourism resources. After the infrastructure development, especially a ribbon road along the coastline, convenient and easily accessed transport seems to bring mass tourism to the destination. Then, a rapid growth in tourism facilities and services takes place in order to respond to this mass consumption leading many coastal tourism destinations to reach a mature phase in a short period of time (Butler, 1980; Knowles \& Curtis, 1999).

The main characteristics of a mature coastal destination involve intensive and extensive development of tourism supply, while tourism demand levels off with increased levels of marketing competition (Knowles \& Curtis, 1999). In general, the mature destination provides a wide range of service sectors that can attract and respond to a wide range of tourist types and needs. However, tourist demand is likely to stabilize or decrease due to the slow rate of repeat visitors. Also, tourists choose to visit more recent or emerging destinations. This circumstance increases competition 
for the mature destination. To maintain its market share, the mature destination may lower its price or develop new tourism products to attract new market segments. In this regard, tourism products become more homogeneous and may separate the destination's image from its original tourism resources.

Although the mature destination may attract a wide range of tourist segments, this stage of development may increase the complexity of destination characteristics and pose challenges to destination managers. This maturity stage can occur when the destination's economy is highly dependent on tourism, which is commonly found at the consolidation and stagnation stages of Butler's destination life cycle model (Butler, 1980). The concentrated physical development and population can exceed the destination's capacity levels. This circumstance may cause negative impacts on natural resources and decrease the quality of facilities and the infrastructure of destinations.

Negative tourism impacts are critical issues commonly found at many mature coastal destinations. They are often initially related to the general environment and natural resources such as congestion, air and water pollution, and the degradation of coastal and marine habitats and ecosystems (EEA, 1999; Harvey \& Caton, 2003; Lundin \& Linden, 2001; Mohammed, 2002). They are also related to local culture and residents' way of living (Dana, 1999) such as demonstration effect, prostitution, drug, and crime. These problems can minimize the quality and uniqueness of tourism products (Bower \& Turner, 2001; EEA, 1999; Greiner, Young, McDonald, \& Brooks, 2000), which can in turn lead to economic impacts at destinations such as a decrease in the number of tourists or a qualitative change in tourist types and high economic leakage. Furthermore, the negative consequences may result from the political and managerial issues in some countries, such as poor tourism development planning, and a lack of quality research to help formulate planning goals, and a lack of knowledge about tourism (Tosun \& Timothy, 2001).

These issues, complex tourism resources and negative tourism impacts, stress the need for appropriate destination management at the destination scale, particularly for mature coastal destinations. Effective management needs to be practised at mature 
coastal destinations in order to maintain their competitiveness in the tourism market, to sustain their economic and environmental conditions, and to compete with many more recently developed destinations.

\subsubsection{Moving forward: from destination development to destination management}

Ideally, tourism destinations need to be developed and managed in a sustainable and competitive manner. In tourism literature, the notions of destination sustainability and destination competitiveness have been widely discussed with regard to the development of tourism destinations. These two notions appear to be closely linked. Ritchie \& Crouch (2003, p. 9) declare: "Competitiveness without sustainability is illusory".

The first notion is that destination sustainability has been seen from two main perspectives: sustainable tourism development and sustainable tourism markets. The concept of sustainable tourism development is widely discussed in the tourism development literature (e.g., Butler, 1980; Mowforth \& Munt, 2000; Sharpley, 2000; Slee, Farr, \& Snowdon, 1997). This concept is transformed from the concept of sustainable development that has been discussed in the Brundtland Report (Hardy \& Beeton, 2001; Mowforth \& Munt, 2000). To balance human needs through development, which is the core concept of sustainable development, this concept encompasses four main areas of development: economic, environmental, social, and political. In tourism literature, the sustainable tourism development concept appears to focus not only on the viability of tourism resources but also on tourism businesses and customers' satisfaction (Hardy \& Beeton, 2001). According to Clarke (1997, cited in Hardy \& Beeton, 2001), the focus of this concept has also been shifted from applying it to small-scale natural tourism to applying it to mass tourism. This shift seems to bring benefits to mass tourism destinations, the places that host many tourists and where the practice of sustainable tourism development is necessary.

Sustainable tourism development implies a commitment of the destination to provide long-term quality tourism resources to tourists. This commitment is vital for the destination to maintain its share of the tourism market (Poon, 1993; Ritchie \& 
Crouch, 2003), the second view of destination sustainability. In order to maintain its share of the tourism market, the destination should move its emphasis from how to develop its tourism to how to sustain its tourism resources. The practice of moving towards this emphasis is important for the destination (Fyall \& Garrod, 1997). Regarding this view, involvement through coordination and cooperation of stakeholders (Jamal \& Getz, 1995) seems to be commonly suggested. Moreover, the balanced management of demand and supply (Font \& Ahjem, 1999; Liu, 2003), especially in the early phase of destination development (Eccles \& Costa, 1996), is also advocated. Although there is little evidence to show what sustainable tourism development looks like, this objective can be achieved by avoiding circumstances that create unsustainable development (Carley \& Christie, 1993). Any operations or activities that degrade the quality of tourism resources are examples. Thus, the destination needs to be competitive in the tourism market in order to maintain its share of visitors. However, competition is very intense. Many of the world's leading tourism destinations have to compete with each other and also with recently developed destinations. In this regard, these tourism destinations may need to put more effort into their management performance to be competitive in the tourism market.

The second notion is that destination competitiveness can be achieved by management practices in relation to the destination's image and quality of its tourism resources. Destination image is "the way in which it [the destination] projects itself and the way in which it [the destination] is viewed by its markets” (Doswell, 1997, p. 51). Tourists are likely to receive information and develop an overall picture of the destination from all kinds of media such as TV, brochures, travel books, and magazines, and from word of mouth. If the destination has a positive image, it can stimulate tourists' desires and actions to visit the destination. This also implies a promise that the destination makes to its visitors. The reality, however, may be different from the image. At the destination, the quality of tourism resources perceived by the tourists becomes significant. Core attributes that create competitive destinations include a range of tourism resources (Crouch, 2006; Dwyer \& Kim, 2003; Enright \& Newton, 2004), the quality and price relationship (Keane, 1997), 
and the coordination of stakeholders (Go \& Govers, 2000; Gomezelj \& Mihalic, 2008).

Safety and security appears to be another attribute that creates destination competitiveness. Ideally, all tourism stakeholders should be responsible for safety at the destination. The tourism-related businesses and services need to provide safety to tourists' lives and assets, while the tourists should avoid any circumstance that may harm their lives and assets. However, incidents such as natural disasters and epidemic diseases in Asia and terrorism in America increase safety concerns to the tourism industry (Paraskevas \& Arendell, 2007), both in terms of tourists and destinations. From the tourists' perspectives, safety can be one of the most important issues the tourists use for destination choices. No matter how attractive the destination is, the tourists may not choose to visit if that place is not safe.

Similar to tourists, tourism providers may realize how important the safety issue is for their businesses and the destination. However, other issues such as infrastructure development, quality of products and services, and quality of natural environments seem to be as important. From the destination's perspective, it may be difficult to prioritise which of these issues is the most important and needs more attention. As mentioned previously, these activities may be the responsibility of different sectors (Westermann, et al., 2005). The coordination of these sectors in destination management seems to be necessary to move toward the concept of destination competitiveness. As Sainaghi (2003, p. 56) stresses, a “destination is the real product and it is a competitive subject that must be managed”.

To move toward the concepts of sustainability and competitiveness, the involvement of all tourism-related sectors in managing the destination as a whole appears to be significant. In tourism management literature, many studies relate to the management of particular activities such as natural resources (e.g., Hassan, 2000; Hu \& Wall, 2005; Mihalic, 2000; Tunbridge, 1999), marketing (e.g., Blain, Levy, \& Ritchie, 2005; Lynne \& Geoffrey, 2003; Richard, 1993), tourist impacts (e.g., Lew \& McKercher, 2006; Tabatchnaia-Tamirisa, Loke, Leung, \& Tucker, 1997), and safety (e.g. Fall, 2004; Paraskevas \& Arendell, 2007). A few studies have been done from 
the overall perspective of destination management (e.g., Carlsen, 1999; Flagestad \& Hope, 2001; Sainaghi, 2003; Westermann, et al., 2005).

Theoretically, destination management needs to be practised in a way that enables the destination to delay or transform its life cycle (Knowles \& Curtis, 1999). It also needs to be practised in a way that harmonizes all tourism elements with a destination's characteristics (Page, et al., 2001; Ritchie \& Crouch, 2003), to prevent/solve the problems, to benefit all stakeholders (Ritchie \& Crouch, 2003; TMI, n.d.), and to maintain the competitiveness of the destination (Poon, 1993; Ritchie \& Crouch, 2003). These needs can be achieved through the collective actions of multiple stakeholders at the destination (Weaver \& Lawton, 2002). However, in tourism literature, the integration of multiple stakeholders, both at the local level and at other scales, to manage or to operate the local destination seems to be unclear. In the following sections, the concept and practice of destination management, the key themes of this thesis, are discussed and clarified and then developed with reference to the principles of management. This perspective will be discussed further in the following section. The term 'tourism destination' used in the following sections refers to tourism destinations in general, with an emphasis on 'mature coastal tourism destinations'.

\subsection{The concept of destination management}

\subsubsection{Existing definitions and concepts of destination management}

Destination management is a description used in a variety of ways, and a commonly agreed upon definition is yet to emerge. Three major aspects of destination management appear in tourism literature: the provision of multiple tourism-related activities, the involvement of multiple agencies, and a desire to achieve common goals.

Firstly, destination management involves the provision of multiple tourism-related activities. In the tourism management literature, these multiple tourism-related activities can be broadly categorized into the management of destination marketing and of destination resources. The operation of destination marketing focuses on branding, positioning, and destination image (Ritchie \& Crouch, 2003; Terzibasoglu, 
2004). Although it may seem similar to tourism marketing, some differences can be identified. Destination marketing requires the cooperation of relevant agencies to promote the destination as a single tourism product through its image, branding, and positioning whereas tourism marketing more generally involves individual businesses promoting their tourism products. This latter practice tends to promote diverse and fragmented tourism products provided at the destination rather than promoting the destination as a product. In terms of destination resources, four primary management activities are involved: tourism resource management, human resource management, safety management, and visitor management (Jamieson, 2006; Ritchie \& Crouch, 2003; Terzibasoglu, 2004). The tourism-related activities may be undertaken independently but they are inter-related. For example, destination marketing is carried out to attract tourists, while destination resources are managed to ensure tourist satisfaction when there. Tourism resources are managed to respond to the tourists' needs and to support a better quality of life for local residents. Human resources are managed to ensure that service standards satisfy the target markets. Safety management ensures security and enhances destination competitiveness. Visitor management is practised to minimise negative impacts arising from tourist activities and enhances visitor satisfaction. The integration of these various activities is required in managing the local destination (Anderson, 2000a). Whether this occurs is often unclear. In order to integrate these multiple activities at the destination, the involvement of related agencies is important.

Secondly, destination management concerns the involvement of multiple agencies in managing the destination. Although multiple tourism providers may act individually at the destination (Westermann, et al., 2005), the management of destination marketing and destination resources requires some level of joint involvement from related agencies. These management agencies (called metamanagers in Sainaghi, 2003) can be public, private, and joint public/private agencies. They can exist at the local and other levels. Examples of destination management agencies are the municipality, city tourism departments, local tourism boards, local to national tourism organizations, local to national governmental agencies, local to national associations, and individual businesses (Ritchie \& Crouch, 2003; Sainaghi, 2003). Their roles and responsibilities in managing the destination may differ. Examples are 
the responsibilities of the municipality in infrastructure construction and control; individual businesses in accommodation management; and tourist organizations, associations, and individuals in marketing (Sainaghi, 2003). How relevant agencies are involved or inter-related in managing particular activities at the destination is often unclear. In the tourism stakeholder literature, collective actions such as coordination, cooperation, networking, and partnering are frequently suggested for stakeholder involvement (e.g., Jamal \& Getz, 1995; Jamal \& Jamrozy, 2006). A few studies have examined how these approaches can be taken at the destination scale. Welford \& Ytterhus's (2004) study shows that the collective actions of related agencies can bring about successful destination management. In their case, involved agencies were all at the local scale and the role of regional and national agencies is unclear. Integration of these agencies, particularly from different levels, in managing all tourism-related activities at the destination scale seems to be crucial for destination management. Furthermore, the integration of the goals and practices of all relevant agencies seems to be necessary for destination management.

Thirdly, destination management can refer to a desire to achieve common goals. In managing the destination, two kinds of goals may be identified: organizational goals and destination goals. In management and organization literature, organizational goals represent the desired future which an organization wants to achieve (Hodge, Anthony, \& Gales, 2003; Samson \& Daft, 2003; Sisk, 1969). They are written statements that represent the purposes for the organization's existence, and can be hierarchically presented in the forms of broad goals to specific goals (Hodge, et al., 2003; Samson \& Daft, 2003). The broad goals can be mission statements about the future condition and guiding principles through identifying products or services, market niches, production methods, and financial objectives of the organizations. The specific goals can be the goals of divisions or departments in operating their units in a way that corresponds to the organization's broad goals. The specific goals can cover all the sub-systems and set standards, and guide what all managers should do on a day-to-day basis. At the tourism destination, all tourism-related agencies may operate in a way that achieves their individual organizational goals. 
While organizational goals are important for the tourism-related agencies, the tourism destination, similar to the organization, should have an overall picture of its desired future state (Terzibasoglu, 2004) as its goal. The future economic, social, and environmental conditions of the destination can be included in its stated goals. Thus, "the fundamental goal of destination management is to evaluate the adequacy and effectiveness of the product, facilities, services, and programmes that altogether provide memorable destination experiences for visitors” (Fuchs \& Weiermair, 2004, p. 212). The destination goals may not be clearly stated in a single document, but statements in official documents and operational performances can reflect key goals in managing the destination. Examples of these destination goals are quality development, competitive strategy, customer satisfaction, brand management, and destination repositioning (see individual case analyses in Sainaghi, 2003). The destination goals are an important component of tourism policy and should integrate all elements necessary for destination competitiveness (Terzibasoglu, 2004). However, it seems to be unclear whether there are destination goals when managing the destination. Common goals shared across relevant agencies seem to represent destination goals, as they are likely to convey shared understanding or shared vision of relevant agencies about the destination.

For successful destination management, common goals for relevant agencies in managing particular activities are necessary (Welford \& Ytterhus, 2004; Westermann, et al., 2005). Common goals refer to an agreement on goals established by relevant agencies in operating tourism projects (see details about tourism project development in Welford \& Ytterhus, 2004) and tourism activities, or a combination of organizational goals from related agencies (see detail in the implementation process of Westermann, et al., 2005). In the tourism literature, Westermann et al. (2005) use the balanced scorecard to develop common goals for the Harz and Thüringen tourism regions in Germany. By combining common goals and performance indicators defined by relevant agencies into a single balanced scorecard, they believed that this attempt can ensure sustainability for the tourism destinations. In their study, political and regional decision makers from both regions successfully defined common goals and performance indicators, but the service providers' balanced scorecards are still in the process of being developed. Cooperation from 
these decision makers may be easier to obtain than the cooperation of service providers since the decision makers seem to share similar goals such as community benefits. In contrast to the political and regional decision makers, individual providers, particularly privately owned businesses, aim for profits. Difficulty and complexity in developing common goals among all private agencies may occur. Although the research project of Westermann et al. (2005) is still ongoing, it suggests that common goals in destination management can be developed if all related agencies are willingly involved in the development. A desire to achieve common goals is vital for successful destination management. Presumably, organizational goals are important for the existence of individual agencies, while destination goals, which can be represented by common goals, are necessary for the sound management of the destination. However, in destination management, it seems to be unclear which goals are being achieved by the relevant agencies and whether there is a desire to achieve common goals in managing the destination.

The three aspects of destination management discussed in this section are drawn together to provide a concept of destination management in the tourism literature. The concept of destination management can be broadly described as an integration of related agencies to combine all activities or techniques to manage or "to shape the development and daily operation of tourism-related activities" (UNEP, 2005) of the local destination for the economic, social, and environmental benefit of all stakeholders (TMI, n.d.) such as the public sector, private sector, tourists, and residents. In relation to this concept, Ritchie \& Crouch (2003, p. 67) further suggest that the destination "must function as a real entity. That is, it must have a sense of itself; it should have a purpose and be managed in a way that promotes the pursuit of that purpose".

Here, the thesis proposes another way of looking at destination management. If the destination must function as an entity, it may be necessary to consider its management as similar to that of a firm. This seems to bring a better understanding of the notion and practice of destination management at the destination scale. The following sub-section examines whether there are parallels between managing a firm and a tourism destination. 


\subsubsection{Parallels between managing a firm and a tourism destination}

Because there are a few studies regarding tourism destination management, it may be useful to look at parallels with managing a firm. The notion of comparing the management of the destination to that of a firm is rather new and has been used by only a few studies in the tourism literature. By comparing the destination to a firm, the concept of strategic management is used to explore the goals of tourism regions (Westermann, et al., 2005) and the management structure of winter resort destinations (Flagestad \& Hope, 2001). According to these studies, the destination is similar to a firm in the sense of seeking competitiveness in the market but differences may be found in terms of ownership and management structure. The similarities and differences between managing a firm and the tourism destination are developed here (Table 2.2) in order to identify the potential for applying this analogy to the concept of destination management.

Table 2.2: Parallels between managing a firm and a tourism destination.

\begin{tabular}{|l|l|l|}
\hline \multicolumn{1}{|c|}{ Management } & \multicolumn{1}{|c|}{ A firm } & A tourism destination \\
\hline Ownership & $\begin{array}{l}\text { Business } \\
\text { owners/shareholders }\end{array}$ & $\begin{array}{l}\text { Usually no single } \\
\text { owner rather multiple } \\
\text { stakeholders }\end{array}$ \\
\hline $\begin{array}{l}\text { Management } \\
\text { structure and } \\
\text { hierarchy }\end{array}$ & Hierarchy of command & $\begin{array}{l}\text { Some forms of } \\
\text { collective actions }\end{array}$ \\
\hline $\begin{array}{l}\text { Management } \\
\text { process }\end{array}$ & $\begin{array}{l}\text {-Coordination of management resources } \\
\bullet \text { Performance of management functions } \\
\bullet \text { Pursuing goals (Sisk, 1969) }\end{array}$ \\
\hline $\begin{array}{l}\text { Management } \\
\text { functions }\end{array}$ & $\begin{array}{l}\text { Planning, organizing, directing, controlling (Sisk, } \\
\text { 1969) }\end{array}$ \\
\hline $\begin{array}{l}\text { Management } \\
\text { environments }\end{array}$ & $\begin{array}{l}\text { Economy, politics, technology, culture (Morgan, } \\
\text { 1997) }\end{array}$ \\
\hline
\end{tabular}

Source: developed from Flagstad \& Hope (2001); Westermann, et al. (2005)

In terms of broader management theory, management is considered as a process to get things done efficiently through other people (Robbins \& Mukerji, 1994). Different levels of managers undertake the management of a firm. They are categorized into three levels of management: top management, middle management, and operational management. The managerial responsibilities and skills between 
these three levels are different (Boone \& Kurtz, 1987; Hodge, et al., 2003; Wren \& Voich, 1984). These three levels of management are hierarchical and presented through the organizational management structure. The management structure assists all managers to operate the firm to pursue its goals. However, the management outcomes can differ depending on the management environments. Broadly, the management of the firm consists of three main features: the management structure, the management process, and management environments.

First, the organizational management structure consists of two elements: differentiation and integration (Hodge, et al., 2003). Differentiation refers to the way all functions or tasks are split and allocated to responsible groups, while integration refers to the coordination to pull those various tasks together to achieve organizational goals. Differentiation and integration can be presented in the form of "labour division, departmentation, span of management and authority that promotes the control and consistency of working performance” (Wren \& Voich, 1984, p.65). The management structure is often depicted in an organizational chart to identify a unity of command and the span of control within a firm. Figure 2.1 gives an overall picture of structure and hierarchy in managing a tourism firm.

Figure 2.1: Structure and hierarchy of command of a tourism firm.

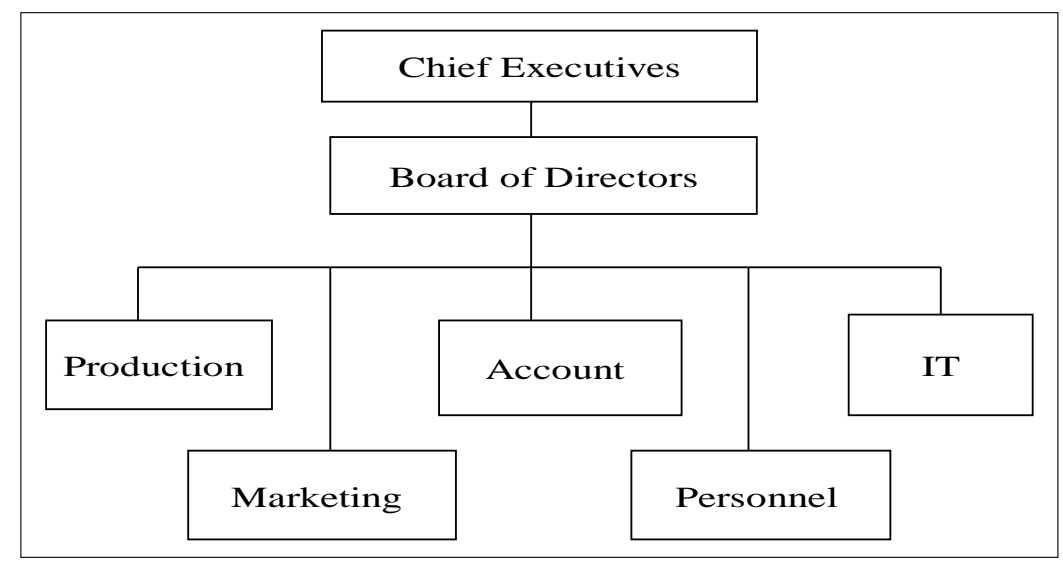

Source: Biz/ed (2005)

Second, the management process consists of three main parts: "first, the coordination of resources; second, the performance of managerial functions as a means of achieving coordination; and, third, establishing the purpose of the management 
process” (Sisk, 1969, pp. 9-10). The coordination of management resources (commonly known as the three Ms: money, materials, and men) between departments/divisions within a firm can be achieved through the utilization of management functions. The performance of planning, organizing, directing, and controlling functions is required to achieve coordination from responsible staff or divisions and to pursue the goals. Management needs to have its purpose. Its purpose can refer to specific or broad organizational goals. However, the management outcomes may or may not respond to all organizational goals, depending on management environments within and outside the firm.

Finally, because organizations can be perceived as an open system, environments within and outside an organization can directly influence the management system and outcomes (Morgan, 1997; Pearce, 1992). These environments include any factor or force outside the direct control of management functions such as the technological, social, economic, political, and international environments. These environments can change over time and these changes must be traced in order to develop better understanding of management issues (Pearce, 1992).

Differences and similarities are found in managing a firm and managing a destination. Although multiple local and other agencies may be involved in managing the destination structurally, the management hierarchy from top to subordinate agencies is less apparent. The destination management structure is often more a form of collective behaviour instead of the hierarchy of command commonly found in the management of a firm. It can be presented through a pattern of formal and informal work relationships between different agencies and stakeholders, their responsible activities, and management functions. Their responsibilities or functions could be differentiated through various agencies and scales and integrated to pursue the destination goals.

Figure 2.2 identifies one broad structure for managing the destination. In this figure, management agencies are categorized according to their administrative systems. Public, private, and community sectors are classified. Multiple agencies from each sector, particularly public and private sectors, are categorized according to their 
organizational operations or types of services. In the private sector, individual businesses and associations of particular businesses may be involved in destination management. The involvement of all relevant agencies could be undertaken in the form of rule and regulation implementation, and serious action practised at the destination level. Their managerial skills may be different depending on their responsibilities and administrative scales.

Figure 2.2: The broad management structure of the tourism destination.

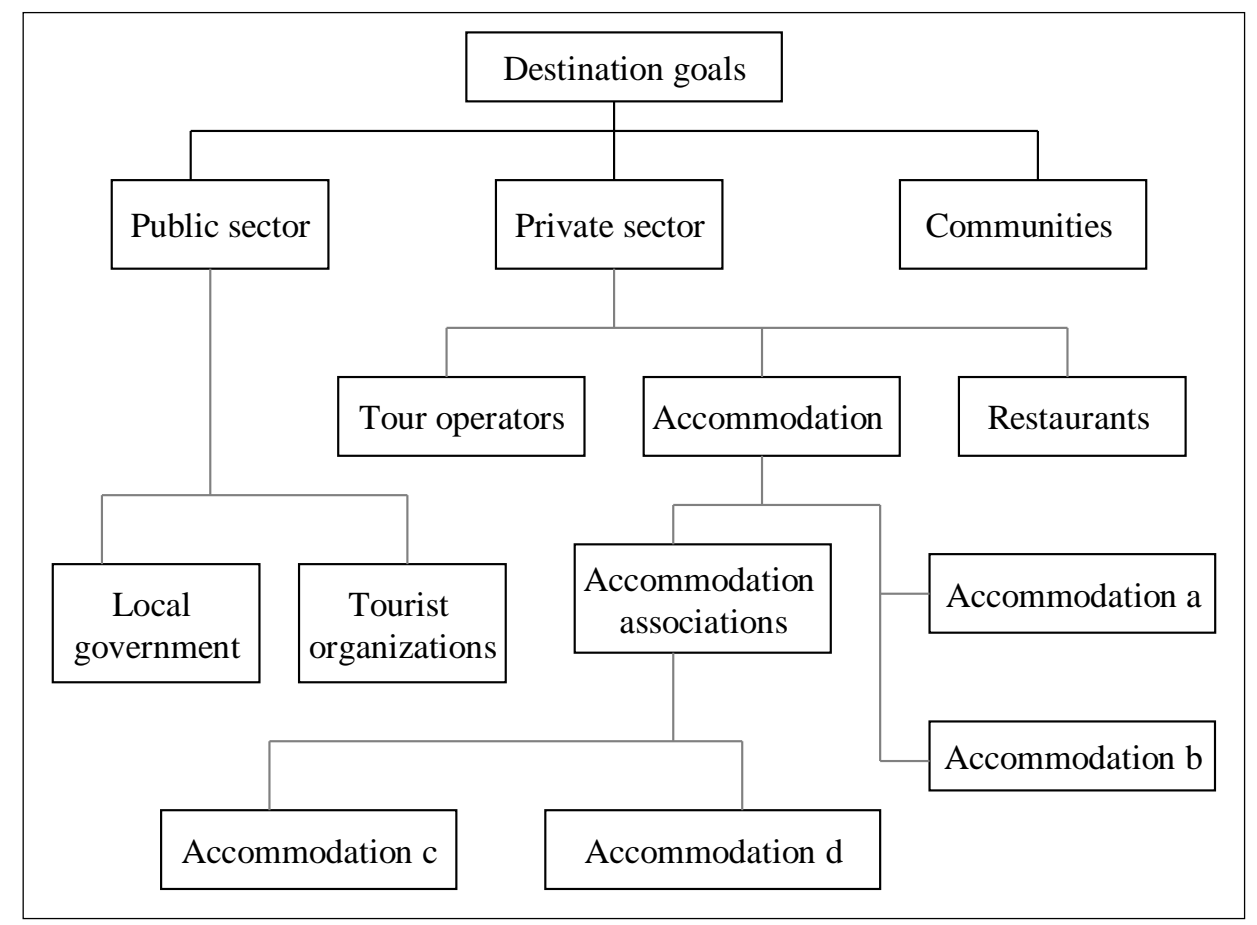

Source: adapted from Westermann, et al. (2005)

Similar to the management of a firm, the cooperation and coordination of management resources from different management agencies seems to be essential. Efficient and effective management could be achieved through the coordination of management resources such as finance, research information, technologies, and human resources from all relevant agencies. The coordination of these resources could be achieved through planning, organizing, directing, and controlling. Moreover, these management functions need to be practised in a way that contributes to the destination goals.

Similar to the firm, the destination is perceived as an open system (Carlsen, 1999; Laws, 1995; Ritchie \& Crouch, 2003). The environments within and outside the 
destination can influence the effectiveness and efficiency of destination management. These environments can change over time.

The above parallels present some similarities and differences in managing a firm and a destination. A destination and a firm are similar in relation to management process, management functions, and management environments but differ in terms of ownership and management structure. Moreover, both cases are similar in a sense of requiring the integration of related managers to operate an entity in a way necessary to achieve goals. Therefore, this analogy brings some insights to the notion of tourism destination management. To move toward this concept of destination management, the implication of this analogy is clarified in the following section. It will describe how the management agencies are integrated at the local level of the destination. It will bring an understanding to "the nature and direction (top down, bottom up, or horizontal) of the interactions which occur among the organizations in the network” (Pearce, 1992, p. 20) of destination management.

\subsection{Practices in destination management}

The previous section identified major aspects of the destination management concept. It described how the management principles could be applied to the destination. In this section, significant dimensions of destination management are proposed and discussed from the management and the coastal management perspectives. Three dimensions of the practice of destination management are managers, management structure, and management process. The integration of these three dimensions at the local scale is required.

\subsubsection{Integration of destination managers}

In developing the tourism destination, all stakeholders - public sector, private sector, NGO, tourists, and host community - are key players (Mason, 2003) but some may have a more significant role than others in managing tourism at the local destination (Ritchie \& Crouch, 2003; Sheehan \& Ritchie, 2005; UNEP, 2005).

The public sector agencies refer to all government bodies relating to tourism planning and management (Mason, 2003). They can include national government, 
related-ministries, tourism organizations, and municipalities. According to Swarbrooke's (1999, cited in Mason, 2003) summary regarding the rights of tourists, the public agencies have prime roles in destination management. The roles of public agencies (or government agencies) can involve tourism marketing, regulating, and providing basic infrastructure and quality tourism at the destination (Mason, 2003; Sainaghi, 2003). The local public agencies such as the municipality, local tourism organization, and other local public agencies are likely to be involved to a larger extent in operational functions at the destination scale (Sainaghi, 2003; Welford \& Ytterhus, 2004). On the other hand, it is possible that the public agencies on broader scales such as provincial or state, regional, and national agencies may be involved to a greater or lesser extent in operations but their focus may be more on strategic management.

The private agencies, the second set of stakeholders, refer to privately owned, tourism-related businesses at the destination, such as purpose-built attractions, accommodations, transportation services, restaurants, and retail shops (Mason, 2003). According to Mason (2003), these businesses are likely to respond to their markets, for their profits, and to serve their business stakeholders. The linkages between these tourism businesses can appear in the forms of ownerships and business alliances (Mason, 2003). Regarding ownership, some operators may own travel agents or have their shares in other tourism businesses such as hotels, restaurants, and carriers. The owners of these tourism businesses may include individuals or organizations located within or outside the local scale of destinations. Some of them may be involved in managing a destination. The involvement of private agencies in destination management seems to bring positive impact to their businesses and a destination as a whole. The study of Lillehammer, Norway (Welford \& Ytterhus, 2004) is an example. In this study, three privately owned accommodation providers participating in the pilot projects of an environmental programme can reduce their financial costs and negative environmental impacts while making use of this profile in their marketing. The benefits they receive from these projects seem to attract more participation from other tourism providers. If all tourism providers participate in these projects, they are likely to create a positive image for the destination. 
The third set of stakeholders, the NGOs, may refer to non-profit organizations that may work directly or indirectly with the tourism industry at the destination, for example social or environmental organizations. They usually focus on one particular issue and act as pressure groups for the tourism destination (Mason, 2003). In destination management, their roles and responsibilities and level of involvement, both from the local and broader scale agencies, can vary depending on the internal and external environments of the organizations (Mason, 2003).

Besides these three sets of stakeholders, local residents, who are not involved in tourism, may or may not participate in destination management. In managing the destination, the roles of these local residents appear to be as supporters or detractors rather than managers. In their supporting roles, their active individual involvement in tourism planning and management can be commonly found in developed countries (Mason, 2003). Otherwise, their participation may appear in the passive form of voluntary groups in some developing and undeveloped countries. They may also participate in tourism planning and tourism management at the destination. The involvement levels of the locals can differ depending on political, economic, and social environments of the tourism destination (Mason, 2003). Thus, their involvement levels tend to depend on individual attitudes or perceptions regarding their roles and responsibilities to the destination. On the other hand, they may become detractors by not participating in any kind of activities. Therefore, the representation of local residents as a managerial group is not as clear as other groups of stakeholders.

Excluding the local residents, these inter-sectoral and inter-administrative destination managers or metamanagers (Sainaghi, 2003) need to act as leaders and coordinators (Ritchie \& Crouch, 2003) in destination management. Cooperation between these multiple destination managers in managing a local destination is required. As such, they should function as follow: 1) work together to develop destination goals 2) influence other stakeholders 3) act as a liaison to obtain involvement from those stakeholders in a way to achieve the destination goals and 4) oversee and control the overall development and management of the destination. In developed countries, cooperation of these agencies commonly occurs in the formal form of destination 
management organizations or DMOs (Ritchie \& Crouch, 2003). These DMOs are usually seen as either a convention and visitor bureau (CVB), a state/provincial/regional tourism office, or a national tourism organization (Anderson, 2000b) that is responsible for marketing and initiating tourism development policy (Haywood, Anderson, \& O'Halloran, 2000). The cooperation in managing the whole destination, as mentioned earlier, seems to be unclear. Thus, the organizational form of DMOs may not exist in all developing and undeveloped countries. Some other forms of integration between all related agencies are required at the destination scale.

According to the coastal management literature, the integration of multiple related agencies has been used in developed countries (e.g., Neuman, 1999), developing countries (e.g., Pollnac \& Pomeroy, 2005), and undeveloped countries (e.g., Mohammed, 2002). Many of these studies relate to the environmental sciences; not many integrate interdisciplinary, economic, and social sciences, for example. In relation to tourism, these studies relate to particular management activities at the destination such as beach management (e.g., Lamberti \& Zanuttigh, 2005) and pollution management (e.g., Mohammed, 2002). An overall study of destination management seems to have been overlooked, but a high level of integration between various agencies in different sectors and on different levels seems to be crucial for successful destination management. However, the responsibilities of these agencies may be different or similar depending on their organizational operations. And it is often unclear what their roles and responsibilities are regarding destination management and what integration occurs at the destination scale. This in turn calls for a closer look at the management structure of these agencies.

\subsubsection{Integration in management structures}

From an organizational perspective, management structure consists of functional differentiation and functional integration (Hodge, et al., 2003). Destination management might also be seen in these terms. Typically, the functions of large companies are differentiated either horizontally or vertically. The structure of destination management seems to be differentiated in both directions (see Figure 2.3). In horizontal differentiation, operative functions are structured by the agencies' 
operational specializations or professions. Their operational functions at the destination can relate to the management of tourism-related activities such as marketing, tourism resources, safety, visitors, and human resources. In any operative function, multiple agencies from different sectors and administrative scales may be involved. The levels of authority, hierarchy or chain of command of these agencies may differentiate their work responsibilities and their roles. This reflects vertical differentiation in the management structure. The local agencies may have major roles in managing the local destination. In terms of safety, for example, relevant agencies such as local police, the municipality, and local businesses may be involved. However, the agencies from other administrative scales, particularly government agencies, may get involved in some circumstances such as initiating policies or controlling the operations of their subordinate agencies. Normally, these multiple agencies may work individually. The integration between related agencies in undertaking one activity, such as safety, is required for destination management. Moreover, the integration of all agencies in operating all activities is necessary for successful destination management. 
Figure 2.3: Horizontal and vertical differentiation of destination management structure.

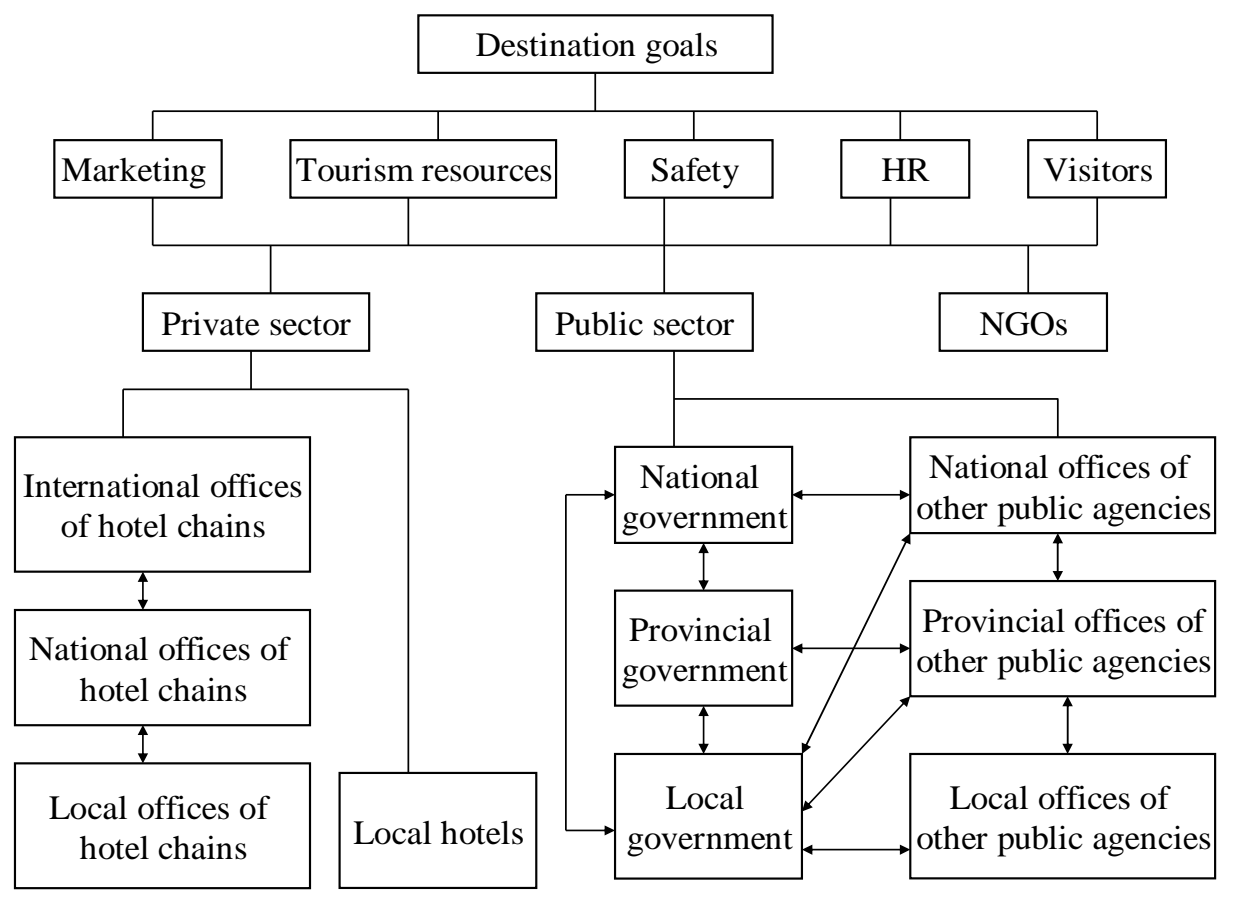

Source: adapted from Hodge, et al. (2003)

While the functions in managing the destination are differentiated horizontally and vertically, they may be integrated through various kinds of collective action. These actions can be done through interactions of two or more agencies (R. H. Hall, 1987; Selin \& Chavez, 1995), and in horizontal and vertical directions (C. M. Hall, 2000; Pearce, 1992). At the destination, functional integration may appear in various forms: inter-organizational relations and coordination practices.

First, according to Hall (1987, p. 234 ), organizations can interact in three basic forms of relationships: 'dyad, set, and network' (Figure 2.4). Dyadic relationships represent the interaction between two agencies (Figure 2.4a). Set relationships involve the interactions of multiple agencies where the focal agency (FA) is likely to have more power in decision making than other agencies (Figure 2.4b). Network relationships represent greater equality in the relationships among multiple agencies (Figure 2.4c). In managing the destination, the interaction between relevant agencies may appear in these three forms depending on the complexity of related issues and numbers of relevant agencies. Furthermore, a hierarchical structure between relevant 
agencies, particularly in the government sector, may exist (see empirical models of destination management in Sainaghi, 2003, pp. 512-516).

Figure 2.4: Forms of organizational interactions.

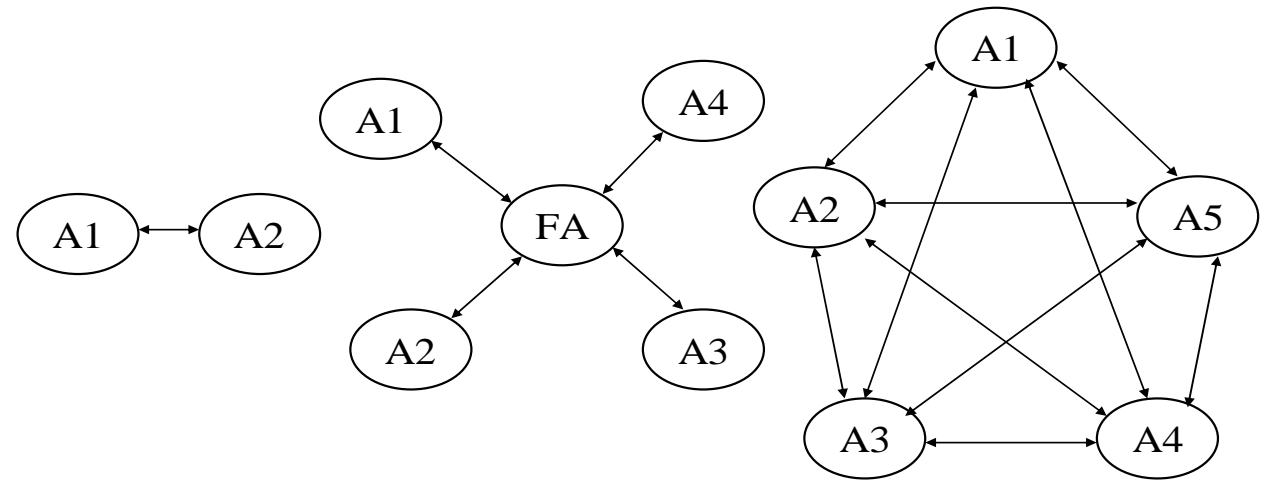
a. Dyadic relationship
b. Set relationship
c. Network relationship

Source: adapted from Van de Ven \& Ferry (1980, cited in R. H. Hall, 1987)

In the tourism literature, organizational interactions are commonly stated in terms of 'partnership', 'network', ‘collaboration', ‘coordination', and 'cooperation'. These interactions aim to accomplish mutual interests or pursue the common goals of the stakeholders (Bramwell \& Lane, 2000; C. M. Hall, 2000; R. H. Hall, 1987; Selin \& Chavez, 1995). Cooperation and coordination seem to be key approaches for successful interactions. In both tourism and management literatures, some lack of clarity regarding the definitions of these two terms seems to exist. The terms 'cooperation' and 'coordination' are often used interchangeably. Other studies try to differentiate their meanings. Their definitions seem to be variously defined depending on the perspectives the scholars have. Regarding the management perspective, the main thrust of this thesis, these two terms are related but do not hold the same meaning (Hatchuel, 2002). According to the International Encyclopaedia of Business and Management, "cooperation is a class of human relations where mutual interests are stressed in opposition to competition or rivalry", while "coordination is more likely to be intentional and formally designed when cooperative behaviour is 
dominant” (Hatchuel, 2002, p. 1060). That is, coordination is likely to be a formal institutionalized relationship (C. M. Hall, 2000) or a working process, while cooperation is likely to be characterised by informal trade-off (C. M. Hall, 2000) or an informal approach taken for expected outcomes. In this regard, coordination appears as the day-to-day activity of the administrative agencies. This clarification of coordination brings an understanding to the second and third forms of functional integration in destination management.

Second, functional integration can be practised through formal and informal forms of coordination. Formal coordination refers to "formal ways in which coordination is institutionalised” (Alexander, 1995, p. 117). Formal coordination appears to be varied based on the extent of relationships and roles of related agencies. Formal coordination happens through laws and regulations, or mandate, however it does not guarantee that the interaction will actually occur (R. H. Hall, 1987). Alexander (1995) classifies formal coordination into three levels: liaison, the organizational group, and the coordinating unit. Each level has different hierarchies and roles. Liaison has the least amount of hierarchy; the organizational group has intermediate levels of hierarchy, and the coordinating unit has the highest degree of hierarchy. In assigned formal roles, liaison acts to coordinate the actions of related agencies. The inter-organizational group usually appears at the central level of government. The coordinating unit is an appointed unit whose main function is to coordinate the activities of the members of its interaction system. The interaction of management agencies at the destination may occur at these different levels of formal coordination. The formal interactions of relevant agencies may occur between single agencies within or across particular sectors. They may occur between multiple agencies within or across administrative scales. They may also occur across particular sectors and administrative scales. Moreover, they may also interact in an informal way.

In informal coordination, the interaction seems to occur on "ad hoc" bases (R. H. Hall, 1987, p. 246) and “inter-personal contacts" (Alexander, 1995, p. 86). According to Hall (1987), ad-hoc coordination occurs when specific needs, problems, or issues among relevant agencies emerge. According to Alexander (1995, p. 86), "it implies links that are not based on authoritative command and control"; he 
identifies two kinds of links in this coordination form: associative links and solidarity links. Associative links can refer to relationships of kinship and community. This relationship can create strong bonds that sometimes influence the behaviour of the others. The associative relationship appears in most organizations. Solidarity links refer to relationships of sharing common values or ideologies. These relationships seem to bring agreement or consensus based on trust between the members.

The functional integration of management agencies (or destination managers) may be practised in various forms of interaction. In order to integrate multiple agencies from different sectors and administrative scales to the destination scale, a set relationship may be required. The local agencies may act as a focal agency in order to coordinate and cooperate with agencies from other scales. However, in undertaking particular functions at the destination, any form of relation is possible depending on numbers of relevant agencies. The numbers of relevant agencies may be influenced by the complexity of issues and operational functions. With less complexity, a dyadic relationship may take place. In addition, the interactions of relevant agencies may be practised through formal and informal forms of coordination. In this regard, all agencies from both local and other scales can cooperate to achieve the expected outcome.

\subsubsection{Management process}

Generally, an effective management process is likely to bring expected outcomes. In management literature, the management process consists of three main dimensions: management purposes in pursuing goals, the performance of management functions, and coordination of management resources (Sisk, 1969). Likewise, management of the local destination can be practised in a similar way.

First, management needs to have its purposes. Broadly, firms are managed to achieve their organizational goals. In destination management, as discussed in section 2.3.1, the purposes of management may be similar - to achieve common goals or destination goals. Ideally, the management agencies need to develop some kinds of common goals to manage the destination. The common goals should represent some level of mutual agreement between all related agencies for the benefits of their 
agencies and related stakeholders. These common goals can be used in a similar way to destination goals since they articulate benefits for all related stakeholders. However, in managing the destination, it seems to be unclear whether there are any written statements regarding common goals or destination goals. They may not appear in a single document. Some statements from individual organizational visions, missions, and objectives may represent linkages of common goals from different agencies. The mission statements of local agencies regarding tourism may indicate their purposes in relation to destination management and be seen as destination goals. If there is no documentary evidence for destination goals and common goals, intangible evidence, such as common/shared values, seem to be significant to present desired purposes and practices in managing the destination.

Second, destination management should be practised in an integrated fashion. The integration of all management features: destination managers, management structure, management purposes, management activities, and management resources is required in the practice of destination management. However, evidence of this integrated practice is more commonly found in coastal management literature than in tourism management literature.

In coastal management literature, integrated practices are broadly accepted as a management approach to minimise negative impacts and promote economic, environmental, and social sustainability in coastal areas. It is defined as "a continuous and dynamic process that unites government and the community, science and management, sectoral and public interests in preparing and implementing an integrated plan for the protection, and development of coastal ecosystems and resources” (Olsen, Tobey, \& Kerr, 2001, p. 264). Therefore, integrated coastal management (ICM) involves horizontal and vertical cooperation from all related agencies (Harvey \& Caton, 2003; Turner, et al., 2001). The goal of ICM is "to improve the quality of life of human communities who depend on coastal resources while maintaining the biological diversity and productivity of coastal ecosystems” (Olsen, et al., 2001, p. 266). Under this goal, many studies of the ICM literature emphasise particular disciplines such as marine ecology or engineering. Not many studies focus on such inter-disciplinary areas such as economics and marine ecology. 
For example, ICM is implemented in both developed and developing countries in the form of interdisciplinary integration (Garcia, Pollard, \& Rodriguez, 2003) and involvement of all related management agencies (Lamberti \& Zanuttigh, 2005; Mohammed, 2002; Neuman, 1999; Rivera-Arriaga \& Villalobos, 2001). This latter group of studies relates to coastal tourism destinations in particular. As with integrated coastal management (Turner, et al., 2001), tourism destinations require integrated management of the various management features such as destination managers, management structure, and management purposes.

Finally, the integration of resources from relevant agencies is required. A high level of management resource integration from all types and scales of the relevant agencies is necessary for successful outcomes to be achieved. Providing sufficient funding, essential tools and important research data to each other is an example. Funding can be used for the management of all tourism-related activities; for the development and improvement of tourism products, infrastructure and facilities; and for research (Bower \& Turner, 2001; Greiner, et al., 2000). Providing appropriate tools to relevant agencies can assist effective management. These management tools consist of hard tools such as Geographic Information System (Feick \& Hall, 2000) and knowledge maps (Pyo, 2005), and soft tools such as network systems (Dredge, 2006b). Research is used to discover facts and to develop a plan of action based on the facts discovered. Without coordination of these resources, all management activities will struggle to meet their goals. However, in reality, resource integration may depend on the intensity of relationships between relevant agencies: "the higher proportion [of resource exchange], the more intense the relationship. The more intense the relationship, the more important it is for the organizations involved" (R. H. Hall, 1987, p. 249).

Significant features of management practices for the notion of destination management are proposed in this section: destination managers, management structure, and management process (management purposes, management performance, and management resources). These features have been developed from the management perspective and the integrated coastal management perspective. In terms of destination management, integration of all management features at the 
destination scale is required. A conceptual framework for destination management practice, particularly applicable to mature coastal destinations, is introduced in the following section. By applying this framework in the study site of Pattaya, this thesis can develop and broaden understanding of the notion and implication for destination management.

\subsection{A conceptual framework for destination management}

Having reviewed the tourism literature and other related fields of study, key issues in relation to the notion of destination management have been identified. In Figure 2.5, these issues are now brought together into a conceptual framework of destination management. In the framework, these issues are illustrated in the features of destination managers and management structure, management activities, and management purposes. These main features are presented differently in the dimensions of management process and management integration. In the dimension of management process, key issues, in particular management features, are illustrated. How these issues are integrated at the destination scale is explained in the dimension of management integration. Moreover, three levels of integration are expressed. 
Figure 2.5: A conceptual framework for destination management analysis.

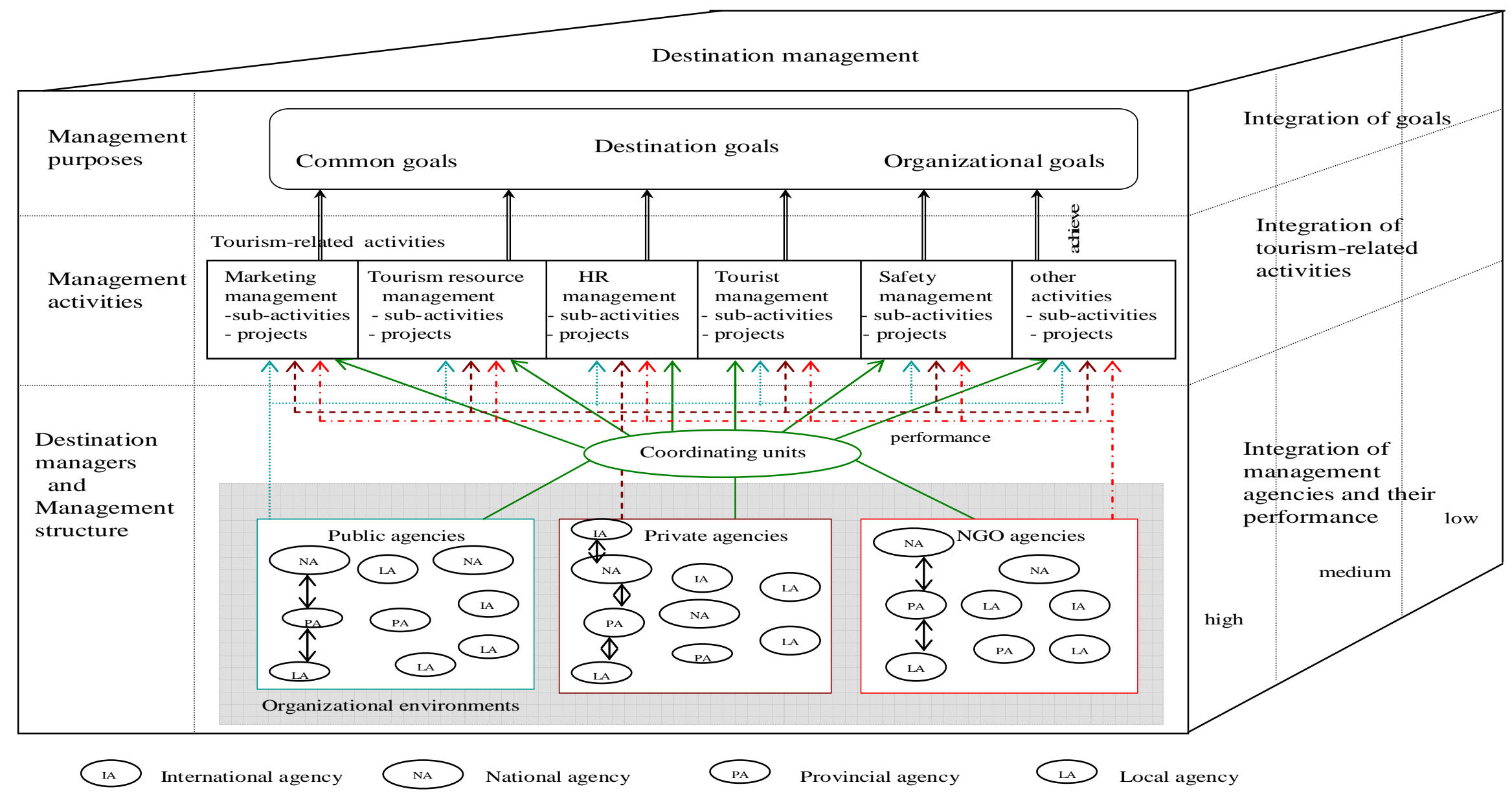


In the first feature, destination managers can be single or multiple agencies from the public, private, or NGO sectors. Within particular sectors, agencies from single or multiple administrative scales may be involved in managing the destination. They may be involved by undertaking single or multiple tourism-related activities (see for the performance of different sectors in operating single or multiple tourismrelated activities). A hierarchy of authority from higher scale agencies to local scale agencies may occur in some agencies. Thus, higher scale agencies in these sectors such as international agencies, national agencies, and provincial agencies may be directly involved in managing the local destination. Moreover, single or multiple agencies across different sectors and administrative scales may work together in coordinating units to carry out single or multiple tourism-related activities (see $\uparrow$ for the performance of coordinating units). The integration of these agencies is presented through numbers of relevant agencies, formal and informal coordination, and multiple resources used in managing particular tourism-related activities. This framework will help to identify destination managers and the management structure at the destination. It will clarify which agencies from which sectors and from which administrative scales are responsible for destination management. It will also clarify the management structure of responsible agencies in managing particular activities and the overall destination.

Ideally, various management activities such as the management of marketing, tourism resources, human resources, safety, and tourist impacts are required in destination management (Ritchie \& Crouch, 2003). Multiple management activities, the second feature of destination management, should be undertaken at the local destination. In managing particular tourism-related activities, the operation of sub-activities, plans, or projects may occur. Sub-activities of tourism resource management, for example, may include attraction management, infrastructure management, and other related subactivities. In each sub-activity, such as attraction management, single or multiple agencies may be involved. This depends on the complexity and issues regarding particular sub-activities or projects. The integration of this feature at the destination scale is measured by numbers of relevant activities involved in managing particular tourismrelated products. However, in the actual operation, single or multiple tourism-related activities may be undertaken at the destination. It is also unclear which activities are 
carried out at the destination. This feature of destination management will help to identify which activities are undertaken in managing the local destination. Thus, it will identify which agencies are responsible for operating those particular tourism-related activities. Besides, it will clarify the purposes in carrying out those activities.

Theoretically, multiple tourism-related activities need to be undertaken to achieve the destination goals, the third feature of the management process dimension. In managing the tourism destination, there seems to be a wide range of possible goals. The existence of multiple management agencies can potentially create a wide range of goals in managing the destination. Basically, these agencies are managed in a way to meet their organizational goals. The management of particular activities requires goals. All goals need to be linked and correspond to the destination goals. In addition, the responsible/management agencies may develop destination goals or common goals in managing particular tourism-related activities. These goals should sustain the destination's economic, social and environmental environment; correspond to the destination's identity or values; and give a clear picture of what the destination aims to be and how the goals can be achieved. Thus, these goals should ensure the quality of tourism resources, to harmonize all tourism elements, and to benefit all tourism stakeholders at the destination. The integration of goals across relevant agencies is presented through their mutual agreements or common goals stated or published as the destination goals. This feature will help to identify which kinds of goals exist in destination management.

In particular management features, the integration of these key issues is rated in three different levels: high, medium, and low (see Figure 2.5 and also Table 2.3). At a high level of integration (represented as 'high' in Figure 2.5 and in Table 2.3), multiple and diverse of management agencies are involved in managing multiple and diverse tourism-related activities to achieve the destination goals. In a medium level of integration (represented as 'medium' in Figure 2.5 and in Table 2.3), various agencies from single or different sectors or administrative scales are involved in managing particular tourism-related activities to achieve some common goals of relevant agencies. At a low level of integration (represented as 'low' in Figure 2.5 and in Table 2.3), single or a few agencies are involved in managing particular tourism-related 
activities. There may be no agreement and even conflict in goals or management purposes may occur. The integration dimension of this framework will help to clarify how and to what extent these key issues are integrated at the destination scale. It will also identify to what extent destination management is generally practised at the local tourism destination.

By using this framework, the thesis can explore how the local tourism destination is managed. The framework will be used to analyse destination management in Pattaya, a mature coastal tourism destination in a developing country. It will enable the researcher to identify destination managers, management activities, and purposes in managing the local destination. Moreover, it will help the researcher to clarify whether there are destination goals or common goals, how different agencies are integrated at the local destination, and to what extent destination management is practised at the destination scale. The outcomes will be the analysis of the destination management practised in Pattaya and recommendations for destination management there and more generally. The result will map out the overall structure of destination management regarding the interactions of relevant agencies and their responsible functions. The management mechanism in managing particular activities and the overall destination will be clarified. All these will be discussed in detail in the chapters that report study results (Chapters 5 - 9). 
Table 2.3: Features and levels of management integration.

\begin{tabular}{|c|c|c|}
\hline \multicolumn{3}{|c|}{ Integration of goals } \\
\hline $\begin{array}{l}\text {-mutual agreements between related agencies for } \\
\text { social, environment, economic benefits of the } \\
\text { agencies and related stakeholders and the destination }\end{array}$ & $\begin{array}{l}\text {-shared visions/values between related agencies } \\
\text { regarding benefits of the agencies and related } \\
\text { stakeholders and the destination } \\
\text {-relationship/linkage between organizational goals of } \\
\text { related agencies in relation to benefits of agencies and } \\
\text { related stakeholders and the destination }\end{array}$ & $\begin{array}{l}\text {-no agreement, no shared visions/values, } \\
\text { no linkage or relationship in } \\
\text { organizational goals of related agencies } \\
\text {-conflict in goals or management purposes } \\
\text { may occur }\end{array}$ \\
\hline \multicolumn{3}{|c|}{ Integration of tourism-related activities } \\
\hline $\begin{array}{l}\text {-multiple/diverse tourism-related activities are } \\
\text { managed to achieve and reflect the destination goals } \\
\text {-diverse sub-activities, plans, projects are undertaken }\end{array}$ & $\begin{array}{l}\text {-some tourism-related activities are to a greater or } \\
\text { lesser extent managed } \\
\text {-some sub-activities, plans, projects are undertaken }\end{array}$ & $\begin{array}{l}\text {-single activities are managed, may or } \\
\text { may not reflect the destination's goals } \\
\text {-few or no sub-activities, plans, projects } \\
\text { are undertaken }\end{array}$ \\
\hline \multicolumn{3}{|c|}{ Integration of management agencies and their performances } \\
\hline $\begin{array}{l}\text { Integration of management agencies } \\
\text {-multiple and diverse agencies from different sectors } \\
\text { and administrative scales are involved in managing } \\
\text { particular tourism-related activities, and the overall } \\
\text { destination }\end{array}$ & $\begin{array}{l}\text {-several agencies from single or different sectors or } \\
\text { administrative scales are involved in managing } \\
\text { particular tourism-related activities }\end{array}$ & $\begin{array}{l}\text {-single or few agencies are involved in } \\
\text { managing particular tourism-related } \\
\text { activities }\end{array}$ \\
\hline $\begin{array}{l}\text { Integration mechanism } \\
\text {-multiple forms of interactions and collective action } \\
\text { are practised by related agencies through their formal } \\
\text { and informal coordination } \\
\text { *formal coordination: e.g. laws, rules, regulations, } \\
\text { mandates, roles of liaison, organizational groups, or } \\
\text { coordinating units } \\
\text { *informal coordination: e.g. ad-hoc actions, associate } \\
\text { links, solidarity links } \\
\text {-diverse and multiple resources are provided by } \\
\text { related agencies in managing particular tourism- } \\
\text { related activities, sub-activities, plans, and projects }\end{array}$ & $\begin{array}{l}\text {-collective actions or interactions are practised } \\
\text { through formal coordination rather than informal } \\
\text { coordination (coordination without cooperation) } \\
\text {-some shared resources are provided by single } \\
\text { agencies, or related agencies in single sectors or } \\
\text { administrative scales }\end{array}$ & $\begin{array}{l}\text {-no evidence of collective action between } \\
\text { related agencies in managing particular } \\
\text { tourism-related activities (conflict in } \\
\text { operation may occur) } \\
\text {-few shared resources are provided by } \\
\text { related agencies }\end{array}$ \\
\hline High & Medium & Low \\
\hline \multicolumn{3}{|c|}{ Dimensions of integrated management } \\
\hline
\end{tabular}


In this thesis, the terms 'tourism destination' and 'destination management' are drawn from the concepts perceived by tourism scholars and by destination management agencies. In tourism literature, these concepts discussed there are expressed by the tourism scholars not the tourism stakeholders. To better understand the notion and nature of destination management, this thesis argues that it is necessary to explore how the tourism stakeholders view the terms 'tourism destination' and 'destination management'. Because they are people who are directly affected by tourism, their views regarding these terms can bring an understanding of their perceptions and involvement in local tourism development and management. However, the views of management agencies are likely to be more important than other groups of stakeholders because they are directly and indirectly responsible for operating the destination. Their views regarding these two terms can bring better understanding of their practices in relation to destination management. Then, the main concepts of these two terms perceived by the management agencies will be incorporated with significant aspects from the tourism literature in order to draw overall concepts of the terms 'tourism destination' and 'destination management'.

\subsection{Conclusion}

This chapter has discussed the notion of destination management with reviews of relevant literature such as tourism management, management principles, interorganizational relationships, and integrated coastal management. However, major aspects drawn from existing literature are those experienced by tourism scholars. This thesis argues that the perceptions of tourism stakeholders, particularly destination management agencies, regarding the terms 'tourism destination' and 'tourism destination management' are important to develop in the notion of destination management. Their perceptions can bring an understanding on how they manage the destination and why they manage it in the way they do. The broad concept of subsequently combining the view of the two groups, scholars and destination management agencies, can bring a better understanding of this notion. Further understanding may result from consideration of the management of the destination in comparison to that of a firm. This analogy can enable the researcher to identify key issues related to major aspects of destination management. These issues indicate that the integration of related agencies to carry out all tourism-related 
activities in a way to achieve the destination goals is required in managing the local destination. Using this analogy, the concept and implications of destination management are clarified and discussed. Key dimensions and features of destination management are illustrated in the conceptual framework. This framework will be used to explore management mechanism regarding destination managers, their roles and responsibilities, and their management structure at the destination scale. The implementation of this framework at the research site will be described in the next chapter. In addition, the methodological approaches used in this study will be explained and discussed in the next chapter. 


\section{Chapter 3 Research Methodology}

\subsection{Introduction}

The review of existing literature regarding tourism destinations and destination management was presented in Chapter 2. Discussions in the literature review raised issues regarding the concepts of a tourism destination, its development and its management. The collaboration of multiple agencies at the local scale destination was underlined, as it is likely to move the destination forward in a sustainable and competitive manner. In the last section of Chapter 2, the conceptual framework of destination management was introduced to illustrate key characteristics in managing the whole destination. This conceptual framework (see Figure 2.5) is used to shape the research design and to structure the research methodology explained in this chapter. Given the complex issues of the study, the research design and methodology are developed in a way to reach the thesis objectives, stated below.

Broadly, this thesis aims to explore how a tourism destination is managed. In pursuit of this aim, the thesis explores what destination management is and clarifies whether destination management is practised in Pattaya. The approaches to achieve these objectives are as follows:

First, the concept of destination management needs to be clarified. In the review of tourism literature discussed previously in Chapter 2, agreement on the meaning of the term 'a tourism destination' does not seem to exist (Framke, 2002; Laws, 1995). Different perspectives regarding this term influence different concepts of destination management. Drawing from the review of the tourism literature, the concepts of destination management can refer to the involvement of multiple agencies, the operation of multiple tourism-related activities, and a desire to achieve common goals. These concepts of destination management are drawn together and visually illustrated in the conceptual framework presented as Figure 2.5. However, the concepts presented are those of tourism scholars not tourism practitioners. This thesis suggests that additional insight into the concept of destination management will be gained from exploring the perspective of practitioners. Then, a broad concept of destination management drawn from both the practitioners' perspectives and the 
tourism literature can be developed. This broad concept will be used to clarify and reflect destination management practised in Pattaya, the study site.

Second, the practice of destination management needs to be explored. Two main approaches need to be undertaken. Firstly, the mechanisms of tourism management need to be clarified and understood. In the review of tourism literature, a variety of issues are found relating to the destination management process: destination managers and management structure, management activities, and management purposes (see Figure 2.5). Some of the tourism stakeholders may act as destination managers (Ritchie \& Crouch, 2003; Sheehan \& Ritchie, 2005) to manage particular tourism-related activities such as natural resources (e.g., Hassan, 2000; Hu \& Wall, 2005; Mihalic, 2000; Tunbridge, 1999), marketing (e.g., Blain, et al., 2005; Lynne \& Geoffrey, 2003; Richard, 1993), tourist impacts (e.g., Lew \& McKercher, 2006; Tabatchnaia-Tamirisa, et al., 1997), and safety (e.g., Fall, 2004; Paraskevas \& Arendell, 2007) in order to achieve particular goals that bring benefits to all tourism stakeholders (TMI, n.d.). The functions for which they are responsible may be differentiated through their organizational operations. These functions may also be integrated through the interactions of different agencies (R. H. Hall, 1987; Selin \& Chavez, 1995) both horizontally and vertically (C. M. Hall, 2000; Pearce, 1992). Methodologically, the management process can be clarified firstly by identifying those managers involved in destination management, their management activities, management structure, and goals; and secondly by clarifying how these aspects are integrated at the destination scale.

Then, levels of integrated management practised at the destination need to be identified. In managing the tourism destination, the integration of destination managers and their management mechanisms, of tourism-related activities, and of goals helps to identify features and levels of integrated management (Table 2.3). In the review of the inter-organizational relationship literature, relevant organizations can interact in various forms of relationships (R. H. Hall, 1987) and through formal and informal forms of coordination (Alexander, 1995; R. H. Hall, 1987). Their interactions occur in managing particular tourism-related activities such as the management of destination marketing and of destination resources. These particular 
tourism-related activities are managed to achieve individual organizational goals and/or the destination goals. Organizational goals may also represent some purposes in relation to destination management. Common goals shared across relevant agencies appear to be necessary for successful destination management (Welford \& Ytterhus, 2004; Westermann, et al., 2005). The methodology used in this study must enable the researcher to identify and assess the levels of integration among destination managers, their coordination, management resources, tourism-related activities and sub-activities, and goals in managing a local tourism destination. This will bring an understanding of the interaction and relationships between relevant organizations and of how they collaborate at the local scale.

In short, given the diversity and complexity of issues regarding destination management mentioned above, this research requires a methodological approach that enables the researcher to clarify the concept and practice of such management. The methodology employed in this study may not enable the researcher to investigate all issues in the destination management literature. However, it must enable the researcher to: 1) identify major issues that will emerge from the research analysis; and 2) integrate those issues to develop an overall picture of destination management. This approach must enable the researcher to explore the concept of destination management from a management point of view and to develop the broad concept of this term, drawing from tourism literature and from a practitioners' perspective. It must also enable the researcher to clarify the destination management process by identifying the destination managers, their management activities, management structures, and goals; and by clarifying how these key characteristics are integrated at the destination scale. In addition, it must enable the researcher to clarify levels of destination management practised at the study site by identifying the integration of destination managers, their coordination, management resources, tourism-related activities and sub-activities, and goals in managing the local destination.

\subsection{Overview of research design}

Considering the exploratory nature of the research objectives, the complex nature of the phenomena under study, and the multiple and complex methodological concerns 
mentioned in the previous section, a qualitative multi-phase case study seems to be an appropriate design for this study. Given the lack of a clear definition of destination management, data obtained using this research design can bring insight and better understanding to the notion of destination management. It also enables the researcher to gather and analyze data in a systematic way. In this research design, four major steps are undertaken: a review of relevant literature, research design development, data collection and analysis, and data integration and interpretation (see Figure 3.1).

Figure 3.1: A flowchart of research methodology.

\section{Research Questions: How is a tourism destination managed? \\ - What is destination management? \\ - Is destination management practised in Pattaya?}

Step 1: A review of relevant literature: Tourism management, principles of management, inter-organizational relationships, and principles of integrated coastal management

- To clarify the concept and practice of destination management (summarized in section 2.3.1; and illustrated in Figure 2.5)

\section{Step 2: Research design}

Multi-phase approach:

To establish a broad concept of destination management

To clarify activities and processes in managing the local tourism destination.

To identify the extent of destination management practised at the study site

A qualitative case study approach:

To deal with complex issues in managing the destination

To gain insight into the management of the local tourism destination

To understand the nature of problems perceived by management practitioners.

\section{$\square$}

\section{Step 3: Data collection and analysis}

Phase I: The conceptualization of the broad subject area and development of interview questions

Data collection methods:

- A review of on-line documents regarding tourism management in the study site Data analytical method

- Document analysis for broadly identifying tourism-related management activities and issues, and destination managers involved in managing tourism at the study site 


\section{Step 3: Data collection and analysis (continued)}

Phase II: Develop preliminary insights into management structure in Pattaya Data collection methods:

- Semi-structured interviews for DM concept from managers’ points of view; and management structure, activities, goals at the study site

- Documents that address destination characteristics and issues; and management structure, activities and goals

- Informal site observation for destination characteristics and issues, and management activities

Data analytical method:

- Coding and content analysis for clarifying the concept of destination management from destination managers' perspectives used for cross-checking the concept in the next interview phase; identifying destination characteristics, tourism-related management activities and relevant issues; and selecting significant management activities for in-depth study in the next phase

Phase III: Background information on the tourism management process in Pattaya

Data collection methods:

- Semi-structured interviews for cross-checking DM concept from managers’ points of view; and for clarifying the practices in managing selected activities

- Documents that address the management process of selected activities

- Formal and informal site observations for management process of selected activities

Data analytical method:

- Coding and content analysis for clarifying the process of managing tourismrelated activities identified and selected from the second phase of the research, and finalizing the concept of destination management from the managers' perspectives

Step 4: Data integration and interpretation

Phase IV: A final analysis of the concept and practice of destination management

- Integration of data from Phase II and Phase III regarding DM concepts for developing a broad concept of DM from the tourism literature and managers’ perspectives

- Integration of data from Phase I to Phase III regarding management practice for clarifying overall practice of destination management at the study site; and identifying the levels of destination management practised there

First, the relevant literature regarding tourism management, principles of management, inter-organizational relationships, and principles of integrated coastal management has been reviewed. This first step was taken to construct a conceptual 
and analytical framework of destination management (summarized in section 2.3.1; and illustrated in Figure 2.5). The conceptual framework depicts the mechanisms that may exist in managing the local destination and is used to bring about a better understanding of the notion of destination management rather than attempt to predict it (Blaikie, 2000). This framework enables the researcher to identify aspects of destination management and to clarify how they are integrated at the scale of a local tourism destination. It is also used to shape the research design and to provide the structure for data collection and analysis through the research process.

Second, the research design is developed using a mixed design of a qualitative case study and a multi-phase approach. This qualitative multi-phase case study enables the researcher to reveal the practitioners' perspectives and their practices relevant to destination management, and to explain what is happening in managing the local tourism destination. A qualitative case study enables the researcher to deal with the diverse and complex issues relevant to destination management that may exist at the local destination. It also enables the researcher to gain broad and in-depth information regarding destination management. A multi-phase approach enables the researcher to systematically clarify the concept and practice of destination management. In this research, three phases of data collection and analysis and one phase of data integration and interpretation are involved.

The third step involves the three phases of data collection and analysis that are systematically undertaken. Results from the analysis of one phase determine issues to focus on in the following phase or phases. A recursive relationship exists between data collection and analysis, and the conceptual framework. The first phase builds an overall picture of the site and its tourism management. The primary respondents are identified in this phase. The interview questions are also synthesized in this phase of the study. The second phase is designed to develop preliminary insights into the management structure at the study site. Primary data are collected and analysed to clarify the concept of destination management from the practitioners' perspectives. The broad concept of destination management drawing from the practitioners' views and the tourism literature is also developed in this phase. Both primary and secondary data are collected and analysed to identify significant tourism 
management activities at the study site. Then, key activities are selected for in-depth study in the next phase. The third phase of data collection and analysis develops background information on the tourism management process existing at the study site. Primary and secondary data are used for clarifying and identifying the process and integrated practices in managing the selected activities. The broad concept of destination management developed in the second phase analysis is also crosschecked against the participants' perspectives in this third phase of research. The concepts of destination management perceived by the practitioners and the process and integration in managing tourism at the local destination are clarified.

Finally, results received from the previous three phases of data collection and analysis are integrated and interpreted in the last phase of research to develop an overall picture of destination management. In this step, the broad concept of destination management, drawing from the tourism literature and the managers' perspectives, is synthesized. In addition, the overall practice of destination management is clarified and the levels of destination management practised are identified. The results obtained from this research methodology will be described in detail in Chapters 5 to 9. Justification for selecting this particular design and the research methods used is given in the following sections of this chapter.

\subsection{A qualitative case study}

In order to explore and explain this substantive area, a qualitative case study is appropriate because it can be used to uncover respondent views (Creswell, 2003; Guba \& Lincoln, 1994) and to gain contextual information and insight into human behaviour (Guba \& Lincoln, 1994) relevant to destination management. In qualitative research, a case study approach is commonly used as "exploratory research, in areas where there are few theories or a deficient body of knowledge" (Hussey \& Hussey, 1997, p. 66). It enables the researcher to focus not only on the research process but also on the context of the case (Stake, 2005), which can bring a better understanding to the way destination management is practised at the study site. Commonly, qualitative research is criticized in relation to the small number of respondents involved, but the qualitative information obtained provides depth and contextual information (Veal, 1997). This provides an opportunity for the researcher 
not only to reveal the management mechanisms existing there but also to understand the reasons behind them (Guba \& Lincoln, 1994).

By using this approach, the researcher can be more flexible in data collection and analysis in order to explore and clarify the complex phenomenon (Creswell, 2003; Morgan \& Smircich, 1980; Stake, 2005; Walle, 1997). Multiple qualitative techniques such as semi-structured interviews with key informants, site observation, and analysis of documents can be used to gain broad, in-depth, and detailed information relevant to the notion of destination management. These techniques also enable the researcher to be more "interactive and humanistic" with the respondents while obtaining the research data (Creswell, 2003, p. 181). Coding (Strauss \& Corbin, 1998) is used in the analysis to identify major themes and patterns of the responses. It also enables the researcher to identify similarities and differences of responses between different groups of respondents.

A qualitative case study seems to be widely employed as it enables the researcher to answer what, how, and why questions. In the tourism literature, a single case study has been used to bring understanding to destination management issues (Welford \& Ytterhus, 2004), performance of tourism partnerships (Augustyn \& Knowles, 2000), collaboration between relevant organizations or stakeholders (Bramwell \& Sharman, 1999; Medeiros de Araujo \& Bramwell, 2000), network or stakeholder interrelations (Dredge, 2006a; Ladkin \& Bertramini, 2002; Lovelock, 2001; Plummer, et al., 2006), and attraction competitiveness (d'Hauteserre, 2000). It is also used in the integrated coastal management literature to understand policy development (Neuman, 1999; Noronha, 2004) and integrated management (Lamberti \& Zanuttigh, 2005; Mohammed, 2002; Xue, Hong, \& Charles, 2004) practised in coastal areas. By using a single case study approach, these studies can examine the overall nature of the research problem and clarify the circumstances and conditions of the everyday situation, the experiences of a person or institution (Yin, 2003), or the phenomenon under observation. However, this holistic case study may lead researchers to overlook specific information that is necessary for the study. This weakness can be minimized by using an embedded case study, i.e., a study of sub-cases within single case research (Yin, 2003). Therefore, a mix between holistic and embedded case 
analysis appears to be the most appropriate single case study design because it can provide specific and holistic information regarding the topic in question.

In this qualitative single case study, a mix of holistic and embedded designs is adopted in order to minimise the weaknesses of a single case study approach and to strengthen the validity of the research process and the results obtained. By using this mixed design, general and specific information regarding issues and mechanisms in tourism management can be revealed to provide an overall picture of destination management. It can bring an answer to 'what' and 'how' questions, while an answer to a 'why' question can be articulated within the case context.

\subsubsection{Selection of the study site}

In terms of destination management, agencies that are involved in managing the mature destinations, particularly mature coastal destinations, appear to have more challenges than those involved in managing newly developed destinations. According to the destination life cycle, mentioned earlier in Chapter 2, there are diverse and complex issues in mature tourism destinations. The management mechanisms adopted there may represent the complex issues regarding destination management such as tourism management activity and interactions between relevant agencies. Thus, the complex characteristics of resort destinations (Aramberri, 2000) seem to propose more challenges to people responsible for destination management. Therefore, the characteristics of a mature resort destination are the significant criteria for the site selection.

Considering the above criteria as well as practicality, Pattaya has been chosen for this study. When comparing to other major tourism destinations in Thailand (as identified in Chapter 2), Pattaya appears to be an excellent case for studying destination management because of its complex characteristics as a beach resort. Its special form of political system in the country tends to involve multiple management agencies which may add managerial complexity and difficulty in destination management. 
First, Pattaya represents a prime case of a mature coastal tourism destination with its diverse tourism products and tourism-related activities. Since tourism has been developed in Pattaya for more than four decades, a variety of tourism products provided create diverse and complex issues regarding tourism development and management. This reflects the typical characteristics of mature destinations (Pattaya City, 2004; Smith, 1992). Practices in operating these tourism-related products and activities in a way to bring out an integrated-whole of the destination seem to be challenging. Thus, contrast characteristics of Pattaya during daytime and night time (will be described in Chapter 4) appear to indicate more challenges in terms of managing Pattaya as a tourism destination.

Second, Pattaya has been selected because there are multiple agencies involved in its tourism development and management. Since Pattaya has greatly contributed to the country's economy, it seems to draw much attention by various agencies in solving its tourism-related issues or problems. Prime responsibility for Pattaya appears to lie in its special form of local self-government (IDRC, 1997), while other agencies from public and private sectors and from different administrative scales are likely to be involved in secondary roles. However, the roles of Pattaya's government and other agencies and their inter-relationships in managing Pattaya are unclear. Analysis of the management of Pattaya may bring better understanding to the diverse and complex nature of the destination management process existing at the mature coastal destination in a developing country. As a result, the roles of Pattaya's local government and other agencies and their relationships in managing Pattaya will be clarified. The context of Pattaya will bring understanding to why destination management is practised the way it is. Contextual issues will be examined in more detail in Chapter 4.

Third, Pattaya has been selected because of its practical suitability in terms of its location and local context. Pattaya is one of the main tourism coastal destinations in the eastern region of Thailand (Anon., 2001; Pattaya City, 2005) and it is also located approximately forty kilometres from the workplace of the researcher. As a Thai university lecturer who grew up and has been working in the eastern region of Thailand, the researcher can give insights into the context of Pattaya regarding its 
local economic, social, and political environments. Although the researcher's appearance in the data collection process is presented as an observer or investigator, her role can also be perceived as that of an insider. Her role may have an impact or influence on the research results. Although every effort is made to ensure objectivity, her background and sensitivity may bring certain biases such as optimistic critique to the study (Creswell, 2003). These biases may shape the way the researcher views and understands the collected data.

In this thesis, Pattaya is selected as a holistic case study, while key areas of management in Pattaya are selected as embedded cases. As a selected case, Pattaya is analyzed to clarify and identify the concept and practice of destination management. In order to bring out an overall concept of destination management, Pattaya, as a whole destination, is used for a holistic case study analysis (Yin, 2003). The broad concept of destination management can be identified by integrating the concept of destination management drawn from the tourism literature to the concept perceived by tourism practitioners. On the other hand, key areas of management, which are obtained from the interview responses, are selected as embedded cases for an indepth study to clarify its management process and practice. Primary and secondary data regarding tourism management in general and embedded cases in particular are used to clarify the overall practice of destination management. The processes in managing these embedded cases can illustrate how the overall destination is managed in terms of interactions/relationships between relevant agencies, their functions, and management purposes. Then, results received from these cases are drawn together to provide a comprehensive view of destination management. The identification and justification of these selected activities will be explained in the next section.

By selecting Pattaya and its key management areas for a mixed-design analysis, broad and in-depth and detailed information regarding the concept of destination management, the management process, and integrated management can be obtained. In this study, respondents represent organizations or agencies that are involved in the daily operation of the local destination. Their actions or management activities appear to influence the condition and existence of the tourism destination and so their perspectives and practices can provide insight into destination management. By using 
a mixed holistic and embedded case study approach, qualitative information regarding the tourism destination, the concept of destination management, and the management process and outcomes can be obtained directly from these respondents. This approach also enables the researcher to examine closely the management mechanisms of tourism-related activities practised at the destination. In this regard, the qualitative study of Pattaya can provide data that brings a better understanding to the notion of destination management, particularly in the context of mature coastal destinations in developing countries. Given the diverse and complex issues regarding destination management and methodological approach, a multi-phase technique seems to be helpful to structure and organize the research process in a systematic way.

\subsection{A multi-phase approach}

Multiple phases of data collection and analysis are necessary as they enable the researcher to systematically obtain broad to specific information regarding the concept and practice of destination management. In this study, four phases are undertaken (see Figure 3.2): subject conceptualization, preliminary insight development, background information development, and the final analysis of the concept and practice of destination management. Initially, general information regarding the destination needs to be conceptualized in order to broadly identify its tourism conditions, tourism-related activities, issues currently existing at the destination, and relevant agencies involved in managing those activities or solving those issues. Then, the concept and practice of destination management perceived by practitioners need to be identified to provide an overall picture of destination management from the respondents' points of view. Next, the process of tourism management is clarified to illustrate practices in managing the local tourism destination. Finally, all data are integrated and interpreted to clarify and identify the overall concept and practice of destination management currently existing in Pattaya. The main characteristics of destination management, illustrated in Figure 2.5, are used as broad categories for data collection and analysis in these four phases. Other categories relevant to destination management that emerged from the data analysis are also used in the subsequent phases of analysis. 
Figure 3.2: A summary of four phases of data collection and analysis.

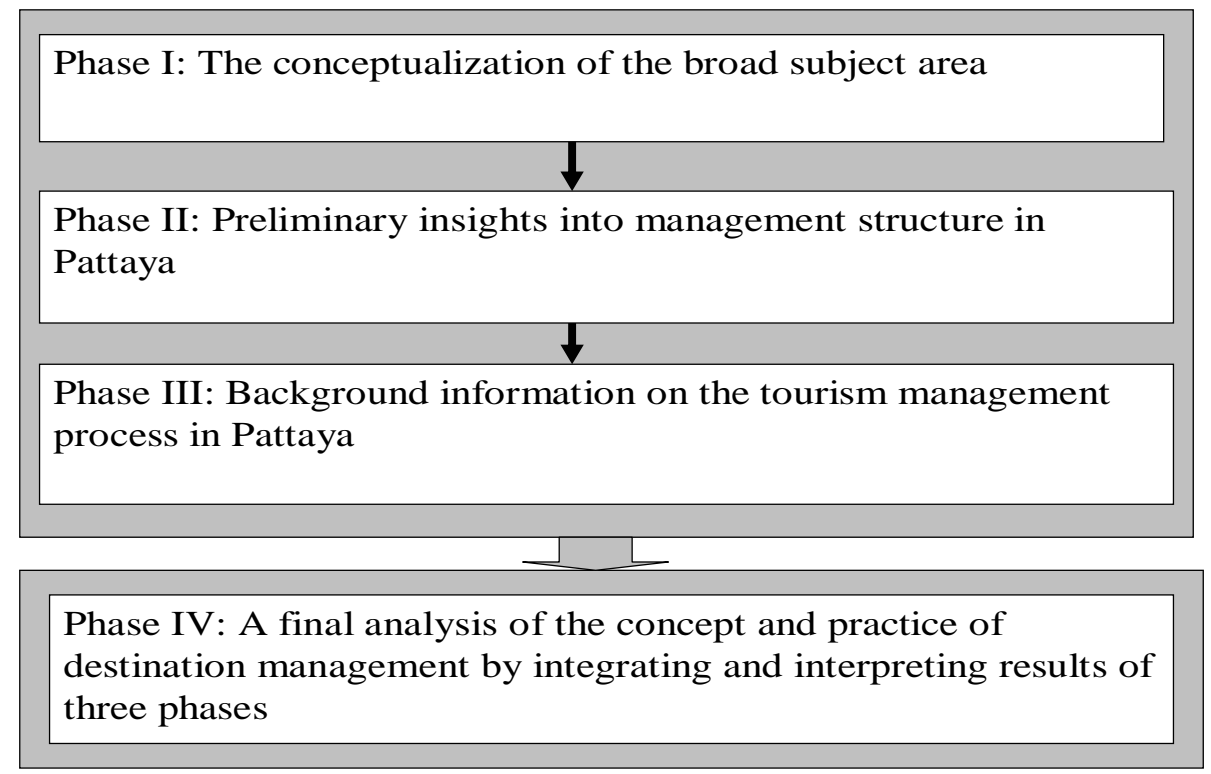

In the first phase, on-line data relevant to tourism management in Pattaya were reviewed to establish general information relevant to the destination and its tourism regarding management agencies, tourism-related activities, and management issues in Pattaya. This method was intentionally used because it enabled the researcher to conceptualize the subject area without visiting the study site. With this method, the researcher was able to investigate the situation of tourism at the study site within the specified time period. It also enabled the researcher to access information conveniently in terms of place and time which significantly reduce the travel expenses of the research project. The information received from this phase was also used to identify primary respondents and develop interview questions used in the next phase.

In the second phase, primary and secondary data were collected to develop preliminary insights into the structure of tourism management at the study site. The holistic view regarding destination management from the managers' perspective was also collected in this phase. General information regarding management agencies, and their activities and responsibilities in managing Pattaya's tourism was collected and identified. Key areas of management, perceived by the respondents, were selected as the embedded cases for an in-depth study in the next phase. 
In the third phase, after both previous phases were completed, an in-depth study to access data relevant to the practices of destination management in the selected subcases was undertaken. Although a range of activities need to be managed in Pattaya, the interview responses from the second phase highlighted three fundamental tourism attractions: beaches, nightlife, and the Pattaya Music Festival. Other activities such as natural resources and infrastructure were not selected since the interviews suggested they would provide less insight into the mechanisms and practices in relation to destination management, particularly management at the local scale. The management of beaches and nightlife represents attractions managed on a daily basis, while Pattaya Music Festival represents project management. Moreover, different types and levels of integration or collaboration seem to occur in the management of these three sub-cases. Primary and secondary data regarding the management process of these three sub-cases were collected and analyzed to obtain specific information regarding the mechanisms and practices and to develop background information on the tourism management process at Pattaya. The concept of destination management developed in the previous phase was also used in this third phase to cross-check the practitioners' perspectives on the concept of destination management.

Finally, data received from the first three phases were integrated in the last phase of the study to finalize the research outcome that provides an overall concept and practice of destination management.

In short, the research design introduced in this section enables the researcher to gain insight into the notion of destination management, particularly from a management point of view. By using qualitative multi-phase case study research, the concept and practice of destination management can be explored, clarified, and explained. It helps the researcher to identify key issues in destination management, to clarify how they are integrated at the destination scale, and to establish the extent of destination management in Pattaya. As noted in previous chapters, the notion of destination management is rather new and complex and research in this area is still largely exploratory. As a result, it is appropriate for this study to focus on the current management process rather than attempt to also analyze management practices in the past and what may happen in the future. A repeat of this study in the future may be 
required to understand the direction and changes of the destination management mechanisms. In the following sections, the information regarding particular phases of data collection and analysis is described. The information regarding why and how these phases are used to gather the research data is explained. Multiple qualitative methods used to collect primary and secondary data are clarified. The presentation of some key findings is necessary to identify issues that are studied in the following phases of the research. The holistic analysis for the concept and practice of destination management is also described at the end of this chapter.

\subsubsection{Phase I: The conceptualisation of the broad subject area}

In this phase, on-line documents were used as an "unobtrusive source of information" that allow the researcher access at any time (Creswell, 2003, p.187). They were collected and reviewed in January and February 2006 to form the basis for the second phase of research. First, four different on-line databases (Table 3.1) related to Pattaya and its tourism between the years 2005 and 2006 were reviewed as well as existing volumes of Thai newspapers (e.g. Manager, Bangkok Post, The Nation) were reviewed to investigate tourism-related issues in Pattaya during the chosen time period. Through this method, current tourism conditions, activities, and general issues were identified. Secondly, on-line information regarding organizational charts and names of executive managers of those agencies was reviewed to identify primary respondents for the second phase of research. Nineteen respondents from sixteen organizations were listed and contacted to participate in the second phase data collection to gain general information on their purposes, roles, and involvement in managing Pattaya’s tourism. 
Table 3.1: Names and scales of databases used for data collection.

\begin{tabular}{|l|l|l|}
\hline \multicolumn{1}{|c|}{$\begin{array}{c}\text { Names of data } \\
\text { bases }\end{array}$} & $\begin{array}{c}\text { Operational } \\
\text { scales }\end{array}$ & \multicolumn{1}{|c|}{ Types of information } \\
\hline Pattaya.com & Local & Local news \\
\hline Pattayacityhall.com & Local & $\begin{array}{l}\text { Organizational information } \\
\text { News related to } \\
\text { organizational activities }\end{array}$ \\
\hline Manager.co.th & National & $\begin{array}{l}\text { News from Manager (daily } \\
\text { newspaper) }\end{array}$ \\
\hline Global.factiva.com & International & $\begin{array}{l}\text { News from Bangkok Post } \\
\text { and The Nation }\end{array}$ \\
\hline
\end{tabular}

Table 3.2: A framework for Phase I analysis.

\begin{tabular}{|l|l|l|l|}
\hline \multicolumn{3}{|c|}{ A review of on-line information } \\
\hline & $\begin{array}{l}\text { Tourism-related } \\
\text { issues }\end{array}$ & $\begin{array}{l}\text { Management } \\
\text { activities }\end{array}$ & $\begin{array}{l}\text { Management } \\
\text { agencies }\end{array}$ \\
\hline 1. & & & \\
\hline 2. & & & \\
\hline $\mathrm{X}$. & & & \\
\hline
\end{tabular}

Data received from this first phase were analysed using the analytical framework, presented in Table 3.2 in order to identify major issues, activities, and responsible agencies related to tourism management in Pattaya. These may be summarized as follows:

- Tourism-related issues

o Degradation of natural resources

o Environmental problem/pollution

o Waste and garbage

o Fresh water shortage/physical development

o Crime

- Management activities 
o Marine resources improvement projects

o Waste water treatment project

o Cleaning projects

o Safety projects

o Tourism promotion and marketing

- Participating agencies

o Local government/Pattaya government

o Provincial government/Chonburi governor

o National/central government

o Regional tourism organization

o Local police office

o Regional tourist police office

o Local and regional tourism/hotel associations

o Local and other scale businesses

o Local and other scale non-profit organizations

The results received in this preliminary phase of analysis support the literature that there are various aspects to managing the local tourism destination, particularly the multiplicity of agencies involved in the management of tourism-related activities. However, the roles of these agencies in managing particular activities and the destination as a whole remained unclear. Thus, it was necessary to examine the managers' perceptions of Pattaya, the terms 'destination' and 'destination management', and management practices in Pattaya. Open-ended interview questions were required to obtain this information. Using the results of this first phase analysis, the interview questions were developed and used for the second phase of data collection. Most of the interview questions related to the respondents' perceptions regarding Pattaya, its tourism characteristic and issues, concepts/definitions of the terms 'destination' and 'destination management', and their practices in relation to tourism management in Pattaya. These interview questions are described in more detail in section 3.4.2.1. 


\subsubsection{Phase II: Preliminary insights into management structure in Pattaya}

In this phase, data was collected from mid March to mid May 2006. The methods to obtain information were semi-structured interviews, informal direct observation, and contextual data.

\subsubsection{Semi-structured interview and interviewing process}

Semi-structured interviews were undertaken to obtain information directly from the respondents. A semi-structured approach is less formal but enables the researcher to take "control over the line of questioning" by using the checklist of questions (Creswell, 2003, p. 186) developed in the first phase of the research. Initially, the researcher attempted to use structured interviews but it proved quite difficult to follow the strict sequence of questions and a semi-structured interview was used instead, since its more conversational style enabled the researcher to access the facts and the respondents' opinions (Caffyn \& Jobbins, 2003; Yin, 2003) about Pattaya and its tourism management.

In this phase of interviews, the respondents, who had been identified from the preliminary analysis, were top or middle executive staff such as the Mayor and council members of Pattaya City, the CEO and managers of public and private agencies, and NGOs involved in managing tourism in Pattaya. Because these respondents are perceived as representatives of the agencies, they are more likely to provide official views of tourism management in Pattaya. Being perceived as important people in the agencies, the top and middle executives are easy to identify, but can be difficult to access (Thomas, 1993).

In February 2006, nineteen respondents from sixteen organizations were contacted for their permission and willingness to participate in the study. Letters and interview questions were sent in advance for interview permissions and appointments. Then, phone calls were followed for interview schedules. These approaches were successfully done mostly with their secretaries or administrators, the 'gatekeepers' of these executives (Thomas, 1993). Fourteen respondents from the public sector, two from the private sector, and three from environmental related NGOs agreed to participate in the interviews (Table 3.3). However, most interview appointments 
were rescheduled due to urgent and more important business. For their convenience, most of the interviews were held at the interviewees' offices; one respondent was interviewed in a hotel lobby. The interviews, each of which lasted approximately one hour, were conducted in Thai to make the respondents feel more comfortable to express their opinions in their own language. All interviews were audio recorded and transcribed by the researcher.

Table 3.3: Phase II interview respondents from different sectors and administrative scales.

\begin{tabular}{|c|c|c|c|}
\hline & Public sector & Private sector & NGO sector \\
\hline $\begin{array}{l}\text { National } \\
\text { agency }\end{array}$ & - & $\begin{array}{l}\text { Bangkok } \\
\text { Airport (1) }\end{array}$ & $\begin{array}{l}\text { Sawasdee Foundation (1) } \\
\text { Green Leaf Foundation (1) } \\
\text { Thai Environment Institute (1) }\end{array}$ \\
\hline $\begin{array}{l}\text { Regional } \\
\text { agency }\end{array}$ & $\begin{array}{l}\text { Tourism Authority of Thailand, Central } \\
\text { Region } 3 \text { office (1) } \\
\text { Marine Transportation office (1) } \\
\text { Tourist Police, Region } 3 \text { office (1) } \\
\text { Water Distribution Sector, Pattaya office (1) } \\
\text { Environmental and Natural Resources, } \\
\text { Region } 13 \text { office (1) }\end{array}$ & - & - \\
\hline $\begin{array}{l}\text { Provincial } \\
\text { agency }\end{array}$ & $\begin{array}{l}\text { Provincial government office (1) } \\
\text { Provincial Administrative Organization (1) } \\
\text { Provincial Environmental and Natural } \\
\text { Resources Office (1) } \\
\text { Dept. of Sport \& Tourism, Chonburi office } \\
\text { (1) } \\
\text { Ground Transportation, Chonburi office (1) }\end{array}$ & - & - \\
\hline Local agency & Pattaya City (4) & $\begin{array}{l}\text { Tourism } \\
\text { Business } \\
\text { Association (1) }\end{array}$ & - \\
\hline $\begin{array}{l}\text { Total } \\
\text { respondents } \\
=19\end{array}$ & 14 & 2 & 3 \\
\hline
\end{tabular}

For the interviews, a check-list of twenty-eight questions had been developed from the previous phase (see Appendix A). These questions were clustered into four main sets: questions regarding respondents and their organizations, questions regarding Pattaya, questions regarding respondents' perceptions of the concepts and definitions of destination management, and questions regarding their operations relevant to destination management. The first set of interview questions was used not only to gather information about the respondents and their organizations but also to establish 
a rapport between the researcher and the respondents. This technique helped the respondents to feel more comfortable to express their ideas in the latter parts of the interview. The second set of questions was related to Pattaya's characteristics and issues. The third set of questions was used to obtain management perspectives on the concepts of 'a tourism destination' and 'destination management'. Regarding the concepts of 'a tourism destination' and 'destination management', the respondents were asked to define these two terms and to reflect on how Pattaya matched their own definitions. They were then asked to read two key statements taken from the tourism literature, to give their views on these statements, and to reflect on how well Pattaya matched them. These two statements were selected as they are clear and concise definitions that could be readily understood by the respondents. The statements used in this second set of questions were as follows:

\footnotetext{
"The destination must function as a real entity. That is, it must have a sense of itself; it should have a purpose and be managed in a way that promotes the pursuit of that purpose.” (Ritchie \& Crouch, 2003, p. 67)

"Destination management is the integrated process of managing any of the three tourism destination types (urban, resort, and rural). It covers four key elements; the destination offering (visitor experience, destination image and attractiveness); the visitor mix (market research); marketing communications (awareness and promotion); and organizational responsibility (leadership and partnership).” (Anderson, 2000a, p. 146)
}

A final set of questions related to the purposes of destination management, responsible functions, involvement levels and the interaction with other management agencies. The last question was used as a snowball technique to ask the respondents, as management agencies, to identify other relevant agencies (Medeiros de Araujo \& Bramwell, 2000) involved in managing tourism in Pattaya. Data obtained from these interview questions were used to clarify management perspectives on their participation in managing Pattaya's tourism.

\subsubsection{Informal site observation}

Besides the interviews, informal direct observation was used in multiple visits to the site (Yin, 2003). This allowed the researcher to "have a firsthand experience" and to "record information as it is revealed" (Creswell, 2003, p.186). This type of data collection enabled the researcher to observe the overall physical and socio-economic context of the site. Photographs taken at the site were used for visual evidence. They 
were also used for additional contextual data regarding tourism characteristics and issues in Pattaya.

\subsubsection{Documents and photographic evidence}

Documents (see examples in Table 3.4) and photographic evidence were compiled while visiting the site. Official documents, such as meeting minutes, reports, and official letters, represent "data that are thoughtful, in that participants have given attention to compiling” (Creswell, 2003, p. 187). The official documents voluntarily provided by the respondents were used to identify their functions and interactions in managing Pattaya's tourism. They were also used to verify general and specific information regarding the roles and responsibilities of the respondents' organizations in managing tourism in Pattaya. Other documents such as tourism statistics and marketing plans were used to provide contextual information regarding Pattaya tourism. Photographic evidence such as contained in brochures, booklets, and $\mathrm{CD} / \mathrm{DVDs}$ is useful in providing additional information about the case and presenting its characteristics to outside observers (Yin, 2003). This material is used for visual evidence regarding overall characteristics and tourism management in Pattaya.

Table 3.4: Examples of documents collected in Phase II.

\begin{tabular}{|l|}
\hline \multicolumn{1}{|c|}{ Documents } \\
\hline • Strategic development plan of Pattaya for the years \\
2005-2009 \\
• A report of environmental impact analysis on Pattaya \\
redevelopment project (Royal Thai Government, 1996) \\
•Pattaya Adminstration Acts 1999 \\
-Domestic tourism statistics in Eastern region \\
(years 1996-2006) \\
-Tourism statistical report years 1996-2005 \\
-Tourism marketing plan for the years 1996-1998, \\
2000-2002, 2004-2006
\end{tabular}

\subsubsection{Data analysis}

The collected data were analyzed during June and July 2006 to form the basis for the following phase of data collection. In this analysis, the collected data were analyzed 
to clarify and identify the concept and practice of destination management, and the case context (see Table 3.5). Regarding the concept analysis, a broad concept of destination management was analyzed by integrating major aspects of this term perceived by the respondents with major aspects of this term drawn from the tourism literature (see details in section 3.4.4.1). This broad concept was used in the third phase interview to cross-check the respondents' perspective. Besides the concept analysis, management activities, relevant agencies, their responsible functions, and their purposes in managing tourism in Pattaya were broadly identified for the practice of destination management. To obtain specific information regarding the practice of destination management, the management of beaches, nightlife, and Pattaya Music Festival was studied in the third phase of data collection. The interview questions used for the third phase of data collection were developed focussing on these three areas of management.

Table 3.5: A framework for Phase II analysis.

\begin{tabular}{|c|c|c|c|c|}
\hline & \multirow{2}{*}{$\begin{array}{c}\text { Concept of } \\
\text { Destination } \\
\text { management }\end{array}$} & \multirow{2}{*}{$\begin{array}{l}\text { A sense of } \\
\text { Pattaya } \\
\text {-characteristics } \\
\text {-issues }\end{array}$} & \multicolumn{2}{|c|}{ Pattaya's tourism management } \\
\hline & & & $\begin{array}{l}\text { Management of } \\
\text { tourism-related } \\
\text { activities }\end{array}$ & $\begin{array}{l}\text { Management } \\
\text { purposes }\end{array}$ \\
\hline Primary/secondary & $\begin{array}{l}\text { Primary/ } \\
\text { Literature } \\
\text { review }\end{array}$ & $\begin{array}{l}\text { Primary/ } \\
\text { Secondary }\end{array}$ & $\begin{array}{l}\text { Primary/ } \\
\text { Secondary }\end{array}$ & $\begin{array}{l}\text { Primary/ } \\
\text { Secondary }\end{array}$ \\
\hline \multicolumn{5}{|l|}{$\begin{array}{l}\text { Destination } \\
\text { managers }\end{array}$} \\
\hline \multicolumn{5}{|l|}{ agency names } \\
\hline \multicolumn{5}{|l|}{ organizational goals } \\
\hline \multicolumn{5}{|l|}{$\begin{array}{l}\text { types and levels of } \\
\text { operation }\end{array}$} \\
\hline $\begin{array}{l}\text { roles and } \\
\text { responsibilities }\end{array}$ & & & & \\
\hline
\end{tabular}

The method used in analysing the interview responses was coding (Strauss \& Corbin, 1998). Interview data were broken down into parts by looking at key words or phrases corresponding to the interview questions. Then, they were compared for similarities and differences. They were grouped and labelled/coded in different 
categories and sub-categories in relation to their shared characteristics (known as 'open coding' method mentioned by Strauss \& Corbin, 1998). In the coding process, the researcher could simply group and code those key words into different subcategories and categories. For example, key words 'beach', 'sea', and 'islands' were commonly mentioned by the respondents when describing the characteristics of Pattaya. These key words shared the same characteristics of coastal resources. Therefore, they were grouped and coded under the coastal resource category. At the same time, key words 'entertainment services', 'beer bars', and 'sex tourism' were also mentioned by the respondents when describing Pattaya's characteristics. They shared the same characteristics of nightlife attraction. So, they were coded and grouped in the nightlife category. These two categories became sub-categories since they shared the same characteristic based on types of tourism attractions. In this case, they were grouped together and coded under the broader category named 'attractions'.

In addition, the frequency of words relating to particular categories or sub-categories mentioned in the interviews was used to clarify the main theme of responses. This technique can be used in qualitative research to discover patterns of ideas in the textual data (Pool, 1959; G. W. Ryan \& Bernard, 2000). Table 3.6 is an example of the frequency of words relating to coastal resources and nightlife mentioned in the interview responses regarding Pattaya's characteristics. Multiple responses were recorded. This process enabled some similarities and differences in responses to be identified, although they must be viewed cautiously given the small number of organizations involved. Table 3.7 and Table 3.8 are examples of the frequency of words relating to coastal resources and nightlife which arose in the same question by different groups of respondents. This technique enabled the researcher to build up a concept of destination management, to identify major characteristics and issues in Pattaya, to identify major aspects of destination management, and to identify key areas of management that were selected as sub-cases for an in-depth study in the next phase. 
Table 3.6: Pattaya's characteristics perceived by nineteen respondents.

\begin{tabular}{|l|l|c|c|}
\hline Categories & \multicolumn{1}{|c|}{$\begin{array}{c}\text { Sub- } \\
\text { categories }\end{array}$} & Frequency & Total \\
\hline Attractions & $\begin{array}{l}\text { Coastal } \\
\text { resources }\end{array}$ & 14 & $29 *$ \\
\cline { 2 - 4 } & Nightlife & 13 & \\
\cline { 2 - 4 } & Other types & 2 & $14^{*}$ \\
\hline Services & $\begin{array}{l}\text { Tourism } \\
\text { services }\end{array}$ & 7 & \\
\cline { 2 - 4 } & Accessibility & 7 & \\
\hline
\end{tabular}

* Responses add up to more than total of respondents as multiple responses were given.

Table 3.7: Pattaya's characteristics perceived by different organizational levels of respondents.

\begin{tabular}{|c|c|c|c|c|c|}
\hline \multirow{2}{*}{$\begin{array}{l}\text { Levels of } \\
\text { respondents' } \\
\text { organizations }\end{array}$} & \multicolumn{3}{|c|}{ Attractions } & \multicolumn{2}{|c|}{ Services } \\
\hline & $\begin{array}{l}\text { Coastal } \\
\text { resources }\end{array}$ & Nightlife & $\begin{array}{l}\text { Other } \\
\text { types }\end{array}$ & $\begin{array}{l}\text { Tourism } \\
\text { services }\end{array}$ & Accessibility \\
\hline $\begin{array}{l}\text { National to } \\
\text { provincial } \\
\text { scales }\end{array}$ & 10 & 9 & 1 & 1 & 3 \\
\hline Pattaya scale & 4 & 4 & 1 & 6 & 4 \\
\hline Total & 14 & 13 & 2 & 7 & 7 \\
\hline & \multicolumn{3}{|c|}{ Total $=29 *$} & \multicolumn{2}{|c|}{ Total $=14^{*}$} \\
\hline
\end{tabular}

* Responses add up to more than total of respondents as multiple responses were given.

Table 3.8: Pattaya's characteristics perceived by different types of respondents' organizations.

\begin{tabular}{|l|c|c|c|c|c|}
\hline $\begin{array}{l}\text { Types of } \\
\text { respondents, } \\
\text { organizations }\end{array}$ & \multicolumn{3}{|c|}{ Attractions } & \multicolumn{2}{c|}{ Services } \\
\cline { 2 - 6 } & $\begin{array}{l}\text { Coastal } \\
\text { resources }\end{array}$ & Nightlife & $\begin{array}{l}\text { Other } \\
\text { types }\end{array}$ & $\begin{array}{l}\text { Tourism } \\
\text { services }\end{array}$ & Accessibility \\
\hline $\begin{array}{l}\text { National to } \\
\text { local public } \\
\text { agencies }\end{array}$ & 6 & 5 & 2 & 4 & 4 \\
\hline $\begin{array}{l}\text { Provincial } \\
\text { government }\end{array}$ & 3 & 2 & - & - & 1 \\
\hline Municipality & 2 & 2 & - & 2 & - \\
\hline NGO & 3 & 2 & - & - & 1 \\
\hline Private & - & 2 & - & 1 & 1 \\
\hline Total & 14 & 13 & 2 & 7 & 7 \\
\hline & \multicolumn{2}{r|}{ Total $=29 *$} & & \multicolumn{2}{c|}{ Total $=14 *$} \\
\hline
\end{tabular}

* Responses add up to more than total of respondents as multiple responses were given. 
The categories developed from primary data analysis were also used for the analysis of secondary data (such as planning documents and annual reports) to inform the researcher regarding tourism characteristics and tourism management in Pattaya. With this analytical method, the concept of destination management, the sense of Pattaya, and the aspects of destination management were identified and summarized in Table 3.9.

Table 3.9: Key themes identified during Phase II of the study.

\begin{tabular}{|c|c|}
\hline $\begin{array}{l}\text { Concepts of } \\
\text { destination } \\
\text { management }\end{array}$ & $\begin{array}{l}\text { - tourism product management } \\
\text { - demand driven management } \\
\text { - required management practices } \\
\text { • integration of products and demand management } \\
\text { - cooperation of responsible organizations } \\
\text { - positive tourism atmosphere }\end{array}$ \\
\hline $\begin{array}{l}\text { A sense of } \\
\text { Pattaya }\end{array}$ & $\begin{array}{l}\text { - diversity of tourism attractions and services } \\
\text { - nightlife and coastal resources are main attractions } \\
\text { - multiple services (e.g. accommodation, restaurants) support 'diversity' characteristics of Pattaya } \\
\text { - diverse and complex issues relevant to natural resources, society, economy, and infrastructure }\end{array}$ \\
\hline $\begin{array}{l}\text { Pattaya's } \\
\text { tourism } \\
\text { management }\end{array}$ & $\begin{array}{l}\text { - Local to national agencies manage Pattaya's tourism } \\
\text { - The municipality is a prime agency, coordinated by other agencies. } \\
\text { - Working relationships between the municipality and other agencies are diverse, depending on } \\
\text { particular situations. } \\
\text { • Management hierarchy appears between the municipality and the provincial office. } \\
\text { - Tourism marketing and promotion is perceived as a common goal in managing Pattaya's } \\
\text { tourism. } \\
\text { - Various levels of integration are practised, such as: } \\
\text { in managing tourism marketing and promotion } \\
\text { through function collaboration and financial coordination. } \\
\text { - Integration is evident in 'project management' such as the operation of Pattaya Music Festival. } \\
\text { - Nightlife attractions are owned and operated by individual businesses. }\end{array}$ \\
\hline
\end{tabular}

The results of this analysis showed that there are several aspects to the concept of destination management perceived by the practitioners, various tourism-related products and issues are Pattaya's characteristics, and multiple agencies are involved in managing Pattaya's tourism. The results also suggested that local to national level agencies from both the public and private sectors are involved in different management structures with some levels of integration practised. The municipality appears to have a prime role in and responsibility for managing Pattaya, while its 
work may relate to other agencies from the public and private sectors. Various levels of integration in terms of goals and practices seem to exist in managing tourism on a daily and project basis, but the interactions and relationships between these agencies remained unclear. Although there seemed to be common goals between relevant agencies, it was unclear what they were and whether they were reflecting organizational goals or the destination goals. Integration is, thus, a central issue in managing the destination which raises questions about how relevant agencies are integrated at the local level. The third phase of research was necessary to investigate these questions. For the reasons described earlier (section 3.3.1), this study focuses on the management of beaches, nightlife, and the Pattaya Music Festival to clarify and identify the practice of destination management in Pattaya in the third phase of research. The concept of destination management that was developed in this phase was also cross-checked in the third phase of data collection.

As there was not a full list of potential respondents in the first phase of data analysis, most responses received in this second phase of analysis were from the public sector (see Table 3.8). Additional responses from the private sector were therefore collected in the next phase of interviews to achieve a better balance between the private and public sectors. Because of the diverse types and scales of hotels and tourism businesses in Pattaya, private sector respondents were selected from different geographical areas of Pattaya. A map of Pattaya was used to identify businesses located in North, Central, and South Pattaya. With this method, nine hotels, two private attractions, and three business associations were selected. Only five hotels and three business associations were willing to participate in the next phase of interviews. Although the number of responses did not fulfil the researcher's initial intention, their operational scales and geographical locations responded to her expectations. These additional respondents were interviewed and analysed in the next phase. A list of interview questions was also developed in the next phase. 


\subsubsection{Phase III: Background information on the tourism management process in Pattaya}

The third phase of data collection was undertaken from September to December 2006. In this phase, the management of beaches, nightlife, and the Pattaya Music Festival was studied to obtain specific data regarding their management mechanisms. The collected data were analyzed to clarify the practice of destination management. Multiple methods, similar to the previous phase, were used to access information.

\subsubsection{Semi-structured interviews and interviewing process}

Semi-structured interviews were used to access specific information regarding the management of beaches, nightlife, and Pattaya Music Festival. The respondents interviewed were executive staff in operational levels such as department/division managers from public and private agencies that are involved in managing these three attractions. Since the operational executives were easier to access by direct contact, most respondents were directly contacted approximately two weeks in advance for interview permission and appointments.

In September 2006, the interview procedure was undertaken in a similar fashion to the previous phase. Seventeen respondents from eight organizations were interviewed regarding the management of these three areas. Twelve were from the public sector, and five were from the private sector (see Table 3.10). Some respondents interviewed in this phase were also involved in the previous phase. All interviews, which were conducted in Thai, were also held at the interviewees' offices and lasted approximately one hour each. All interviews were audio recorded and transcribed by the researcher. To preserve the respondents' anonymity, they are only referred to by the scale and sectors of operations, for example, 'Local public 1' refers to someone from Pattaya municipality and 'Local private 1' refers to someone from the private agency. 
Table 3.10: Phase III interview respondents from different sectors and administrative levels.

\begin{tabular}{|l|l|l|}
\hline & \multicolumn{1}{|c|}{ Public sector } & \multicolumn{1}{c|}{ Private sector } \\
\hline $\begin{array}{l}\text { Beach management } \\
\text { - Local agency }\end{array}$ & Pattaya City (7) & $\begin{array}{l}\text { Beach Parasol Club (1) } \\
\text { Tourism Boat Club (1) } \\
\text { CCO** (1) }\end{array}$ \\
\hline $\begin{array}{l}\text { Nightlife management } \\
\text { - Local agency }\end{array}$ & Tourist Police, Region 3 office (1) & - \\
\hline - Regional agency & Pattaya City (1) & Walking Street Committee (1) \\
\hline $\begin{array}{l}\text { Pattaya Music Festival } \\
\text { - Local agency }\end{array}$ & Pourist Police (*) & \\
\hline- - Regional agency & $\begin{array}{l}\text { Tourism Authority of Thailand, } \\
\text { Central Region 3 office (1) } \\
\text { Tourist Police (*) }\end{array}$ & \\
\hline- - National agency & $\begin{array}{l}\text { Tourism Authority of Thailand, } \\
\text { Bangkok office (1) }\end{array}$ & \\
\hline Total respondents $=17$ & \multicolumn{1}{|c|}{12} & \\
\hline
\end{tabular}

* the same respondent; ** contracted company for operating CCTV

The interview questions in phase three were clustered into three main parts: questions regarding respondents and their organizations, questions regarding the management process, and questions regarding management issues (see Appendix B). As in the previous phase, the first set of questions was used to gather information about the respondents and their organizations. The second set was specifically related to the management process of the selected attractions: beaches, nightlife, and Pattaya Music Festival. This set of questions was used to identify relevant agencies and their structure, their purposes, their functions, and resources used in managing these particular attractions. The last set of questions was used to identify issues relevant to facilities and services, marketing, and overall practices in managing the particular activities. The broad concept of destination management developed in phase two of the study was also cross-checked in this set of questions.

Regarding the additional respondents from the private sector, as mentioned in the previous section, they were contacted approximately two weeks in advance for interview permission and appointments. Eight respondents (five hotels and three business organizations) agreed to participate in the interviews (see Table 3.11). This group of respondents was particularly concerned about their anonymity and so are 
referred to by the scale of administration. 'Regional private 1' and 'International private 1' are examples.

Table 3.11: Additional interview respondents from the private sector.

\begin{tabular}{|l|l|l|}
\hline & \multicolumn{1}{|c|}{ Hotels } & \multicolumn{1}{c|}{$\begin{array}{c}\text { Business } \\
\text { organizations }\end{array}$} \\
\hline - Local agency & $\begin{array}{l}\text { Mike Beach Hotel } \\
\text { Nautical Inn } \\
\text { Pattaya Park Hotel } \\
\text { Royal Cliff Hotel }\end{array}$ & $\begin{array}{l}\text { Pattaya Bus } \\
\text { Corporation Ltd. }\end{array}$ \\
\hline - Provincial agency & & $\begin{array}{l}\text { Chonburi Tourism } \\
\text { Attractions Club }\end{array}$ \\
\hline - Regional agency & & $\begin{array}{l}\text { Hotel Association, } \\
\text { Eastern Region }\end{array}$ \\
\hline - National agency & & \\
\hline - International agency & Sheraton Hotel & \multicolumn{1}{|c|}{3} \\
\hline Total respondents =8 & 5 & \\
\hline
\end{tabular}

In order to gain their responses, the interview questions were developed and clustered into three main sets (see Appendix C). The first set of questions was used to gain information about the respondents. The second set of questions was used to access their perceptions on the concepts of 'a tourism destination' and 'destination management' and on overall characteristics of Pattaya and its tourism-related issues. The last set of questions was used to obtain their perceptions on management issues in Pattaya, both generally and with particular regard to the management of beaches, nightlife, and the Pattaya Music Festival. The concept of destination management, developed from the second phase of analysis, was also used to obtain and to crosscheck the private sector's perspectives regarding this term. Other responses from this group of respondents were also used in the fourth phase to reflect tourism management, both generally and particularly in managing the beaches, nightlife, and Pattaya Music Festival and to consider the overall practice of destination management in Pattaya.

\subsubsection{Formal and informal direct observation}

Formal and informal direct observation was also used to gain more information about the destination, particularly the process of managing beaches, nightlife, and Pattaya 
Music Festival; the activities and functions of relevant agencies and their management resources.

Formal observation was used to obtain more insight into how the beaches and nightlife are managed. In relation to nightlife management, the researcher attended three meetings of the Walking Street Committee between October and December 2006. Their meetings are organized monthly and open to the public. In contrast, meetings related to beach management are not open to the public and meeting schedules are organized independently depending on relevant organizations/divisions and deal with particular issues. Although every attempt was made to gain this information, the researcher was only able to attend one meeting related to the management of beach security. After the meeting, she was invited to observe the routine work of the beach security staff. This observation provided information on how beach security works on a daily basis and proved useful in clarifying the roles of relevant agencies in managing beaches and nightlife in Pattaya. This method provided an opportunity for the researcher to directly see the reality of tourism management practised there.

As in the second phase, site visits were frequently made while carrying out interviews. In addition, the researcher spent three days and two nights in Pattaya in order to specifically observe the management of the beach and nightlife attractions. In this particular observation, the researcher's role was in between a tourist and an observer, a position that enabled her to capture the general characteristics of Pattaya during the day and night. Although the Pattaya Music Festival was not held during this period, the researcher was familiar with the event from her previous participation. Photographs taken at the site were used for visual data. Field notes were also used in both observation techniques.

\subsubsection{Documents and photographic evidence}

Documents such as official documents, archival records, and photographic evidence were also obtained (see Table 3.12). Various kinds of official documents such as agendas, announcements and minutes of meetings, reports of events, and reports were collected and used to verify general and specific information regarding the roles 
and responsibilities of the respondents' organizations in managing particular attractions in Pattaya. Moreover, other public documents such as local newspapers were gathered and used to reflect the actual practices in managing beach, nightlife, and Pattaya Music Festival. The Pattaya Development Plans between the years 1996 and 2005 were also collected to provide information regarding destination management and Pattaya's context. Visions, missions, and objectives stated in the plans were also used to clarify and identify the official purposes in managing Pattaya. They were also used for additional information regarding overall tourism management in Pattaya to show the state of tourism development in Pattaya and its relationship to tourism in Thailand. Photographs and brochures provided additional data regarding the overall management of the three attractions.

Table 3.12: Examples of contextual data collected in Phase III.

\begin{tabular}{|c|}
\hline Contextual data \\
\hline •Pattaya development plans (years 1996 to 2005) \\
\hline •Local newspapers from September 2002 to November 2006 \\
\hline •Projects for Pattaya Music Festival for the years 2002, 2003, 2005, 2006 \\
\hline -A list of functional committees of Pattaya Music Festival 2005 \\
\hline •Pattaya Music Festival Research in years 2004, 2005 \\
\hline $\begin{array}{l}\text { •Meeting reports of Walking Street Committee from July } 2004 \text { to October } \\
2006\end{array}$ \\
\hline -A booklet of waste water treatment and waste management in Pattaya \\
\hline $\begin{array}{l}\text {-A brochure of Larn Island and regulations related to buildings control and } \\
\text { transportation services }\end{array}$ \\
\hline -A handbook for the security training project \\
\hline -Regulations for using the pier in South Pattaya \\
\hline •Regulations for organizing Pattaya, Wongamart, and Jomtien beaches \\
\hline $\begin{array}{l}\text {-Regulations for organizing beach shops on Pattaya and Jomtien beaches and } \\
\text { Larn Island }\end{array}$ \\
\hline •Annual Summary Report of Pattaya City (1996 to 2005) \\
\hline
\end{tabular}

\subsubsection{Phase III analysis}

In this analysis, the collected data were grouped into the three embedded cases: beach management, nightlife management, and Pattaya Music Festival management (see Table 3.13). 
Table 3.13: Analytical framework for attraction management process.

\begin{tabular}{|c|c|c|c|}
\hline & Beaches & Nightlife & Pattaya Music Festival \\
\hline $\begin{array}{l}\text { Management process and management } \\
\text { integration }\end{array}$ & \multicolumn{3}{|c|}{ Sequence of data analysis } \\
\hline $\begin{array}{l}\text { Destination managers and management } \\
\text { structure: } \\
\text { agency names } \\
\text { sectors } \\
\text { scales } \\
\text { responsibility functions }\end{array}$ & \multicolumn{3}{|c|}{$\begin{array}{l}\text { interviews, documents, archival records, direct } \\
\text { observation }\end{array}$} \\
\hline $\begin{array}{l}\text { Management activities: } \\
\text { sub-activities } \\
\text { projects }\end{array}$ & \multicolumn{3}{|c|}{$\begin{array}{l}\text { interviews, documents, archival records, photos, } \\
\text { direct observation }\end{array}$} \\
\hline $\begin{array}{l}\text { Management resources: } \\
\text { personnel } \\
\text { money } \\
\text { materials }\end{array}$ & \multicolumn{3}{|c|}{ interviews, official documents, archival records } \\
\hline $\begin{array}{l}\text { Management purposes: } \\
\text { organizational goals } \\
\text { common goals } \\
\text { destination goals }\end{array}$ & \multicolumn{3}{|c|}{ official documents, archival records, interviews } \\
\hline
\end{tabular}

The interview and written data were analyzed in a similar way to that discussed for Phase Two. The categories that emerged from the previous phase were used in this analysis. For examples, categories of 'product driven management', 'management practice', and 'tourist driven management' and their sub-categories were used to analyze responses from the private sector. New concepts emerging in this third phase of analysis, such as 'management process' and 'management factors', were also grouped and labelled in relation to their shared characteristics. Then, all categories were analyzed to identify their relationships between concepts (known as 'axial coding' mentioned by Strauss \& Corbin, 1998). The relationships between conditions, actions/interactions, and consequences of these categories emerged which were analyzed for this coding method. For examples, categories related to responsibilities and functions that emerged, from the analysis were 'safety', 'general organization', and 'marketing'. These categories were grouped together and coded as 'management activities' since they represented tourism-related activities that are undertaken in Pattaya.

The interview data were used as the primary data source for the analysis of destination managers and management structure, their functions and management activities or sub-activities or projects, and management resources used in undertaking 
those tasks. The secondary sources provided additional information to cross-check the primary data. This revealed both consistencies and contradictions in the findings. For example, the interviews mentioned the security project carried out by Pattaya City and police agencies to keep prostitutes away from the beaches and to create a secure atmosphere there, while local newspapers reported stories on prostitution along the beach which resulted in a negative image and crime. In this case, direct observation was used to confirm whether the newspaper's report was correct. These issues will be dealt with in detail in the results chapters.

In other cases, the process was reversed. The secondary sources, particularly the official documents such as development plans and annual reports, were initially analyzed to identify the purposes of managing particular activities. The interview responses were then analyzed for additional information regarding management purposes. This cross-checking helped clarify the issues.

The results from this phase of analysis related to the overall concept of destination management from the practitioners' perspective and the process of managing beaches, nightlife, and the Pattaya Music Festival. These results were analyzed in the next phase to finalize the holistic view of destination management in Pattaya, both conceptually and practically.

\subsubsection{Phase IV: A final analysis for a holistic view of destination management}

In this final phase of analysis, all data gathered from Phase I to Phase III were integrated and interpreted for the holistic analysis of destination management. First, the broad concept of destination management from the managers' perspective and the tourism literature was developed. Second, the overall practice of destination management in Pattaya was clarified and identified. Results from this final phase of analysis represented a holistic view of destination management and identified how they were integrated at the local scale of a tourism destination.

\subsubsection{Coding and analysis for the concept of destination management}

The key concepts that emerged from the interviews in the second and third phases of analysis were integrated and compared with the key concepts summarized from the 
tourism literature. Then, the data were drawn together to produce a general concept of destination management (see Figure 3.3). For the analysis of the destination management concept, major themes/categories that centrally relate to destination management were coded (Strauss \& Corbin, 1998). This general concept was used to clarify and reflect the overall practice of destination management in Pattaya.

Figure 3.3: Analytical framework for the general concept of destination management.

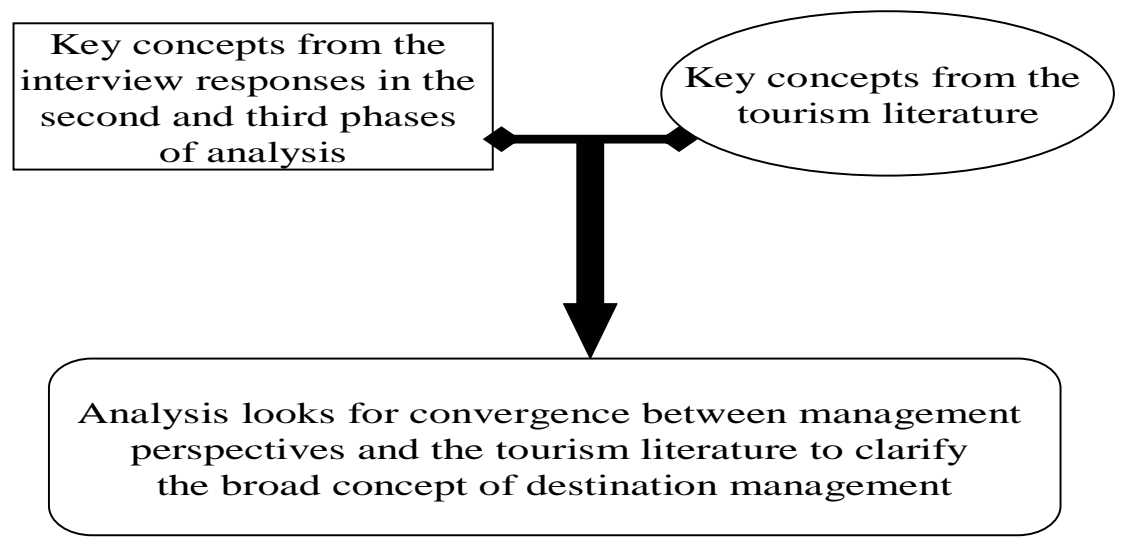

\subsubsection{Coding and analysis for practice of destination management}

An analytical framework was used to structure the relationships between the management processes of beaches, nightlife, and Pattaya Music Festival (see Table 3.14). From the concept analysis, 'management integration' was identified as a central category that can relate to major dimensions and aspects of destination management (see Figure 2.5). Categories and sub-categories that emerged from the previous three phases of analysis were also integrated and filtered through these preset categories of destination management. By using this analytical framework, integration within the tourism management process was analyzed. Integration between the management of selected activities and other tourism suppliers at the destination was also analyzed. The levels of integration were analyzed by identifying interactions of destination managers, types of management activities, and the clarity of destination goals (see Table 2.3 for details). Axial coding was used to clarify the relationships between categories (Strauss \& Corbin, 1998). Results from this analysis were related to the general concept of destination management to reflect the overall practice of destination management in Pattaya. In addition, the results regarding characteristics and issues in Pattaya, received from the first three phases of analysis, 
were used to clarify why the destination is managed in the way it is. Based on this analytical technique, the holistic view of destination management can be identified.

Table 3.14: Analytical framework for the practice of destination management.

\begin{tabular}{|c|c|c|c|c|c|c|}
\hline \multicolumn{7}{|c|}{ Overall practice of destination management } \\
\hline & \multicolumn{6}{|c|}{ Management integration } \\
\hline & \multicolumn{5}{|c|}{ Tourism management process } & \multirow{3}{*}{$\begin{array}{c}\text { Relation to } \\
\text { other } \\
\text { tourism } \\
\text { suppliers }\end{array}$} \\
\hline & \multicolumn{2}{|c|}{ Management structure } & \multirow{2}{*}{$\begin{array}{l}\text { Management } \\
\text { purposes }\end{array}$} & \multirow{2}{*}{$\begin{array}{l}\text { Management } \\
\text { activities and } \\
\text { sub-activities }\end{array}$} & \multirow{2}{*}{$\begin{array}{l}\text { Management } \\
\text { resources }\end{array}$} & \\
\hline & Managers & $\begin{array}{l}\text { Differentiation } \\
\text { and integration } \\
\text { of responsibility } \\
\text { functions }\end{array}$ & & & & \\
\hline & $\begin{array}{l}\text { Results } \\
\text { from } \\
\text { three } \\
\text { phases of } \\
\text { analysis } \\
\end{array}$ & $\begin{array}{l}\text { Results from } \\
\text { three phases of } \\
\text { analysis }\end{array}$ & $\begin{array}{l}\text { Results from } \\
\text { the second } \\
\text { and third } \\
\text { phases of } \\
\text { analysis }\end{array}$ & $\begin{array}{l}\text { Results from } \\
\text { three phases } \\
\text { of analysis }\end{array}$ & $\begin{array}{l}\text { Results from } \\
\text { three phases } \\
\text { of analysis }\end{array}$ & $\begin{array}{l}\text { Results } \\
\text { from three } \\
\text { phases of } \\
\text { analysis }\end{array}$ \\
\hline $\begin{array}{l}\text { Results f } \\
\text { the third } \\
\text { phase of } \\
\text { analysis }\end{array}$ & & & & & & \\
\hline beaches & & & & & & \\
\hline nightlife & & & & & & \\
\hline $\begin{array}{l}\text { Pattaya } \\
\text { Music } \\
\text { Festival }\end{array}$ & & & & & & \\
\hline
\end{tabular}

\subsection{Limitations of the research methodology}

Notwithstanding the wealth of data generated, some limitations can be found in this research. The method used in the first phase of study limits the destination scale and the groups of interviewed respondents. Thus, the respondents' views to refine the concepts of “a tourism destination” and “destination management” are limited.

First, the review of on-line documents in the first phase study limits the destination scale. Although this method enabled the researcher to investigate tourism management of the destination without visiting the place, it is suitable to study only major destinations. On-line information relevant to tourism development and tourism management of major tourism destinations appear to be widely available and accessible, while on-line information of smaller scale or less significant destinations are limited. Another methodological approach, such as ethnography, might be 
required to investigate tourism development and management of smaller scale destinations.

Second, the review of on-line documents limits the initial groups of interviewed respondents. This method enabled the researcher to identify several groups of stakeholders that are largely involved in tourism management of the destination. Other groups of stakeholders, which might be less explicit in tourism management, were rarely mentioned in the documents. As presented in the case of Pattaya, various public and private agencies had been involved in Pattaya's tourism management during 2005-2006; while its local residents and tourists were rarely mentioned in relation to tourism management. This limited the groups of interviewed respondents to focus only on the groups of tourism practitioners rather than to interview all groups of tourism stakeholders. Inclusion of all groups of stakeholders in the first phase interview would provide more fruitful information relevant to their roles and responsibilities in relation to destination management.

Third, the research methods limit the number of issues to be studied. As seen in this study, the research methods enabled the researcher to define and identify major issues that appeared to be significant to the destination in a period of time. Some other issues that would be perceived as significant to the destination but rarely found in the analysis were excluded on purpose. This study has presented that various activities relevant to environmental management were undertaken in Pattaya, while management activities related to social and cultural issues were rarely found in the analysis and were only briefly mentioned. Even though the social and cultural issues are significant and challenging to destination management practices, the diversity and complexity of these issues would require substantially longer period of time for an in-depth study. Future studies should include these areas as so doing would benefit the destination management theory in terms of identifying all activities that are undertaken in managing the overall destination.

Fourth, the views to define the concepts of 'a tourism destination' and 'destination management' are limited. With an emphasis on management practices, the practitioners' views regarding the concepts of tourism destination (TD) and 
destination management (DM) were taken into account. The practitioners' views not only reflect their attitudes towards these two terms but also mirror their managerial practices at the destination. As the views of other stakeholders, particularly of local residents and of tourists were excluded in the study, additional study of views would be useful to refine the concepts of TD and DM which would represent the views of all tourism stakeholders.

With respect to the preliminary and exploratory nature of the research, methodological limitations are presented in the study and acknowledged above. Along these limitations, the study has indicated room for further research. Suggestions to extend the study relevant to destination management along with the avoidance of study limitations will be addressed in the final chapter of this thesis.

\subsection{Conclusion}

Few studies have attempted to clarify how tourism destinations are being managed. In this thesis, a range of literature is drawn together to provide better understanding of this notion. As there are diverse and complex issues involved in managing the destination, various approaches that enabled the researcher to closely examine this notion were used. This chapter has described the qualitative multi-phase case study approach employed in this research as it is the most appropriate design to investigate these issues. The strengths of the research design and methodology adopted in this study were present.

First, regarding the research design, a mix of holistic and embedded case studies has enabled the researcher to effectively obtain broad to specific information relevant to destination management. Pattaya is used as a holistic case to explore the overall concept of destination management, while the management of beaches, nightlife, and Pattaya Music Festival are used as embedded cases and brought together to reveal the extent of overall destination management practice. The overall concept of destination management obtained from the holistic case is used to reflect to what extent destination management is practised in Pattaya. This mixed design helps to bring better understanding to the notion of destination management. Regarding the case study research, the general characteristics and environments of Pattaya provide a 
particular context that may or may not be generalized to other mature coastal destinations. As stated by Mingers (2006, p. 25), “social structures are localised in both space and time"; in this sense, different contexts of the case can bring different answers to the 'why' question of a case study approach. However, the results of this research can bring better understanding to the overall concept of destination management and the complex mechanisms in managing the local tourism destination, which can be applied in studying management other tourism destinations.

Second, the multi-phase approach has strengthened the research methodology. This approach used to systematically gather primary and secondary data has enabled the researcher to reveal broad to specific mechanisms and issues in managing the tourism destination. The results from the earlier phases enabled the identification of significant themes examined in the following phases. In particular, use of the early phases of the holistic study to identify embedded cases and then bringing back those embedded examples into the last phase strengthen the validity of this methodology. Moreover, triangulation of the respondents' view in different phases of research has been used to clarify the overall concept of destination management from the practitioners' perspectives. The identification of the destination management concept obtained and analyzed in the second phase of research has been cross-checked by the respondents in the following phase. This approach enhances the validity and quality of interview responses as the concept of destination is identified and verified by the respondents. On the other hand, the review of on-line data in the first phase did not provide a full list of preliminary respondents and resulted in an imbalance of public and private sector responses in the second phase. Consequently, additional responses from the private sector were obtained in the third phase and subsequently incorporated with those from the second phase, and then re-analyzed.

Third, triangulation of data sources has also strengthened the research methodology. Multiple data sources such as interviews, documents, observation, and photographic evidence were used in the analysis. The method of identifying and verifying the concept from the respondents' perspective greatly clarified the concept. In terms of the practice of destination management, the analysis has been done using both primary and secondary data collected from Phase I to Phase III. Sequences of data 
analysis become crucial since there are various aspects of destination management involved. Different sources of data provided different information and characteristics of destination management. Generally, the interview data were initially used to identify categories and sub-categories relevant to aspects of destination managers and their structure, and their management activities. These categories were then used in the analysis of documents and observation or other visual evidences. In terms of management purpose analysis, official documents are used as a primary source to identify categories and sub-categories, then, followed by interview responses.

The results obtained from this methodological approach will be presented in the following chapters. In Chapter 4, the next chapter, the context of Thailand and Pattaya will be described. The country's economic, social, and natural environments in relation to tourism development and management will also be discussed. The findings regarding Pattaya’s tourism characteristics and issues will also be presented to provide a context of Pattaya in terms of a tourism destination. This local and national context will bring understanding in relation to destination management. Chapter 5 will present the findings regarding the concept of destination management. Chapters 6 to 8 will present the findings regarding the management process of beaches, nightlife, and Pattaya Music Festival, respectively. Then, Chapter 9 will draw the management of these three sub-cases together to clarify overall practice of destination management in Pattaya. It also will address the notion of destination management in relation to the relevant literature. The lessons drawn from the Pattaya case study and recommendations will also be described in this final chapter. 


\section{Chapter 4 The Research Context: Thailand and Pattaya}

\subsection{Introduction}

The previous chapters provided information regarding the concept of destination management and approaches to pursue a better understanding regarding this concept. In Chapter 2, the review of existing literature highlighted key aspects in managing the local tourism destination such as the collaboration of relevant agencies, the management process, and management purposes. The relationships of these key aspects were visually illustrated in the conceptual framework of destination management. Subsequently, a qualitative multi-phase case study approach, as described in Chapter 3, was undertaken to examine destination management in Pattaya. Since the case context is likely to affect the case itself (Mingers, 2006), the context of the case at a particular time and space needs to be understood. In particular, the political system and socio-cultural environment of the country and the characteristics of the locality are likely to affect the way a destination is managed. In this chapter, the Thai political system and its society and culture are broadly described at the national level and in more detail locally.

This chapter acts as a contextual introduction to bring better understanding to the political system and socio-cultural context of Thailand and Pattaya. First, broad information on Thailand's political and socio-cultural environments is briefly described in section 4.2.1. Second, general information regarding tourism development and management is described in section 4.2.2 to illustrate the current condition of Thailand's tourism. Third, public tourism organizations are discussed in section 4.2.3. The issues regarding the overlap of their responsibilities, particularly at the local scale are mentioned. Fourth, background information on Pattaya is presented in section 4.3.1. Its government and political system is also discussed as a special form of the local government. Fifth, its major tourism characteristics are discussed and illustrated in section 4.3.3. Lastly, the current economic, natural, social and cultural environments of Pattaya are discussed. As mentioned in the previous chapter, this chapter draws both from secondary sources and the insights provided by the respondents. The Pattaya issues discussed were widely mentioned by several respondents from different operational scales and different organizational types. 
Some issues, mentioned by particular organizational scales or types of respondents, are also stated.

\subsection{Thailand: the national context}

\subsubsection{Overview of the country}

Situated in the heart of Southeast Asia, Thailand borders Laos and Myanmar to the north, Cambodia and the Gulf of Thailand to the east, Myanmar and the Indian Ocean to the west, and Malaysia to the south. The country is divided into five main regions: the North, the Central Plain, the Northeast Plateau, the Eastern Seaboard, and the Southern Peninsula (Figure 4.1).

Figure 4.1 Thailand and its neighbouring countries.

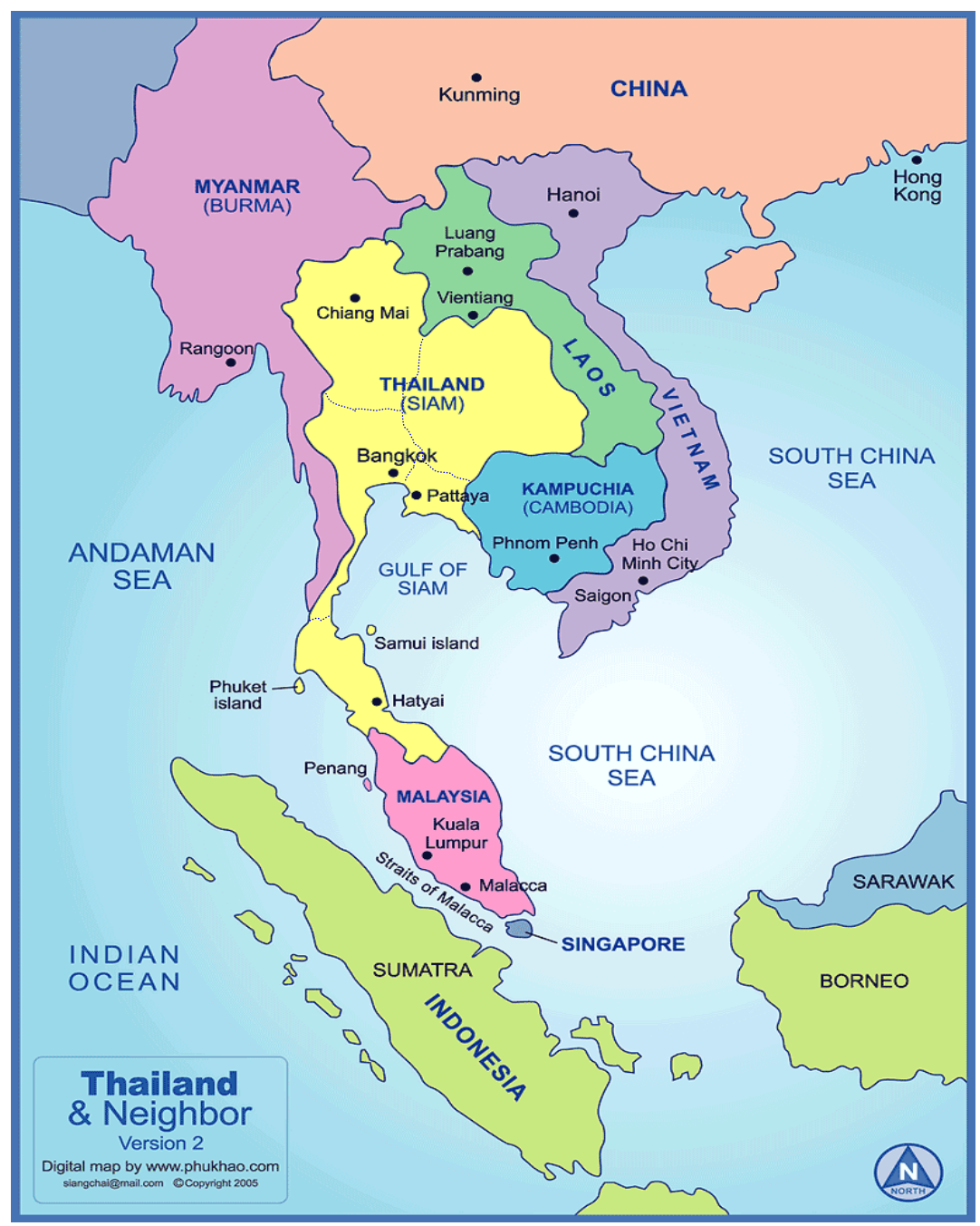

Source: google.com (2005) 
The North is a mountainous region comprising natural forests, ridges, and deep, narrow alluvial valleys. The Central region is a lush fertile valley with the most extensive rice-producing area in the country. Bangkok, the capital city, is located in this region. The Northeast region is characterized by a rolling surface and undulating hills. The Eastern Seaboard is a coastal, agricultural, and industrial region. It is domestically well-known for the cultivation of tropical fruits and for famous beaches and islands. It is the first region for industrial development and investment. Pattaya is located in Chonburi province which is the centre for regional investment and businesses. The Southern region is hilly to mountainous. It is the centre for the production of rubber and the cultivation of other tropical crops. These five regions are divided into 75 provinces (excluding Bangkok) that are administered by different levels of government.

\subsubsection{Government and political systems of the country}

Thailand is governed by a constitutional monarchy with a bicameral parliamentary form of government, whereby the Prime Minister is the head of government and a hereditary monarch is the head of state. The judiciary is independent of the executive and the legislature. Under the Organization of State Administration Act 1991, the Thai government is divided into three levels of public administration: central, provincial, and local (see Figure 4.2). First, the central administration falls under the basic concept of centralization (Tummakird, 2003) and consists of 20 ministries. Each ministry is headed by a politically appointed minister (Pattaya City, 2005), and all are seen as the major units of an administrative organization in the Thai bureaucratic system (Siffin, 1979). This central administration delegates some of its power and authority to its officers who work at the provincial administrative level. Secondly, under the concept of de-concentration (Tummakird, 2003; UN, 2004), each of the 75 provinces is administered by a governor, who is appointed by the Ministry of the Interior, while, theoretically, other ministries' provincial offices are under the supervision of a governor (IDRC, 1997). These 75 provinces are subdivided into districts, sub-districts (or Tambons, or groups of villages), and villages (TAT, 2008b). Finally, the local administration is established under the concept of decentralization (Krueathep, 2004; Tummakird, 2003; UN, 2004). At present, there are two types of local administrative organization in Thailand: general 
and specific. The general type, which exists in 75 provinces, consists of: 1) Provincial Administration Organization (PAO), 2) Municipalities, and 3) Sub-district or Tambon Administration Organization (TAO). They appear to function as single units which are headed by locally elected persons. The special type consists of two forms of local government: 1) Bangkok Metropolitan Administration (BMA), and 2) Pattaya City. These two specific forms of local administration are administered by publicly elected governors. Bangkok is the only city operated at the local authority level, while Pattaya City, though perceived as another specific form of local administration that has its own government, is headed by the provincial governor. The Pattaya City government will be described later in the Pattaya context. These three levels of governments operate within their defined geographical and political boundaries.

Figure 4.2 Structure of Thai Public Administrative System.

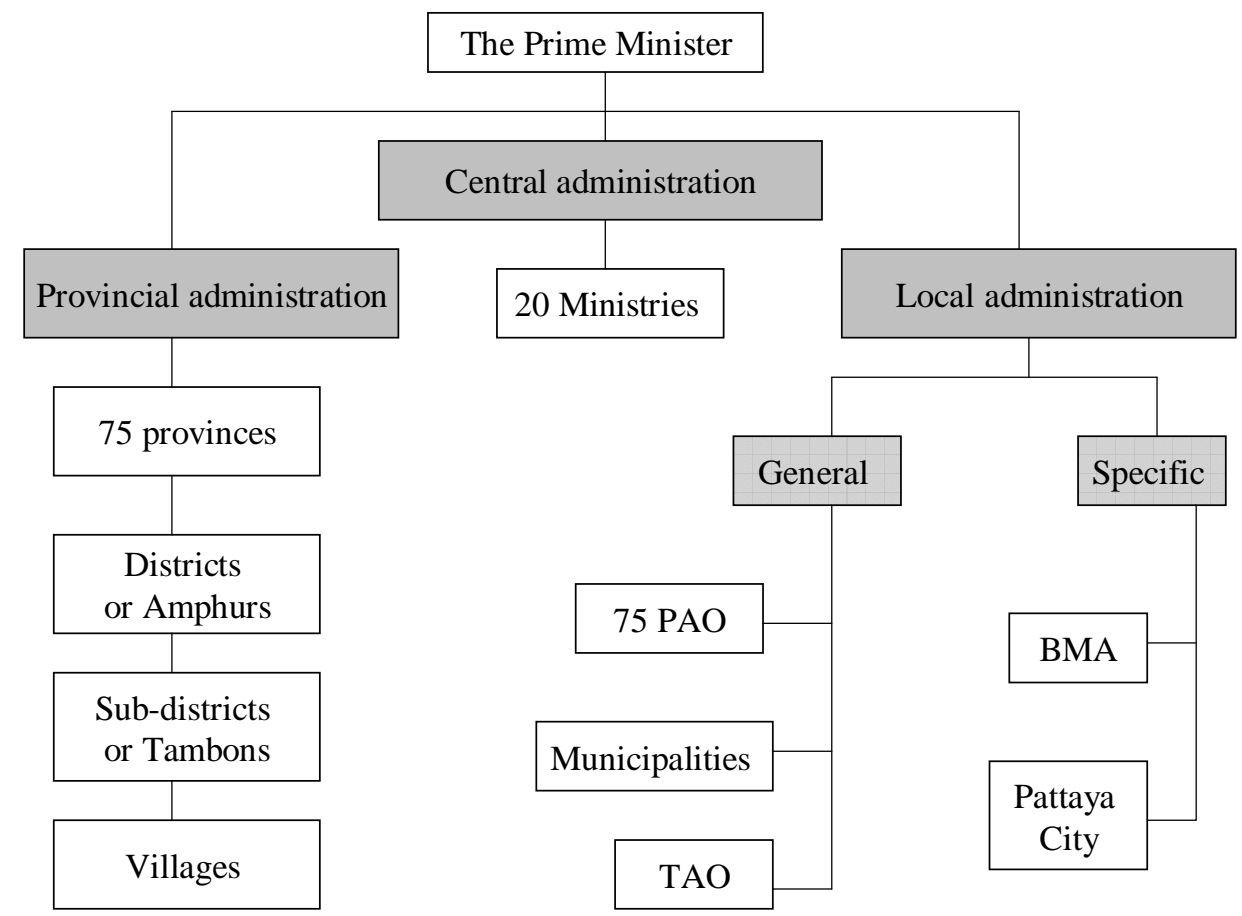

Though the Western political system has been adopted into Thailand, it has been modified to fit Thai culture (Cohen, 1991; Neher, 1990). The particular characteristics of the Thai political system appear to bring complexity and difficulty to the practice of its public administration. These characteristics involve a complex bureaucratic structure and an overlap between formal and informal power. 
Because of its long establishment, the Thai bureaucracy is extremely diverse, fragmented, and complex, factors that contribute to a habit of slow and timeconsuming decision making (Elliott, 1987). Basically, the provincial authority level is formed to delegate the authority of central government into the local areas. However, it seems to create a slow administrative system since almost every project must be authorized from the central level through the line of its complex bureaucratic structure. Similarly, although the local authority level is formed to minimize this problem and intended to create more flexibility in providing local public services regarding its development planning and budgeting, some major projects still need to be advised and authorized by the Ministry of Interior (Krueathep, 2004). Moreover, the slow administrative process may reflect the weakened political philosophy of Thai politicians and bureaucrats (Elliott, 1997). The authority of these politicians and bureaucrats is personal and can be performed in an officially administrative hierarchy or informally (Siffin, 1979; Tamada, 1991). The overlap between formal and informal power can create more complexity and difficulty in public administration. Hence, authoritative boundaries can be found between ministries, or between departments within the same ministry, or between offices within each authoritative level (Siffin, 1979).

\subsubsection{Cultural and social environments of the country}

Generally, the culture of Thailand is influenced by religion, Buddhism in particular. Although many religions are practised by people in the country, Buddhism is practised by more than 90\% of all Thais (TAT, 2008b). Everything, from the arts and literature, habits, customs, to the social system is developed and clustered around Buddhism. Its principles have a strong influence on the daily lives of Thais. As it is believed that people are born in different hierarchy depending on their actions (or 'karma' in Buddhism term) in previous lives, the differences in social status are acceptable and believed to be changeable depending on their previous and current actions. The Buddha taught his followers to cultivate Metta, good will towards all sentient beings, and Karuna, compassion for those who are less fortunate than we are. Regarding these teachings, each Thai should help others in the lower social hierarchy to increase his/her own merit and move his/her status in the hierarchy. At the same time, people who receive help should return this kindness with their loyalty 
and respect, and also help others to gain their merits and to move up the social hierarchy. When something unfortunate happens, one must gracefully submit to external forces beyond one's control, such as the effects of past actions. Furthermore, Thai people believe that social harmony is best maintained by avoiding any unnecessary friction in their contacts with others. In general, people will do their utmost to avoid personal conflict. Outward expressions of anger are also regarded as dangerous to social harmony and as being obvious signs of ignorance, crudity, and immaturity. Therefore, Thais are often passive and not critical in public. Although there are many principles and beliefs related to Buddhism, perhaps those mentioned above are most commonly reflected in Thai society.

Thai society is characterized by a client-patron or patronage system (Cohen, 1991; Hanks, 1975; Laird, 2000; Neher, 1979, 1990). The main characteristic of Thai patronage system is clearly explained by Neher (1979, p. 91):

\begin{abstract}
When two or more persons interact there is an automatic "feeling out" of relative status to ascertain who is superior and who is subordinate. In most cases there is little, if any, ambiguity, since one person will clearly be older, wealthier, better educated, and the holder of a higher position. Once the superior-subordinate relationship is established, proper behaviour patterns emerge. The superior, for example, is expected to have the qualities of "compassion, loving kindness, empathetic joy, and equanimity," and he is expected to manifest these four qualities by protecting, aiding, complementing, and giving generously to those whose status is inferior. In return, the subordinate, or client, is expected to act deferentially to the superior, who is his patron.
\end{abstract}

However, the relationship between a patron and his clients varies, depending on the degree of affection and trust from both parties, is voluntary, and can be terminated by either party (Hanks, 1975). In this aspect, the patronage system brings advantages and disadvantages to the Thai society. Perceived as creating personal informal power (Tamada, 1991), linkage of entourage circles (Hanks, 1975), and influence networks (Laird, 2000), the patronage system appears to bring negativity to the Thai society such as creating corruption and leading to ineffectiveness/weakness in the Thai legislature. Although mentioned to a lesser extent, the system may also bring benefits to the country, for example, voluntary coordination in road constructions between public and private sectors, and the residents in some local areas may bring more immediate action than waiting for central government authorization. 


\subsubsection{Tourism in Thailand}

Tourism has played an important role in the growth of the Thai economy. It has become the country's largest foreign currency earner ahead of rice export (Muqbil, 1995). The country's diverse natural and cultural resources and hospitable people bring large numbers of tourists and revenue to the country (Table 4.1).

Table 4.1: Thailand tourist arrivals and tourism revenue from 1996 to 2006.

\begin{tabular}{|l|r|r|}
\hline Year & No. of Tourist Arrivals & Revenue in million baht (US\$) \\
\hline 1996 & $7,192,145$ & $219,364(6,463)$ \\
\hline 1997 & $7,221,345$ & $220,754(6,504)$ \\
\hline 1998 & $7,764,930$ & $242,177(7,135)$ \\
\hline 1999 & $8,580,332$ & $253,018(7,454)$ \\
\hline 2000 & $9,580,332$ & $285,272(8,405)$ \\
\hline 2001 & $10,061,950$ & $299,047(8,811)$ \\
\hline 2002 & $10,799,067$ & $323,484(9,531)$ \\
\hline 2003 & $10,004,453$ & $309,269(9,112)$ \\
\hline 2004 & $11,650,703$ & $384,360(11,324)$ \\
\hline 2005 & $11,516,936$ & $367,380(10,824)$ \\
\hline 2006 & $13,821,802$ & $482,319(14,210)$ \\
\hline
\end{tabular}

Source: The Tourism Authority of Thailand (2007)

The development of Thai tourism is influenced by the country's political and economic stability and global trends. Multiple forms of tourism have been developed and promoted to attract tourists to the country. Examples are mass tourism, ecotourism, business tourism, medical and healthcare tourism, and spa tourism. In the context of the economic development, the push of mass tourism officially began in the late 1950s by catering to American soldiers in the Vietnam War (Elliott, 1987; Peleggi, 1996). With the help of the American government, public infrastructure, specifically roads, was rapidly developed in the rest and recreation areas, particularly in the coastal areas such as Pattaya (Peleggi, 1996). Various types of tourism-related services such as hotels, restaurants, bars, and massage parlours were also rapidly established in those areas. It appeared to improve the economy and help political stability in the country through the 1970s. Since then, the Thai government seems to have recognized the importance of tourism to the country's economy. The government's commitment was evident when tourism was first included in the 
Fourth National Economic and Social Development Plan (1979-1981) (Chon, Singh, \& Mikula, 1993; Peleggi, 1996). However, the development of mass tourism appeared to bring a negative image as a sex tourism destination, which was minimized by remarketing the country with its cultural resources in the 1980s (Peleggi, 1996). Cultural tourism was promoted in an effort to attract more women travellers and presented the different faces of the country. In the 1990s, the destruction of natural resources in major destinations and the financial crisis in Asia created instability in tourist numbers and changed the characteristics of the tourism market. Recently, the Thai government has tried to improve the quality of tourism resources and promoted the country for niche markets such as cooking, sports, spas, and medical and healthcare tourism. To sustain its marketing growth, the country still needs to continue catering to mass tourism while increasing its ability to develop niche markets and to attract high-end visitors (The Nation, 2006).

Although many efforts were made to improve the quality of tourism, tourism development in Thailand has long been creating various social and environmental issues, particularly at major destinations. Prostitution and the degradation of the natural environment seem to be major issues with which the Thai government has to deal. As prostitution or sex tourism appeared to bring embarrassment and shame to the country, the Thai government made an effort to solve this issue by legislating and implementing the Prostitution Suppression Act 1960 to make prostitution “criminalized” (Jaiyen, 1997, p. 27). However, the sex service industry still seems to play a major role in drawing a vast amount of money to the country (Leheny, 1995). Regarding the issues of natural environment, pollution in marine water and degradation of natural resources occurred in some major destinations, particularly coastal resort destinations such as Pattaya and Phuket (Peleggi, 1996). In attempting to solve this issue, the Environmental Act 1992 was legislated and implemented, but pollution and illegal buildings can still be seen in these resorts. The attempt to solve social and environmental issues was made again by focusing on a concept of sustainable development in the Eighth and the Ninth National Economic and Social Development Plans. Actions to achieve social and environmental sustainability seem to be challenging and require serious management from the Thai government. 
As discussed above, the Thai government has attempted to solve tourism-related issues by legislating regulations and acts. However, these acts and regulations are sometimes dealt with more by lip service rather than actual practice (Elliott, 1997). A lack of law enforcement by the government seems to be an issue rather than a lack of legal controls (Jaiyen, 1997). Diverse social and environmental problems that can be seen at the local destinations are evident. Therefore, effective coordination between governments and relevant sectors in solving tourism-related issues is necessary for the sustainability of the Thai tourism. As the editor of The Nation commented (The Nation, 2006): “chasing more visitors is pointless without maintaining the attractions that draw them here in the first place”.

\subsubsection{Tourism organizations in Thailand}

Under the Ministry of Tourism and Sport (MOTS) (see Figure 4.3), two offices are directly responsible for tourism: Office of Tourism Development (OTD) and Tourism Authority of Thailand (TAT). As a recently developed office, the OTD is primarily responsible for establishing the development plan regarding the standard of tourism and services, particularly at attraction sites. It also monitors and follows up the performance of tourism development. The primary task of TAT is tourism marketing and promotion for domestic and inbound tourists through its regional and international offices. Its responsibility is also related to the development of tourism that can be summed up as: to initiate infrastructure and facilities development for tourists; to provide safety for tourists; to give information, advise and coordinate with relevant sectors regarding tourism development, training, and tourism education; to collect and compile data and statistics relevant to the tourism industry; and to provide or borrow financial resources for the investment and enhancement of tourism industry. There appears to be tension and a lack of close coordination between the OTD and the TAT (The Nation, 2006), particularly at the local scale of tourism destinations. 
Figure 4.3: An organizational chart of the Ministry of Tourism and Sports of Thailand.

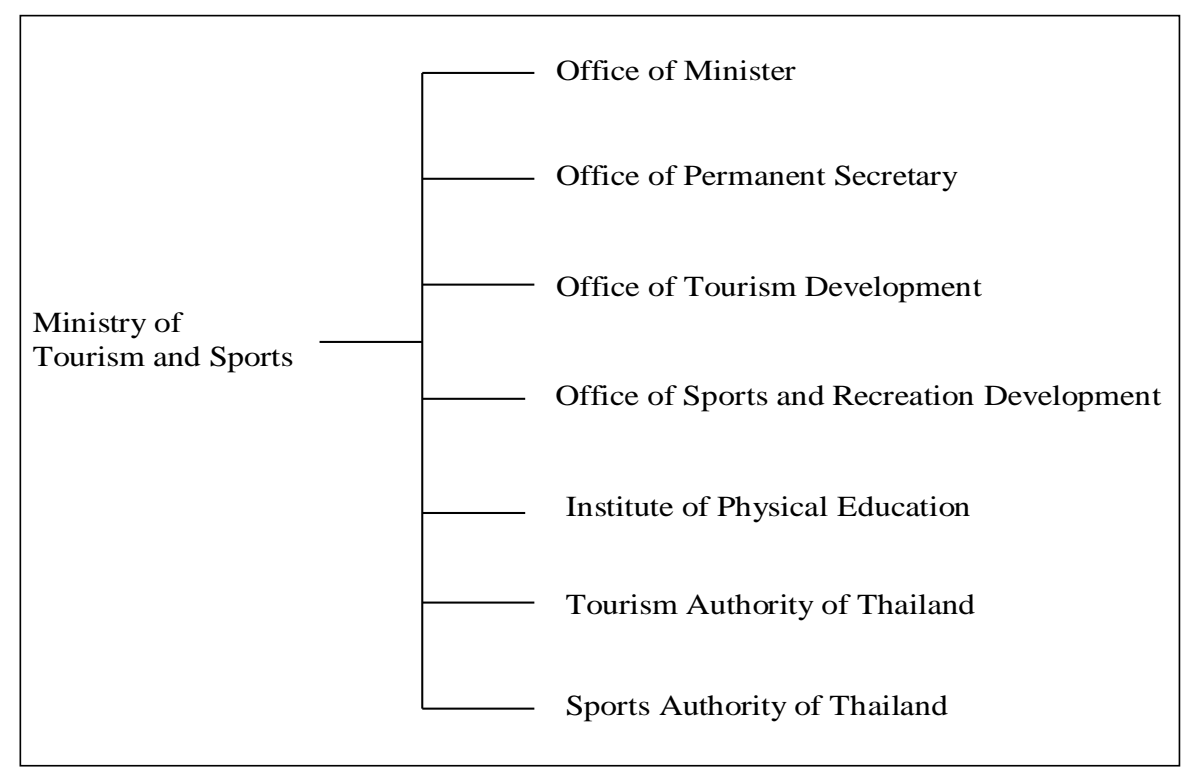

Source: The Ministry of Tourism and Sports (2007)

For local destinations, the TAT seems to have major roles regarding tourism marketing and development, while the roles of the OTD in relation to tourism are unclear. As the first tourism organization in Thailand, the TAT has made a substantial contribution to the growth of tourism in the country (Elliott, 1987) and has established a network of offices within and outside the country. There are now 22 regional offices throughout the country and 16 international offices (TAT, 2008a). Although the TAT has much freedom in marketing tasks, its power and resources related to the development tasks appear to be limited (Elliott, 1987). TAT regional staff need to have the ability to build good relationships, both formally and informally, with local key stakeholders for successful tourism development, such as the Amazing Thailand campaign in 1998 and 1999 (Jantarat \& Williams, 2000). On the other hand, there are provincial offices of the MOTS. Generally, these provincial offices seem to be responsible for developing and promoting tourism and sport in their territories. It seems to be unclear to what extent they represent the OTD, and how their roles differ from those of the TAT regional offices. Moreover, there may be conflict between these two agencies in competing for government funds (The Nation, 2006). 


\subsection{Pattaya: the local context}

\subsubsection{Overview of Pattaya}

Pattaya is located on the eastern coastline of Thailand's Gulf of Siam. It is approximately 150 kilometres southeast of the capital city of Bangkok. It is divided into five areas: North Pattaya, Central Pattaya, South Pattaya, Jomtien Beach, and Larn Islands (Figure 4.4).

North Pattaya, or Naklua, represents to some extent a Thai lifestyle coastal village through its wooden houses, narrow streets, fishing boats, and a marketplace. Because of its narrow beaches, it does not attract many tourists to the area. However, its market is well-known to the locals, domestic tourists, and some of inbound tourists who come for fresh and inexpensive seafood. North Pattaya ends at the Dolphin Roundabout and the beginning of Beach Road is the entrance to Central Pattaya. Compared with North Pattaya, many smaller hotels are situated in Central Pattaya. Along the Beach Road, there are plenty of bars, restaurants, and shops. Two main shopping malls are also located in this area. South Pattaya tends to be older and busier than the remainder of the city. South Pattaya Road curves sharply off from Beach Road, taking the traffic away from Walking Street, the pedestrian-only zone in Pattaya. There are various services along Walking Street such as fast tailoring services, sport goods, jewellery, and souvenirs. There are also many bars and big seafood restaurants. Jomtien Beach is divided off from the rest of Pattaya by the hill which rises on the inland side of South Pattaya. The beach is popular with windsurfers and for water sports because the sea is less congested with boats. It is a residential area with beachside hotels, bungalow complexes, condominiums, and restaurants. Larn Islands are located 7.5 kilometres from Pattaya Bay. The islands consist of Larn, Krok, and Sark islands. The islands used to be known among tourists as the Coral Islands because there are many different types of coral that are the closest to Bangkok. 
Figure 4.4: A map of Pattaya.
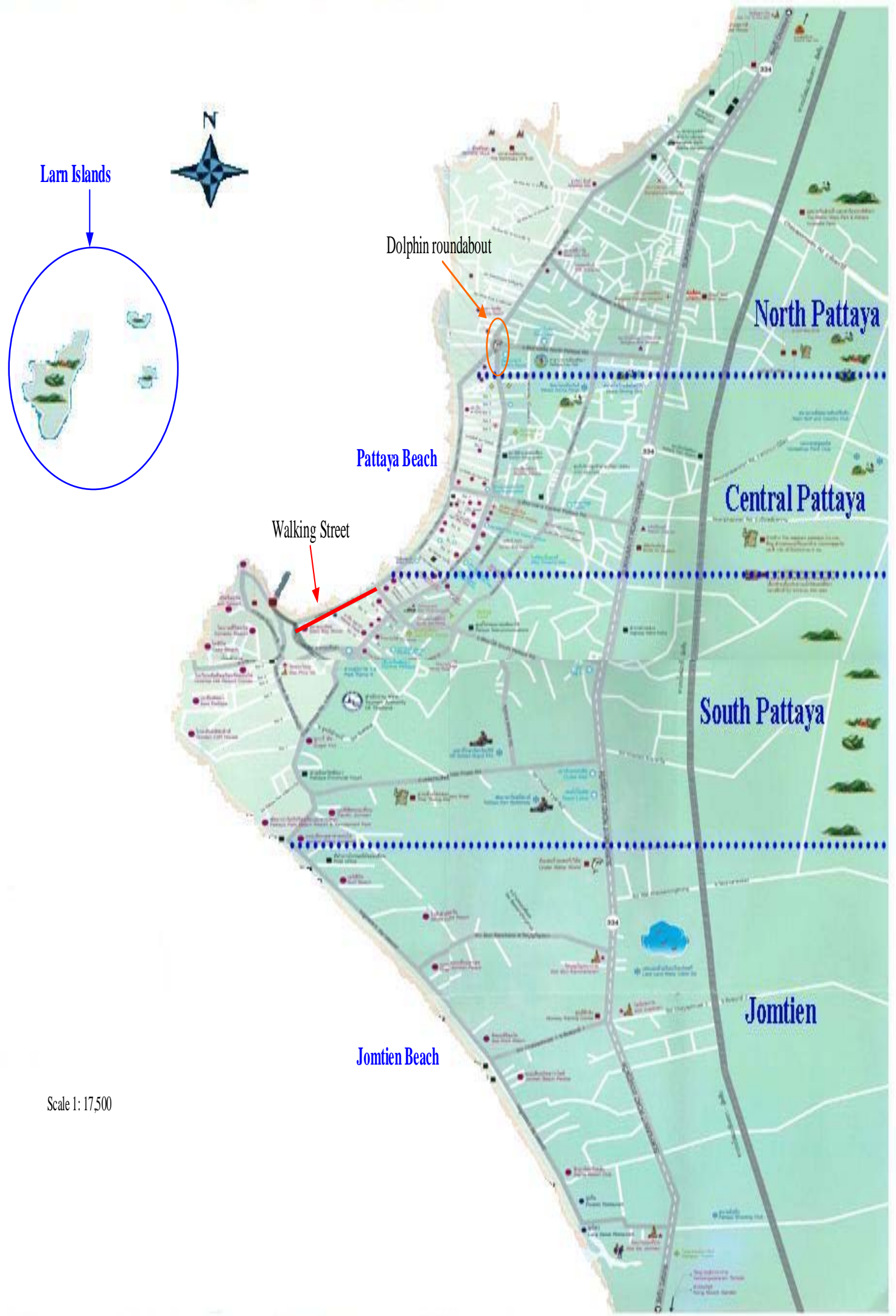

Source: Pattaya City (2006) 


\section{Government and political system in Pattaya}

Pattaya City has been established as a special form of local administration organization since 1999 (Pattaya City, 2007). Under the Pattaya City Administration Act 1999, the Pattaya Administration consists of two main bodies: Pattaya Congress and Pattaya's Mayor (see Figure 4.5). According to the Act, both bodies are publicly selected by registered residents of Pattaya and serve a four-year term. Pattaya's congress members elect one chairman and two vice-chairmen and present them to the provincial governor. The chairman has the authority to run the congress meeting in which congress members can question the works of the Pattaya Mayor. The congress has the role of monitoring the works of the Pattaya Mayor. On the other hand, the mayor has the right to nominate four deputies that are not members of the congress to help out with the assigned workloads. The mayor is responsible for Pattaya City's administration and acts as the head of all city officials and employees. The city's chief manager is the second highest official next to the mayor in terms of the Pattaya administration and day-to-day operations of the city. This includes the pawnshops operated by Pattaya City. The city's chief manager is also responsible for work assigned by the mayor. At present, there are nine units in the Pattaya administration (Figure 4.5).

Figure 4.5: Pattaya City organizational chart.

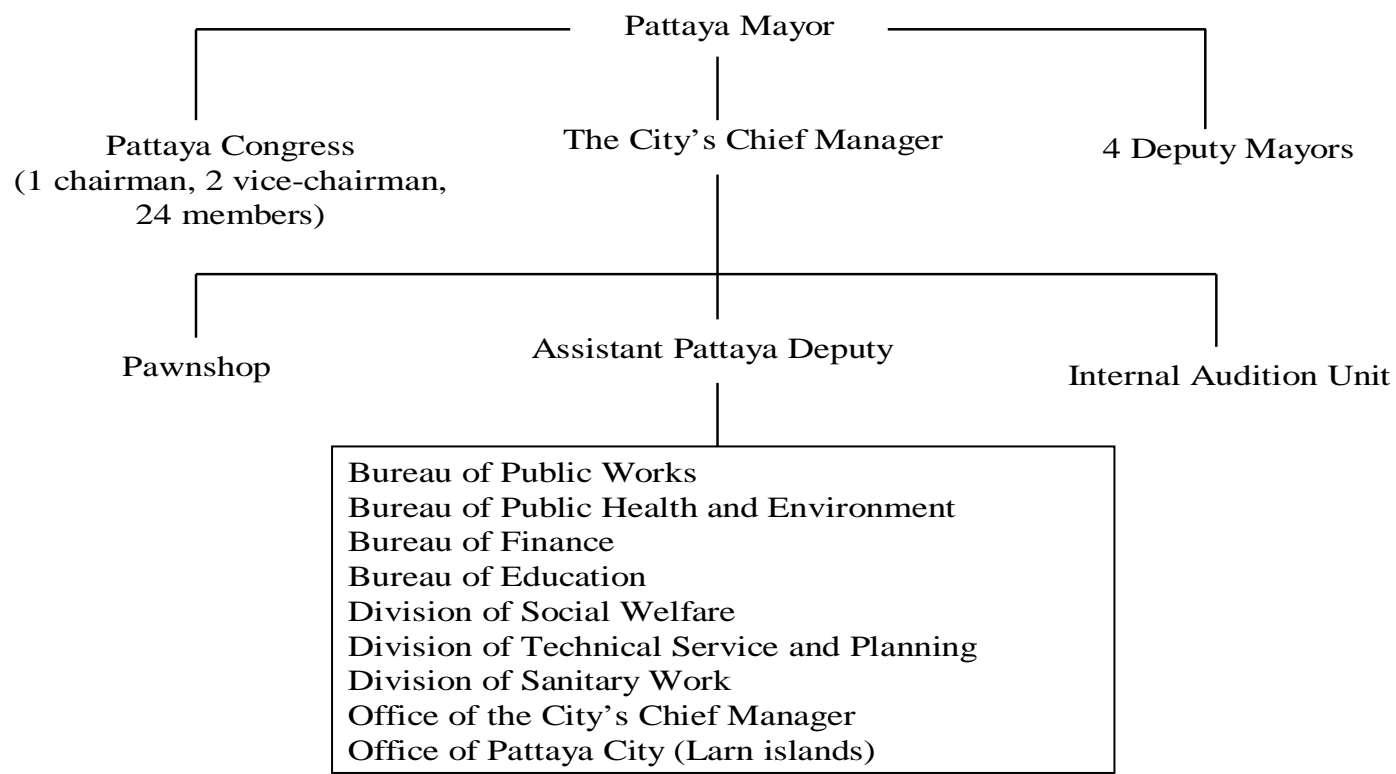

Source: Pattaya City (2007) 
Although Pattaya City is a special form of local administration organization, its administrative authority is limited and influenced by the centralized nature of the Thai bureaucracy (Chaiphadung, 1996; Sirilerttragoon, 1996). Firstly, Pattaya City is a local government with limited authority. It is under the supervision of the Ministry of Interior, which is represented by the Chonburi governor (the provincial governor). According to articles 94 to 99 of the Pattaya City Administration Act 1999, the provincial governor has the authority to monitor and control the overall work of Pattaya City. In particular, s/he has the authority to advise, warn, and dismiss the Pattaya mayor. S/he also has the authority to suggest that the ministry dismisses the Pattaya congress for the benefit of Pattaya residents and/or the country. This issue was well recognized by the Pattaya government, as it is likely to limit them in managing the city independently and more flexibly. This is reflected in the following quotes from respondents interviewed:

Pattaya City is the only organization. However, it receives policies from many organizations. Sometimes from the ministry, such as the policy regarding drug control. The city does not have authority to arrest but the authority to keep an eye on the issue. ... We have all divisions/units working in our responsibilities, and get cooperation from other agencies depending on the issues. ... Our authority is not absolute, only in the Act. If [we have to] relate to other agencies, we just ask for their cooperation.

(Local public 1)

It does not have real authority. To make it easy, the structure of Pattaya City is not similar to Bangkok. Although it looks similar [as specific forms of local government], it is not really. Bangkok has more freedom in its administration system. For us, we still have to depend on other agencies.

$$
\text { (Local public 2) }
$$

However, the respondents from other public agencies and private sector perceived Pattaya City to be autonomous and to have more administrative flexibility and freedom than other local government agencies in the country. With this particular system the Pattaya government should be able to operate the city more successfully. Their responses are reflected in the following quotation:

Pattaya City is a special form of local administration organization. Its authority is much more open compared to other local administration organizations. It has high flexibility. It is a city with a lot of budget. People [staff] working there are capable [of managing Pattaya]. However, it has long been managed in another [unsustainable] direction. The use of its people and money is not efficient. The city concentrates too much on material development.

(National NGO3)

Although some of the problems in Pattaya may relate to its particular form of government, the complex nature of the Thai bureaucracy seems to have a major 
influence on Pattaya's political system. The complex and fragmented structure of the bureaucracy, ineffective and time-consuming processes, and corruption seem to be present in Pattaya City. To manage the city successfully, the administrative and political system should be more flexible and transparent. This issue is clearly raised in the following quote:

\begin{abstract}
Its management must pursue the goals not the bureaucratic system. If you want it [Pattaya] to grow this way, the organizational administration must be flexible and effective for the city environments. However, Pattaya has been developed and structured by the bureaucratic system. It has been growing until today not by the bureaucracy but by other sectors such as businesses, NGOS, and residents. Besides, the bureaucracy becomes the barrier to the growth of Pattaya. If it [bureaucracy] is eliminated, it [Pattaya] will be very good. The police may work in Pattaya because they can earn some money. The Ministry of Interior exists in Pattaya because there are places for extra money. All these are barriers to the growth/development of Pattaya.
\end{abstract}

(National NGO1)

\title{
4.3.2 Tourism in Pattaya
}

Since the Vietnam War, Pattaya has been developed intentionally to draw foreign currency to the country. It was firstly developed as a rest and recreation resort for US military personnel based in Thailand (Pattaya City, 2007). Because there have been major developments in infrastructure, services, and entertainment businesses in the area, Pattaya has been promoted as one of Thailand's major coastal tourism destinations for overseas markets. It has been playing an important part in generating revenue for the local, regional, and national economy (see Table 4.2). 
Table 4.2: Pattaya tourists' arrivals and tourism revenues in 1996 to 2006

\begin{tabular}{|c|c|c|c|c|c|c|c|c|}
\hline \multirow[t]{2}{*}{ Year } & \multicolumn{2}{|c|}{ No. of visitors } & \multicolumn{2}{|c|}{$\begin{array}{l}\text { Revenue in Million } \\
\text { Baht / (US\$) }\end{array}$} & \multirow{2}{*}{$\begin{array}{l}\text { Overall Average } \\
\text { Expense } \\
\text { Bht/person/day } \\
\text { (US\$) }\end{array}$} & \multirow{2}{*}{$\begin{array}{c}\text { Overall } \\
\text { Average } \\
\text { Stay } \\
\text { (day) }\end{array}$} & \multicolumn{2}{|c|}{$\begin{array}{l}\text { Accommodation } \\
\text { Establishment }\end{array}$} \\
\hline & Thai & Foreign & Thai & Foreign & & & Rooms & $\begin{array}{c}\text { Occu. rate } \\
(\%)\end{array}$ \\
\hline 1996 & $1,030,805$ & 1,825,884 & $\begin{array}{r}4,480.46 \\
(113)\end{array}$ & $\begin{array}{r}30,830.49 \\
(908)\end{array}$ & $\begin{array}{r}2,799.69 \\
(82)\end{array}$ & 4.31 & 23,229 & 57.21 \\
\hline 1997 & $1,100,573$ & $1,870,496$ & $\begin{array}{r}4,406.96 \\
(129)\end{array}$ & $\begin{array}{r}23,598.50 \\
(695)\end{array}$ & $\begin{array}{r}2,692.30 \\
(79)\end{array}$ & 3.42 & 23,427 & 51.87 \\
\hline 1998 & $1,008,829$ & 2,192,366 & $\begin{array}{r}4,352.67 \\
(128)\end{array}$ & $\begin{array}{r}28,391.21 \\
(836)\end{array}$ & $\begin{array}{r}2,758.02 \\
(81)\end{array}$ & 3.70 & 23,427 & 56.14 \\
\hline 1999 & $1,046,553$ & 2,408,039 & $\begin{array}{r}4,657.10 \\
(137)\end{array}$ & $\begin{array}{r}30,271.64 \\
(891)\end{array}$ & $\begin{array}{r}2,723.20 \\
(80)\end{array}$ & 3.73 & 23,608 & 58.32 \\
\hline 2000 & $1,120,761$ & $2,531,704$ & $\begin{array}{r}5,173.02 \\
(152)\end{array}$ & $\begin{array}{r}32,720.21 \\
(964)\end{array}$ & $\begin{array}{r}2,802.70 \\
(82)\end{array}$ & 3.73 & 23,608 & 60.20 \\
\hline 2001 & $1,177,762$ & 2,679,888 & $\begin{array}{r}5,587.03 \\
(164)\end{array}$ & $\begin{array}{r}34,366.73 \\
(1,012)\end{array}$ & $\begin{array}{r}2,824.61 \\
(83)\end{array}$ & 3.69 & 23,960 & 59.44 \\
\hline 2002 & $1,305,598$ & 2,878,825 & $\begin{array}{r}6,218.78 \\
(183)\end{array}$ & $\begin{array}{r}36,173.66 \\
(1,065)\end{array}$ & $\begin{array}{r}2,813.03 \\
(82)\end{array}$ & 3.64 & 24,648 & 61.08 \\
\hline 2003 & $1,463,304$ & 2,790,170 & $\begin{array}{r}7,743.61 \\
(228)\end{array}$ & $\begin{array}{r}32,450.64 \\
(956)\end{array}$ & $\begin{array}{r}2,893.62 \\
(85)\end{array}$ & 3.45 & 25,349 & 58.09 \\
\hline 2004 & $1,680,824$ & $3,329,740$ & $\begin{array}{r}9,753.49 \\
(287)\end{array}$ & $\begin{array}{r}38,918.23 \\
(1,146)\end{array}$ & $\begin{array}{r}2,991.25 \\
(87)\end{array}$ & 3.42 & 26,503 & 57.15 \\
\hline 2005 & $1,804,240$ & 3,533,769 & $\begin{array}{r}8,441.67 \\
(248)\end{array}$ & $\begin{array}{r}40,080.46 \\
(1,180)\end{array}$ & $\begin{array}{r}2,819.60 \\
(82)\end{array}$ & 3.41 & 34,007 & 57.78 \\
\hline 2006 & 2,026,179 & 4,088,768 & $\begin{array}{r}9,289.02 \\
(273)\end{array}$ & $\begin{array}{r}43,955.09 \\
(1,295)\end{array}$ & $\begin{array}{r}2,866.82 \\
(84)\end{array}$ & 3.18 & 37,595 & 62.63 \\
\hline
\end{tabular}

Source: The Tourism Authority of Thailand (2007)

As presented in Table 4.2, Pattaya appears to be popular among foreigners since the numbers of foreign tourists are double those of Thai tourists. The overall average expenditure per person is fairly stable. The foreign tourists spend more than Thai tourists, approximately 1,000 baht (or US\$ 29) a person a day. The overall average length of stay is decreasing, particularly among foreign tourists. However, the increasing rate of room establishment can indicate that Pattaya still maintains its positive condition for business investment even though the occupancy rate is not high. The tsunami that affected the Andaman coast of Thailand at the end of 2004 appeared to benefit accommodation investment in Pattaya due to the reduction of tourist demand in Phuket.

\subsubsection{Tourism characteristics of Pattaya}

The respondents from all sectors seemed to agree that a variety of tourism resources, its low prices, and location are the main factors that draw large numbers of tourists to 
Pattaya. The price of tourism products and services provided in Pattaya is inexpensive compared with other major coastal destinations such as Phuket. Also given its location close to Bangkok, tourists can easily access Pattaya. All these factors are reflected in the following quotes:

Frankly, one point that we all can see about the strength of Pattaya is its variety in the tourism industry. You can have fun 24 hours a day, like it's promoted. What do you want to start? Natural type, you can go to the beaches or the islands. You can play marine sport, golf. You can go to spa. If you want to go to man-made [private] attractions, there are many such as a botanical garden or a zoo. At night, you want to go wild, to jazz, to dance. There is all of that [entertainment]. These are tourism products of Pattaya. The second point is its location, especially after opening Suwannaphum airport, it’s very close [to Pattaya].

(Regional private 1)

Pattaya has everything - sea, beaches, and islands for nature. There are also other activities and private attractions such as Nongnuch garden, Stone garden, and many shows. There are varieties [of tourism products] that people can choose. And all the entertainment creates a colourful city [Pattaya]. Another point is that it's not far from Bangkok, convenient transportation. ... Besides, the cost of living is not too high. I mean there are varieties of typical foods, both expensive and inexpensive. It's easy for the tourists to decide what to consume.

(Regional public 1)

The above quotations also indicated that tourism products and services in Pattaya are extremely diverse. Beaches and marine tourism activities, private attractions, shows and performances, shopping, bars, restaurants, and hotels are examples. The slogan of 'The city of variety' is used to officially promote and emphasize a variety of tourism products and services provided there (see Figure 4.6).

Figure 4.6: Homepage of Pattaya City.

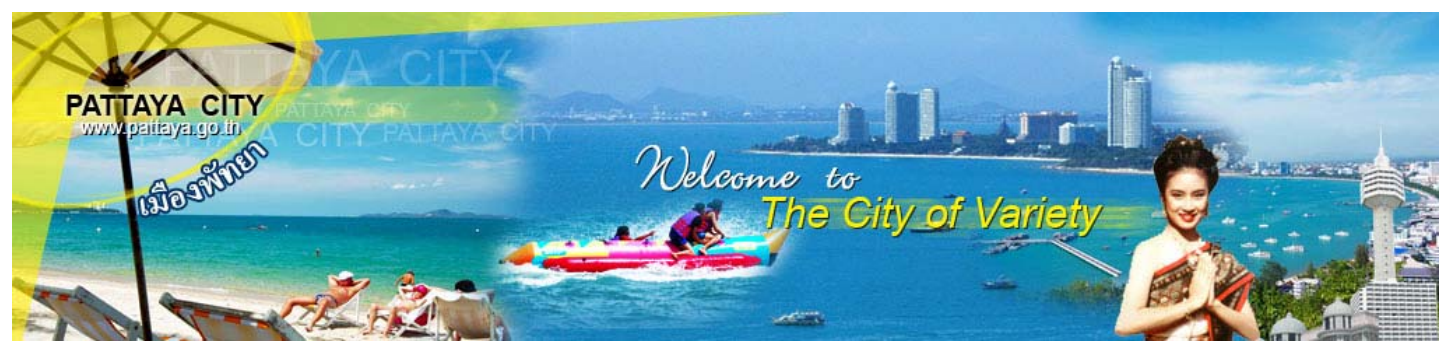

Source: Pattaya City’s homepage (2006)

A 'variety' of products tend to be an emphasis when marketing Pattaya as it may be perceived as helping to minimize its image of a sex tourism destination. Numerous road-shows held in and outside the country with the cooperation of the public and private sectors were widely mentioned by respondents. Multiple forms of tourism 
information publication such as booklets, brochures, leaflets, and CDs are also distributed to the tourists. Various tourism campaigns, such as 'Fun every square inch in Pattaya' and 'Amazing Pattaya Sale 2007' used to promote Pattaya's tourism, were also presented in the on-line news. All these activities seem to be carried out by the cooperation of several agencies, such as Pattaya City, the Tourism Authority of Thailand, and some private agencies. Examples of these marketing activities are reflected by the following quotations and presented in Figure 4.7.

I think they [Pattaya City and relevant agencies] want Pattaya to be a tourism city. They try to promote Pattaya as a place that has everything people want. They organize road shows to promote that Pattaya is not the same as in the past. Some people never visit here so they can not see the picture. That's why they need to promote Pattaya in other countries. This is done by the cooperation between Pattaya City and relevant agencies. Pattaya City cannot do it alone. Other related agencies such as hotels and restaurants must cooperate with the City to promote Pattaya. There are many road shows. Hotel representatives are cooperating with them. TAT is the main agency to promote the destinations, not only to promote Pattaya but also other tourism destinations.

$$
\text { (Local private 3) }
$$

There are many activities managed by Pattaya City. ... TAT cooperates with the private sector such as the Hotel Association and the Tourist Guide Association. They always work and give feedback to each other. In organizing road shows, [they discuss] "which countries we should go, what the weaknesses and strengths of these countries are. For examples, Japan doesn't like Pattaya, we should go to other countries like Ukraine and Russia.” They always discuss about that. ... Recently, Pattaya City focused more on the social issues.

(Provincial public 1)

Figure 4.7: Marketing activities to promote Pattaya's tourism.

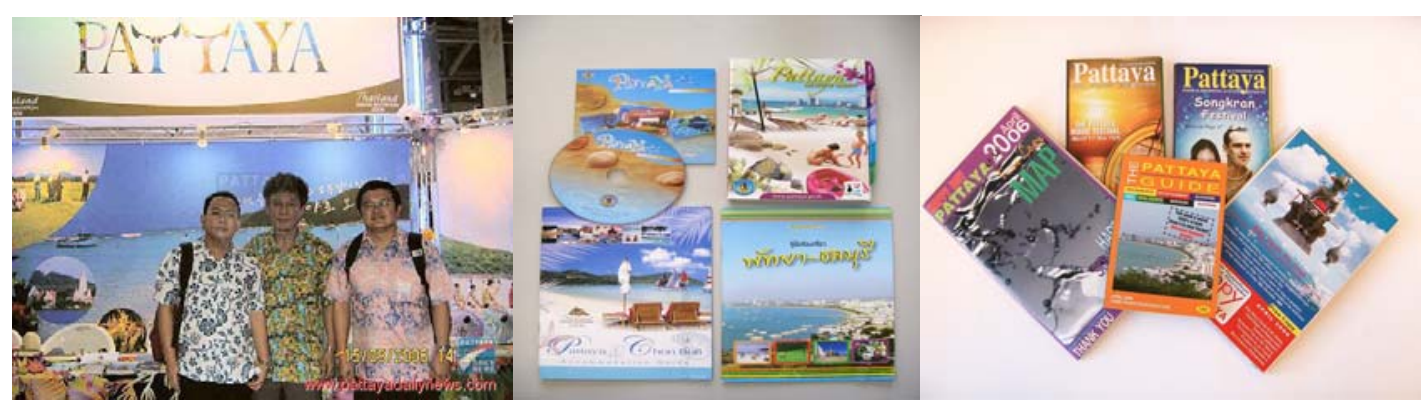

Source: google.com (2006), The author (2006)

The diversity of tourism resources can be categorized into three groups: beach and marine tourism, nightlife and entertainment, and events and festivals. Other tourism resources such as accommodation and food services are the supportive elements that strengthen a variety of tourism resources in Pattaya. 


\section{Beaches and marine tourism}

Most respondents perceived that beaches are the primary tourism resource that attracts people to visit Pattaya. The main beaches in Pattaya consist of three beaches in the city area and four beaches at Larn Island. The three beaches in the city area are Wong Amat Beach, Pattaya Beach, and Jomtien Beach. The latter two and Larn Island's beaches are popular among tourists (see Figure 4.8). There are multiple marine tourism activities along those beaches such as jet skis, rental boats, banana boats, snorkelling, scuba diving, sea walking, fishing, and parasailing.

Figure 4.8: Beaches in Pattaya and Larn Island.
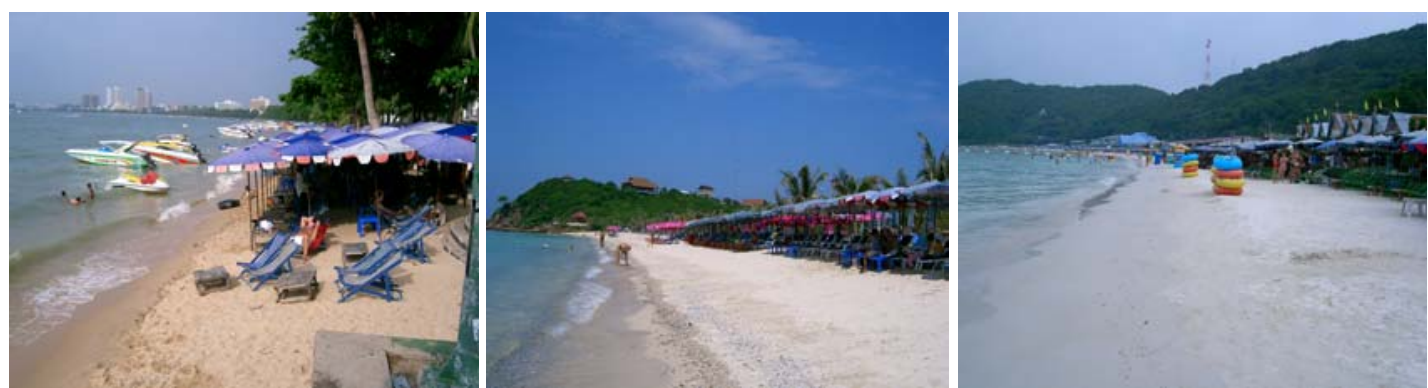

Source: The author (2006)

\section{Nightlife and entertainment}

Nightlife is perceived as another main tourism attraction in Pattaya (see Figure 4.9). It includes a variety of types of night entertainment such as cabaret shows, discotheques, massage parlours, cocktail lounges, pubs, karaoke bars, go-go bars, and beer bars. The nightlife businesses in Pattaya are separated into two groups: those clustered in Walking Street, located in South Pattaya, and those spreading over the city area. 
Figure 4.9: Pattaya's Nightlife, Walking Street, and other entertainment attractions.
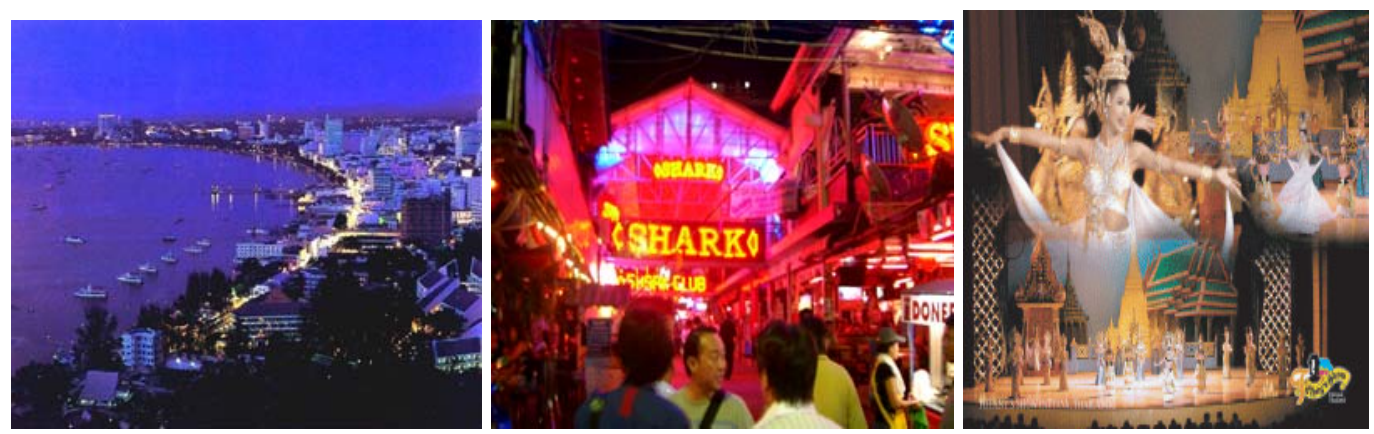

Source: google.com (2006), The author (2006)

\section{$\underline{\text { Events and festivals }}$}

Besides the beaches and nightlife attractions, Pattaya is also perceived as a destination for sports and cultural events (see Figure 4.10 for examples). Although mentioned to a lesser extent by the respondents, approximately 45 events are initiated and run by Pattaya City eleven months a year from October to August the next year. The events organized in Pattaya can be divided into two categories: those developed by Pattaya City and those by other agencies. Regarding the calendar of Youth Activity, the events of Pattaya City are aimed at promoting local youth activity, culture and tradition, religion, and sport and recreation. However, there are some major events that appear to be organized to promote tourism in Pattaya, for example International Beach Football in December, Pattaya Volleyball Open in March, and Pattaya Marathon in July. As Pattaya Music Festival is initiated and promoted under the project “Thailand Grand Festival” by the Tourism Authority of Thailand, it is not officially stated in the city's calendar. However, Pattaya is chosen as a destination for the music festival held in the third weekend of March every year because its facilities and services can cater to large numbers of tourists. 
Figure 4.10: Cultural events and Pattaya Music Festival in Pattaya.
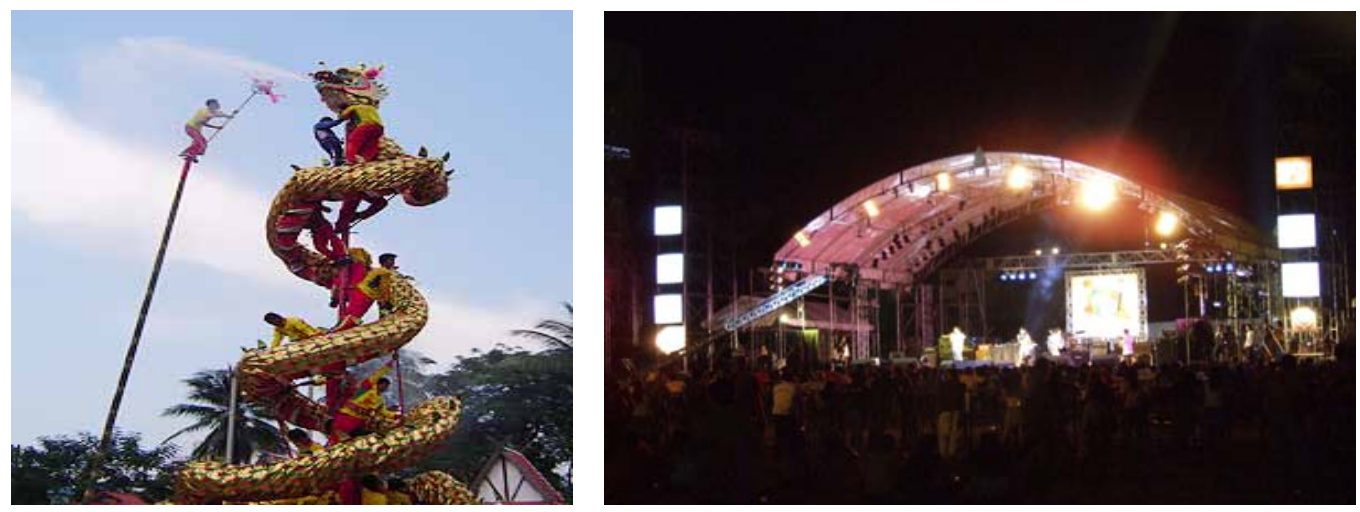

Source: pattayamail.com (2006)

On the basis of these three groups of attractions and related services, Pattaya's tourism characteristics can be separated into two distinct time periods, day and night, which appear to create contradictory images of Pattaya. In daytime, Pattaya provides natural coastal resources and activities as primary attractions to tourists, which creates an image of Pattaya as a typical resort city (Marchant, 2006). From field observations, Pattaya is very quiet and peaceful in the early morning. The beach is clean and empty without any beach chairs or umbrellas. At that time, most of tourists start their trip to the Larn Islands. Pattaya starts to wake up in late morning when vendors start setting up their shops along the beaches, and some domestic and foreign tourists start to visit the city area. In the afternoon, when most bars and shops are open, Pattaya, particularly along the Beach Road, starts to be busy with many vehicles and tourists.

At night, many tourists stroll along Walking Street, visiting an icon of Pattaya. In other areas of the city outside Walking Street, hundreds of bars are also opened to welcome tourists. Many service ladies stand in front of their shops calling, in both Thai and English, for tourists' attention. This scene creates an image of a vibrant and exciting coastal resort for Pattaya. However, there is some entertainment related to sex services which create an image of a sex tourism resort. Although the image of a sex tourism resort may bring a negative image to Pattaya, the respondents from all sectors insist that it is one of Pattaya's characteristics and likely to bring a vast amount of money to the city and to the country. This issue was illustrated by the following respondents although they were not happy mentioning it. 
Many issues that we cannot say no to, such as there are many night-service businesses, many beer bars, and many prostitutes. Then, we have to accept that it is one part of the city. What we are trying to do at this moment is see how to zone them, such as separating entertainment or some businesses which are perceived as not good for Pattaya's image to be unseen for other groups of tourists such as family tourists. It is not what we want, but it's true that there are tourists who come for this in particular. We have to accept that it's one part of Pattaya.

(Local private 1)

Actually, in my opinion, this is a very personal response [the respondent emphasized his response as personal idea]. About sex tourism in Pattaya, beer bars, or other sex-related businesses, I think it's one attraction drawing tourists [to Pattaya]. Yes? Frankly speaking, tourists who come here they don't come just only for swimming, eating exotic foods, or seeing the culture. They want variety, so they go for a massage, for something like that. Make it simple, they do not come only for travelling. They want to experience many things.

(Local public 3)

One respondent mentioned that the image of sex tourism will create a negative reputation for the whole nation, not just Pattaya. Otherwise, the sex tourism image is likely to generally create a negative atmosphere for Pattaya, which can reduce tourist numbers to the area and to the country.

\title{
4.3.3 Socio-economic environment
}

\section{Pattaya is a mature coastal resort which has experienced extensive tourism development that has created an environment that differentiates Pattaya from other cities in the country. Its environment is illustrated well by the following respondent:}

\begin{abstract}
First, tourism benefits Pattaya. Income per head is higher, certainly. It may be from more employment, from the services, and others. Therefore, it benefits from revenue. Also it benefits the workforce...more jobs. However, there are disadvantages. Like I said, the city has expanded rapidly. Public infrastructure does not work at the same pace. There is a higher level of cultural shock. Existing tradition or culture will be replaced by tourists' culture. Another point is more people will migrate to the city. Sometimes, we feel that the locals have to move away. There are many people from other regions in Pattaya. There are not many original Pattaya residents. This is why other cultures can be brought in the area. I don't mean it's bad or good. It's happening. Another point that we should be concerned about is the environment. If relevant agencies can provide enough infrastructures, there will not be environmental problems. Now it may be difficult. Because it's not only implementing the law, it needs to build/create consciousness [in environmental conservation]. It's not easy to do, especially with short term tourists. One thing that they should start doing is to build up good culture of the city. ... when coming to this city, the culture is this way. This is something that should be done.
\end{abstract}

(Provincial private 3)

The above quotation reflects the socio-economic environment of Pattaya. Five major themes were identified from the interview responses. 


\subsubsection{Tourism-based economy}

Pattaya's economy depends highly on the tourism sector. As more than $80 \%$ of the population works in the industry (Pattaya City, 2006), tourism is perceived to bring a positive impact to Pattaya's economy. Many respondents accepted that tourism benefits Pattaya's economy, particularly in investment, and more job opportunities for Pattaya's population. The importance of tourism to Pattaya's economy is stated by the following respondent:

Tourism contributes to Pattaya's economic growth. We can see that $90 \%$ of economic growth in Pattaya is from tourism because it is the main product of Pattaya. Actually, it is a main vein of Pattaya.

(Regional private 1)

However, many tourism products seem to have a negative economic impact on the destination. One respondent raised an issue of a "price war" - competition between service providers to lower their prices to attract as many tourists as they can. He said that this situation occurs when supply is higher than demand, which can be found in Pattaya. The price war seems to lower the quality of tourism products and services. It can also lower the marketing position of the destination and reduce its tourism revenue in the long term, as reflected by the same respondent:

Money flow is what people in Pattaya gain. ... The amount of money is big but the return on the rate of investment is rather low. If comparing to Phuket, Pattaya is 3 times lower. Examples of hotels, they should receive 4,000 baht (US\$ 117), but can get only 700. So, it's lower in that sense.

$$
\text { (Local private 5) }
$$

According to the Annual Summary Report of Pattaya City from 1996 to 2006, the Pattaya government has recognized that the low quality tourism products can bring economic problems to the area. Many efforts seem to have been made to minimize any issue that might bring a negative impact to Pattaya’s economy. One successful approach that can be seen in Pattaya is the improvement of its natural environment.

\subsubsection{Improvement of natural environment}

Since the destruction of natural resources could harm its economic prosperity, serious action is required to solve the problems existing in Pattaya. Information received from the respondents and the official documents reflected that the problems regarding the natural environment of Pattaya have been reduced. In the past, marine 
water pollution was its major problem. The Environmental Act was initiated and implemented in Pattaya in 1992. In responding to this Act, two waste-water treatment sites were established (Sripirom, 1999). Many businesses were involved in building waste-water treatment sites or paying a fee to Pattaya City. With their cooperation, the quality of marine water was improved and attracted tourists back to the city. At present, the quality of marine water allows for safe swimming standards (the Coliform bacteria count is approximately $1000 \mathrm{MPN} / 100 \mathrm{ml}$; MPN = most probable numbers). However, some environmental problems can be seen in the area, such as garbage and waste along the beach, the destruction of beach structure/formation, and the destruction of marine resources by tourism activities. These problems are mentioned by the respondents, stated in official documents, and are also evident on site. A few respondents emphasized that seawater problems, similar to those seen in the past, occur in nearby areas such as Larn Islands and Jomtien Beach. Some of these problems are recognized by Pattaya City and reported continuously in the Annual Summary Reports of Pattaya City from 1996 to 2005. Real improvement seems to be taking more time. Some respondents viewed the implementation from relevant agencies as weak and likely to cause these problems:

\footnotetext{
However, the implementation is getting weaker and weaker. The problem will occur in Larn Island. An example is Sea Walker [a marine activity that by wearing diving masks, tourists can walk under the sea to view the marine creatures], based on the 1992 Environmental Act this activity is illegal. This is a problem. I think the Coastal Resource Division [under The Ministry of Natural Resource] and Pattaya City are the ones who implement the Act.

Pattaya can be held back because of the Act. What I'm worried about is the nearby areas such as Na Jomtien [a nearby district, next to Jomtien beach of Pattaya]. Because Pattaya is still growing and expanding, any activity that cannot be done in Pattaya will be done there. In $\mathrm{Na}$ Jomtien, there is no waste water treatment. The garbage management system is not correct. At present, there is not much development. However, it seems to have plans to support the expansion of Pattaya. This is my personal opinion.
}

(Regional public 5)

The above respondent also pointed out that the weak implementation may result from overlapping responsibilities between relevant public agencies. The complex nature of Thai bureaucracy can cause this problem. Thus, although many laws have been used in the country for some time, the serious implementation of public agencies is extremely influenced by the Thai patronage culture. This is also evident in Pattaya, as indicated by the following quotation:

Because there are many influential people, with this Act, Pattaya City can control them by saying that their businesses do not correspond to it [the Act] ... Therefore, in my opinion, 
Pattaya City wants this Act to help the city in theory. Actually, [sometimes] the city can say no. But because it's local government, it needs to support something. In the decision making, it needs to consider the priority of the locals. [Sometimes] the city cannot say yes or no by itself. It may try to get support from environmental specialists or some legislation.

(Regional public 5)

In contrast to the responses from other groups, these issues were not mentioned by the local public agencies. This also links to the ethical issue of relevant agencies, which was mentioned by a few respondents. One respondent commented that the government concentrated more on material issues but not on people's ethics. Although ethics are important, they tend to relate to human behaviour, which seems to be difficult to measure and to understand the implications. Thus, the behaviour of all relevant sectors appears to be highly influenced by cultures of the country and of their own sectoral cultures. Changing long-established attitudes or behaviour in all the agencies is a challenge but seems to be the only way to strengthen the serious actions/involvement of all relevant sectors.

\subsubsection{Social structure and culture}

As it has been intentionally developed to be a tourism destination, Pattaya's sociocultural environment is likely to be different from other parts of the country. This issue was mentioned by some respondents. Data received from the respondents and the site observations indicated that Pattaya's residents can be divided into two groups: foreigners and Thais. The majority of Pattaya's residents, particularly in the city area, seem to be foreigners. Many of them may run businesses or do nothing but rely on pensions received from their countries. Although there are no statistics about how many foreigners permanently reside in Pattaya, a few respondents pointed to the different ratio between Thais and foreign residents:

Pattaya is growing in a way of a multi or international city because the society in Pattaya is an international society. It is not original Thai society, nor original Western society. It is so diverse. It's similar to America as a melting pot. All are blended in there...Indian, Thai, Chinese, Japanese, Korean, Russian, German, for example. The interesting point is the mix of cultures.

(Regional private 1)

People who come to work in the tourism industry [in Pattaya] such as in hotels and entertainment are from other provinces. Retired foreigners also live here or come here for long stay. Some are not retired but stay for 6 months, then go back for 6 months. Too many [foreigners] to define. I went to Mae Sriruen restaurant...eating and looking around. Then, I realized that only my table is Thais. Other tables were all foreigners or half Thais half 
foreigners. At the others [local restaurants]...fried pork or somtam [typical Thai foods that average income people can afford] are all foreigners.

(Local private 4)

From the above comments, differences in the social status between foreign and Thai residents are evident. As the cost of living in Pattaya is rather low, compared to the Western world, these foreign residents seem to live a luxurious lifestyle. They can be perceived as privileged residents, while most of the Thais are working residents, specifically providing services to them.

Although these foreigners are permanent residents, they appear to have freedoms similar to tourists. One respondent raised an issue of the freedom that Pattaya gives its tourists. As a tourism destination, tourists are likely to have more freedom of expression than the local people. As M R Kukrit Pramoj (Pattaya City, 1980), a Renaissance man of the country, noted:

Pattaya City is for tourists. Thais' way of living in Pattaya needs to get along with the tourists. It means any work/activity should provide convenience and comfort to the tourists. More of them can visit and bring more foreign currency to the country.

Whether it was interpreted accurately or differently from his meaning, his comment appears to have some influence on the development of Pattaya's tourism. As a city with a diversity of cultural differences and freedom of expression, the culture of people in Pattaya appears to be unique and different from their original cultures. This would be the reason why some families do not want their grandchildren to be brought up within Pattaya's culture, as commented by one respondent. It is a social issue of concern, as it may spread into other areas of the country and minimize or threaten Thai culture in the future (Saksri, 2003).

\subsubsection{Short-term migrants as population majority}

The majority of the population in Pattaya are not perceived as Pattaya residents (Pattaya City, 2006). Excluding the tourists, most Thais migrate to Pattaya for a short time. Particularly in the high season (from November to January each year), large numbers of people from other parts of the country migrate to Pattaya with expectations of earning some money before heading back to their home regions when the season is over. They work in bars, pubs, restaurants, or become peddlers who sell food and souvenirs to the tourists along the beaches. Some of them may be involved 
in prostitution. The issue of the migrant population is seen by many respondents to be important and linked to multiple social problems in Pattaya. According to the Annual Summary Reports of Pattaya City from 1996 to 2005 and the interview responses, social problems in Pattaya are diverse and complex. Examples are prostitution, sexually transmitted diseases, drugs, and crime. When there is a criminal incident in the area, sometimes caused by this migrant group, Pattaya City struggles to identify the misbehaving person since there is no personal identity such as identification numbers, house numbers, or relatives. This leads to an issue of safety, which is very important to Pattaya's reputation and is well recognized by the respondents from local public agencies:

\begin{abstract}
Pattaya is an open city. People from 76 provinces [75 provinces and Bangkok] come here. We cannot select people who come here. To select only good quality people to live in Pattaya is impossible. Therefore, there are many levels of people who live here from low, medium, to high. There are four levels. The lowest is homeless people, salaried people are the second, businessmen, and then investors. Real social problems relate to the lowest level and very low salaried people. When they migrate to Pattaya, the lowest level has to collect food from garbage. Their kids do not go to school. This starts the social problem....residing in private properties or public assets. Although not having enough money, they still drink. Then, get involved in crimes such as robbery and pick-pocketing. The second level, with very little salary, has similar problems. Then, stray kids or gangs become another social problem.
\end{abstract}

(Local public 1)

However, the above quotation seems to blame Thai migrants for causing all social problems. A few respondents perceived that some tourists also create social problems. Involvement in prostitution and drugs is an example. Because the immigration system is rather freely open for many countries (Henderson, 2004), low quality tourists can easily enter the country. They may visit or live in Pattaya. In the worst scenario, they may have their own gangs and be involved in crimes. These issues were raised by several respondents:

Related to the society, there are beggars, stray kids, all gender prostitutes. Children can be involved in the sex service very easily, as we can see, many people/tourists are ready to buy. It brings the problem of child prostitution. This social problem results from the development of Pattaya.

$$
\text { (Regional private 1) }
$$

There are gangs coming to take advantage in the area. There are more crimes. Now even foreign gangs are in Pattaya. This is an issue related to safety.

(Local private 5) 


\subsubsection{Unlimited growth}

Pattaya seems to grow continuously at a rapid and unlimited pace. This results in a problem of insufficient public infrastructure. Generally, the intensive development of infrastructure and densely concentrated population causes physical problems. According to the comments made by Smith (1992), some physical problems have diminished, such as the quality of natural resources, while some are still evident today such as insufficient water supply, particularly in summer. These problems, specifically water supply and traffic congestion, were also reflected in the Annual Summary Report of Pattaya (e.g., Pattaya City, 2004, 2006) and by many respondents, particularly from the local private sector. They also mentioned other kinds of public services such as telephones and electricity which need to correspond to the size of the population. Their responses suggested that the development of the city and its public infrastructure was not occurring at the same pace and that town planning was not effective. All these issues regarding basic public infrastructure and services are illustrated well in the following quotes:

When many people live in the area, there is an effect. More consumption, more waste water, and more garbage. There is also the impact of an insufficient amount of water and electricity. The city has to be responsible for providing all these to support the city expansion. The public infrastructure should be expanded at the same pace to support it.

(Local private 4)

Infrastructure is not enough. About infrastructure, we cannot say about Pattaya only, but about the whole province. For example, roads are not enough. Every road to Chonburi, to Sri Racha, to Laem Chabang, to Pattaya has traffic problems. It is not enough and causes traffic jam. Or water supply, there was a serious problem last year. It has still not improved over the long term. Or electricity, telephone, these are basic facilities required, but they are not developed at the same pace as the city.

(Regional private 1)

Although the underdevelopment of infrastructure is recognized by the Pattaya government, more building has been authorized for the near future. This may bring more problems to the infrastructure development, the city environment, and its society.

\subsection{Discussion and conclusion}

Background information on Thailand and Pattaya has been presented in this chapter. The comments regarding the three levels of Thai governments indicated that besides 
the local government, other levels of government may be involved in managing the local tourism destination. The comments of Thai bureaucracy illustrated the complex authoritative structure between relevant public agencies. The cultural context, particularly the patronage system, underlines the informal power that could weaken or strengthen the implementation of public agencies.

All these issues seem to be reflected in the management of Pattaya's tourism. Though it has been developed for more than 40 years, Pattaya is still an extremely dynamic city. Currently, it is characterised by its diverse tourism products and services, and still makes a major contribution to the country's economy. It seems to have been developed without a clear direction and has reached its mature stage of a tourism destination. It needs to focus on maintaining its tourism quality for the longterm benefit of its economy. Thus, current tourism-related issues such as underdevelopment of infrastructure, degradation of natural resources, and crime need to be managed to improve the quality of its tourism resources and to maintain the feasibility of the destination. These multiple and complex problems can indicate that multiple tourism-related activities need to be managed in Pattaya. Because the Pattaya government does not have absolute authority, other levels of government seem to be involved in managing the destination. Their interactions in managing these activities, particularly at the Pattaya scale, need to be clarified. These issues will be discussed in the following chapters.

In Chapter 5, the findings regarding the concept of destination management will be provided and discussed. It will be used to reflect on destination management practised in Pattaya. In the subsequent chapters, details of the tourism management process will be presented. They will be represented by the findings of the management process of the beaches, nightlife, and the Pattaya Music Festival. Then, the management of the three sub-cases will be drawn together to clarify the overall practice of destination management in Pattaya. The discussions and recommendations for its further use and application are made in the concluding chapter of the thesis. The final chapter will also present general and specific lessons drawn from the Pattaya case study. 


\section{Chapter 5 Concepts of a tourism destination and destination management}

\subsection{Introduction}

As mentioned in Chapter 3, this chapter draws from the interview data collected in the second and third phases of research. In the second phase, the respondents were asked to provide their perspectives regarding the terms 'a tourism destination' and 'destination management'. They were asked to define these two terms in their own words and to reflect on how Pattaya matched their definitions. They were then asked to give their views on two statements taken from the tourism literature and reflect on how well Pattaya matched them. Key aspects derived from the interviews were combined with the aspects drawn from the literature to develop a broad concept of destination management. The concept of destination management developed from this second phase was used to cross-check the practitioners' perspectives in the third phase and synthesized in the final phase of research. These techniques helped to illustrate how the practitioners perceive this term, to develop the general concept of destination management, and to provide some understanding on how they might manage the destination. Comparisons between the practitioners' views and the concepts expressed in the literature are presented in the conclusion of this chapter. The general concept of destination management will be used to clarify and reflect the overall practice of destination management in Pattaya.

\subsection{Defining a tourism destination}

\subsubsection{Defining in the practitioners' own words}

When asked to define a tourism destination in their own words, the respondents tended to say that they did not know much about the topic and broadly defined a destination in relation to examples of tourism supply and demand. Respondents from public and private agencies from the Pattaya level tended to identify tourism supply more than the respondents from other levels. 
Different features and types of tourism attractions, activities, and services were mentioned by most respondents as tourism products required at the destination. Some of the respondents felt that these products should present the destination's "uniqueness" or "identity" that draws tourists to the area in the first place. Besides the beauty of attractions and quality of facilities provided there, some respondents mentioned that "safety and security" is required at the destination. A few of them suggested that all the tourism products should be provided at a "low" price to the tourists. Examples of tourism products that should be provided at the destination are illustrated by the following quotations:

It [a tourism destination] is a place that is providing public services, facilities, accommodation, food services, entertainment, and attractions. It should have everything that the tourist wants. Because if the tourist has difficulty in finding a room to stay, food to eat, transportation to get around, it cannot be [a tourism destination]. Therefore, it is a place that is ready for the tourist to visit and can feel real relaxed when visiting the place.

(Local private 3)

It is a place that people want to visit and to see in order to relax, to feel good, or to visit someone. It also needs to provide services and facilities to the visitors. Private attractions or natural attractions such as the beaches, islands, and sea are examples. The facility is a supportive element for tourists' convenience. Examples are accommodations and restaurants.

(Regional public 1)

Besides providing multiple tourism products, the respondents both from the public and private sectors in Pattaya and other scales defined the destination regarding its ability to respond to the tourists' needs and desires. Many respondents insisted that the destination should "respond to the tourist needs", both physically and emotionally. The tourists' needs for "convenience and comfort”, "safety”, and "places to eat and stay" while at the destination were widely mentioned. The ability to serve those needs was seen to be important for the destination, as it tends to create positive feelings in the tourist which can benefit the destination in return. The terms "happiness”, “relaxation”, “enjoyment”, and "pleasure” were commonly mentioned to describe the tourists' feeling when visiting the destination. Positive feelings are likely to bring satisfaction, make an impression on the tourist and lead to repeat visitation in the future. The importance of serving tourist demand was well illustrated by the following respondents. In their statements, the ability of the destination to serve high numbers of tourists and to respond to various needs of the tourists was also indicated. 
... a tourism place needs to be defined by the needs of customers, by the demand side not by the supply side. ... In this new era, the needs of people are different and diverse. Therefore, it's justified by the demand. If you are in the area that can serve most demands you will have the advantage.

(National NGO 1)

It is a place that people want to go to make them feel better and to make their minds more calm. ... Sometimes people are stressed from work; they may think...'uh, better travel'. What they think of, it's a tourism place that they can find happiness. It doesn't matter whether it's a natural, an art and cultural, or an entertainment place. It's a place that they can find happiness and release their suffering feeling or anything. Then, they can relax, be happier, and be able to go back to work again.

(Provincial public 3)

By defining the term 'a tourism destination' in their own words, the respondents tended to define it by identifying the multiple tourism products required there. These tourism products are likely to be recognized by the respondents at the local scale more than the respondents on the other scales. Otherwise, both groups of respondents defined the destination by the needs of tourists. They tended to consider the tourists' needs as something that the destination must be concerned with and respond to for the benefit of the destination in return.

\subsubsection{Perceptions of Ritchie and Crouch's concept}

Following this unstructured elicitation, the concept of a tourism destination was examined in relation to Ritchie \& Crouch's (2003, p. 67) statement that:

The destination must function as a real entity. That is, it must have a sense of itself; it should have a purpose and be managed in a way that promotes the pursuit of that purpose.

When encouraged to comment on this statement, other aspects relevant to a tourism destination were added. Most respondents from both the public and private sectors in Pattaya and the other scales agreed that the tourism destination is a place that requires management. Typical of their responses are the following quotations:

I agree because the destination cannot naturally occur by itself although it comprises natural resources. It [a destination] requires a good management system depending on its scale: small, medium, or large. ... Sometimes it needs to be improved by responsible agencies, both public and private sectors. We [all relevant agencies] will do this and do that, not leaving it [the destination] freely [unmanageable], or letting anyone do anything in a way s/he wants. It should not be that way.

(Provincial public2)

I think there must be an advertisement to bring a lot of people to the place. What should have been done beforehand is to think how to manage those people, how to manage the resources, and how to distribute those resources to the locals and to share with the newcomers. Therefore, I agree that the destination must have a goal, its identity and be managed. It needs to be planned in advance.

(National NGO 2) 
Many respondents identified key aspects relevant to management required at the destination: responsible agencies, collaboration, and management structures. The respondents believed that there must be some groups of people or agencies from both the public and private sectors involved in managing all tourism products and the destination. These agencies should "have knowledge of the destination" and "know the limitation of the destination”. Collaboration between relevant parties appears to be necessary in managing the destination. Being aware of and acting on their roles and responsibilities can be one kind of collaboration practised by these agencies. One respondent pointed out that "the acceptance from the local government and the residents” is an important factor for successful management. A few respondents also suggested that the management structure should be "flexible" or "informal", which can be operated and changed when needed. Referring to Pattaya, the following respondent underlined the lack of collaboration between relevant agencies in managing the destination:

In theory, I think it's correct, but in reality it's quite difficult, especially in Thailand. Pattaya is an example. There are four or five organizations involved in this small city. First is the central government. Second is the provincial government. Third is the provincial local administrative organization. Fourth is Pattaya City as a municipality. Another one is the private sector in the area. The private sector acts as an informal organization involved in driving Pattaya to the direction that it should be. Pattaya depends on the budget from many related organizations. They do not cooperate.

(Local private 1)

Besides the management requirement, some respondents agreed that the destination must have its own sense of a tourism destination. The "uniqueness" of tourism attractions, activities, and services was mentioned as the destination's sense of identity. A few respondents explained that the sum of the tourism products provided at the destinations can differentiate and distinguish one destination from another. These products also attract tourists to the area. Destination identity can be specific or diverse; however, it is likely to reflect the destination's goals. Some respondents suggested that the main purpose of the destination is to satisfy tourists. They insisted that by providing a diversity of tourism products, tourists can be satisfied. One respondent commented that if the destination is perceived as an entity then making a profit should become its main purpose. He believed that tourist satisfaction will bring profit to the destination. Another respondent suggested the destination should have "sustainability as its purpose". Similar to what is commonly suggested in the 
literature, he suggested the destination should aim to sustain its tourism resources for the benefits of all stakeholders.

Although most respondents agreed with Ritchie and Crouch's (2003) concept, some of them also commented that this concept was too theoretical and may be difficult to apply in the real world. A few respondents further stated that the concept was too narrow and could be applied to only some types of destinations such as "private attractions" and "museums”. For them, some places such as "market places” and “temples” were not managed to be tourism destinations although they can attract tourists to the areas. However, their comments appeared to support the view that some levels of management are required in those places to pursue any goals they aim to achieve.

\subsubsection{Reflections on Pattaya}

When asked to match Pattaya to their own definitions and to Ritchie and Crouch's (2003) concept, two key aspects were noted by most respondents. From their perspective, Pattaya is a tourism destination because it provides various types of tourism attractions and services and can serve all the tourists' needs, represented by the following quotation:

Pattaya has everything in itself... something naughty, diverse activities, some peaceful places, some places for meditation. In short, it's a city of diversity in cultures, activities, foods and all things for consumption. There is everything you want: clothes, food, and sex. So, it matches my definition.

(National NGO 1)

Some of them insisted that a variety of tourism products is a key part of the identity of Pattaya and provision of that diversity becomes a broad goal for Pattaya. They also agreed that some level of management was practised to operate Pattaya in a way to pursue that goal.

If the destination is to function as an entity it has to include its identity. The word 'Pattaya' aims to sell itself, but Pattaya itself is special. It has diversity in itself. It can sell the sea, entertainment, island, and all nearby areas. All these are sold in one package. ... Therefore, the goal of the word 'Pattaya' is diversity. Pattaya sells diversity. Conversely, Pattaya cannot run itself. It needs an organization to manage and control it in order to achieve its goal. Pattaya cannot run itself.

(Local public 1) 
Many respondents, particularly from the private sector in Pattaya and the other scales, defined the tourism destination by reflecting on Pattaya's issues. Specific issues relevant to management practice were mentioned. They commented that diverse groups involved in Pattaya may result in different management directions. Thus, overlap and conflict of responsibilities may occur and cause management difficulties. This issue was clearly expressed by the following respondent:

It [Ritchie and Crouch's (2003) concept] can be applied to Pattaya. We are doing like this. We are trying to manage everything such as vendors or shops. However, there is something that we cannot do. Traditional massage shops or beer bars are examples. They have to apply for the licences from the district. We can control only small detail such as noise control. How many decibels do they require? If there is no complaint, we can't do anything.

(Local public 3)

The above respondent also indicated the administrative boundary that exists between the public agencies in managing Pattaya. Again, the importance of collaboration between relevant agencies in managing the destination was indicated. Although the coordination of management resources can be seen in Pattaya, a greater degree of collaboration was suggested in its management by a number of respondents. A few respondents commented that the vision of destination managers and tourism businesses was important in managing the destination. Although there are development plans for Pattaya, tourism management appears to "follow the problems” rather than to follow the plans. Without a clear vision, its tourism seems to have "no specific goal" and "no limitation of diversity". A high degree of coordination between relevant agencies in developing the destination goals and managing the tourism-related activities appears to be absent.

Moreover, a positive tourism atmosphere was indicated as another aspect of the tourism destination. Some respondents, particularly from the private sector in Pattaya and the other scales, commented that the negative environment and quality of tourism attractions may diminish the tourism atmosphere in Pattaya. Physical issues such as “congestion”, “crowded population”, “traffic jams”, "low quality of natural attractions”, “many and unorganized vendors”, and "prostitutes along the beaches” were mentioned. 


\subsection{Defining destination management}

\subsubsection{Defining the term in practitioners' own words}

When asked to define destination management in their own words, the respondents tended to define this term specifically related to management practices. From their responses, key aspects of destination management were identified: those relating to product management, tourist management, the management process, and management factors.

Several respondents defined destination management as the practice of providing quality tourism attractions, facilities, and services at the destination. This included the management of existing natural resources for the benefit of locals and tourists. It also refers to the management of providing new tourism resources and harmonizing them with the original natural resources. The phrases "to sustain the destination in the long term”, “without having too much negative impacts on the destination”, and "for the highest benefits without destroying natural resources” were stated. This view was illustrated by the following respondents:

To manage the destination, we need to look at to what extent we can maintain the original characteristics of the destination and what new things we can add without affecting the attraction conditions. For example, how can we take care of our beaches? We need to clean them...something like this. In the opposite way, how can we attract the tourists to see other things besides the beaches and the sea? We need to build something. However, we need to know how to match it to the original environments.

(Local public 1)

It means the practice to organize everything [related to tourism] efficiently, and effectively. ... It concerns to what extent the use of resources in the tourism area can benefit its visitors. If we perceive that we are the tourism place, the tourists should revisit us. If they come once and never come back, it means we have a problem related to efficient management. ... Effectiveness will occur when the resources used can serve all needs of the tourists. If the tourism place can respond to tourist needs, tourist re-visitation will be the result. This refers to efficiency. All resources used are worthy if the tourists come back.

(Regional public 2)

The above respondents also implied that destination management was the practice of attracting tourists and responding to their needs. This aspect was also reflected by other respondents. Although tourist needs can be diverse, the destination should be able to respond to their fundamental needs such as security, comfort, and convenience. When the tourist needs are fulfilled, there is a possibility that the tourists may revisit in the future. Repeat visitation can reflect the effective management of the destination. 
Thus, destination management was defined by its management process and practice. In the process of management, it appears to be necessary for the destination to have plans in order to identify its main customers, its goals, and how to achieve them. Some respondents suggested that destination goals could provide a clear direction for what the destination wants to be and how to achieve them. Diverse functions and activities are also required in managing the destination. The terms relevant to management functions such as "planning”, “organizing”, and “penalizing” were directly mentioned. All these functions should be managed by relevant parties, such as public and private sectors and residents, as suggested by the following respondent:

\begin{abstract}
It needs to go back to the target customers who are the main group of our customers and what their expectations and needs are. Then, all facilities and everything need to be managed to serve the needs of those groups. There are two aspects that need to be managed. First, fundamental needs of tourists such as convenient and comfortable life, and security in life and assets are the basic aspects that all destinations need to manage. If you cannot do it, certainly, you will not be able to sell [the destination]. Second, it is related to the needs of specific groups of customers. In this aspect, the private businesses can serve their customers. However, the public sector should be responsible for stopping deception, for controlling a fair price for customers. It's only taking care of the customers' rights. That's it.
\end{abstract}

(Local private 1)

Although the above respondent tended to differentiate the responsibilities of relevant parties, collaboration between them is required, as reflected by some respondents. One respondent indicated that collaboration in providing financial resources was the most important factor for management. His statement also reflected the importance of collaboration between responsible agencies and the local residents in managing the destination, in which the local residents were rarely recognized by other respondents:

In management, the problems of a tourism place need to be identified and tourists' needs should be understood. Hence, we need to have sufficient personnel and budget to successfully operate it. If we can think but have no money, we can do nothing. Moreover, residents need to participate in thinking and operating stages as well. They [residents] should not leave the city to take responsibility alone.

(Regional public 3)

\title{
5.3.2 Perceptions of Anderson's concept
}

Reactions to Anderson's (2000, p. 146) concept of destination management were also used to obtain the practitioners' perspectives regarding destination management. Anderson defined destination management as: 
... the integrated process of managing any of the three tourism destination types (urban, resort, and rural). It covers four key elements; the destination offering (visitor experience, destination image and attractiveness); the visitor mix (market research); marketing communications (awareness and promotion); and organizational responsibility (leadership and partnership).

When commenting on this statement, most respondents, particularly those from the Pattaya scale, agreed that integration, particularly of tourism-related management activities for quality tourism products and services provided to the tourists, was the major aspect of destination management. Public relations and tourism promotion, management of destination characteristics, destination image, quality of tourism products, and marketing research were mentioned as examples of these activities. Integration of relevant agencies to carry out these activities, to run the destination, and to solve problems was also seen as necessary. The phrases "need to work together" and "to integrate ideas and practices to become one" were widely used. The integration of relevant agencies in managing the destination was highlighted by the following respondent:

I agree because it is not about working only one or two components in managing tourism area. It relates to many components. The advantages from each component need to be integrated for the destination benefits. For the first element [destination offering], it refers to what the destination sells to tourists. It can be a story, which may be a history or activity about that place. ... It can relate to local life, arts and cultures. All these are selling products. I also agree with the second element [visitor mix]. No matter how good tourism products are if they cannot be promoted to the customers they will be useless. Therefore, we need to select the customers that can benefit us the most. This is the central element. For the third element, marketing communications support information distribution. It helps to expand more marketing channels. People who do not intend to visit; they may change their minds after receiving the information. The final element [organizational responsibility] is crucial. It is a main mechanism [of destination management] whether the tourism place can be as I defined: to have quality, efficiency and sustainability. ... It gives a direction to where the tourism place is going.

(Provincial public 2)

One respondent disagreed with Anderson's (2000) concept. He argued that "this concept is too theoretical and definitely impractical to apply to general destinations”. From his point of view, Anderson's concept is more practical if applied to newly developed destinations because they can be started by planning the target market and developing the products that correspond to the target groups. However, he felt that most destinations developed their products without first identifying the target customers. Later, other activities such as marketing and research could be applied to those destinations. His comment, however, underlined the need for integration of 
relevant activities and agencies since it appeared as a strategy to improve the quality of destinations and to sustain them in the tourism market.

\subsubsection{Reflections on Pattaya's management}

When reflecting on Anderson's (2000) concept and the concept of destination management obtained in the second phase research on Pattaya, many respondents, particularly those from the Pattaya scale, agreed that integration was the key aspect of destination management. The integration of multiple tourism-related activities and of relevant agencies was added when describing their views. Since Pattaya can provide a variety of tourism products, multiple tourism-related activities are managed there. Moreover, as many agencies are involved in managing particular activities in Pattaya, some level of integration between relevant agencies is needed.

Multiple activities relevant to product management, destination marketing and research, and tourist management were frequently stated. Some respondents perceived that multiple tourism products in Pattaya are managed to promote a "city of variety” image. This image may create positive and negative images to the destination. Several respondents commented that "beer bars" and "entertainment” create a negative image for Pattaya. Moreover, marketing activities such as providing "updated news to the media" and organizing "familiarization trips" and "road shows" were intentionally used to communicate to the tourism market and to attempt to attract large numbers of tourists to Pattaya. Diverse tourist groups such as those from “Hong Kong, Korea, Russia and Ukraine” and “Chinese and Taiwanese...European” were mentioned by some respondents. All these tourism-related activities are undertaken by some organizations, as expressed by the following respondents:

It is [reflected Anderson's (2000) statement], but many aspects need to be integrated. ... For examples, TAT, the City, and the Provincial Administration Organization are responsible for the tourist research. We [the public sector] are responsible for our marketing groups on how we can serve them. For the tourism promotion, we do it every year. For the organizational responsibility, we, the Provincial Administration Organization, and a few of the private associations are coordinated by providing financial resources and operating the projects.

(Local private 1)

Pattaya is managed similarly to this definition [Anderson's] but not in all elements. For the first element, Pattaya has its character. There is a picture the tourists can see when talking about Pattaya. They experience Pattaya and some of them may be impressed by what they experienced. The attractions may be the beautiful sea. I think Pattaya has its marketing groups, but the practice is not integrated. There are many agencies that do marketing research such as the City, TAT and the private sector. It looks like they work in their own ways. They 
never compare the research results. They have their own plans. For marketing communications, the City uses a lot of this element, but the private sector acts more [in promoting the destination]. For the responsibility and organizations element, I think Pattaya has a problem. Like I said that there is no collaboration. ... In short, Pattaya has all elements in this definition, but not in a good result. It cannot be applied a hundred percent.

(Provincial public 2)

The above respondents also implied a high level of integration between all related agencies is necessary in managing the destination. In managing Pattaya, some level of integration occurs. Cooperative practices such as meetings, training, and activities to solve problems such as "water shortage", or to carry out particular projects such as the "Pattaya Music Festival” and "cleaning projects” were mentioned, particularly by the public sector. Cooperation from the residents is seen in particular projects such as “volunteer group for security”. A few respondents stated that Pattaya City acts as a coordinator to cooperate with all relevant agencies, while one respondent perceived that both Pattaya City and TAT coordinate all relevant agencies to run Pattaya as a destination. Cooperation in the management of resources, such as money and manpower, was again mentioned. However, some respondents, particularly from the private sector, commented that a higher level of cooperation in Pattaya is required. One suggested that the public agencies, particularly the national and local governments, need to have primary roles in planning, directing, and controlling the operation of the destination. All these functions should be supported by the private sector. All these issues are illustrated in the following quotations:

For the responsible organizations, we have budget cooperation and work together with the provincial local organization, the City, the provincial office, and a few private associations. Each organization has a different way of working. For example, the provincial local organization and the City allow the private sector to have some level of independence. They give us the budget. We discuss within our sector regarding what we want to do this year, how much money we want, and propose to them the plan. It looks like we have some influence in setting the direction. However, the budget [from the central government] is rather small when comparing to the tourism receipt that Pattaya distributes. Pattaya makes approximately forty or fifty thousand million baht (US\$ 1,473 million) a year, but the budget for marketing promotion is only fifteen million. It is very little. The City is better than the provincial office. It looks like they [provincial officers] already plan what they want to do, but want our responses as yes or no. Sometimes we give a lot of information about what should be done or should not be done. If they listen to only half of what we said, we will be lucky enough. Sometimes it looks like they already have their expectation that they want to do this project this year. As for the private sector, we just support or suggest they change the methods for more efficient and effective results by using the same amount of money.

(Local private 1)

It [the concept of DM] is correct because Pattaya and TAT are the main agencies in managing Pattaya and the private sector is coordinated. We are doing like this concept. However, it depends on the results or how sustainable the practice is. They [Pattaya City and TAT] always have an annual plan of what they want to do each year. ... Actually, the plan is 
quite good but it should be consistently and seriously implemented. ... not doing it just for a short period of time and stop. ... Another issue is about the benefit. Benefits of most people should be the principles, not for some particular groups of people. Yes? If it benefits only for some groups the management practice will not be able to achieve the real destination goals. ... [However] it's more about the benefits of some particular groups and election votes.

$$
\text { (Local private 4) }
$$

Definitely [Pattaya is] trying to create positive tourism. It's serving tourist demand but... some certain areas of infrastructure do need to be improved. ... It's all people that have to participate in this. It's all parties. Yes? It starts with national government, going down to local government. ... That, to me, it has got to come from the top, it's got to come from the local government, and the private sector is still there to support whatever. ... At the end of the day, it is regards the local government. Yes? It is town planning when they say 'yeah....we will allow five hundred beer bars, and go-go bars to be set up in the city'. The private sector can not...ah... [pause]...... you know, it's very hard. It's very hard. Before that, they tried to close them down, and next minute they are like mushrooms. They pop up in other areas, which in their previous ideas these beer bars will be in one area. .... Ah...but that is because of town planning, and I think so because developing such a fine, better area makes a lot more money. So, definitely, one big area that needs to be done, not just here [Pattaya] but in Asia, is better town planning. ... So, I think that is where the management of the destination, no matter how good the private sector versus the local government and the federal government, either makes that happen or changes it around.

(International private 1)

The above respondents indicated difficulty in managing Pattaya. This management difficulty might be influenced by the Thai bureaucracy, discussed in the previous chapter. Because Pattaya's municipality does not have absolute power, it requires the authorization from higher organizations such as provincial and national governments. The statements "the central government has to say 'Yes' then Pattaya City can start doing something" and "it needs to pass through the provincial office, or sometime the ministries" and "it needs to raise the issues and be approved" were expressed by several respondents, particularly those at the municipality. Moreover, an issue of organizational differences in goals, working systems, and organizational cultures and backgrounds may obstruct successful cooperation between relevant agencies. In this sense, destination goals appear to be necessary for destination management as they give direction to what the destination wants to be or what management needs to achieve. Reflections on Pattaya highlighted the integration between relevant agencies in providing management resources and developing destination goals, as a major aspect of destination management. 


\subsection{Discussion and conclusions}

In this chapter, the concepts of a tourism destination and destination management from the practitioners' perspectives have been clarified. Three techniques were used to obtain their views regarding these two terms. The respondents were asked to define these two terms in their own words, to comment on the statements taken from the existing literature, and to reflect on their definitions and the statements with regard to Pattaya. Key aspects of the tourism destination and destination management obtained from the practitioners are presented and discussed below.

\subsubsection{The practitioners' perspectives of a tourism destination (TD)}

Table 5.1: A summary of key aspects of a tourism destination defined by the practitioners

\begin{tabular}{|l|l|}
\hline \multicolumn{2}{|c|}{$\begin{array}{c}\text { Key aspects of a tourism destination from } \\
\text { the practitioners' perspectives }\end{array}$} \\
\hline In their own words & $\begin{array}{l}\text { provides multiple tourism products } \\
\text { has an ability to respond to demand }\end{array}$ \\
\hline $\begin{array}{l}\text { Comments on } \\
\text { Ritchie \& Crouch's } \\
\text { (2003) statement }\end{array}$ & $\begin{array}{l}\text { requires management } \\
\text { must have its own identity }\end{array}$ \\
\hline $\begin{array}{l}\text { Reflection on } \\
\text { Pattaya }\end{array}$ & $\begin{array}{l}\text { provides multiple products } \\
\text { has an ability to serve tourist demand } \\
\text { has its own identity } \\
\text { has some level of management } \\
\text { has a positive tourism atmosphere }\end{array}$ \\
\hline
\end{tabular}

As summarized in Table 5.1, the practitioners defined a tourism destination differently in their own words and in their comments on Ritchie \& Crouch's (2003) statement. In their own words, a destination must, first, provide multiple tourism products, and second, have an ability to respond to tourist demand. The practitioners tended to perceive that tourists are important for the destination. The needs of tourists at the destination appeared to be given emphasis in their definitions. The multiplicity of tourism products was seen to enable the destination to respond to the diverse demands of tourists. The quality of tourism products and their reasonable/low prices were believed to create tourists' satisfaction that may bring them back to the destination in the future. 
Moreover, tourism providers and tourists were identified as the main stakeholders involved in the destination. The tourism providers seemed to include public and private agencies that provide tourism products to the tourists. Although the local residents were not directly mentioned as tourism stakeholders, they tended to be referred to indirectly with reference to the local cultures. The practitioners might perceive that local culture is a tourism product and every person at the destination is involved as a tourism provider, either directly or indirectly.

Their views on a tourism destination appeared to be broadened when reading Ritchie \& Crouch’s (2003) statement. Two main aspects related to management were added, namely that the destination requires management and must have its own identity. Since the respondents did not mention these two aspects in their initial responses, it can be seen that they tended to focus on the physical components of the destination rather than its operation. Although management was indicated in their initial responses, they did note that a destination requires management only when respondents read Ritchie \& Crouch’s (2003) statement. In their responses, multiple agencies from different sectors and operational scales were mentioned. The collaboration between relevant agencies was raised as a necessity to manage the destination. Local acceptance and participation was seen as important for successful management. Local residents were not seen as prominent stakeholders by most respondents. As a result, practitioners tended to see them as followers rather than decision makers. Moreover, management was needed to bring out the destination's identity or its uniqueness and to represent the destination's goals. Whether the destination is managed for the tourists' satisfaction, profitability, or its sustainability, its identity seems to play a major role in enabling destination goals to be achieved. The practitioners tended to realize the importance of this when reading Ritchie \& Crouch’s (2003) statement.

These four aspects, mentioned above, were restated as major aspects of a tourism destination when the practitioners were asked to reflect on Pattaya. A particular scale of the destination tended to come through in their comments. They tended to refer to the local (rather than regional or national) scale of a destination when defining this term. Moreover, a positive tourism atmosphere such as tidiness and cleanliness was 
added as another important aspect of a tourism destination, as it was seen as a requirement for Pattaya, where issues tended to indicate difficulties for destination management.

Therefore, a tourism destination from the practitioners' perspectives can be defined as a place that provides multiple tourism products, has an ability to respond to demand, has its own identity, requires some level of management, and has a positive tourism atmosphere. Their views of a tourism destination are likely to influence their perspectives of destination management and to reflect their actual practices in managing the destination.

\subsubsection{The practitioners' perspectives of destination management (DM)}

Table 5.2: A summary of key aspects of destination management defined by the practitioners

\begin{tabular}{|c|c|}
\hline \multicolumn{2}{|r|}{$\begin{array}{l}\text { Key aspects of destination management from } \\
\text { the practitioners' perspectives }\end{array}$} \\
\hline $\begin{array}{l}\text { In their own } \\
\text { words }\end{array}$ & $\begin{array}{l}\text { - product management (practices to provide quality } \\
\text { products) } \\
\text { - tourist management (practices to attract tourists and to } \\
\text { respond their needs) } \\
\text { - management process (purposes, functions, activities) } \\
\text { - management factors (resources, local involvement) }\end{array}$ \\
\hline $\begin{array}{l}\text { Comments on } \\
\text { Anderson's } \\
\text { (2000) } \\
\text { statement }\end{array}$ & $\begin{array}{l}\text { - integration of multiple tourism-related activities } \\
\text { - integration of relevant agencies }\end{array}$ \\
\hline $\begin{array}{l}\text { Reflections on } \\
\text { Pattaya }\end{array}$ & $\begin{array}{l}\text { - integration of multiple tourism-related activities } \\
\text { - integration of relevant agencies } \\
\text { - integration of management functions and resources }\end{array}$ \\
\hline
\end{tabular}

Table 5.2 summarizes the practitioners' perspectives on destination management in their own words, in their comments on Anderson's (2000) statement, and in their reflections on Pattaya. In their own words, the practitioners tended to define this term based on their knowledge and their experiences in management in general. Although some of them, particularly from the other scales, did not seem to perceive themselves as tourism practitioners, their knowledge and experiences as executives 
of their organizations were reflected in the responses. In their definitions, the practitioners tended to link a general concept of management to the destination as a whole. They broadly identified activities (what needs to be managed), practices (how the management is done), and factors (what is required for successful management) in managing the destination. They perceived destination management as the practices to manage tourism products and tourists. The product management was perceived to be done by providing high quality new and existing tourism resources and harmonizing them with the original natural resources for the benefit of the locals and tourists. Tourist management (or visitor management) was perceived to involve attracting tourists to the destination and responding to their fundamental needs. Tourist impacts were not addressed. In carrying out these activities, the purposes and management functions were seen as important. Planning was perceived as a function to establish the management purposes and to provide clear directions for management practice, while monitoring and controlling functions were perceived as enabling the practitioners to achieve their plans. Integration between relevant agencies to provide sufficient financial resources and to obtain local involvement was seen as an important factor for successful management. These aspects seemed to provide a broad picture of destination management, which was also reflected in their comments on Anderson's statement.

When responding to Anderson's statement, their views seemed to be broadened. While not mentioned in their initial responses, the notion of integration was widely accepted as the key aspect for destination management. Their responses to Anderson's (2000) statement might suggest that the respondents believe in the idea of integration in theory but that integration rarely occurs in Pattaya. The integration of relevant agencies and of multiple activities was further added in their comments. The collective action of these agencies to carry out the multiple tourism-related activities such as tourism promotion and marketing was also suggested. The practitioners' reactions to Anderson's (2000) statement seemed to reflect the issues that are happening in Pattaya.

All aspects of destination management mentioned above were reflected in Pattaya. The practitioners, particularly at the local scale, tended to emphasize 'integration' as 
a core concept for destination management. Even though Pattaya was perceived to be managed by multiple agencies through various tourism-related activities, their activities there were not felt to be effectively integrated. Although the practitioners, particularly in the municipality, widely mentioned that integration was practised in Pattaya, others, particularly in the private sector, called for a higher level of integration. The contradictory views between these two groups of practitioners seemed to indicate a low level of integration in Pattaya. Moreover, the practitioners, particularly those at the local level, added the integration of management functions and resources as another aspect for destination management. This also indicated that a low level of management integration exists there. Therefore, from the practitioners' perspectives, the concept of destination management can be defined as the integration of multiple tourism-related activities (or supply and demand management), of relevant agencies, and of management functions and resources.

It can be seen that the practitioners tended to define destination management based on their knowledge and experiences in management. The agreement with the Anderson's (2000) concept of integration, particularly from the respondents at the local scale, might suggest that the local practitioners tended to define destination management based on their experiences as tourism practitioners more than the respondents from other scales. The issues or problems reflected in Pattaya, particularly by those at the local scale, tended to suggest that local practitioners are likely to understand issues or problems existing at the destination better than the practitioners from other scales. However, the local public sector respondents tended to define the term related to successful practices such as the management of Pattaya Music Festival, while the local private sector tended to define the term related to existing management issues or problems such as the low level of integration of agencies. The local context, such as local politics and socio-economic environment, as discussed in the previous chapter, also tended to have a major influence in the practices of destination management. Otherwise, both public and private practitioners from Pattaya and other scales tended to define destination management based on their experiences as organizational managers. They tended to believe that a high level of integration is likely to bring successful destination management. 


\subsubsection{The practitioners' perspectives of TD and DM}

Table 5.3: A summary of the practitioners' perspectives of TD and DM.

\begin{tabular}{|l|l|}
\hline A tourism destination (TD) & Destination management (DM) \\
\hline - provides multiple products & - is the provision for quality \\
- is able to respond to tourist & attractions, facilities, services \\
demand & - is the practice of attracting tourists \\
- requires some level of & and responding to their needs \\
management & - involves multiple management \\
- has its own identity, which & functions and destination goals in the \\
reflects destination goals & management process \\
- has a positive tourism & - requires collaboration for successful \\
atmosphere & management \\
& - involves integration of multiple \\
& tourism-related activities \\
& - involves integration of relevant \\
& agencies \\
& - involves integration of management \\
& functions and resources \\
& \\
\hline
\end{tabular}

In Table 5.3, key concepts of TD and DM from the practitioners' perspectives are summarized. The discussion in previous sections indicated that the practitioners tended to define these terms based on their knowledge and their experiences regarding these two terms. Since they tended to define a destination as a place with an emphasis on tourism supply and tourist demand, the way they manage Pattaya seems to reflect their views of the destination.

Regarding the supply side, providing multiple and diverse tourism products seem to be the primary purpose of destination management. Multiple tourism-related activities are undertaken at the destination to provide and maintain the quality of existing and new tourism products. In Pattaya, diverse tourism products, as discussed in the previous chapter, are present. Multiple related activities to promote, provide, and improve the quality of those products are carried out there. The use of many marketing activities to promote those products under the name of Pattaya is an example. Various approaches adopted to improve its natural environment, mentioned in the previous chapter, is another. As a tourism-based destination, the multiplicity and diversity of tourism products seem to become more important to Pattaya as they tend to be intentionally used to attract high numbers of tourists to the area. 
Regarding the demand side, to create tourist satisfaction seems to be another purpose of destination management. Most tourism-related activities are likely to be undertaken for the benefit of tourists rather than of other stakeholders. Since the practitioners tended to believe that the tourists' satisfaction would bring benefit to other stakeholders and the destination in return, the operation of tourism-related activities for tourists' satisfaction seems to be the main purpose in managing Pattaya. Offering tourist freedom of choice may be seen as one strategy to create their satisfaction. A diversity of tourism products provided there tends to enable Pattaya to respond to the diverse needs of its customers, which may help increase their satisfaction. The activities to provide quality tourism products and to create tourists' satisfaction tend to be carried out by multiple agencies from both the public and private sectors at the local and other scales.

A high level of integration between relevant agencies in undertaking all tourismrelated activities and the whole destination seems to be crucial for its successful management. As suggested by the practitioners, particularly from the private sector, this level of integration may be achieved by establishing destination goals and providing financial resources. In Pattaya, a clear statement that represents destination goals does not seem to exist. The provision of diverse tourism products, though perceived as fundamental to Pattaya's identity and a broad goal for its tourism management, may create a different understanding among relevant agencies of what should be provided. Moreover, this identity could be problematic since there is no clear picture to illustrate the meaning and scope of its variety and diversity. The unlimited growth of tourism supplies, discussed in the previous chapter, can reflect this issue. Although some level of integration is practised there, it seems to be practised more on a project basis than on a widespread daily basis. Negative physical issues raised by the practitioners also imply the unsuccessful results of daily management. Although the practitioners realize the importance of integration in theory, it may not occur in actual practice. The management issues related to organizational administration and the local political environment might cause difficulties in their integrated practices. These issues will be identified and discussed in the following chapter. 
The implications of the tourism destination and destination management discussed in this section show that the practitioners tend to manage the destination based on their initial views of a tourism destination. The practitioners interviewed in this study tend to view a tourism destination as a place with an emphasis on tourism supply and tourist demand. The way they manage the destination, in this case Pattaya, appears to correspond to their views of the destination. A multiplicity of tourism products is required at the destination to attract tourists and to respond to their diverse needs. Although achieving such satisfaction appears to be the main purpose of destination management, the practitioners tend to believe that it will benefit the destination as a whole in return. If this belief is true, other related stakeholders will benefit.

\subsubsection{Relationship between the practitioners' views and the literature}

The practitioners' views of a tourism destination and destination management might be further identified by considering their views in relation to points raised in the literature. Key aspects of these terms tend to be mentioned by both sources. In other instances, the practitioners' views add to what has been missing in the tourism literature while some aspects from other studies help to clarify what might have been overlooked by the practitioners.

Table 5.4: Key aspects of TD and DM from the practitioners and the literature.

\begin{tabular}{|l|l|}
\hline \multicolumn{1}{|c|}{ From the practitioners' perspectives } & \multicolumn{1}{c|}{ From the literature } \\
\hline Key aspects of a tourism destination (TD) & \\
\hline - provides multiple products & - is a particular geographical area \\
- is able to respond to tourist demand & - must be selected by tourists \\
- requires some level of management (comments on & - provides some kinds of products \\
Ritchie \& Crouch's (2003) statement) & - involves multiple stakeholders \\
- has its own identity which reflects destination goals & - must function as a real entity \\
- has a positive tourism atmosphere & \\
\hline Key aspects of destination management (DM) & \\
\hline - provides quality attractions, facilities, services & - operation of multiple tourism- \\
- involves attracting tourists and responding to their & related activities \\
needs & - involvement of multiple agencies \\
- involves multiple management functions and & - a desire to achieve common goals \\
destination goals in the management process & - integration of four elements: the \\
- requires collaboration for successful management & destination offering, the visitor mix, \\
- involves integration of multiple tourism-related & marketing communications, and \\
activities & organizational responsibility \\
- involves integration of relevant agencies & \\
- involves integration of management functions and & \\
resources & \\
\hline
\end{tabular}


As summarized in Table 5.4, the Pattaya practitioners tended to provide a specific view, while the literature tended to offer a more general view of a tourism destination and destination management. The practitioners and the literature (e.g., Cho, 2000; Pearce, 1989; Ritchie \& Crouch, 2003) seemed to agree that tourism products and tourists are primary aspects of the destination. At the destination, the provision of attractions, amenities, and accessibility is required. A variety or diversity of particular products, as mentioned by the practitioners, might not be necessary for all destinations. Although the multiplicity or diversity of tourism products may enable the destination to respond to the diverse demand of its tourists, it might depend on the stage of the destination life cycle whether and to what extent diversity is required. Both the practitioners and the literature (e.g., Framke, 2002; Leiper, 1990) also agreed that the tourism products provided at the destination help create its own identity that differentiates one destination from another.

Regarding the comments on Ritchie and Crouch's (2003) statement that the destination must function as a real entity, the practitioners' views tended to suggest that all tourism products need to be managed to bring out the destination's identity. While the tourism products are provided there, multiple activities are also required to draw tourists' attention, to bring them to the destination, and to deliver those products to them. As in the literature (e.g., Jamieson, 2006; Ritchie \& Crouch, 2003), these activities can be categorized into two groups: those related to destination marketing and those related to destination resources. Multiple activities and projects are used to market the destination and to manage its tourism resources. These activities are undertaken by single or various agencies from the same or different sectors; therefore, multiple agencies from diverse sectors and operational scales are involved. To provide quality tourism products and to attract tourists seem to be primary purposes for destination management. At the tourist origin, tourist demand refers to the psychological and physical needs of individual tourists (Leiper, 1990; Pearce, 1995), which tends to influence destination choice and selection. At the destination, tourist demand tends to be expressed in numbers and types of tourists. It tends to reflect the types and quality of tourism products provided at the destination. Tourist demand at the origin and at the destination appears to be important for the destination’s existence. 
Moreover, the practitioners' views tended to add a positive tourism atmosphere as another aspect of the destination. A positive atmosphere can refer to the cleanliness, tidiness, and orderliness of the overall destination. Their comments reflected the fact that this atmosphere does not exist in Pattaya. Furthermore, the disorganization and dirtiness evident in the area was believed to create a negative atmosphere for Pattaya and to minimize its ability to correspond to the practitioners' definitions of a destination. To provide quality tourism products and to create a positive atmosphere, some level of management was perceived to be required at the destination. Regarding the practitioners' reactions to Anderson's concept of integration, they tended to suggest that integration should be an emphasis of the practice of destination management. It can act as a central concept that brings all aspects of destination management together. Although the integration between relevant agencies was already underlined in the literature (e.g., Go \& Govers, 2000; Gomezelj \& Mihalic, 2008), the influence of the literature on practitioners tended to provide further information on how the relevant agencies can integrate in managing the destination. From their perspectives, all relevant agencies can integrate by establishing destination goals, implementing management functions, and providing management resources throughout the management process. In Pattaya, the practitioners tend to have some common understanding on what they aim to achieve for the operation of particular projects. In terms of daily management, common goals do not seem to exist. This might be the reason why practitioners tended to focus more on the necessity of establishing destination goals or having common goals for destination management. However, their suggestions tended to reflect problems or issues that occur in Pattaya rather than what the actual practices are.

Although the practitioners' views can bring more insight to the notions of the destination and destination management, some important aspects seemed to be overlooked by them. In the literature (e.g., Cho, 2000; Laws, 1995; Papatheodorou, 2006; Pearce, 1989; Ritchie \& Crouch, 2003), the destination was differentiated geographically as opposed to the tourist origin and diverse scales of a destination were identified. This geographical aspect of the destination tended to be overlooked by the practitioners who more likely to refer solely to the local scale, especially when reflecting on Pattaya. Other practitioners who live in the origin area, such as the 
Tourism Authority of Thailand officers in other countries, may recognize this aspect better than the practitioners in this study.

Multiple stakeholders were also emphasized in the tourism literature, but mentioned to a lesser extent by the practitioners. In the tourism literature (e.g., Pearce, 1989; Sautter \& Leisen, 1999; Sheehan \& Ritchie, 2005), the multiple stakeholders were identified as public and private sectors as tourism providers, NGOs, local residents, and tourists. In the practitioners' views, tourism providers and tourists seemed to be perceived as the key stakeholders of the destination. Other groups of stakeholders, particularly the local residents, seemed to receive less attention since the practitioners tended to focus more on the tourists. If the practitioners' views do influence their practices, there is the possibility that the destination might be managed solely for the tourists' benefit rather than for the benefit of the local residents. As a result, what has been suggested in the tourism literature may not happen in reality. Thus, although the involvement of all stakeholders was broadly mentioned by the practitioners, some stakeholders, such as local residents, may not play a major role in destination management (e.g., C. M. Hall, 2000; R. H. Hall, 1987; Pearce, 1989; Selin \& Chavez, 1995). This may suggest that the practitioners realized the importance of involving all parties even though it rarely happens in reality. While the practitioners tended to emphasize the necessity of destination goals, more information on how these destination goals can be developed was described in the literature (Welford \& Ytterhus, 2004; Westermann, et al., 2005). This may also reflect that the importance of destination goals for destination management, but without strong effort and willingness from all relevant agencies, they may not be easily established.

\subsubsection{Broad concepts of a tourism destination and destination management}

In the previous section, the relationships between the concepts of a tourism destination and destination management from the practitioners' views and the literature were discussed. Both views tended to bring more insight to the meaning of these two terms. With respect to a tourism destination, the practitioners' views tended to emphasize the destination's ability to provide tourism products and respond to tourist demand, while the literature tended to emphasize the destination's physical 
components such as attractions, amenities, and accessibility. With regard to destination management, the practitioners tended to focus on actual management practices, while the literature tended to provide a general view of destination management. However, both sources tended to emphasize the importance of integration.

To study destination management, the application of both views seems to be necessary. Since the practitioners' views appear to be specific to the destination, other aspects which might come across in the study may be overlooked by the researcher. In order to balance and refine these views, all aspects from both sources are drawn together.

A mature destination such as Pattaya can create and bring out its identity and positive atmosphere, provide multiple products, and attract and respond to tourist demand in an effort to maximize competitiveness and sustainability. In managing the destination, the integration of relevant agencies in managing particular activities and bringing them together as a whole destination appears to be challenging but crucial. From this view, the concept of a tourism destination can be refined as:

A local geographical area (a village, a town, or a city) that requires management to bring out its particular tourism identity, and to provide multiple tourism products in order to attract and respond to tourists' specific needs and to create positive feelings and a tourism atmosphere for its visitors.

The concept of destination management can be refined as:

The collaboration of relevant agencies responsible for providing multiple tourism products at the destination in a way to achieve common goals or destination goals. These goals may include creating a positive tourism atmosphere, enhancing the destination identity, and attracting and serving tourist demand. Broadly, it can be practised through the integration of management functions and management resources from all relevant agencies. 
These refined concepts of the destination and destination management will be used to develop insight into Pattaya and its management as a destination. These concepts will be used in the subsequent chapters to clarify how a destination is managed, and whether, in what ways, and to what extent, destination management is practised in Pattaya. In order to carry these concepts forward, key dimensions shared by the concepts of the destination and destination management are presented in Table 5.5.

Table 5.5: Broad concepts of TD and DM used in the study.

\begin{tabular}{|l|c|l|}
\hline \multicolumn{1}{|c|}{\begin{tabular}{c}
\multicolumn{1}{c|}{$\begin{array}{c}\text { Broad concepts of a tourism } \\
\text { destination }\end{array}$} \\
Management basis
\end{tabular}} & $\begin{array}{c}\text { Shared } \\
\text { dimensions }\end{array}$ & $\begin{array}{c}\text { Broad concepts of destination } \\
\text { management }\end{array}$ \\
\hline $\begin{array}{l}\text { To enhance destination identity } \\
\text { To provide multiple products } \\
\text { To attract and respond to tourists } \\
\text { To create positive feelings and } \\
\text { atmosphere to tourists }\end{array}$ & purposes & $\begin{array}{l}\text { To achieve destination goals or } \\
\text { common goals }\end{array}$ \\
\hline $\begin{array}{l}\text { Provision of multiple products } \\
\text { Tourism promotion and marketing } \\
\text { Marketing research }\end{array}$ & tourism-related & activities \\
$\begin{array}{l}\text { Integration/collaborative practice } \\
\text { pourism providers (public and } \\
\text { Local residents } \\
\text { Tourists }\end{array}$ & stakeholders & $\begin{array}{l}\text { Product management } \\
\text { Tourist management } \\
\text { Destination marketing }\end{array}$ \\
\hline
\end{tabular}

In Table 5.5, four key dimensions shared by both concepts are presented. First, management is broadly reflected as the fundamental concept underlining a destination, while integrated management is emphasized in the concept of destination management. Second, the purposes of the destination represent an overall picture of what practitioners want the destination to be, while its management should aim and be practised in a way that corresponds to those purposes. These purposes may be expressed through goals. Third, multiple tourism-related activities exist at the destination. These activities can be categorized into different groups of management activities and should be carried out in a way to achieve the destination purposes. Finally, multiple stakeholders are involved at the destination. However, some of them are more involved in management activities than others. They can come from 
the public and/or the private sectors, and from the local and/or other administrative scales. These shared dimensions help to clarify the connection of these two concepts, which is used for the analysis of destination management practices, presented in the following chapters.

The findings in this chapter help to develop the framework for the subsequent chapters, namely that in managing the tourism destination, multiple stakeholders, multiple tourism-related activities, and multiple purposes are involved. Moreover, integration is a core concept in the practice of destination management. If destination management is practised in Pattaya, the integration of management stakeholders, management activities, and management purposes should occur. In the following chapters the dimensions presented in Table 5.5 will be used to clarify the process of managing Pattaya's tourism. These dimensions will be used in the analysis to clarify its purposes, tourism-related activities, and stakeholders, both generally and specifically. Integration will be discussed at the end of individual chapters (Chapters 6 - 8). To identify the level of integration practised in Pattaya, the interactions of management agencies, multiplicity of tourism-related activities, and the clarity of destination goals or common goals, presented in Table 2.3, will be used.

As mentioned in previous chapters, the beaches and nightlife were perceived as the main tourism attractions of Pattaya. These two major attractions tend to create two images of Pattaya as a tourism destination: a typical beach resort at daytime and a vibrant and exciting beach resort at night. The study of the management of beaches and nightlife shows how the local destination manages its tourism attractions on a daily basis. In contrast, the study of the management of the Pattaya Music Festival shows the management of tourism projects at the destination. This project was selected because it was frequently raised as an example when the respondents mentioned integrated practices in the management of Pattaya's tourism. The study of these three attractions can bring a better understanding of the practice of managing local tourism destinations. The findings in managing particular attractions will be described and discussed in the following chapters. The management of beaches, nightlife, and Pattaya Music Festival will be presented in Chapters 6 to 8. The results of these three chapters will then be drawn together and discussed in Chapter 9 to 
clarify how Pattaya is managed and to identify whether, in what ways, and to what extent, destination management is practiced there. Lessons learned from this case study will also be described in this final chapter of the thesis. 


\section{Chapter 6 Beach management}

\subsection{Introduction}

In this chapter, beaches and marine activities, perceived as the primary tourism product of Pattaya, are used as a sub-case study to explore destination management. The study of beach management presented in the following sections can shed light on whether and how destination management is or is not happening in practice. Multiple methods were used to collect data.

As mentioned in Chapter 3, this chapter draws from the primary and secondary data collected in the third phase of the research (see section 3.4.3). Interview data, site observation, both formal and informal, and official documents were used as the primary data source for the analysis of beach management. The categories that emerged from the analysis of the interviews were used for the analysis of secondary sources collected in the same phase of the study. The dimensions of the destination management concept, described in Chapter 5, were used for the analytical structure in the context of management in the beach zone.

The chapter is structured to address the different dimensions of destination management. First, the beach zone examined in this study is described in order to provide necessary background. Second, key agencies involved in managing the beach zone are identified to provide the context for further analysis and discussion. Their management purposes are also clarified to find out what they are and whether and how they are relevant to the actual management of the beach and the destination. Third, a discussion regarding the management activities and their responsibilities in managing the beach zone follows. Fourth, resources used in the beach management are discussed. Finally, the integration of relevant agencies in carrying out particular activities is described. At the end of this chapter, all these aspects are brought together to discuss and identify the level of integration present in the beach management. A variety of specific examples are used to illustrate general points throughout the chapter. In order to identify key agencies involved in beach management, geographical areas and physical characteristics of the beach zone need to be clarified. 


\subsection{The characteristics of the beach zone}

As one of major beach resorts of Thailand, Pattaya's beaches are promoted as a major tourism resource in marketing materials. The city is first and foremost a beach destination that also offers a variety of tourism products and services to visitors. Most respondents noted that these beaches are considered one tourism product; a few of them added that the beaches are marketed in brochures along with the nightlife and festivals. This is illustrated by the following quotations from a respondent and advertisements.

I think Pattaya has many tourism products. The beaches are only one product. Pattaya City is trying to sell many things. As I used to work in other places before, I can say that Pattaya does attract many tourists. Larn Island is one attraction for marine activities. Jomtien Beach is also emphasised in the marketing. Pattaya Beach has been redeveloped for better scenery. There is also Walking Street and other things [to attract tourists].

(Local public 6)

Colourful and alive with activities, it is unrivalled as a beach resort, offering more attractions in greater profusion than any other single destination in South-east Asia.

(Stated in Pattaya Brochure promoted by TAT)

Pattaya is Asia's premier beach resort, and caters with equal appeal to families, couples and single visitors.

(Stated in Pattaya Tourist Guide CD promoted by Pattaya City)

As mentioned in Chapter 4, these beaches are located in the city area and on the islands. Major beaches that are always promoted in the advertising materials are Pattaya Beach, Jomtien Beach, and the beaches on Larn Island (see Figure 4.4). The differences among these popular beaches can be seen at the site. In the city area, Pattaya Beach is highly developed in terms of infrastructure and crowded with shops and vendors, while Jomtien Beach is more peaceful with some water sports and fewer shops and services provided. As they are located 7.5 kilometres away from the city, the six main beaches on Larn Island, Ta Waen Beach, Thong Lang Beach, Sangwan Beach, Tien Beach, Samae Beach, and Nual Beach, seem to be more pristine compared with the beaches in the city. Ta Waen Beach is the most popular on Larn Island with various marine activities provided, while other beaches are more peaceful with fewer shops and marine activities.

At the beaches, diverse facilities and services provided to the tourists can be seen. They may be provided by individual businesses or by the public sector. To identify the types of facilities and services provided in the beach zone and the sectors 
responsible for their provision, the geographical characteristics of the beach zone need to be classified. Based on site observation, diverse physical characteristics and issues and various tourism-related products and services can be seen at Pattaya Beach more than at Jomtien Beach and the beaches on Larn Island. Its environment tends to illustrate diverse physical characteristics and issues that are relevant to the study of management. Therefore, Pattaya Beach is used as the main example to show the characteristics, facilities, and services provided in the beach zone. As presented in Figure 6.1, Pattaya Beach can be separated into five areas: the beachside buildings $(A)$, the beach road (B), the promenade (C), the beach area (D), and the seawater (E). By dividing the beach zone into five different geographical areas, the tourism-related products, facilities, and services provided to the tourists and the issues existing in these areas can be identified.

Figure 6.1: Geographical and physical characteristics of Pattaya Beach.

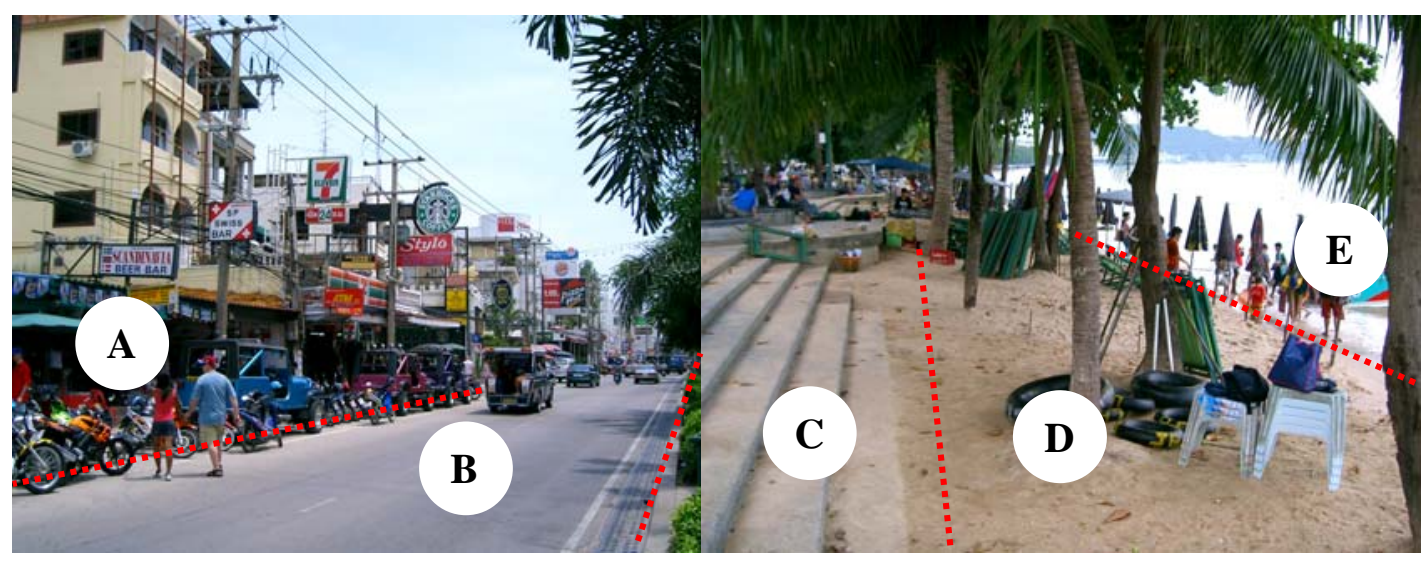

Source: The author (2006)

First, the beachside road is crowded with various styles, types, and colours of buildings. There is a sidewalk, approximately one and a half metres in width, which connects these buildings and is used by pedestrians. By walking along this sidewalk, a variety of tourism-related products and services can be seen and accessed. The examples are accommodation providers, beer bars, restaurants, souvenir shops, convenience stores, travel agencies, jewellery shops, massage parlours, and shopping malls. Some shops are locally owned; others are international franchises (e.g., Starbucks, McDonald's, and Sizzlers). However, public facilities such as electricity and water supply are provided by public organizations. Some issues that can be seen 
in this area include the crowding of buildings/shops and signposts, illegal buildings, sex-related businesses, a very narrow sidewalk in some parts of the area, peddlers, and noise pollution.

Second, the beach road is a one-way access road. The road is provided by the municipality, while local police are responsible for road traffic. A variety of transportation services seen in this area are provided by individual businesses. Examples include public transportation services such as locally operated taxis (known as Rot Song Taew, see Figure 6.2) and motorcycle taxis, and rental services such as rental cars/jeeps and motorcycles. Some of them may organize into formal business groups or clubs. For examples, Pattaya Bus Co-operative Limited represents the interests of local taxis. These local taxis are similar to public bus services. Along the beach road, posted time schedules and stop signs for the local taxis do not seem to exist. Pedestrians seem to be able to stop them wherever they want to. Some of them may also be rented by tourists and do not provide normal public services. Without a clear sign to show its route and availability, this can create confusion and frustration for public transportation users. For many tourists, understanding how the taxis operate is difficult. Beside these unorganized public transportation services, the common issues seen in this area are traffic congestion, illegal taxi services, limited parking space, and peddlers.

Figure 6.2: Local taxis in Pattaya.

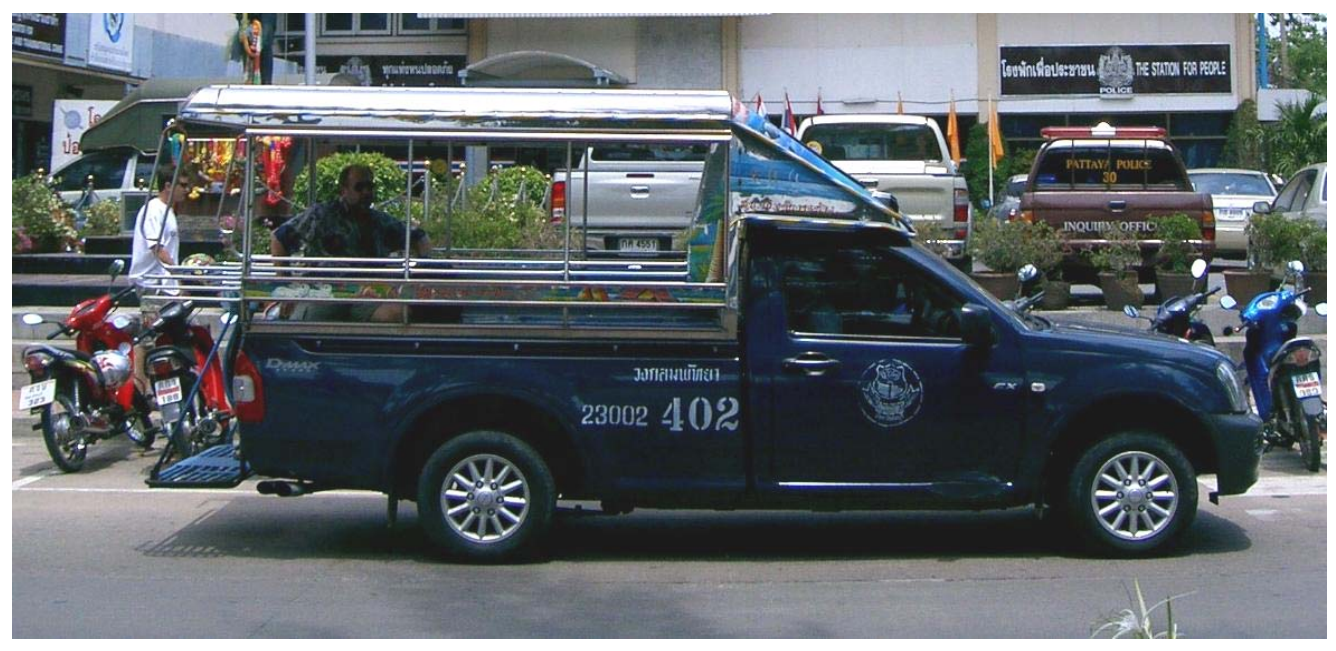

Source: The author (2006) 
Third, the promenade is a concrete pavement along the beach road. In both phases of the fieldwork, the promenade was in the process of redevelopment. It could be seen that a walking/running path and concrete benches were present, lamp posts were erected, and palm trees were planted along the promenade. Construction was ongoing and it would take a few more months to complete. Generally, Pattaya City is responsible for the promenade area; however, other public agencies are involved in providing public facilities such as electric lights for promenade users at night. Similar to other beaches in the country, there are no public toilets or showers provided in the promenade area. They are rarely provided by the municipality, but some private shops located in zone A offer them. Tourists have to pay for these services. In Pattaya, an attempt to provide these facilities is evident. A mobile toilets truck provided by the municipality can be seen at the site on weekends (see Figure 6.3). Although garbage bins are provided along the promenade area, some plastic bags, bottles, and foam containers are left on the benches and the promenade. Also, prostitutes and peddlers operate in the area.

Figure 6.3: Mobile toilets truck.

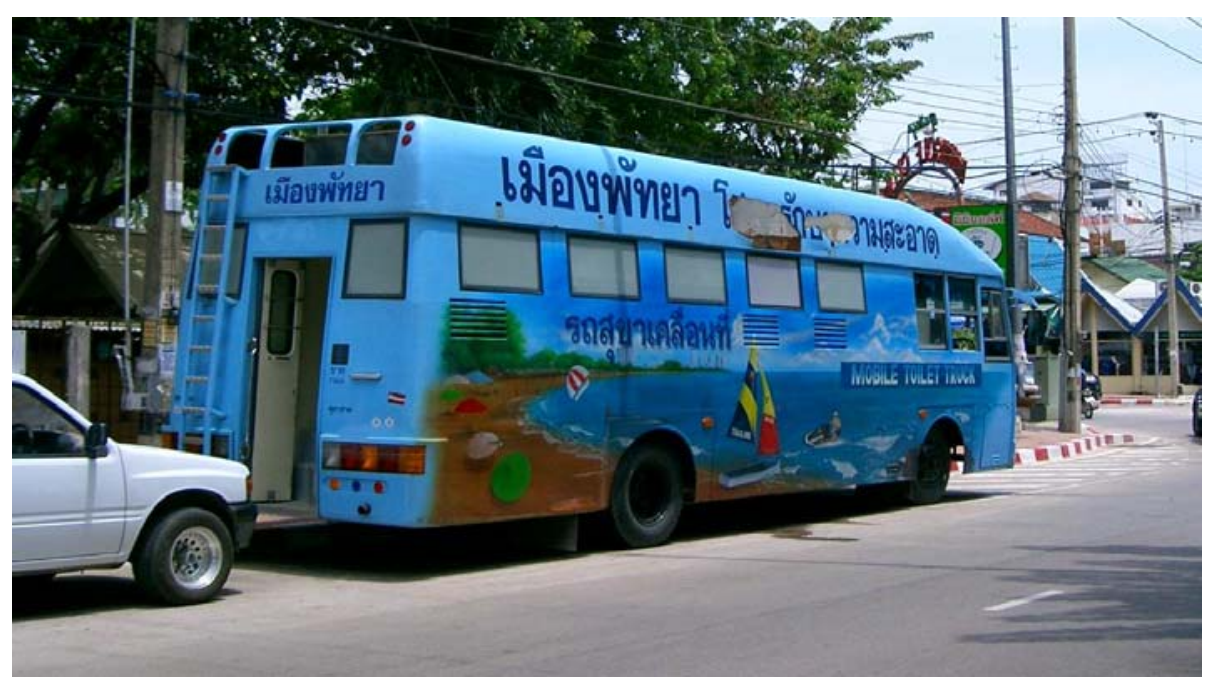

Source: The author (2006)

Fourth, the beach area, particularly along Pattaya Beach, seems to be filled with hundreds of beach umbrella shops. Some spaces, connected to the promenade steps, are left empty so that tourists can access the seawater. According to the regulations for beach umbrella shops in Pattaya Beach, Jomtien Beach, and Larn Island, each 
vendor is allowed to operate within an area of $7 \times 7$ metres, in which they can provide 40 beach chairs and 35 umbrellas. They are responsible for cleaning their shops and the surrounding area within the service times of 7 a.m. to 6.30 p.m. Normally, these shops are operated to lease beach chairs and inflatable swimming rings to tourists. These shop vendors are not allowed to cook food in the area, but they can sell food and drinks to tourists. In this case, these vendors may have their own shops or may know some shops in area A that cook food for tourists. According to the interviews and the club regulations, although these shops are individually operated, they must be members of the Beach Umbrella Club located in their areas. The Jomtien Beach Umbrella Club and the Pattaya Beach Umbrella Club are examples. According to a club member, all members need to pay fees to the clubs and Pattaya City. With hundreds of these shops, the beach area is crowded. The physical issues seen in this area are garbage/waste, peddlers, and limited empty space for tourists' use.

Finally, the seawater area starts at the border line between areas D and E and stretches out into the sea. Multiple tourism-related products and marine activities are provided in this area. Ferries, rental boats, swimming, snorkelling, scuba diving, banana boats, and parasailing are examples. These tourism-related products and services are operated by the individual businesses/vendors, while marine security is provided by Pattaya City. Ferries and the rental boats are perceived as providing convenient transportation for residents and tourists to commute between the city and the islands.

[Ferries] are convenient for people, because people will not be able to go to Larn Island. Even Pattaya's workers still need to use their services, particularly the ferries.

(Local public 10)

For me, I think ferries are better [than jet boats]. I used to work in Larn Island and had to commute back and forth everyday. I think the ferries can promote tourism better than the jet boats. Other local businesses can benefit from the ferries, such as shops and motorcycle taxis at the piers. For speed boats, they can go to the specific locations. Only they benefit, not other businesses, particularly the locals. The ferries seem to distribute revenue to all areas.

(Local public 6)

Similar to the beach umbrella vendors, the jet boat and ferry operators must be members of clubs depending on the services they offer and their location. The Tourism Boat Clubs of Pattaya Beach, Jomtien Beach, and Larn Island, and the Ferry 
Club are examples. According to a respondent from the Pattaya Beach Tourism Boat Club, there are approximately 200 members with almost 600 jet boats to serve tourists. The club rents an empty space near Bali Hai pier from Pattaya Ciy for parking approximately 300 boats. The members who want to park their boats on this rental space need to pay membership fees to the club in order to use it. The congestion of service boats can be seen at the beaches in the city and Larn Island. Garbage/waste in the sea was also evident on the trip from Pattaya Beach to Larn Island.

The above description illustrates that different geographical areas are present in the beach zone. In different areas, tourism-related products and services and physical issues can be found. All these areas seem to require some kind of management to solve those issues and to bring out overall quality of beach tourism for tourists' satisfaction. As indicated in the above description, some regulations are implemented in the beach zone to regulate tourism-related activities undertaken in the areas. Areas $\mathrm{C}, \mathrm{D}$, and $\mathrm{E}$ tend to receive the most attention in terms of beach management. Multiple activities seem to be carried out by different agencies in managing different areas of the beach zone. The agencies involved in carrying out those activities tend to come from the public and the private sectors. Key agencies involved in the management of the beach zone and their purposes need to be identified to provide context for the discussion of responsibilities, activities, and resources.

\subsection{Management agencies and their purposes}

According to the interviews and the local newspaper, different agencies are involved in beach management. These agencies are from both the public and the private sectors. The public agencies are from diverse scales: national, regional, provincial, district, and local, while the private agencies are from the local scale only. A summary of these agencies is presented in Figure 6.4. 
Figure 6.4: Key agencies involved in beach management.

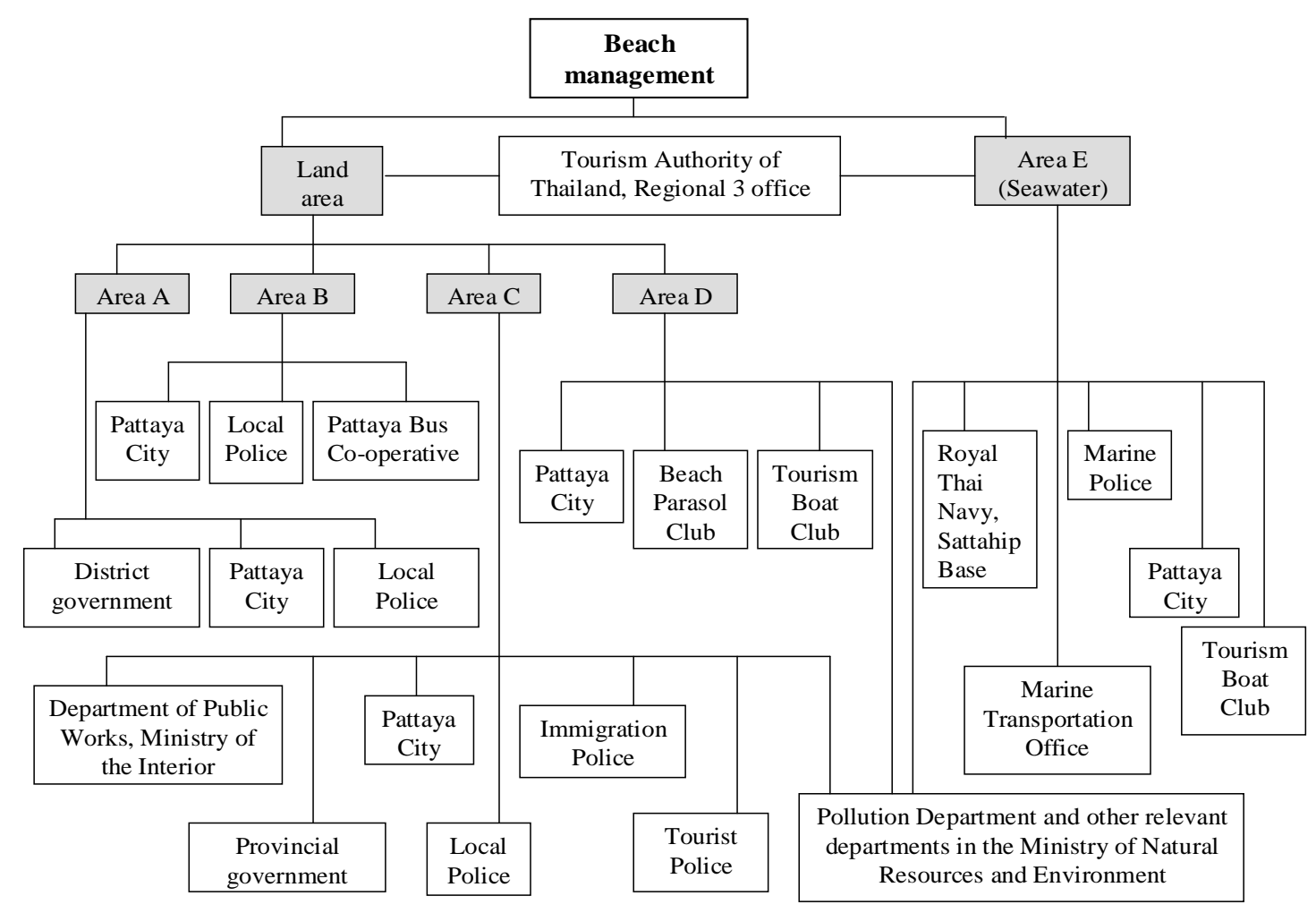

As illustrated in Figure 6.4, multiple agencies are involved in managing the beach zone. The management of certain areas of the beach zone typically involves some combination of different agencies. It can be seen that Pattaya City is involved in all areas, while other agencies are involved in one or a few particular areas. Business clubs/organizations are involved only in particular areas such as areas B, D, and E.

In practice, Pattaya City is primarily responsible for all areas of the beach zone but works with other agencies depending on particular issues or situations related to their organizational operations. Based on the organizational chart of Pattaya City (Pattaya City, 2006), almost all working units in Pattaya City are involved in beach management. The Office of the City's Chief Manager is responsible for safety and the promotion of tourism in the city. The Bureau of Public Works is responsible for authorizing and controlling building construction and infrastructure construction and improvement. The Bureau of Public Health and Environment deals with cleaning public areas, consumer protection, and environmental promotion. The Division of Sanitary Work handles water quality management, drainage system management, 
and garbage and waste management. The division tends to be responsible for all areas of the beach. The Office of Pattaya City (Larn Island) is responsible for the functions mentioned above on Larn Island.

Other agencies, both from the public and the private sectors, work in conjunction with city-based agencies. Some of them are involved in the daily operation of the beach zone, while some are involved only in particular projects. Different agencies responsible for different areas of the beach zone are shown in Figure 6.4. The police offices, from the local and regional scales and the immigration police, are responsible for the safety of the city area and areas A to D of the beach zone. The district government is involved in authorizing business licenses for beachside vendors in area A. Other district offices such as electricity and water supply are involved in providing these services to residents and businesses in areas A, B, and C. The provincial government is involved in the authorization of some beach development projects, particularly in areas B, C, and D. The marine police regional office is involved in marine safety and tries to identify illegal service boats in area E. The marine transportation regional office is involved in implementing regulations regarding the quality of service boats and drivers, monitoring service boats, and policing marine traffic for boat vendors in area E. The Royal Thai Navy is involved in area $\mathrm{E}$ in major issues related to marine safety, such as helping people whose boats or ships are in distress. The Tourism Authority of Thailand Regional 3 Office is responsible for marketing and promoting Pattaya's tourism overall. It does not directly relate to the beach management but it seems to be involved in research regarding the overall improvement of Pattaya's tourism and initiating development projects for Pattaya City and the central government. The promenade development projects were examples (Chulalongkorn University, 1993; TAT, 1995). The Ministry of Interior's Department of Public Works is involved in some major projects related to beach development, particularly in areas B, C, and D. The Ministry of Natural Resources is involved in construction or environmental conservation projects, particularly in areas D and E (e.g., artificial marine habitat development) of the beach zone that may have a positive impact on coastal ecology. The Pollution Department of the Ministry of Natural Resources is also involved in monitoring the quality of seawater in Pattaya and other coastal areas of the country. 
Although some public agencies appear to have similar responsibilities, those responsibilities tend to be different in terms of jurisdiction and activities undertaken. For example, the police, Pattaya City, and the Royal Thai Navy have similar responsibilities for safety. The police are responsible for areas A to D while Pattaya City is responsible for safety in areas C, D, and E and the Royal Thai Navy is responsible for area E. Thus, activities undertaken by these individual agencies tend to be different. While the police are responsible for suppression and prevention of prostitution and crimes in the beach zone, Pattaya City tends to be more focused on reducing peddling and increasing marine safety. The Royal Thai Navy tends to deal with safety and major incidents in the water. The interaction between these public agencies in carrying out their responsible activities seems to be crucial. This concern will be described later in the chapter in the section on management integration.

Most beach vendors, particularly in areas D and E, must be formally registered with the relevant business clubs or associations. The Beach Umbrella Club, the Ferry Club, and the Tourism Boat Club are examples. These clubs are involved in beach management by establishing the rules and regulations for club members to follow. All members are required to follow the regulations of the clubs, otherwise their memberships will be terminated and they will not be permitted to trade. The Beach Umbrella Club is an example. According to the regulations for beach umbrella services in Pattaya Beach, Jomtien Beach, and Larn Island, twenty rules are identified for all vendors to follow. The punishments for violators are also clearly stated. Some of these rules are presented in Table 6.1 below. There are 20 rules in total: 
Table 6.1: Examples of regulations for the beach umbrella services on Pattaya Beach.

1. All vendors need to operate within an area of 7 x 7 metres per shop. Each shop can provide 40 beach chairs and 35 beach umbrellas along the promenade or in the areas identified by Pattaya City between 7.00 a.m. to 6.30 p.m. everyday. If the shop operates more than the regulated time, individual shop vendors need to ask for permission from the City through their clubs.

2. Within the operating time, vendors must use all the beach chairs and umbrellas they have without piling them up in the shop areas. After finishing the services, all beach chairs and umbrellas must be collected and kept in the regulated areas. No vendors or shop staff are allowed to sleep on the premises. In case of there being four or more days off, all beach chairs and umbrellas must be collected and kept away from the beach area.

3. The vendors must operate only in the areas stated in Rule 1 without blocking pedestrian access to the sea. They must be responsible for the cleanliness of their operational and surrounding areas: front, back, and empty spaces on left and right sides. They must also provide their own garbage bins for customers, collect all garbage in the black rubbish bags, and leave them at the places and times regulated by Pattaya City.

4. The vendors must not charge a price higher than the price regulated by the City. If there are any complaints or witnesses to claim that the price is overcharged or any conspiracy between vendors, Pattaya City will follow rule number 20.

5. Each vendor can provide no more than 10 swimming rings. These rings must be kept in the back area of the shop. For the shops located closely to the footpaths, these rings must be kept on the left side of the shops.

10. The vendors must not boil, steam, grill, bake, or cook food or use charcoal or gas stoves in the areas.

11. The vendors must clearly list the prices of food, drink, beach chair, and swimming rings.

12. The vendors must not allow any peddlers to sell food or other products in the areas. Gamblers are also not allowed in the areas.

15. If Pattaya City wants to use the area for the City's activities, the vendors must leave the area within the timeframe of those activities without any condition. Pattaya City will not be responsible for any costs or damages occurred to the vendors.

19. The vendors must follow all the rules stated in this official notice and other future notices, rules, orders, and regulations of Pattaya City. They must also cooperate and follow the recommendations or suggestions of Pattaya City's staff.

20. Any vendor, who violates the rules stated in this document, breaks the laws stated in articles 62(7) and (12) of Pattaya City Administration Act 1999. That person will be punished as follow:

First violation: fined 500 baht

Second violation: service discontinuation for 7 days

Third violation: service discontinuation for 1 month

Fourth violation: service termination

Source: Pattaya City (n.d.)

Regarding the different sectors and operational scales, these agencies tend to have different purposes in managing the beach zone. Based on the interview and contextual data, they tend to manage the beaches to achieve their individual organizational goals. Broadly, the public agencies manage the beach for community benefit, while private agencies may be involved for their own benefit. Individual public or private agencies may have different purposes that may or may not relate to beach management in particular. Achievement of their individual goals tends to be the primary purpose of the organizations involved (see Table 6.2). The vision or 
mission statements in the official documents of the public agencies were perceived by the interview respondents as their organizational goals.

Table 6.2: Key agencies and their management purposes.

\begin{tabular}{|c|c|c|c|c|}
\hline \multicolumn{5}{|c|}{ Beach management } \\
\hline Area A & Area B & Area C & Area D & Area E \\
\hline $\begin{array}{l}\text { District } \\
\text { government }\end{array}$ & $\begin{array}{l}\text { Pattaya Bus } \\
\text { Co-operative }\end{array}$ & $\begin{array}{l}\text { Ministry of the } \\
\text { Interior }\end{array}$ & $\begin{array}{l}\text { Ministry of } \\
\text { Natural Resources } \\
\text { and Environment }\end{array}$ & $\begin{array}{l}\text { Ministry of Natural } \\
\text { Resources and } \\
\text { Environment }\end{array}$ \\
\hline Pattaya City & Pattaya City & $\begin{array}{l}\text { Ministry of } \\
\text { Natural } \\
\text { Resources and } \\
\text { Environment }\end{array}$ & Pattaya City & $\begin{array}{l}\text { Royal Thai Navy, } \\
\text { Sattahip Base }\end{array}$ \\
\hline \multirow[t]{5}{*}{ Local police } & Local police & Tourist police & $\begin{array}{l}\text { Beach Umbrella } \\
\text { Club }\end{array}$ & $\begin{array}{l}\text { Marine } \\
\text { Transportation } \\
\text { Office }\end{array}$ \\
\hline & & $\begin{array}{l}\text { Immigration } \\
\text { police }\end{array}$ & $\begin{array}{l}\text { Tourism Boat } \\
\text { Club }\end{array}$ & Marine police \\
\hline & & $\begin{array}{l}\text { Provincial } \\
\text { government }\end{array}$ & & Pattaya City \\
\hline & & Pattaya City & & Tourism Boat Club \\
\hline & & Local police & & \\
\hline \multicolumn{5}{|c|}{ Management purposes: To achieve individual organizational goals } \\
\hline
\end{tabular}

In the review of their organizational visions and missions, the goals of individual organizations are diverse. They reflect a series of broad objectives and express what organizations wish to achieve in the future. When examined together, the organizational goals of key agencies provide a broad picture of how the destination is managed overall. The goals of key agencies include being a well-known destination, to provide safety and a high quality of life to residents and tourists, and to maintain the quality of natural resources. In relation to beach management, they tend to reflect different responsibilities and activities required to be undertaken at the beach zone. The vision statement of Pattaya City focuses on overall environmental improvement. In theory, all beaches should be managed in a way that improves the physical and natural conditions and quality of coastal resources. Therefore, effective beach management would be consistent with the goals outlined in the vision statement. The visions of other public agencies are not directly related to the vision of Pattaya City, but tend to reflect their responsibilities and activities carried out at the beach zone. Responsibilities for ground and marine safety and pollution management are 
examples. The visions of Pattaya City and other key public agencies are presented in Table 6.3 below.

Table 6.3: Examples of organisational goals of key agencies.

\begin{tabular}{|c|c|c|}
\hline $\begin{array}{l}\text { Operational } \\
\text { scales }\end{array}$ & Agencies & Organizational visions \\
\hline National & $\begin{array}{l}\text { Ministry of the } \\
\text { Natural Resources } \\
\text { and Environment }\end{array}$ & $\begin{array}{l}\text { To be an organization which society trusts and has confidence in the } \\
\text { management of pollution for a better environment and a better quality of life }\end{array}$ \\
\hline \multirow[t]{4}{*}{ Regional } & $\begin{array}{l}\text { Royal Thai Navy, } \\
\text { Sattahip Base }\end{array}$ & $\begin{array}{l}\text { RTN will be regional leader with a modern well-balanced force under quality- } \\
\text { enhanced management. }\end{array}$ \\
\hline & $\begin{array}{l}\text { Marine } \\
\text { Transportation, } \\
\text { Chonburi office }\end{array}$ & $\begin{array}{l}\text { To develop water transport system to ensure safety, convenience, rapidity and } \\
\text { efficiency along with marine environmental management; also to promote prope } \\
\text { distribution of water transport and the expansion of the transport network in } \\
\text { order to increase the potential for trade and service competition which will lead } \\
\text { to a better quality of life for the people. }\end{array}$ \\
\hline & Marine Police & $\begin{array}{l}\text { Uphold the country's benefits in marine, coasts, and piers with good and } \\
\text { transparent administration for people's benefits. }\end{array}$ \\
\hline & $\begin{array}{l}\text { Tourist Police, } \\
\text { Region } 3 \text { office }\end{array}$ & $\begin{array}{l}\text { Responsible in crime prevention and suppression, investigating and arresting } \\
\text { concerning about the tourist and international crimes in case that may cause } \\
\text { impact on tourism industry, help facilitating and providing safety of life and } \\
\text { belonging for the tourists and working together with or giving support to other } \\
\text { related agencies or those being assigned to. }\end{array}$ \\
\hline \multirow[t]{2}{*}{ Local } & Pattaya City & $\begin{array}{l}\text { To be a well-known tourism destination regionally and globally with an } \\
\text { emphasis on natural and environmental resource conservation, to have } \\
\text { competency in sustainable economic and social development by obtaining } \\
\text { residents' participation in the transparent development of the city. }\end{array}$ \\
\hline & $\begin{array}{l}\text { Royal Thai Police, } \\
\text { Pattaya office }\end{array}$ & $\begin{array}{l}\text { To be a modern organization, people are central, and laws and regulations must } \\
\text { be enforced with transparency, sincerity, and justice. }\end{array}$ \\
\hline
\end{tabular}

Sources: Ministry of the Natural Resources and Environment (2007), Royal Thai Navy (2007), Marine Transportation (2007), Marine Police (2007), Tourist Police (2007), Pattaya City (2007), Royal Thai Police (2007)

For the private clubs, protecting the benefits and interests of club members tends to be their primary purpose. In the interviews with the members of beach umbrella and tourism boat clubs, they often commented that they have been making a living in the area before Pattaya City was established. They tended to imply that, because they came first, the municipality should listen to them and they should have more right to operate businesses in the way they want. These beach vendors had operated freely and in an unorganized fashion for a long time; efforts by Pattaya City to organize them tended to create a conflict between these vendors and the municipality. The protests of these vendors to show their dissatisfaction with the regulations initially 
implemented by Pattaya City were reported in the local newspaper. It could be seen that these vendors may realize that they have more benefits in the formal form of private clubs or groups rather than individually dealing with the government sector. Thus, the large numbers of club members seem to enable the clubs to have more power in negotiating with Pattaya City. At the moment, it may be seen that the power of these clubs can influence Pattaya City to cooperate with them in the establishment and implementation of regulations. The City and the clubs may have mutual interests. All these issues are expressed by the following respondents.

The club is established for group power, to enhance the strength to negotiate with the politicians. If everyone is doing it in their own way, we may easily have problems. It is also the City's policy to initiate that if we form a club we are able to negotiate for our own benefits. ... Actually, the City does not want to have the shops on the beaches. We don't know what they will do in the future. Since we have the club, it seems that we have more potency. When the City wants to do something, it will discuss it with us. The club strengthens our power to talk to the City. As a group, it might be difficult for the City to do something. Yes? We have been making a living in the area before the City was established [so the City should listen to them]....

(Local private 8)

We are organized by the City. In the past, we scattered along the beaches and used the beaches [D area] for parking. Then, the City asked us not to do that. We demanded our rights as we have been making a living in this area for a long time. ... When we started the club, we asked the City to provide the empty area for us to park the boats. We demanded that the City levelled the area and to provide a public facilities such as water and electricity for us. The City agreed to do what we requested so we agreed to move there. ... When the City wants to initiate the new regulations/rules, it needs to discuss with club members whether they can follow those regulations/rules.

(Local private 9)

In addition to achieving their organizational goals, all agencies tend to be involved in beach management for some purpose. There seem to be four main purposes in relation to the beach management: for the physical attractiveness of the beach and of the city, for tourism promotion, for solving problems that arise, and for natural resource conservation and environmental improvement. Multiple activities carried out in the beach zone involve improving the physical attractiveness of the beaches and of the city and tourism promotion. These purposes were frequently mentioned by the respondents and illustrated in the local newspaper. Examples include the implementation of regulations by Pattaya City for beach vendors in Pattaya and on Larn Island. Moreover, the local newspaper also showed that some activities tend to be undertaken to solve major issues/problems occurring in Pattaya at the time, for example, meetings between Pattaya City, the Marine Department Region 6 Office, and the boat vendors to create an understanding about and to implement the safety 
regulations after there was an accident in which a boat had sunk due to the overloading of passengers. Some activities were frequently undertaken to improve the quality of the physical environment of the area: for example, collecting garbage and broken glass along the beaches and diving to retrieve garbage.

Common goals are not reflected in the organizational visions/missions or stated by the respondents. However, all respondents appeared to have similar perceptions that their operations are for the benefit of tourism in Pattaya. The public agencies tended to perceive that their operations are to improve the beach and the city's physical attractiveness, through which Pattaya's tourism would be promoted. The respondents from the business clubs tended to indicate that their club members realize that they must follow the regulations. Although they may not be satisfied with the regulations, they still cooperate with Pattaya City for the benefit of tourism in Pattaya. These views are reflected by the following respondents:

I want it [the beach] to be clean. I also want the vendors to follow the regulations. To leave some spaces for tourists to access the sea area or to sit on the beach is an example. ... We work for the tourists' satisfaction. Recently, there was a case that a tourist parked his car in front of the shop but didn't visit that shop. The shop vendor didn't want him to park his car in that space. They were arguing; I had to solve that problem. Actually the shop vendors do not have any right to reserve the parking space for their own benefits. It's a public space. Anyone can park in that area. ...

(Local public 6)

Our members are required to follow the regulations and cooperate with the club and the City. For more than ten years, most members follow the rules. ... Sometimes, our members are not satisfied with some rules but we still need to follow them. ...

(Local private 9)

This section indicates that agencies involved in managing the beach are diverse. In managing different areas of the beach zone, a combination of public and/or private agencies from different operational scales is involved. They can come from different sectors and different operational scales. Pattaya City, as the municipality, participates in managing all areas of the beach zone. Other agencies, both from the public and the private sectors, are seen to be involved in the management of one or a few areas of the beach zone. Their management purposes tend to be reflected in their organizational goals. Their organizational goals are not directly related to beach management, but rather reflect broad purposes linked to overall destination management. In terms of beach management, their organizational goals tend to reflect responsibilities exercised by their organizations in the beach zone. Since 
different agencies are involved in managing different areas of the beach zone with multiple purposes, their responsibilities are different.

\subsection{Management activities and their responsibilities}

Agencies' responsibilities tend to differ depending on their organizational goals, management purposes, and the tasks they perform. The public agencies tend to be responsible for the daily operation of the beach zone, while the private agencies are responsible for their own commercial operations at the beach. Based on the interviews, the public agencies tend to initiate and implement rules and regulations, while the private agencies are typically required to follow the rules and regulations implemented by the public sector. Regarding their different management purposes, their responsibilities in managing the beach zone tend to vary depending on the tasks they perform.

Based on the interviews, the responsibilities of all agencies are generally exercised through three management functions: organizing, monitoring, and controlling. Commonly, all public and private agencies operate individually and independently; they tend to have their own administrative system to organize, monitor, and control their operations. In the public sector, these functions can be exercised through the line of authority from the national operational scale to the local operational scale. In the private clubs/associations, these functions are frequently exercised by the club presidents or club committees. These three functions are also commonly exercised by different agencies to manage different areas of the beach zone, particularly by the public and private agencies. Pattaya City and the public agencies responsible for organising, monitoring, and controlling the daily operation of the beach umbrella vendors and rental boat vendors are examples. These functions are reflected in the following interview responses:

\footnotetext{
We have the regulations that all members must follow. Then, our committee members are responsible for particular zones: North Pattaya, Central Pattaya, and South Pattaya. This helps us to monitor the operations of all zones. If there is any problem, they will report to the president. ... Usually, we have monthly meetings. The agenda, mostly, is about the policy or the rules regulated by Pattaya City. We instruct members to follow the policies and rules. If someone does not follow them, we will warn them the first time. If there is a second time, we will talk to them and warn them again. If there is a third time, we will terminate their memberships and stop their businesses. ... When the City knows something, it will report directly to the club's president.
}

(Local private 8) 
There is an announcement by Pattaya City that there are four swimming areas. ... This is managed by the City. The boats can moor outside the swimming areas. When providing services to the customers, they [the boat vendors] need to explain to their customers, in which areas they can go. If someone does not follow the rules, the City will take care of it. The club does not have any right to protect them. It's the City that must implement its regulations. ... In our club, if someone does not follow the regulations... if you are reported by the City frequently, we will not extend the memberships. ... If the membership is terminated, it isn't only about losing the workplace but also the parking space on land. Sometimes they may want to be disobedient, but they cannot because of this effect. ... If someone always does wrong, we will warn them. Or sometimes, we humiliate them in the club meetings in order to let the members control each other. This is working well.

(Local private 9)

Sometimes we have meetings with the beach umbrella shops to inform them of the new policy or new rules. Or sometimes there are issues or incidents related to them; we call them to meetings. A recent issue of a tourist's injury by using an umbrella stick as a weapon is an example. We called for meetings to inform the shops to collect all beach umbrellas and bring them back to their home or keep them in better places because they can be used as weapons to injure tourists. My team and I check every evening whether they follow the rule. If they do not follow them, we might give a few warnings. If they still do the same, we will punish them.

$$
\text { (Local public 6) }
$$

As illustrated in the previous sections, multiple agencies with their own goals and purposes have a variety of responsibilities related to the management of the beach zone. This tends to contribute to the multiplicity of tourism-related activities required to be undertaken for beach management. Some activities such as cleaning seem to be required in all areas of the beach zone, while some seem to be undertaken in particular areas such as seawater quality control. These activities are linked to the daily operation of the beach zone. The activities discussed in this section were perceived by the interview respondents as important to beach management. The multiplicity of activities required for beach management was also illustrated by them.

I think it [beach management] is related to cleanliness. If the beach is clean, it can attract many tourists. If it's dirty, no one wants to visit it. It is also related to the seawater quality. It [the seawater] was so bad in the last ten years. Now it is much better. Scenery improvement is also necessary, the same as the tourists' safety.

(Local public 6)

It's about the environment of the beach and the sea. It's also related to seawater quality, garbage, safety of tourists, and the area's decorum. The facilities, such as toilets and showers and parking spaces, should be more ready than this. The swimming areas and the parking areas for service boats need to be organised.

(Local public 7)

Although the respondents realised that these activities are currently carried out in Pattaya, their responses usually indicated that these practices are not at a satisfactory level. These activities tend to be operated on a daily basis by Pattaya City and other 
relevant agencies, depending on their relevant operational responsibilities and the beach areas. Based on the interview responses and the local newspaper, these multiple activities can be categorised into four groups: those related to the general organization of the beach zone, safety, cleanliness, and the physical environment (see Table 6.4). Since there are many activities, some activities are used as examples to clarify how they are carried out in relation to beach management.

Table 6.4: Management agencies and their responsible activities.

\begin{tabular}{|c|c|c|c|c|c|}
\hline & Agencies & $\begin{array}{c}\text { General } \\
\text { organization }\end{array}$ & Safety & Cleanliness & $\begin{array}{c}\text { Physical } \\
\text { environment }\end{array}$ \\
\hline \multirow{11}{*}{$\begin{array}{l}\text { Public } \\
\text { agencies }\end{array}$} & Ministry of the Interior & $\mathrm{X}$ & $\mathrm{X}$ & & \\
\hline & $\begin{array}{l}\text { Ministry of Natural Resources and } \\
\text { Environment }\end{array}$ & & & & $\mathrm{X}$ \\
\hline & Royal Thai Navy, Sattahip Base & $\mathrm{X}$ & $\mathrm{X}$ & & \\
\hline & Marine Transportation, Chonburi office & $\mathrm{X}$ & $\mathrm{X}$ & & \\
\hline & Marine police & $\mathrm{X}$ & $\mathrm{X}$ & & \\
\hline & Tourist police, Region 3 & $\mathrm{X}$ & $\mathrm{X}$ & & \\
\hline & Immigration police, Pattaya office & $\mathrm{X}$ & $\mathrm{X}$ & & \\
\hline & Chonburi provincial government & $\mathrm{X}$ & $\mathrm{X}$ & & \\
\hline & Banglamung district government & $\mathrm{X}$ & $\mathrm{X}$ & & \\
\hline & Pattaya City & $\mathrm{X}$ & $\mathrm{X}$ & $\mathrm{X}$ & $\mathrm{X}$ \\
\hline & Local police & $\mathrm{X}$ & $\mathrm{X}$ & & \\
\hline \multirow{3}{*}{$\begin{array}{l}\text { Private } \\
\text { businesses } \\
\text { and } \\
\text { organizations }\end{array}$} & Pattaya Bus Co-operative & $\mathrm{X}$ & $\mathrm{X}$ & & \\
\hline & Tourism Boat Club & $\mathrm{X}$ & $\mathrm{X}$ & $\mathrm{X}$ & \\
\hline & Beach Umbrella Club & $\mathrm{X}$ & $\mathrm{X}$ & $\mathrm{X}$ & \\
\hline
\end{tabular}

Generally, all activities are carried out in areas A to E of the beach zone, but they may be carried out by different agencies. Table 6.4 illustrates activities that are undertaken in managing the beach zone. The ' $\mathrm{X}$ ' marks indicate which activities are undertaken by particular agencies. One agency can be responsible for a single activity or multiple activities: single or multiple agencies maybe responsible for a particular activity. The activities relevant to general organization of the beach zone, safety, cleanliness, and the physical environment undertaken by relevant agencies in 
different areas of the beach zone are subsequently described in the following subsections.

\subsubsection{General organization of the beach zone}

Various activities and regulations that are linked to the general organization of the beach zone are undertaken by multiple agencies. Examples include regulations for the operation of the beach umbrella shops in Pattaya Beach, Jomtien Beach, and Larn Island and the regulations for sea area usage at Pattaya Beach, Wong Amat Beach, and Jomtien Beach. All beach vendors are required to follow the regulations. The operations of beach vendors in areas D and E are examples. According to the beach umbrella shop regulations, individual beach umbrella vendors are responsible for cleaning their shops and surrounding areas within their operating hours. After finishing for the day, they need to properly collect all the beach umbrellas and chairs. From the informal site observations, all these activities can be seen at the site (see Figure 6.5).

Figure 6.5: Beach umbrella shops on Pattaya Beach.

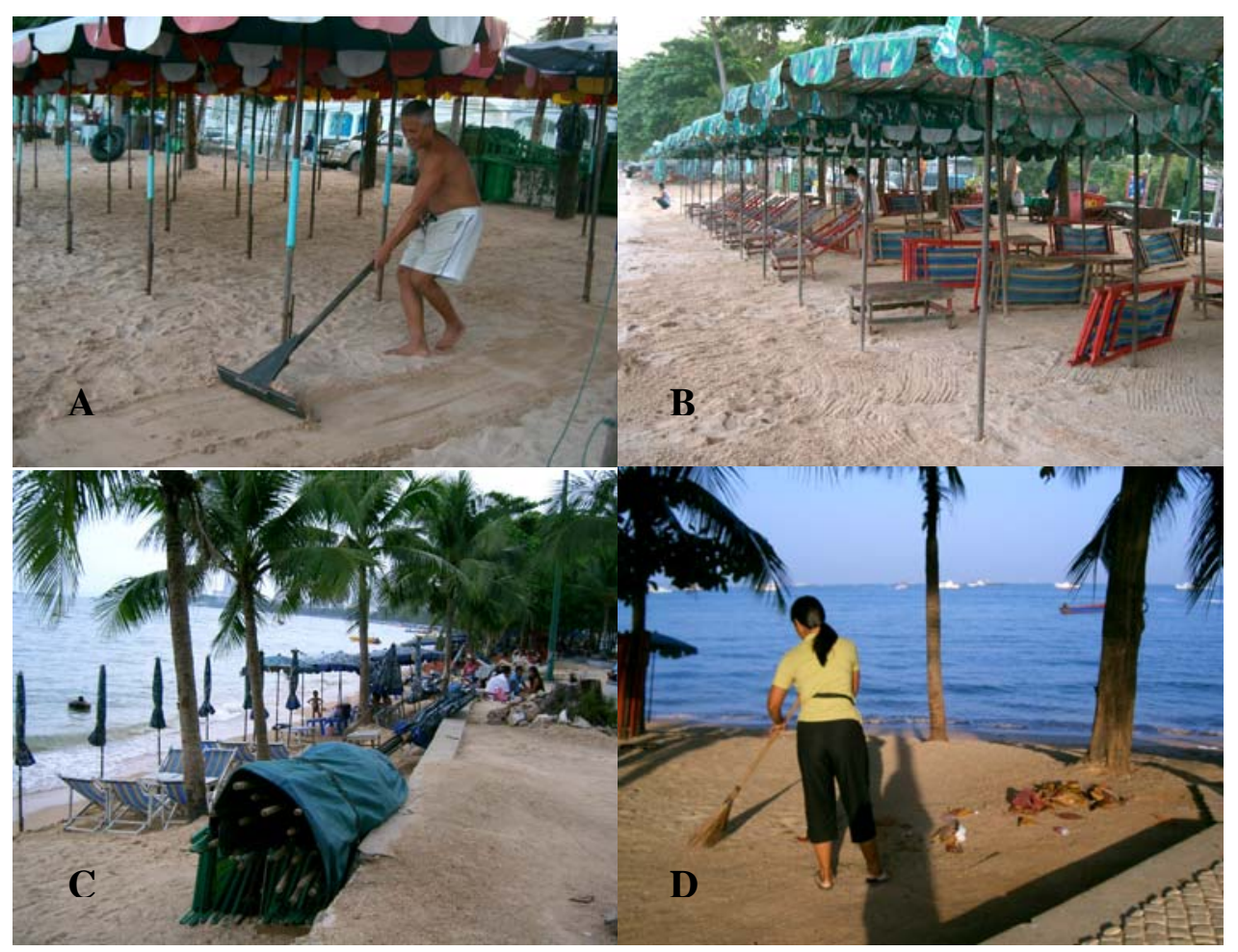

Source: The author (2006)

Description of Illustration: A, smoothing the sand; B, setting out of chairs; C, umbrellas furled and stacked away, D, rubbish collection. 
Different areas of the sea adjacent to the beach area are marked out for different purposes (see Figure 6.6). According to the regulations, swimming areas in Wong Amart Beach, Pattaya Beach, and Jomtien Beach are clearly identified by coloured markers and buoys. The width, length, and geographical location of each swimming area are clearly stated in the regulations for tourist safety. Boats such as jet skis and banana boats must moor outside of the swimming areas. Other boats such as the rental jet boats are allowed to moor in the area of orange coloured buoys. Signposts are used to indicate the areas for swimming and service boats. Different colours and types of buoys are used to divide the different recreational uses of the seawater.

Figure 6.6: The organization of the beach and marine resources.

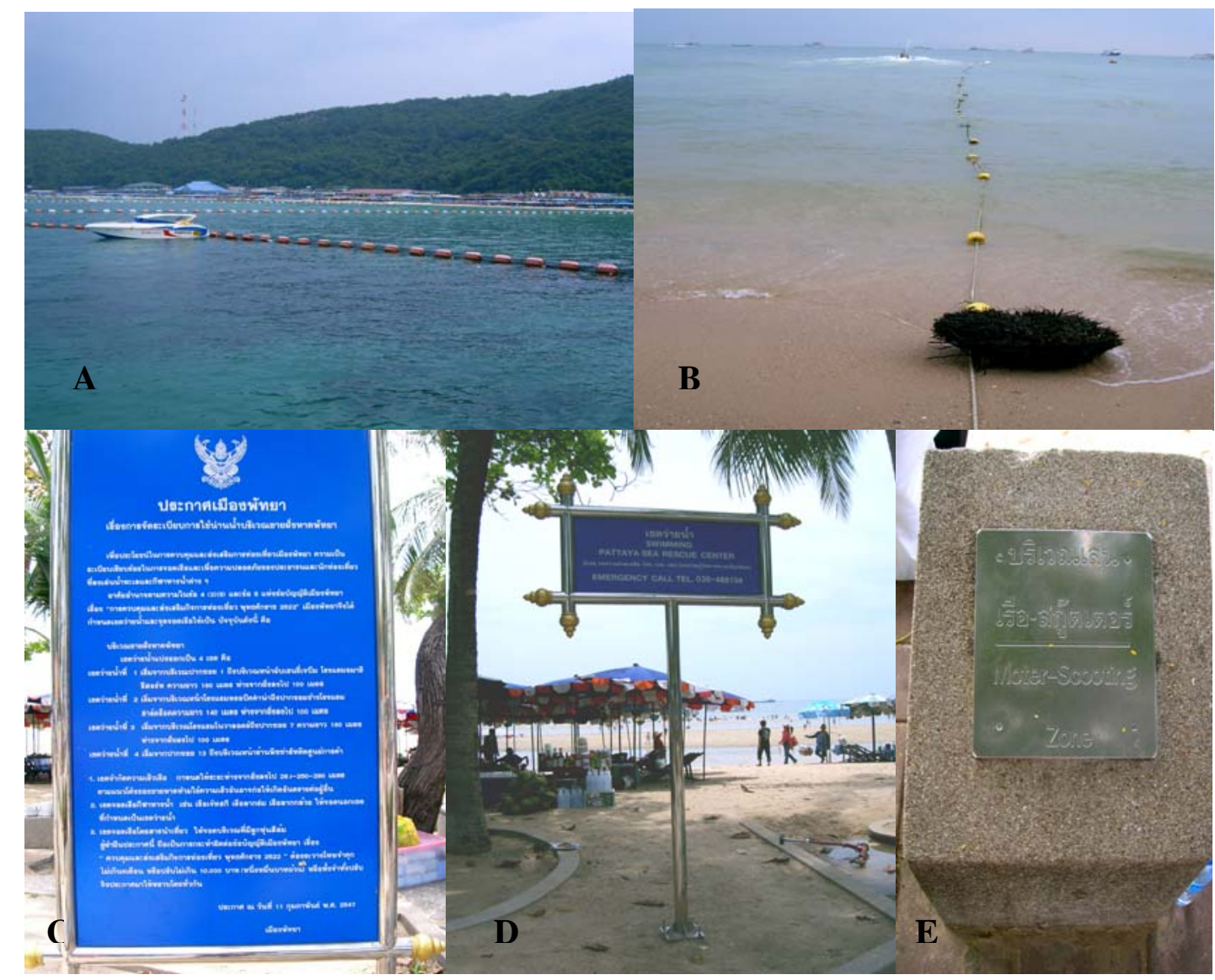

Source: The author (2006)

Description of Illustration: A, orange buoys to identify boat mooring areas; B, yellow buoys to identify swimming areas; C, a signpost to identify different locations of swimming areas; D, a signpost to indicate a swimming area; E, a signpost to indicate a motor-scooting zone. 


\subsubsection{Safety}

Some activities are undertaken to provide safety in the beach zone. According to the interview responses and the local newspaper, the major issue regarding beach safety tends to relate to crime and prostitution along Pattaya Beach, particularly at night time. In the daytime, the issues usually relate to peddlers and marine accidents. The issues of prostitution and peddlers can be seen at the site, particularly along Pattaya Beach (see Figure 6.7). Generally, the police, from local and regional offices, are primarily responsible for preventing crime and the suppression of prostitution, while Pattaya's security staff are responsible for preventing peddlers from operating in the beach areas.

Figure 6.7: Pattaya Beach.

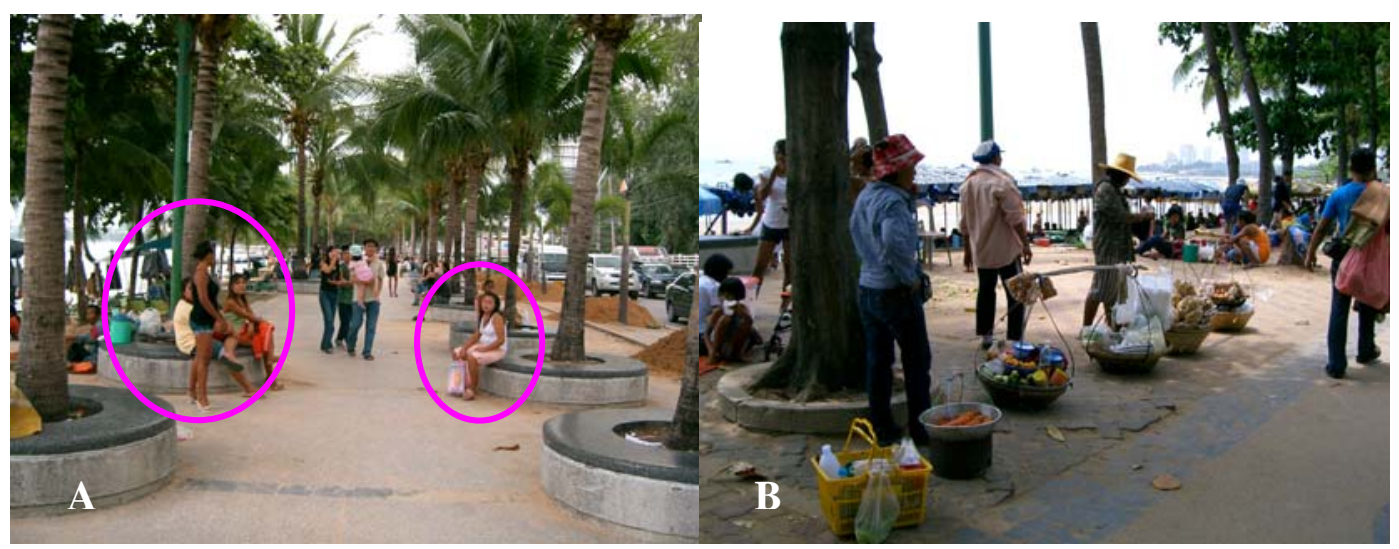

Source: The author (2006)

Description of Illustration: Prostitutes (A) and peddlers (B) on Pattaya Beach.

In Pattaya, prostitution tends to be a major issue that links to other social issues such as poverty, drugs, and crime. Although monitoring and prevention along the promenade area of Pattaya Beach have been frequently carried out by the local police and Pattaya City and frequently reported in the local newspaper, the number of prostitutes on Pattaya Beach does not seem to be decreasing. Because of less severe punishment for sex providers (Jaiyen, 1997), there are approximately 300 prostitutes along Pattaya Beach (Thanatkasidet, 2005). Prostitutes operate by sitting along the beach and chatting to other sex providers in the group while negotiating with customers who visit them (Thanatkasidet, 2005). This passive form of prostitution 
makes it difficult for the police to suppress it though the prostitutes are quite obvious (circled in Figure 6.7). Moreover, when the police are on duty and try to get them off the beach, they may walk away and come back after the police have left. The ineffectiveness of daily operation leads to the implementation of the Safety and Prostitution Prevention Project operated by Pattaya City and the relevant police offices. This project was established to prevent prostitution and to create a safe atmosphere along the beach zone at night time, as it can shape Pattaya's tourism image. The details of the project will be described in the section on management integration.

In addition to the safety activities, by observing the routine work of Pattaya's security staff to prevent peddling along the beach, it can be seen that security staff do not seriously want to arrest peddlers. Security staff warn them and remind them to move away from the promenade and the beach area (areas $C$ and $D$ ) rather than attempting to arrest them. The peddlers, when seeing the cars driven by the security staff, walk away from the areas, but resume their activities when the security staff depart. This does not seem to be a practical solution to the perceived problem of peddlers. For the safety of beach users, Pattaya City also hires a private company to operate closed circuit cameras (CCTV) along the beaches. Approximately 85 cameras are located at Pattaya Beach and Jomtien Beach. A main office is located in Pattaya City Hall from which all the cameras are operated. However, big trees and crowded beach umbrellas along the areas $\mathrm{C}$ and $\mathrm{D}$ tend to minimize the effectiveness of those cameras.

\subsubsection{Cleanliness}

A few activities are frequently undertaken in relation to beach cleanliness. The major activity undertaken by Pattaya City tends to relate to garbage and waste collection. Daily promenade cleaning and beach garbage collection are examples (see Figure 6.8). Garbage bins are provided along the beach roads. The garbage in these bins is collected four times a day by city staff. Most garbage in the beach areas is from the beachside buildings, beach umbrella shops, and tourists. 
Figure 6.8: Beach cleaning activities.

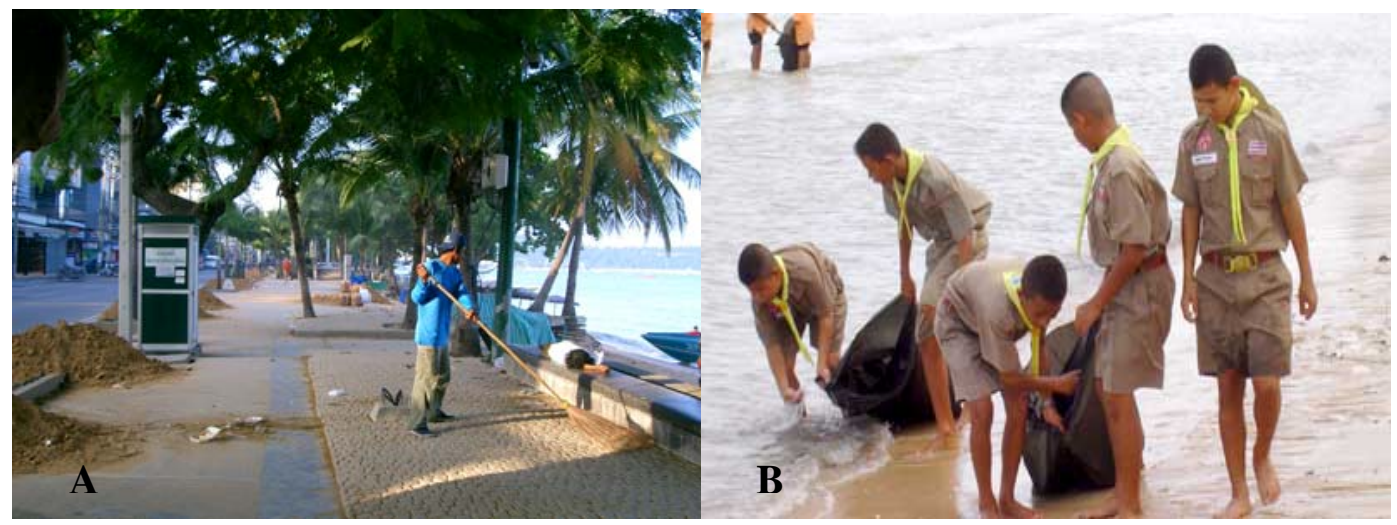

Sources: The author (A) (2006), pattayamail.com (B) (2005)

Description of Illustration: A, on the promenade and B, at the water's edge.

According to the city staff, beach cleaning projects are also operated by Pattaya City, particularly on public holidays such as the King’s and Queen’s birthdays. According to the local newspaper and on-line news, the cleaning projects appear to be a popular activity that involves a wide range of organisations. The beach cleaning and sea garbage collection projects were frequently undertaken by a number of agencies. The Scuba Diving Club, Bangkok-Pattaya Hospital, and Pattaya Tourism Business Association are examples. Most projects tend to be related to environmental conservation. However, agencies seem to be required to inform Pattaya City about the projects they intend to do.

The cleaning projects, mostly, are carried out on national holidays. Examples are December the fifth [King's birthday] and August the twelfth [Queen's birthday]. We organise the project by asking for cooperation from other agencies such as newly conscripted soldiers from the Royal Navy, students from the local schools, or members of associations or clubs in Pattaya. Approximately 200 people help clean the beaches and some roads in the city area. ... For other projects [organised by other agencies], they inform us in advance about the details of projects: how many people are involved, what time they want to come, morning or afternoon, and do they want to do it formally or informally. For the big projects, we have to call meetings to plan for the projects' organization and operation. We always receive information about these projects.

(Local public 10)

\subsubsection{Physical environment and natural resource}

In an attempt to improve the quality and condition of its physical environment and natural resources, multiple activities tend to be carried out by Pattaya City and relevant agencies. Activities to improve natural resources and the beach scenery are examples. The establishment of waste water sites and artificial marine habitats was 
undertaken to improve marine resources (see Figure 6.9). As discussed in Chapter 4, although natural resources in Pattaya have been improved, some environmental problems still persist. In relation to the implementation of the Environmental Act, two waste water treatment sites in the Pattaya area and one site on Larn Island have been established to help improve seawater quality. According to an interview with a member of Pattaya City's staff, most big hotels are using the service of Pattaya City by connecting their drainage system to the city's main pipe, while smaller businesses tend to have their own on-site treatment since they have less waste water. The disposal of unused drainage pipes into the sea is also carried out in an attempt to create artificial reefs and habitats for marine creatures.

Figure 6.9: Activities to improve natural resources.

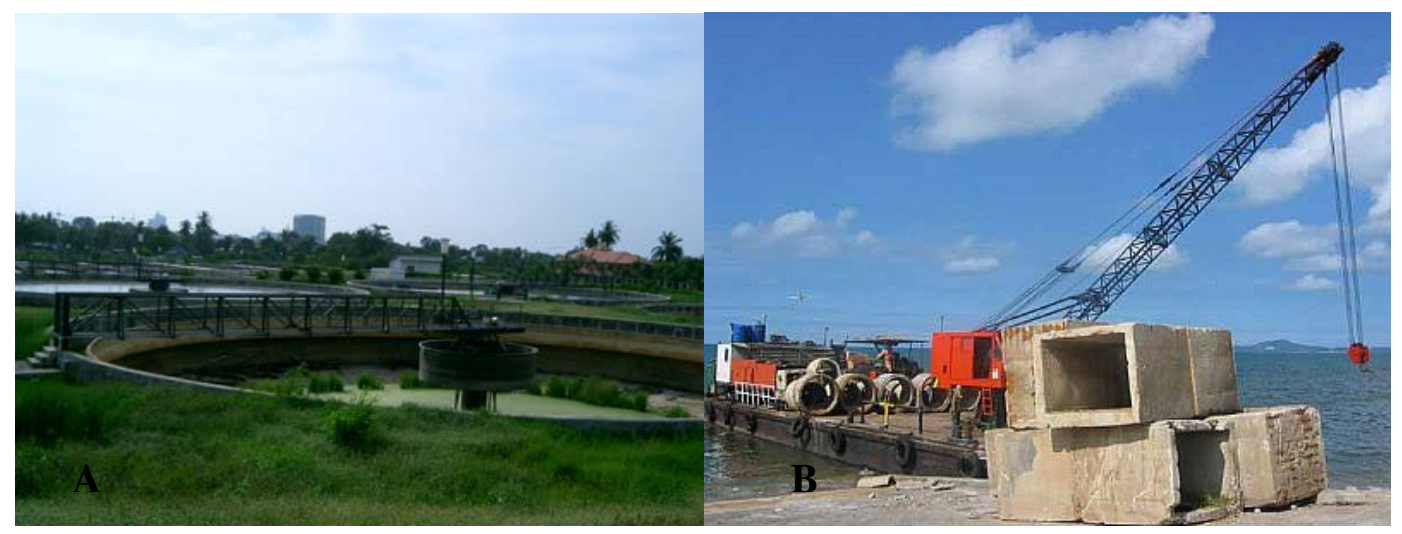

Sources: The author (A) (2006), pattayamail.com (B) (2005)

Description of Illustration: Waste water treatment site (A) and unused drainage pipes for artificial marine habitats (B).

According to interviews with Pattaya City staff, water monitoring is also carried out by Pattaya City. It is undertaken approximately three to four times a year, depending on the budget. Pattaya City is responsible for collecting the samples of seawater and sending them to the contracted company, which is responsible for measuring the numbers of coliform bacteria in the sampled seawater and reporting back to Pattaya City. The Marine Pollution Section of the Pollution Control Department in the Ministry of Natural Resources is also responsible for monitoring marine water quality in Pattaya and other coastal areas of the country. A star rating system is used to identify the environmental quality of tourism beaches (see Figure 6.10). The 
factors used to rate the beaches include the quality of the seawater, the amount of garbage present, the beach's physical geography, and the level of physical development. According to the same respondent, the work of this marine section is usually carried out independently and separately from the work of Pattaya City, mentioned above.

Figure 6.10: Public notices of star rating system for beach quality identification.

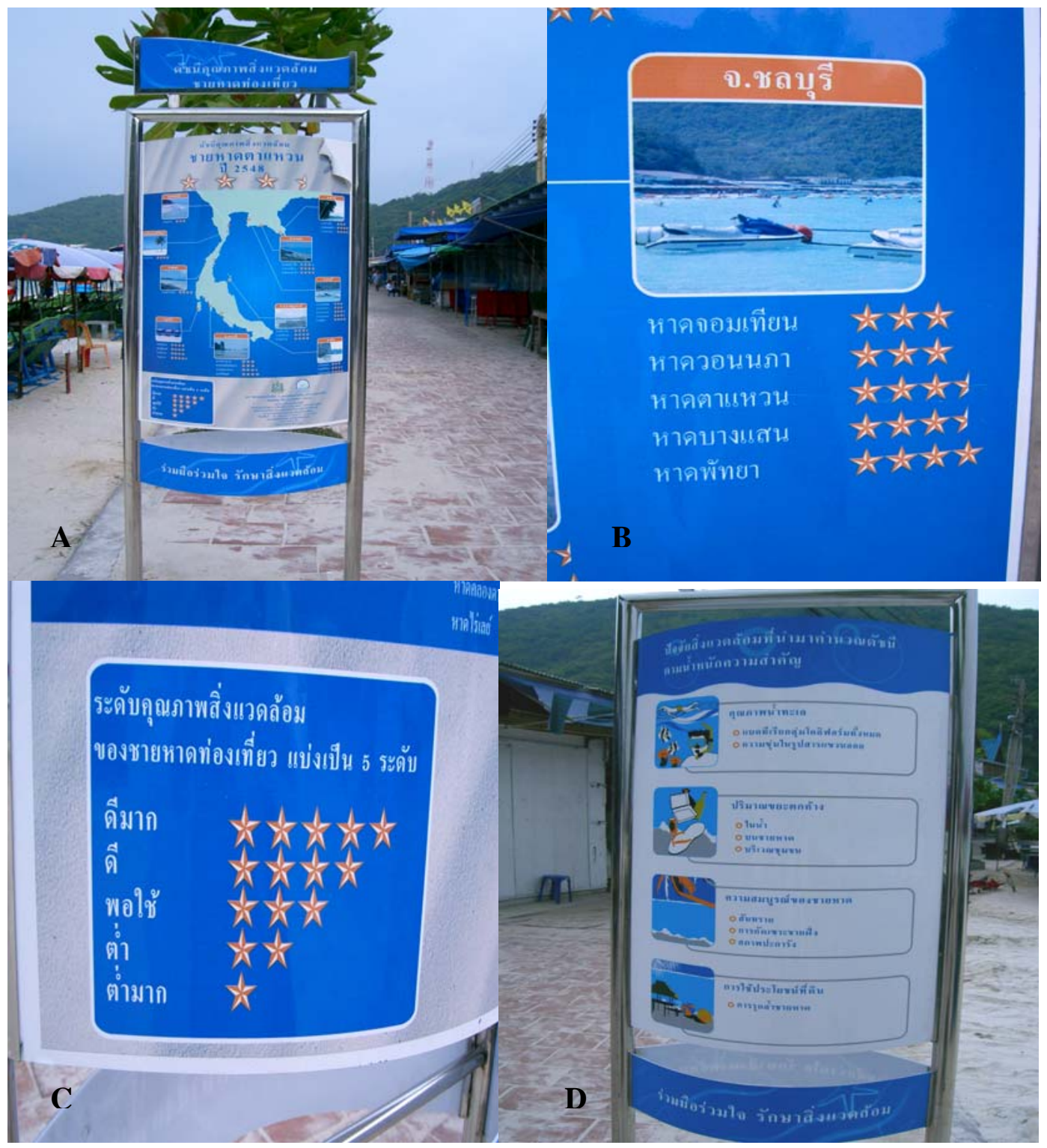

Source: The author (2006)

Description of Illustration: A, rated tourism beaches throughout the country; B, rated beaches in Chonburi province; C, stars rating system; D, factors used to rate beaches 
During fieldwork, between mid March and mid May 2006, and between mid September and mid December 2006, a major project of promenade redevelopment to improve the physical attractiveness of Pattaya Beach was clearly evident (see Figure 6.11). According to the project information board, the construction was to take place between April 1, 2006 and November 26, 2006 with an almost 50 million baht (US\$ 1.5 million) budget. In the second phase fieldwork, the project was still in progress.

Figure 6.11: Promenade redevelopment project.

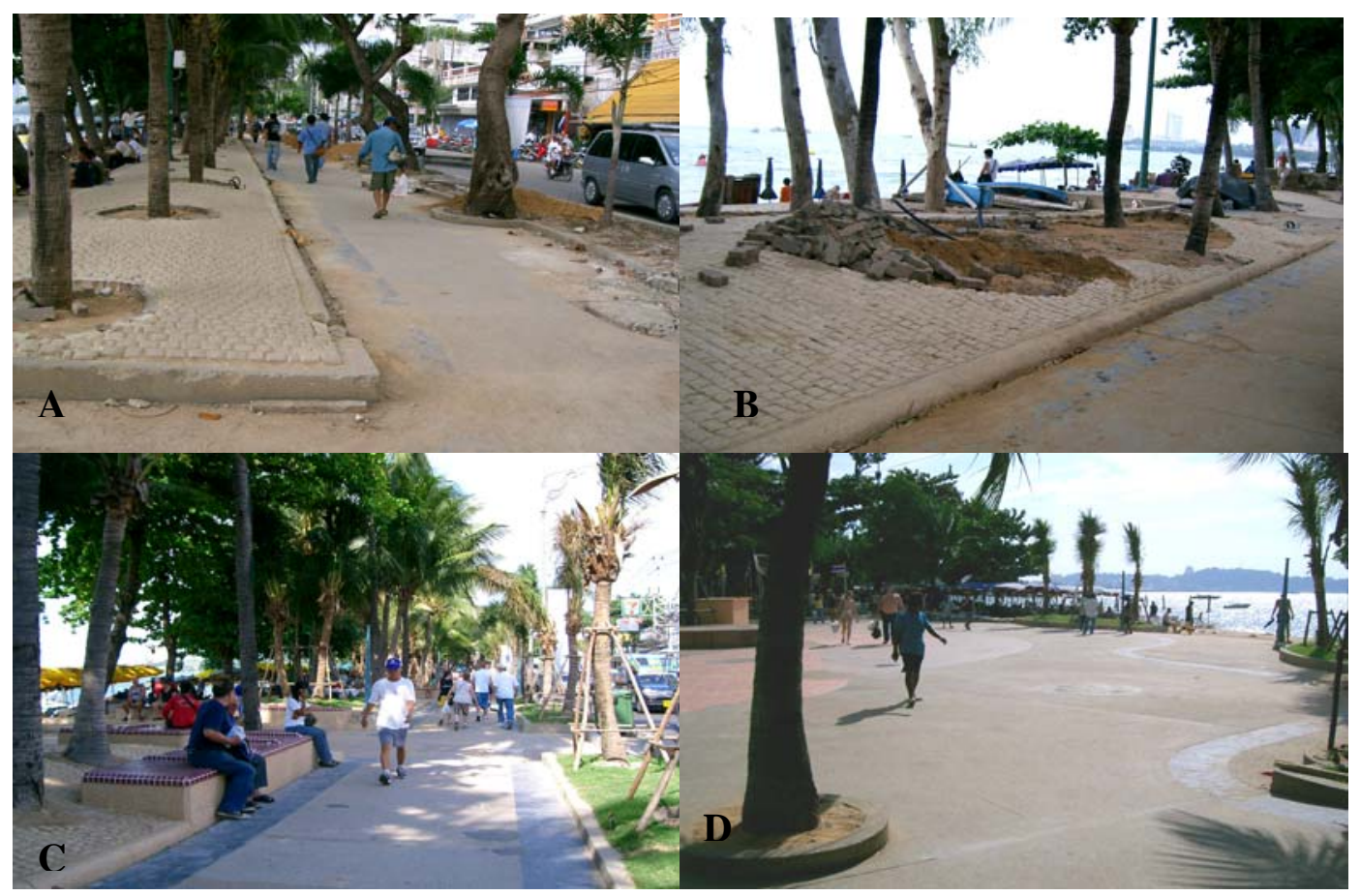

Source: The author (2006)

Description of Illustration: between mid March and mid May 2006 (A and B) and between mid September and mid December 2006 (C and D).

Although the project appeared to be a major project related to beach management, an attempt to get more information was unsuccessful. Detailed information regarding this project was not available, particularly from the municipality's respondents. One respondent who is responsible for the CCTV along the promenade commented that the redevelopment project caused some problems for the operation of CCTV cameras. His comment seemed to reflect that there was no planning integration between agencies responsible for the redevelopment project and those responsible for the CCTV installation project. One respondent from Pattaya City indicated that there 
were issues related to overlap and unclear administration between the public agencies, particularly between different levels of government. The unclear role of Pattaya City, as the municipality, in the decision-making process regarding this redevelopment project tended to be reflected in his response.

As I said, it's the money [from the central government] approximately 50 million baht (US\$ 1.5 million). .... It is the financial aid, which we cannot neglect. It was not our [Pattaya City's] project; it came directly from the central government. I don't know who made decisions about the project. It seems like, this city is developing...here is the money, 50 million, to improve your beach scenery.

(Local public 5)

As seen in this section, multiple activities are undertaken in different areas of the beach zone. All activities tend to be important for ensuring safety, orderliness, tidiness, and physical attractiveness. Many activities are tied to the beach's daily operation and maintenance. Particular activities can be undertaken by one agency or by different agencies. Some projects are usually carried out for short-term results such as garbage collection projects, while some projects tend to be carried out for long-term results such as the promenade redevelopment and the marine habitats conservation projects. However, some projects, such as the safety project, seem to emerge as a response to less effective daily operations. The interactions or relationships between different agencies in carrying out these activities seem to be crucial to achieving a better understanding of beach management and destination management. Examining the resources available to different agencies is also fundamental to understanding management. Management resources used by individual agencies in carrying out their activities need to be clarified. The coordination of resources between relevant agencies in carrying out particular activities also needs to be understood to provide information regarding interactions between those responsible agencies.

\subsection{Management resources}

According to the interviews and the local newspaper, three main resources are used in conducting the management activities: human resources, materials, and money. Most respondents tended to agree that they have insufficient human resources for their operations. Regarding their responses, this problem is generally influenced by the job descriptions and the wages/salaries paid by the public sector. Garbage 
collection is an example. Although it may require people who have less education and skill, the work itself seems to be less attractive. The staff have to collect garbage and waste, while receiving a low level of income. Some works, such as marine rescue and security, seem to be interesting. However, the high responsibility with a low level of income tends to attract few people. These issues were reflected by the following respondents. The first respondent discussed garbage collection jobs, while the second respondent discussed marine security jobs:

Frankly speaking, it's difficult to find people who want to work in this job. Every time we want to recruit people, only 5 to 10 people apply when we want 20 . When we don't have enough people, the work effectiveness is less. We have enough instruments and machines but not enough people to use them, so our work is less effective. It's very difficult to find staff....have to keep looking for them.

(Local public 10)

It's a 24 hour job. It's not easy. And the qualification is very high. [The applicants] have to be good at swimming, to know how to use the radio communication and other instruments, and to speak English ... too many qualifications. Most people with high education, they find jobs somewhere else. It's difficult. For example, if we want to recruit 40 staff, only 5 people may show up. The fringe benefit is also important. For a 24 hour job like this, it should provide the accommodation that is located near the sea for the staff. When an accident occurs, they can work immediately. ... Work motivation is very important for human resource management. ...

(Local public 8)

Most respondents agreed that they have sufficient materials or instruments necessary for their work. Only one respondent mentioned that the material resources in her division are not enough, particularly for technical instruments such as seawater collection kits. Based on the responses received from Pattaya's staff, Pattaya City tends to focus on material resources, particularly big machines and expensive equipment, rather than technical instruments or employee expertise. Thus, they seem to focus on the number of machines more than considering whether it will correspond to the staff they have. Moreover, the specifications of some machines do not seem to match the type of sand in Pattaya and minimizing their effectiveness. This is reflected by the following respondent:

At the moment, the [Pattaya] government tends to see the importance [of cleaning work]. So a big budget is provided for us. Examples are machines and instruments. We receive many of them, until I told the government that I cannot find enough people to use those machines. Macro trucks are examples. We have two of them but only one staff member who can drive them. Moreover, some machines that we have are not matched with the beach areas. They are useful to some extent, but cannot be used effectively.

(Local public 10) 
Regarding financial resources, most respondents from Pattaya City and the private clubs claimed that they have enough money for their operations. However, one respondent from another public agency indicated that his organization does not have enough financial resource. In carrying out a particular project, he received financial support from Pattaya City.

The budget for my organization is not sufficient. Usually, we receive a budget for fuel expenses from the central office of the police department. We receive the financial support from the City in monitoring the beach safety.

(Regional public 3)

Pattaya City tends to be the local government agency that has financial stability and is able to depend on itself. According to the Summary Report of Pattaya City Year 2005, Pattaya City earned 1,000 million baht per year (approximately US\$ 29 million) since 2002 and had more than 300 million baht (approximately US\$ 8 million) of net income in 2005. Its revenues are from business taxes; fees, fines, and licences; properties; public utilities and commodities; miscellaneous incomes; and financial aid from the central government (Pattaya City, 2006). With its financial stability, money does not seem to be a major problem for the overall management of the city. This was reflected in the local newspaper and in the interview responses:

We earn income from taxes. It is approximately 1,300 million baht (US\$ 38 million) per year. This portion of money, we save for an investment. The mayor will keep it for facility development or whatever. ... And we receive the financial aid from the central government, approximately 1,200 million baht (US\$ 35 million) per year. ... And some other funds are received from other agencies.

$$
\text { (Local public 5) }
$$

Some of money is from the City and some is from the central government. At the moment, we can earn our own income from the taxes. It is just started. ... If we don't have enough money, just tell the executive members of Pattaya City. They understand. Like I said, we are different from other islands. We don’t have any problem with money. ...

(Local public 11)

The financial resources seem to be used for the overall management of the city. According to the budget report described in the Pattaya Development Plans (from the years 2001 to 2008), Pattaya City has spent the budget mostly for economic development, environmental development, and natural resource management. Pattaya City has shown an attempt to improve the natural and environmental resources and to promote Pattaya's tourism. However, the distribution of finances seems to be a major issue in the operation of Pattaya City. Money is generally used 
to finance major or urgent projects, but the daily operations of particular divisions or departments may not always receive the resources they need. Thus, the money to invest in human resources seems to be overlooked by Pattaya's government, as reflected by a few respondents.

We have every kind of resource, which are better than other islands in the whole country. I have almost 200 staff, but the turnover is very high. They work for a while and then quit. The cost of living there [on Larn Island] is very high. The salary is not enough for living. ... The public sector doesn't motivate people to work there [on the island]. I risk my life but receive salary as much as others. They don't make the island as a special area that staff there will receive more salary than staff here [in the municipality]. They don't have something like this. There is no fringe benefit while paying higher costs of living. The staff with low positions [low salary] cannot survive there.

(Local public 11)

The problem is the benefits that staff can receive. We have modern instruments such as GPS to read the map and good quality of binoculars and diving gear, but not enough staff. When we ask for a larger budget, they [the executives] said 'wait'. The local budget is from the income that we [the municipality] collect in the area, isn't it? However, it depends on the commanders [whether and how they use the budget]. ... If people can choose, they go somewhere else because marine work has more responsibility and higher risk.

(Local public 8)

The insufficient budget is the barrier for our operation. We don't have enough budget to buy technical instruments or to hire enough people, such as hiring staff for marine water collection, or hiring the scientists. Actually, we need to have at least one main staff to only take care of this issue [marine water quality]. [What we have now is] one person responsible for doing many tasks.

(Local public 9)

Money, human resources, and materials are necessary resources for the operation of individual agencies and for beach management. Money seems to be the most crucial resource for any organization. Insufficient money or the poor distribution of money tends to lead to many issues related to other kinds of management resources. How money is used usually reflects managerial visions and the abilities of organizations' managers/executives. With an aim of creating a well-known tourism destination, Pattaya's government may see that sufficiency and quality of infrastructure and tourism-related facilities are important for the city. This might be the reason why the municipality uses money on large-scale projects. In terms of beach management, although most agencies have enough resources for their daily operation, the coordination of resources between different agencies occurs in order to carry out particular projects. The coordination of money and human resources for the safety project is clearly evident. Resource coordination tends to indicate that some level of integration is practised in Pattaya. As mentioned in the previous chapter, integration 
is seen as crucial for the practice of destination management and it is necessary to clarify whether and how the integration is happening in beach management.

\subsection{Management integration}

Although management agencies are working independently as a result of their daily organizational responsibilities, some forms of collective action seem to occur. With regard to the inter-organizational relationship literature, collective action can be done through interactions of two or more agencies (R. H. Hall, 1987; Selin \& Chavez, 1995). In carrying out some activities, relevant agencies tend to collaborate through different inter-organisational relationships. According to the interviews, the interactions between relevant agencies can be clustered in two forms of relationships: dyadic and set. A dyadic relationship is an interaction between two agencies, while a set relationship is an interaction between groups of different agencies (R. H. Hall, 1987). Relationships can occur between public agencies and between public and private agencies. Public agencies from different operational scales are also presented. The interactions between different agencies tend to occur formally and informally. Different types of arrows are used in Figures $6.12-6.16$ to show different types of relationships. For example, solid arrows represent formal relationship while broken arrows represent informal relationship. The extent of coordination between relevant agencies tends to be varied. In the relationships between relevant agencies, five forms of integration occur: dyadic relationships between public agencies; dyadic relationships between Pattaya City and business vendors; dyadic relationships between other public agencies and individual beach vendors; mixed dyadic relationships between public agencies and between Pattaya City and vendors; and set relationships.

First is the dyadic relationship between public agencies. It is an interaction of two public agencies in carrying out particular activities. This relationship tends to occur based on the organisational regulations or administrative acts of Pattaya City and other public agencies (see Figure 6.12). Both agencies separately and independently carry out the activities, but are formally coordinated through their organizational responsibilities. Because of their different responsibilities and authorities, both agencies appear to interact in a horizontal direction. The monitoring and controlling 
functions tend to be present within individual agencies, but not in their relationship. One agency does not monitor or control the other. Instead, they collaborate.

Figure 6.12: The dyadic relationship between Pattaya City and other public agencies.

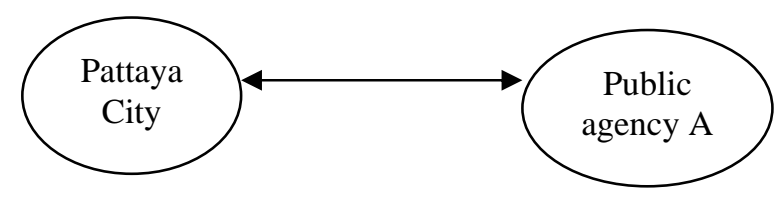

For example, the local police office is the main agency responsible for safety by arresting and fining the violators, while the security staff of Pattaya City are responsible for arresting and fining peddlers. The security staff of Pattaya City tend to be the eyes and ears for the local police. They usually inform the local police when there is any incident beyond their authority. This relationship was illustrated by the following respondents:

The police are responsible for suppression; we are responsible for cleanliness and beach decorum. Our work involves prevention and prohibition rather than suppression. We can arrest the peddlers. If there are homeless people, we have to coordinate with the provincial social services. The police are responsible for arresting the prostitutes. ... We and the police are working together in monitoring the beach areas.

(Local public 6)

On the road, we are responsible for rental vehicle vendors; the police are responsible for traffic and the services of Rod Song Taew [local taxis]. We are also related to the police in relation to the traffic. ... If we see the accidents, we call them. On the promenade, the police are responsible for controlling the prostitution. ... We are responsible for prohibiting the peddlers. We are responsible for different laws. There is no leading agency. We work together in a coordinated fashion with the police, both the local police, the tourist police, or the immigration police. Sometimes, they also ask for our cooperation [in providing security staff].

(Local public 7)

Second is the dyadic relationship between Pattaya City and the beach vendor clubs.

This form of relationship normally occurs based on the enforcement of beach vendor regulations by Pattaya City. According to the regulations, public agencies have the power to control the operations of beach vendors. However, this relationship seems to occur in a horizontal direction since the beach vendors usually have the power to negotiate with Pattaya City regarding the initiation and implementation of regulations (see Figure 6.13). Thus, the extent of their interactions and communications seem to be different. Pattaya City formally interacts with the clubs 
through the implementation of rules and regulations, while the clubs tend to interact with Pattaya City in a less formal way and with less frequency. The solid line in Figure 6.13 represents formal rules and regulations, while the dotted line represents more informal relationships and negotiation.

Figure 6.13: The dyadic relationship between the public agencies and the private agencies.

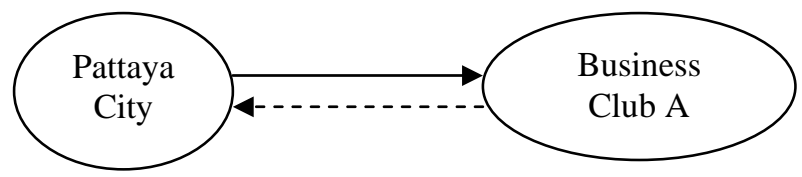

In this relationship, Pattaya City formally regulates and implements the rules for the operation of beach vendors, particularly in the D and E areas, through their clubs. Pattaya City's efforts to regulate beach vendors involve rules and a formal approach to management (solid arrow), but the authority to monitor and control their operations tends to be influenced by the relationship between Pattaya City and the clubs' presidents or committees. The monitoring and controlling functions tend to be practised within the clubs by the club members while Pattaya City implements the regulations. For example, if there are any complaints to Pattaya City about the services of particular vendors, Pattaya City will directly inform the clubs' presidents or their committees, or call for meetings to notify them about the problems to work out a solution. Since the clubs, particularly in the D and E areas, have operated for some period of time, they tend to have power to negotiate with Pattaya City regarding their operational rules. The clubs' presidents can call Pattaya City for meetings to solve problems beyond their abilities, or to negotiate about some regulations with which they are not satisfied. These actions are more informal (broken arrow) and these meetings happen less frequently. Moreover, a few of the clubs' presidents appear to be publicly elected as congress members of Pattaya City. They are the city councillors and can create understanding between Pattaya City and the club members. This form of relationship is reflected by the following respondents.

We are responsible for all rules regulated by the City. Just follow the rules. If the regulations are implemented but we don't like them, we can negotiate which regulations we can follow and which we cannot follow. It's more like a compromise to live together. ... When the municipality has any problems or concerns and wants to discuss with us, we will be invited to attend the meetings. It might happen only a few times because the presidents of the clubs are primarily responsible for solving all issues. If the presidents cannot solve the problems or 
follow the rules implemented by the City, they will call for meetings to explain what is happening.

(Local private 8)

When asked by the City, we always help. Most decisions that come from the City are from the congress members, which means that they are from the residents. We mostly get along well, there is no conflict. Whatever Pattaya City wants, it is usually within our abilities to do it. Until now, I don't have any problem [to follow the rules implemented by Pattaya City].

(Local private 9)

The third relationship is the dyadic between other public agencies and vendors, such as boat vendors. This form of relationship is similar to the previous form; however, public agencies tend to have absolute authority regarding their own organizational operations. They can directly monitor and control the operations of individual beach vendors based on national policies, rules, and regulations. The interaction tends to occur in a vertical direction with a hierarchical relationship since the individual businesses are required to follow the policies or regulations implemented by these public agencies (see Figure 6.14).

Figure 6.14: The dyadic relationship between other public agencies and the beach vendors

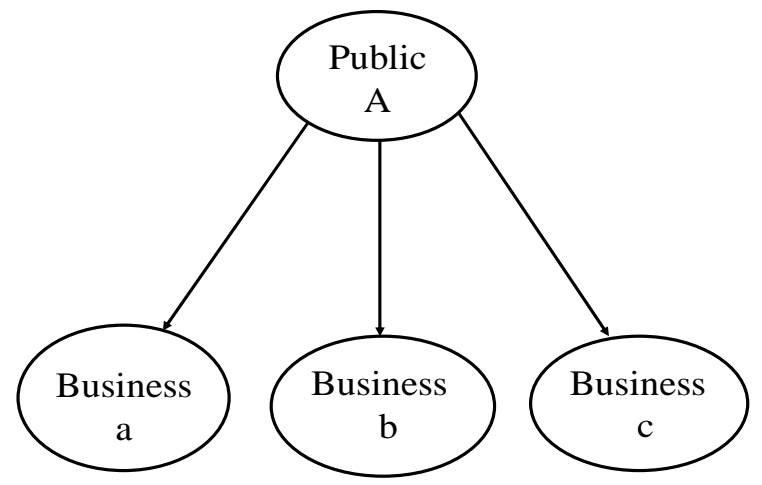

The marine transportation office and the rental-boat vendors are examples. In their daily operation, individual rental-boat vendors are required to follow the laws regarding marine vehicles. The marine transportation office is responsible for monitoring and controlling their operation and ensuring they follow the laws. Its officers have the authority to fine or arrest the violators. This relationship is reflected by the following respondent:

Usually, we have rules that the boat drivers must have driving licences, the boats must have registration numbers, and the life vests must be provided for passengers. The marine transportation officers will randomly check the boats. If they find something wrong, such as no driving licence or expired registration numbers, they should warn the boat driver and let 
them go. Then, that boat vendor will go to see the officers when they finish work. We are trying not to get the tourists into trouble.

(Local private 9)

Fourth is a mix of dyadic relationships between Pattaya City and other public agencies and between Pattaya City and individual vendors. This form of relationship usually occurs informally in solving urgent issues or situations (see Figure 6.15). Generally, the relationship between Pattaya City and other agencies, both public and private, is horizontal in nature (see the relationships marked "1" in Figure 6.15). The organizing, monitoring, and controlling functions are practised within individual organizations. When urgent incidents or issues occur, the private agencies located in the area will inform the relevant units of Pattaya City about them. If the issues or incidents are beyond the ability of Pattaya City to solve, it will inform other public agencies that are directly responsible for the issues. The communication used in providing information usually happens in informal ways such as using radio communications or mobile phones (see the relationships marked “2” in Figure 6.15).

Figure 6.15: A mix of dyadic relationships between Pattaya City and other public agencies and between Pattaya City and the private agencies.

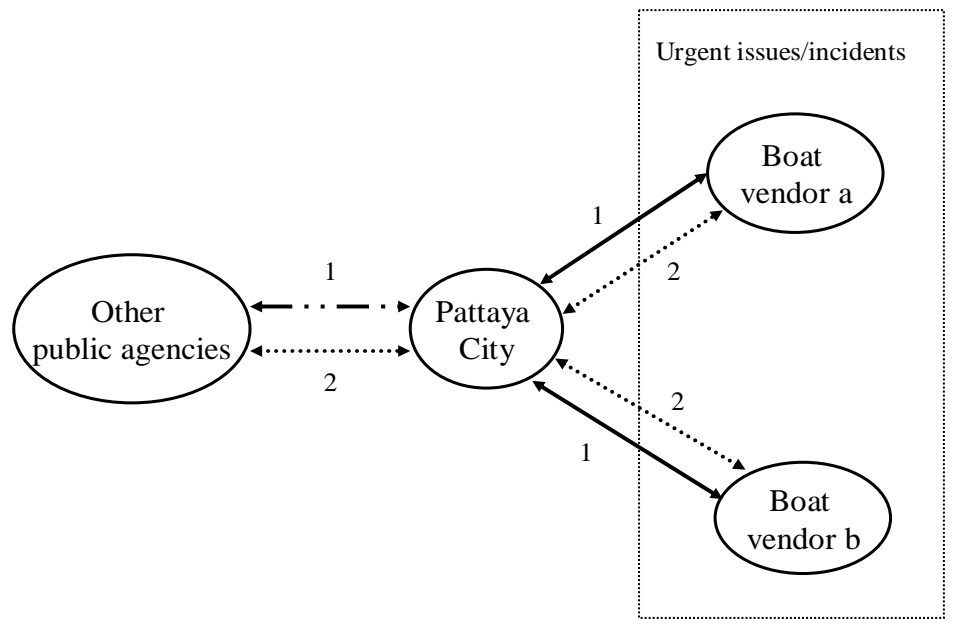

An example is the operation of Pattaya's marine rescue office. Generally, the marine rescue office is responsible for providing marine safety to the tourists and residents. Under the regulations for sea area usage at Wong Amart Beach, Pattaya Beach, and Jomtien Beach, the rescue staff have the authority to monitor the operations of the service boats and whether they follow the regulations. To park the jet boats in the 
regulated areas is an example. When there are drowning swimmers, these boats will call the rescue staff for help. If there are incidents beyond their abilities, such as sinking ferries, the rescue staff will inform the Royal Thai Navy for coordination. This form of relationship is reflected by the following respondent.

\begin{abstract}
We have all radio channels. Now mobile phones are convenient for our work. ... In a major case, such as sinking boats, that needs coordination from other agencies, we inform the Royal Navy, Sattahip Base. If there are small cases such as drowning swimmers, we can do it by ourselves. Our networks, such as the ferries, the fishing boats, and other service boats, always report to us when there are accidents.
\end{abstract}

(Local public 8)

Fifth is the set relationship between Pattaya City and relevant public agencies. This type of relationship tends to happen formally to carry out particular projects that may solve major issues in the beach zone. Since Pattaya City does not have the authority to solve the issues by itself, it depends on other public agencies that have the required authority. The projects, then, are officially established to obtain a higher degree of coordination from relevant public agencies. Pattaya City, as the project developer and coordinator, acts as the central agency to coordinate all relevant agencies and to provide financial and other resources required by them (see Figure 6.16). With this approach, the working unit is officially established. Multiple meetings may occur for planning and monitoring the project's progress. However, even though Pattaya City is the project coordinator and a main financial sponsor, it cannot control the operations of these agencies. Their relationships between Pattaya City and relevant agencies tend to occur in a horizontal direction.

Figure 6.16: The set relationship between Pattaya City and other public agencies

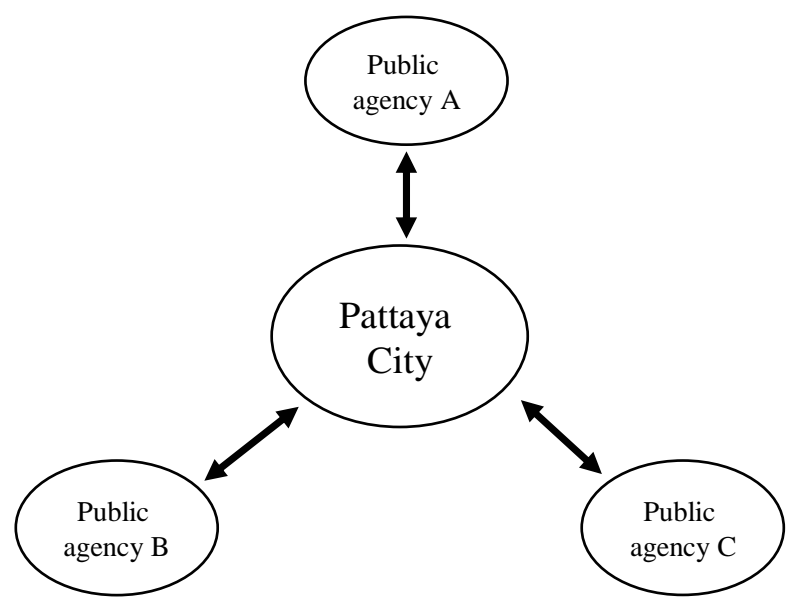


An example is the Safety and Prostitution Prevention Project along the promenade of Pattaya Beach at night. The cooperation between Pattaya City and relevant police agencies is formally practised through its working unit. There are three police offices involved in this project: the local police, the tourist police, and the immigration police. Generally, the local police are primarily responsible for safety in the city and areas $\mathrm{A}$ to $\mathrm{D}$ of the beach zone. However, it has been decided that the number of local police are insufficient for effective safety management along the beach zone. In this regard, other police offices are involved in the project. The meetings between these agencies are established to allocate responsibilities, to determine the number of people required to complete the task, and set up the budget. In the operation, one police office is responsible for approximately one kilometre of Pattaya Beach (see Figure 6.17). The police officers in different operational areas communicate through their radios. Pattaya City is responsible for coordinating and sponsoring the financial resources for all relevant agencies, while human resources and materials are provided by individual police offices. However, since Pattaya City cannot control these agencies, they usually operate independently. Their operational outcomes may need to be satisfied by all relevant agencies. The operation of this project seems to raise some issues regarding its operational timeframe and effectiveness. It is unclear as to when this project will come to an end. As Pattaya Beach is the busiest beach in Pattaya, this project may need to be operated as a long-term project in order to bring and maintain safety in the area. This project may continue if it is deemed to be successful and there is money available for it. This also raises the question of how much money Pattaya City will need to support the project. 
Figure 6.17: Areas of jurisdiction in the safety project on Pattaya Beach.

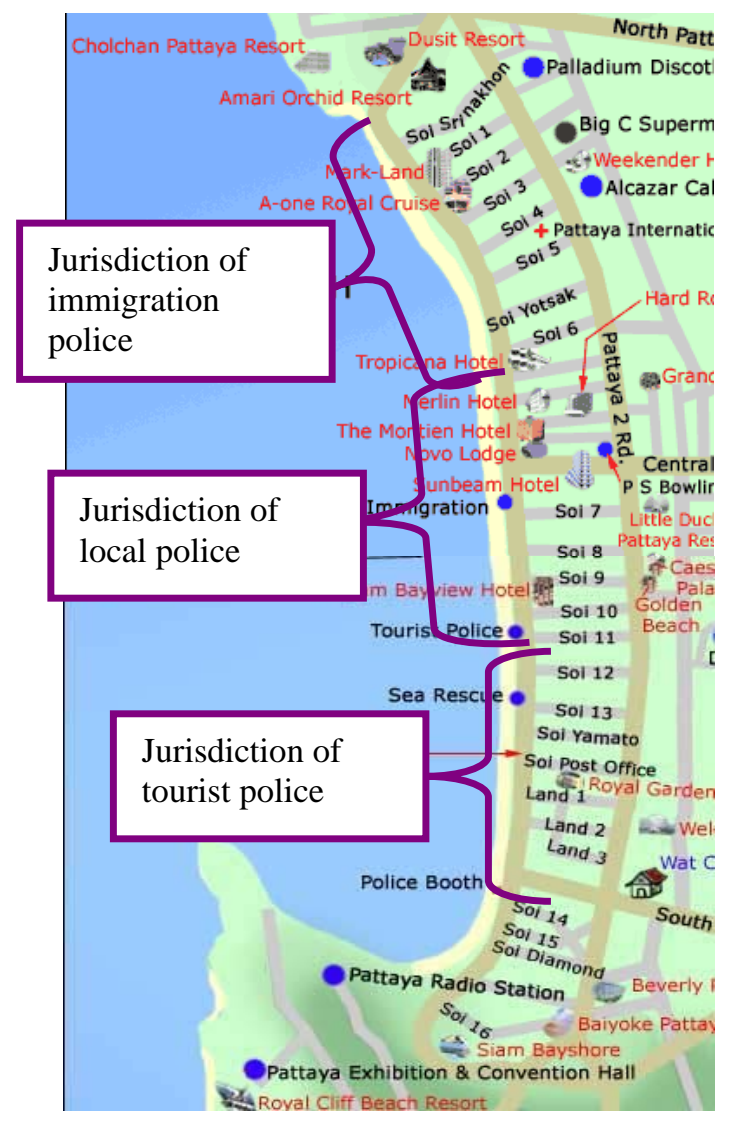

Map Source: google.com (2005)

The five types of integration discussed above can illustrate three different levels or degrees of integration between and among relevant agencies: high, medium, and low. A high level of integration usually appears in set and mixed dyadic relationships. In the set relationship, a high degree of integration occurs through formal coordination in the establishment of a working unit and frequent meetings in monitoring its progress. In this case, the safety project deals with particular issues and the project's scope is well defined. A small number of relevant agencies, which can be easily identified, are involved. Cooperation between set members can be easily practised. Although Pattaya City cannot control other public agencies, the set relationship can enable the municipality to monitor operational progress closely. A high level of integration is frequently present in the mixed dyadic relationship. In this relationship, cooperation arises when an emergency incident or issue occurs. This form of relationship enables Pattaya City to also act as a focal agency in carrying out the activities. Thus, other public agencies can help Pattaya City because solving a particular problem or issue may be beyond its ability. 
A medium level of integration is commonly present in the dyadic relationship between public agencies and private agencies. The relationship arises through cooperation in their operational responsibilities. The public agencies usually have the authority to monitor and control the operations of individual beach vendors through the enforcement of rules, regulations, and policies. In theory, these individual vendors must follow the rules. In practice, they may not follow the rules and try to avoid punishment. In this regard, business clubs frequently help the public agencies to monitor and control the operation of their individual members. If there are issues or problems that may minimise or create a negative image of Pattaya's tourism, Pattaya City asks for coordination with these business organizations. Although Pattaya City has the authority to control individual vendors through the enforcement of related operational regulations, it often leaves the control function to the clubs' presidents or committees. Their input is taken into account by the municipality. In relation to other public agencies, Pattaya City can comment on or inform the responsible public agencies regarding the issues.

A low level of integration tends to be reflected in the dyadic relationship between the public agencies. Since these public agencies have their own regulations and higher authoritative agencies, the coordination between them normally occurs formally based on organizational regulations. The municipality, in this case Pattaya City, may have difficulty getting the public agencies' involvement since it cannot command or control them. The authority of the municipality can come only through asking for their cooperation. These public agencies may say 'yes' or 'no' to that request depending on their decisions whether the request is appropriate or related to their organizational responsibilities. In the case of Pattaya City, it might be seen as fortunate that the 'no' responses seem to occur less often. As they may have similar perceptions regarding the tremendous value of tourism to Pattaya's economy, most public agencies are usually willing to coordinate with Pattaya City.

\subsection{Discussions and conclusions}

This chapter has discussed how the beach zone is managed in Pattaya. It has shown that the beach is the site of a variety of activities related to management. It can be concluded that multiple agencies are involved in carrying out multiple activities in 
the management of the beach. Some level of integration, mentioned in Chapter 5, as the core concept of destination management, occurs in the management of Pattaya's beaches. In Table 6.5, major aspects in managing the beaches in Pattaya are summarized. Some degree of integration is also reflected in individual aspects of the beach management.

Table 6.5: A summary of beach management practice.

\begin{tabular}{|c|c|}
\hline $\begin{array}{l}\text { Management } \\
\text { aspects }\end{array}$ & A summary of management practices \\
\hline $\begin{array}{l}\text { Management } \\
\text { agencies }\end{array}$ & $\begin{array}{l}\text { Multiple agencies from the public and private sectors are involved: local to national public agencies and local } \\
\text { private beach vendor clubs } \\
\text { Pattaya City is the main agency and works in relation to other public and private agencies }\end{array}$ \\
\hline $\begin{array}{l}\text { Management } \\
\text { purposes }\end{array}$ & $\begin{array}{l}\text { Agencies' primary purposes are to achieve their organizational goals } \\
\text { Particular goals in relation to beach management are for beach and city decorum, tourism promotion, problem } \\
\text { solving, and natural resource improvement } \\
\text { No common goal, but there is shared perception that their operations are for the benefit of Pattaya's tourism }\end{array}$ \\
\hline $\begin{array}{l}\text { Management } \\
\text { activities }\end{array}$ & $\begin{array}{l}\text { Multiple activities in relation to the general organization of the beach zone, safety, cleanliness, and physical } \\
\text { environment are carried out on a daily basis } \\
\text { Different agencies carry out different activities } \\
\text { Some projects are carried out for short-term and long-term solutions } \\
\text { Some projects are carried out to solve major problems/issues that help to shape its tourism image, but the } \\
\text { projects tend to indicate the ineffective daily operation }\end{array}$ \\
\hline $\begin{array}{l}\text { Management } \\
\text { resources }\end{array}$ & $\begin{array}{l}\text { Most resources used on a daily basis are from all agencies responsible in the areas } \\
\text { Coordination of resources can be seen clearly in the project basis operation, e.g. the safety project: Pattaya } \\
\text { City provides money and materials; other relevant agencies provide human resources } \\
\text { Provision of financial resources by the national government to the municipality is reflected in the promenade } \\
\text { redevelopment project, though there is no clear evidence about the project }\end{array}$ \\
\hline $\begin{array}{l}\text { Management } \\
\text { integration }\end{array}$ & $\begin{array}{l}\text { Multiple forms of dyadic relationships commonly occur in daily operations, with formal and informal forms of } \\
\text { coordination } \\
\text { A set relationship occurs on a project basis, with a formal form of cooperation: there is a working group/unit } \\
\text { establishment with frequent meetings for planning and monitoring its working progress } \\
\text { A low level of integration is present in daily management; while a high level is present in project management }\end{array}$ \\
\hline
\end{tabular}

The first aspect of management is that different agencies are involved in managing different areas of the beach zone with different management purposes. The agencies involved in beach management in Pattaya range from national to local public agencies and also local private agencies. The municipality is responsible for all areas of the beach zone, while other agencies are responsible for particular areas. Different responsibilities are exercised in different areas of the beach zone. Since diverse agencies are involved, their responsibilities tend to be differentiated by their 
organizational tasks. Although similar responsibilities may occur, the activities undertaken by relevant agencies tend to be different. Organizing, monitoring, and controlling functions are exercised by different public agencies as such Pattaya City, the local police, and marine police. These functions seem to reflect the management hierarchy or hierarchy of command between different agencies. Normally, the management hierarchy between public agencies in different operational scales is visible. The management hierarchy between the national government and the smaller scale government bodies such as provincial, district, and local governments is an example. Another is the hierarchy of command from the Ministry of Interior to regional, provincial, district, and local police offices. Within the same agencies, these planning, organizing, monitoring, and controlling functions tend to be used to get coordination from different operational scales agencies to achieve the organizational goals. When these functions are exercised by different agencies, they are generally used to get coordination and cooperation from all relevant agencies in carrying out particular activities. Two or more agencies may interact in conducting particular activities or projects. The interaction of relevant agencies tends to reflect their operational integration. This will be discussed in the last section below that addresses the integration of management agencies.

Second, all these agencies frequently have different management purposes. Although no common goals have been formally established by relevant agencies, these agencies are in many ways complementing each other through their operations. Since these agencies are aware that tourism is important to the economy of Pattaya and the nation, they tend to have the same perception that their involvement is for the benefit of Pattaya's tourism. Their involvement through this shared perception is usually for their own benefit or to ensure their existence.

For example, the business clubs may realise that they need to follow the regulations implemented by the public sector for the continued existence of their clubs and members. As reflected in the interview responses of these clubs, they often observed that they had been operating in Pattaya since before the municipality was established. They may eventually realise that this might be a reason to not negotiate with the municipality. They may also realize that they could lose the right to negotiate with 
the municipality, which might bring uncertainty and insecurity to the existence of their businesses. When Pattaya City was established as an autonomous municipality in 1999 and implemented the regulations in 2003, the clubs tried to follow them. They had to do so to stay in business. For other public agencies, they may realize that to be involved in managing Pattaya is their organizational responsibility. Thus, as Pattaya is one of the main tourism destinations of the country, public agencies that operate in the area may be able to initiate/propose development projects that receive government funding. The involvement of other public agencies, in particular projects operated by Pattaya City (e.g., the project to put power lines underground), seems to reflect this point.

Third, the integration of management activities is often reflected through the diversity of activities and projects in relation to beach management. As the beach and islands are the only natural tourism resource in Pattaya, their quality is important to draw tourists to the area. If Pattaya City attempts to create an image of a beach resort, the natural tourism resources (such as the marine environment and the beach) are crucial. Multiple activities and projects regarding the general organization of the beach zone, its safety, cleanliness, and physical environment are undertaken in an attempt to improve the physical condition and quality of the beaches and natural resources. Thus, some projects are undertaken to solve major problems or issues in the beach areas that may create a negative image of the destination as a whole. However, these activities and projects can reflect the physical issues existing in Pattaya at the moment. For example, safety, beach organization, and cleaning activities may reflect a need to prevent Pattaya becoming unsafe, messy, and dirty. These activities may also indicate that a low level of integration is present on a daily basis, as reflected in the interviews. The monitoring of seawater quality and the promenade redevelopment project are examples. The Pollution Control Department in the Ministry of Natural and Environmental Resources and Pattaya City do not seem to collaborate in monitoring seawater quality. Garbage, peddlers, and prostitutes at the beach zone in the daytime may also indicate that the daily operation of Pattaya's beaches needs more managerial effort for better physical attractiveness. A higher level of integration between relevant agencies seems to be reflected in the carrying out of some beach projects. 
Fourth, the integration of management resources tends to happen with work on particular activities and projects. Since some of these activities are primarily undertaken by Pattaya City and some by other public agencies, the resources used for daily activities tend to come from different agencies. The integration of resources between these agencies in the daily operation of the beach zone does not seem to exist. The interview responses clearly reflected that resource coordination occurs to a greater extent in carrying out particular projects rather than daily activities. In a project such as the safety project, the collaboration of finance and human resources between relevant agencies is present. Among other projects, although information regarding the promenade redevelopment project was not accessible, the interview responses noted that there is financial coordination between the national government and the municipality. However, the interview respondents who spoke about this project seemed to indicate that there was a lack of transparency with respect to the project. Requests for information about the project were not answered by the municipality. As Pattaya is one of the major destinations of the country, the distribution of money from the national government to the city's government seems to be necessary. A lack of collaboration between different administrative scales of the government bodies in decision making seems to be reflected in this project.

Finally, the integration of management agencies is reflected in five different forms of interaction between relevant agencies. Different levels of integration in beach management are also illustrated. Different agencies are integrated through different forms of inter-organizational relationships: dyadic and set. For daily operation, most activities are carried out in the form of single dyadic relationships. A low level of integration is reflected in this form of dyadic relationship. A higher level of integration is reflected in mixed dyadic relationships and in set relationships, as with the management of particular issues and project management.

Because most daily activities are carried out in dyadic relationships between public agencies, a low level of integration tends to be present for overall beach management. The slow and complex nature of bureaucratic administration may be a main factor shaping the low level integration between public agencies. Since the public agencies are administered in a bureaucratic system, the way they operate tends 
to be more passive. Pattaya City does not have authority to control any other relevant public agencies. Formal coordination between Pattaya City and other public agencies may not guarantee that a high level of integration will occur. Ambiguous roles and responsibilities between relevant public agencies may be the case. Thus, the relationship between Pattaya City and the private clubs tends to reflect the negotiation of power and benefits existing in the local context. Although the clubs can help Pattaya City by gaining cooperation from their members, they are also able to act as a group to pressure the City to protect their interests. Local culture and politics such as the patron-client culture between local politicians and specific groups of residents or businesses may exist. These issues can cause ineffective practices and unsuccessful management outcomes.

Moreover, physical issues identified at the beach zone tend to reflect the way it is managed. Based on site observation, diverse physical issues at the beach zone, particularly at Pattaya Beach, tend to demonstrate that a poor level of integration characterised beach management. Garbage/waste, peddlers, and prostitutes can be seen at the beach zone. Congestion and disorderliness, especially amongst beach vendors, local taxis, rental boat vendors, and beach umbrella shops, are also evident. Although it can be seen that the seawater quality has been improved, it is only of average quality for swimming. The total coliform bacteria (TCB) are approximately $1,000 \mathrm{MPN} / 100 \mathrm{ml}$ (MPN = most probable number). The municipality should aim to reduce coliform bacteria further for better quality seawater in Pattaya. The poor level of integration, demonstrated by these physical issues, was also reflected by a number of interview respondents.

This chapter has clarified the beach management practised in Pattaya. Different aspects of management were identified and discussed to bring a better understanding to how the destination is managed in the context of beach management. The findings of this chapter can support the discussion in Chapter 2 that multiple agencies are involved in carrying out particular management activities at the local destination. As Pattaya is one beach resort which is important to the country, multiple agencies are involved in managing its beaches and marine resources. However, this chapter shows that the multiplicity of agencies involved in the management does not necessary lead 
to a high level of management integration. Monitoring and controlling functions seem to be necessary for more effective management and better outcome. The purposes and responsibilities of agencies are different and exercised in different areas of the beach zone. Although common goals do not exist in beach management, the perception shared by all relevant agencies could be used to develop common goals. These common goals could also be used as destination goals for Pattaya. Developing common goals or destination goals could be the first step toward better cooperation amongst relevant agencies.

In the next two chapters, Chapters 7 and 8 , the management of nightlife and the Pattaya Music Festival will be presented and discussed using a similar structure to provide more information in relation to destination management in Pattaya. The similarities and differences in the management of these three attractions will be discussed and what they say about destination management practised in Pattaya will be identified in Chapter 9. The lessons learned from these case studies will also be identified and described in this final chapter. 


\section{Chapter 7 Nightlife management}

\subsection{Introduction}

In this chapter, nightlife, perceived as a major tourism attraction in Pattaya, is used as a second case study to shed light on the practice of destination management. This chapter is structured similarly to the one on beach management. First, different locations of nightlife attractions are provided for background information. Second, key agencies involved in managing nightlife attractions and their management purposes are identified to provide the context for further analysis and discussion. Third, activities undertaken by key agencies and their responsibilities are described. Then, resources used in carrying out these activities are discussed. Finally, the integration of relevant agencies in carrying out particular activities is clarified. All these aspects are brought together at the end of this chapter to discuss and identify the level of integration present in managing Pattaya's nightlife. A variety of specific examples are used to illustrate general points throughout the chapter.

\subsection{The characteristics of nightlife attractions}

Pattaya's nightlife started in the Vietnam War period (1959-1975) when the city was used as a rest and recreation area for American soldiers. Various types of nightlife businesses mushroomed at that time (Peleggi, 1996). Since then, the development of nightlife businesses seems to be increasing to provide more products and services to tourists. A newly established entertainment complex is an example. The 1,600 square metre facility was established downtown at a cost of 1,200 million baht (approximately US\$ 35 million) with the aim of providing various types of bars and entertainment for tourists (Krungthep Turakij, 2006). There are very few regulations limiting development at the moment. The city tends to be filled with a variety of entertainment businesses, particularly beer bars, go-go bars, pubs, and massage parlours. They tend to provide different services to different groups of customers. Mild to explicit sex-related services can be found in some of these nightlife businesses. They vary in terms of their emphasis on sex, and some, the cabarets and the pubs and cafés in particular, have little, if any, link to sex tourism. The cabarets host scheduled shows between 5 p.m. and 10 p.m., while most nightlife businesses 
are open approximately 7 p.m. to 2 a.m. Table 7.1 lists the different types of nightlife attractions in Pattaya. Businesses listed towards the top of the table have less of a connection to sex tourism. Those towards the bottom are more related to sex tourism.

Table 7.1: Examples of nightlife businesses in Pattaya

\begin{tabular}{|c|c|}
\hline Types & Services provided and groups of customers \\
\hline Cabarets & $\begin{array}{l}\text { places that provide stage costumed performances } \\
\text { a show takes approximately one hour and it is performed approximately } 3 \text { or } 4 \text { times daily } \\
\text { most customers are part of group tours }\end{array}$ \\
\hline $\begin{array}{l}\text { Pubs and } \\
\text { cafes }\end{array}$ & $\begin{array}{l}\text { provide food, drink, and music } \\
\text { some places may provide live music } \\
\text { customers are both male and female Thais and foreigners }\end{array}$ \\
\hline Karaoke bars & $\begin{array}{l}\text { large rooms and various private rooms in the same building } \\
\text { in each room, there is a big screen TV, microphones, and song lists from which customers can pick the songs; also, there is a } \\
\text { table for placing food and drinks } \\
\text { some places may provide service girls as singing partners for the customers } \\
\text { customers are both male and female Thais and foreigners }\end{array}$ \\
\hline $\begin{array}{l}\text { Cocktail } \\
\text { lounges and } \\
\text { night clubs }\end{array}$ & $\begin{array}{l}\text { provide food, drink, and music } \\
\text { there are service girls who socialise with customers } \\
\text { most customers are Thai and foreign men }\end{array}$ \\
\hline Beer bars & $\begin{array}{l}\text { open-air shops with a big bar counter and chairs for customers to sit around the bar } \\
\text { there are bar girls who sell drinks and entertain customers } \\
\text { most customers are foreign men }\end{array}$ \\
\hline Go-go bars & $\begin{array}{l}\text { similar to strip clubs with bar girls dancing to entertain customers } \\
\text { mild to explicit sex related shows may be provided } \\
\text { sell drinks to customers } \\
\text { most customers are foreign men }\end{array}$ \\
\hline $\begin{array}{l}\text { Massage } \\
\text { parlours }\end{array}$ & $\begin{array}{l}\text { massage shops that provide massage rooms with showers/bath tubs } \\
\text { service girls are chosen by the customers; some places may show the girls' pictures and numbers or nicknames on the booklist, } \\
\text { some places may show these girls in a glass room for the customers to view, some places may put their pictures and numbers or } \\
\text { nicknames on the internet and provide some call-out services } \\
\text { most customers are Thai and foreign men }\end{array}$ \\
\hline
\end{tabular}

At present, hundreds of nightlife businesses are scattered throughout the city. Some businesses are clustered in the Walking Street area, while most are dispersed all over the city. In Figure 7.1, the red line represents Walking Street; a circle represents several small clusters of nightlife businesses that are scattered throughout the city area. Walking Street tends to be a major nightlife attraction as it is promoted in many brochures and booklets provided in the area. 
Figure 7.1: Nightlife businesses in Walking Street and those dispersed elsewhere throughout the city

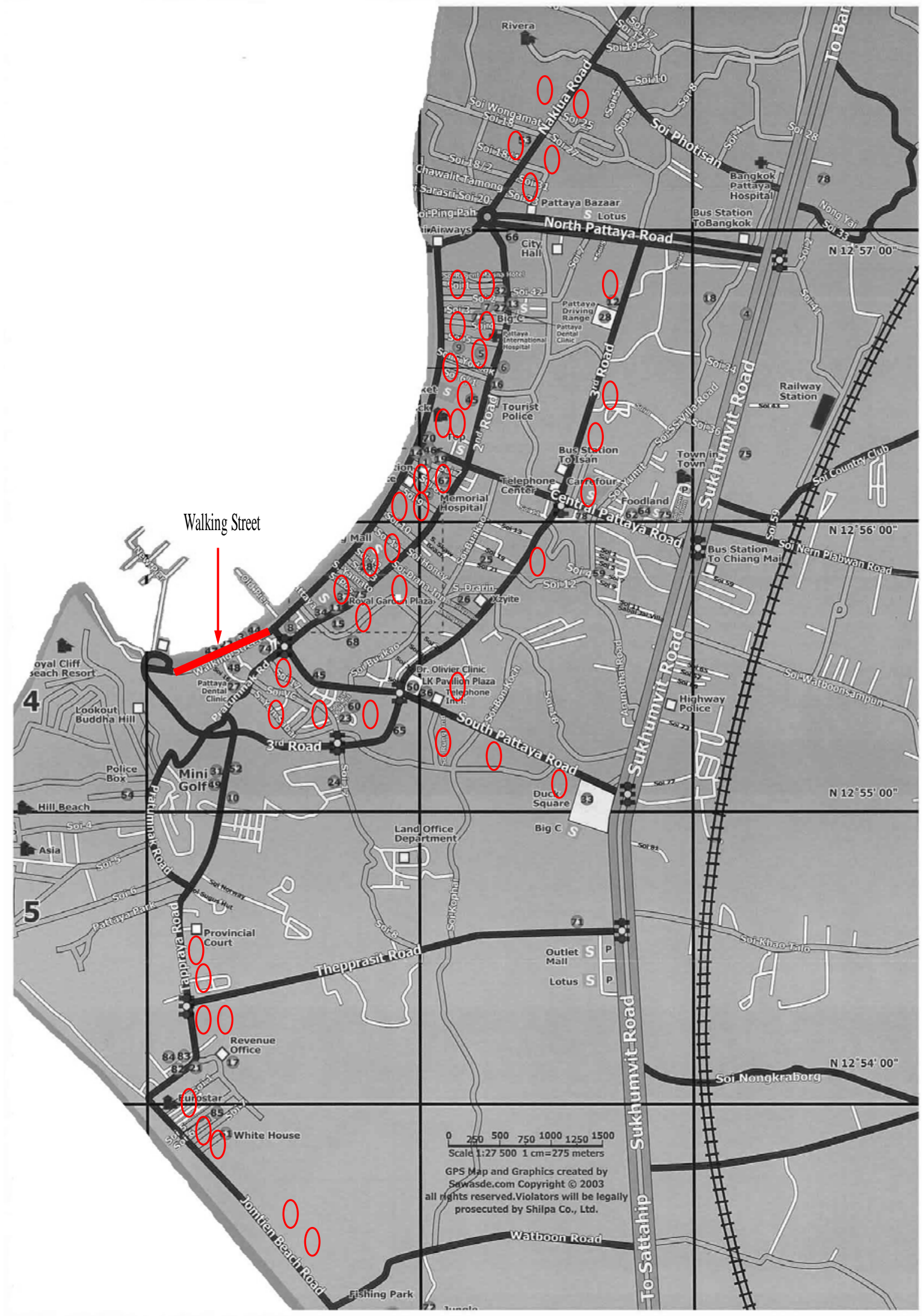

Source: Shilpa Co.,Ltd. (2006) 
Walking Street was developed as the city's main nightlife attraction with cooperation between the local businesses clustered in the street and the municipality. According to the interviews, Walking Street was developed to address the economic crisis (the IMF crisis in 1997) because of a decrease in tourist numbers at that time. Moreover, the local newspaper noted that it was developed to solve the conflict between local businesses and the government sector over the environment. As seen at the site, both sides of the street are intensively crowded with many businesses, both related and unrelated to sex services. Some businesses located on the seaside were built out over the sea. As these businesses have been operating in this cluster for years, they tend to be perceived as polluting seawater in South Pattaya. Some of the businesses did not have modern plumbing; they disposed of their wastewater directly into the sea. In 1997, they were ordered to be demolished by a court in order to improve the quality of the seawater and the natural environment. These businesses did not want their properties demolished and many government staff did not want to enforce the court order. One Walking Street business respondent commented that many businesses in other areas of the city also have a negative impact on seawater but Walking Street was the only target for demolition. There seemed to be conflict between local businesses and the government sector that the municipality needed to solve at that time. Walking Street was the solution. This street, the only pedestrian nightlife district in the city, was initiated by these businesses with the cooperation of the municipality. At present, this nightlife district is important for Pattaya's tourism and its economy. The issue of demolition seems to have faded away. As claimed by the same respondent, "the demolition of Walking Street would be a foolish thing to do because the street can attract large numbers of tourists to the city”.

As Walking Street is located at the end of Beach Road and the start of South Pattaya Road, it is noticeable and easily accessible. Behind the arch-shaped entrance sign of Walking Street, multiple types of tourism-related products are available to tourists (see Figure 7.2). Along a distance of approximately one kilometre, more than hundred shops with various kinds of services are on both sides of the street. Between approximately 3 a.m. to 7 p.m., the street is accessible to vehicles. Some shops such as convenience stores, tailors, and some bars are open for service. From approximately 7 p.m. to 3 a.m., the street is only open to pedestrians. All shops are 
open to tourists. While strolling along Walking Street, tourists can visit all types of bars and nightclubs, from simple Thai style beer bars (typical open-air bars with Thai girls to entertain tourists) to exotic European go-go bars (with only European girls), or they can eat at different types of restaurants, from family seafood restaurants to western style restaurants with live music. They can also shop for various kinds of souvenirs, from wooden crafts to finely designed jewellery. They can also have inexpensively tailored-made suits within a few days. Convenience stores, tailors, and health and beauty shops are also open at night time. All these businesses are privately owned and operated. The public sector is involved in the area by providing public facilities such as the street, electricity, and the water supply. Some issues present in this area are garbage/waste, peddlers, beggars, and the endangered animals with handlers. A strong odour of waste water from the drains can be smelled.

Figure 7.2: Pictures of Walking Street.

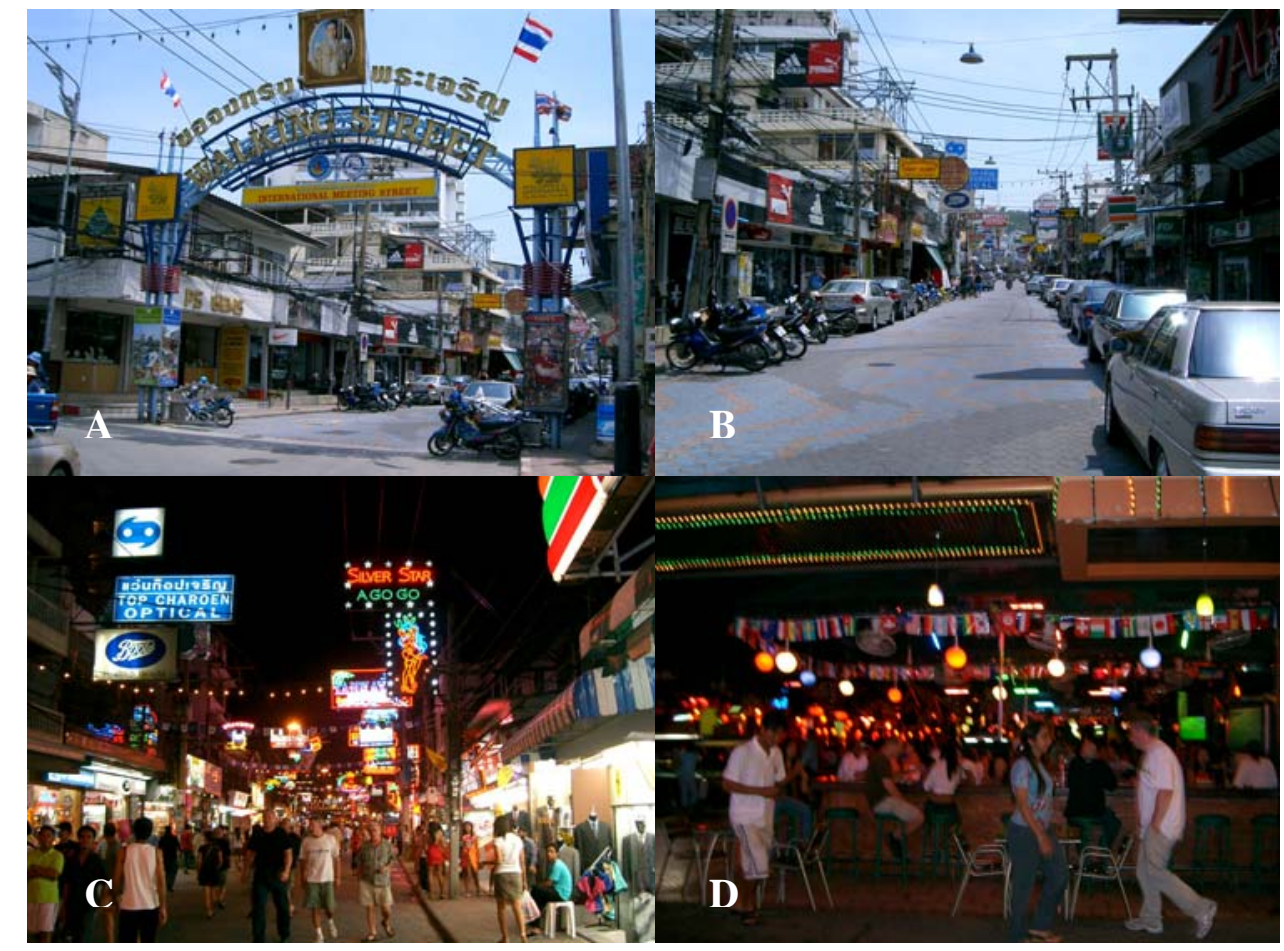

Source: The author (2006)

Description of Illustration: At day (A and B) and at night (C and D)

As shown in Figure 7.1, most nightlife businesses are dispersed throughout the city. Beer bars are the most popular type of nightlife business since hundreds of them are located along Beach Road and other main roads in the Central Pattaya area. Many of 
them can also be seen in North Pattaya and the Jomtien area. Besides beer bars, there are also other entertainment services, such as cabaret shows and live performances (see Figure 7.3). Cocktail lounges, pubs, cafes, and restaurants are also provided by individual businesses and by some hotels. Similar to Walking Street, the infrastructure is provided by the public sector. Garbage/waste, peddlers, beggars, and the handlers of endangered animals are present. Prostitutes can also be seen, particularly along the promenade of Beach Road.

Figure 7.3: Examples of nightlife businesses located outside Walking Street.

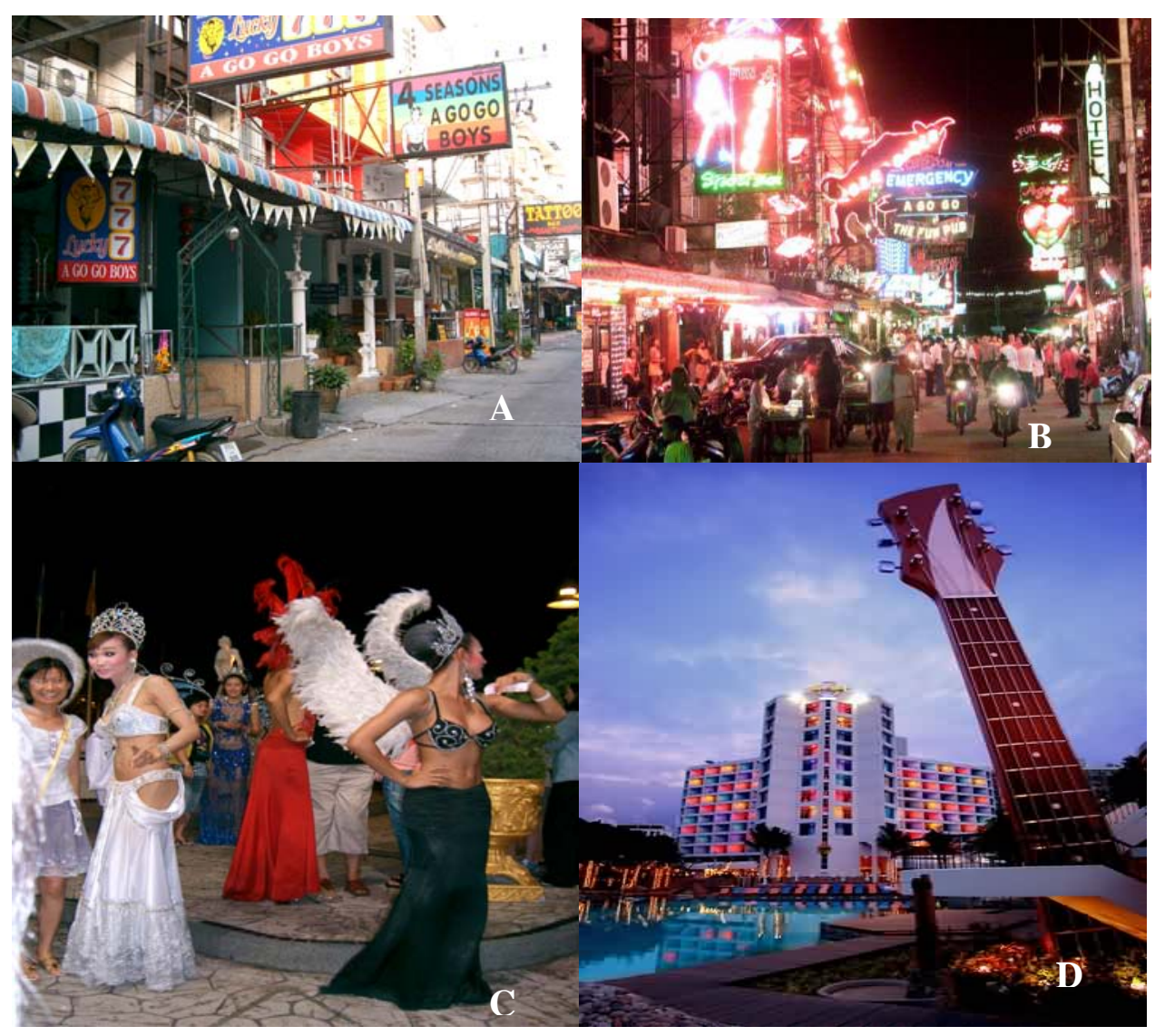

Source: The author (A and C) (2006), google.com (B and D) (2006)

Description of Illustration: A, go-go bars at daytime; B, go-go bars at night; C, cabaret show; D, restaurants at Hard Rock hotel.

Walking Street and all nightlife businesses are perceived as one type of tourism attraction in Pattaya. Based on an interview with one of Pattaya City's staff, only Walking Street and certain types of nightlife businesses that are acceptable to Thai culture are officially promoted when marketing Pattaya's tourism. Walking Street, as 
the only pedestrian nightlife district of Pattaya, is usually emphasised when marketing Pattaya's nightlife. Some entertainment businesses outside of Walking Street such as transvestite cabarets, pubs and cafes, and karaoke bars are also promoted. Sex-related businesses are not officially promoted by the municipality when marketing Pattaya, but they are present at the site. However, the municipality and other tourism-related businesses realize that Pattaya is famous for sex-related services. This image of Pattaya is downplayed in official marketing material.

Actually when we market in foreign countries, we do not focus much on the nightlife. We tend to emphasise other attractions relevant to the resort and family destination and all the facilities we have. ... We emphasise the mass market such as families and retired tourists. We promote private resorts, natural attractions, and sports. Other attractions that we can market are mildly risqué shows such as cabarets. They are for all ages. For other entertainment, we don't focus on it when marketing Pattaya's tourism. We promote typical shows. We don't need to promote sex related tourism; the tourists know by themselves which areas provide which kinds of those services [sad smile].

(Local public 13)

Maintaining an image of a vibrant and exciting resort destination but also minimizing the city's sex tourism destination image seems to be challenging for the agencies involved. Since Walking Street is quite small when compared with the city area as a whole, as illustrated in Figure 7.1, its management tends to be more intensive and more effective than the management of other nightlife businesses dispersed outside the cluster. As Walking Street is officially promoted as a major nightlife attraction of the city, it is used as the main example to examine aspects and issues that are relevant to the study of nightlife management. The dispersed nightlife businesses will be mentioned if they are managed differently from what happens in Walking Street. The agencies involved in managing Pattaya's nightlife and their management purposes are clarified in the next section to provide the context for discussion in the following sections presented in this chapter.

\subsection{Management agencies and their purposes}

Typically, all nightlife businesses are individually owned and operated. However, the operations of these businesses are commonly regulated and managed by some agencies to ensure regulations are followed to maintain the overall quality of nightlife attractions. In managing Pattaya's nightlife, several agencies are involved. They are from different sectors and operational scales. Key agencies involved in 
managing Walking Street and the dispersed nightlife businesses are illustrated in Figure 7.4.

Figure 7.4: Key agencies involved in managing Pattaya's nightlife.

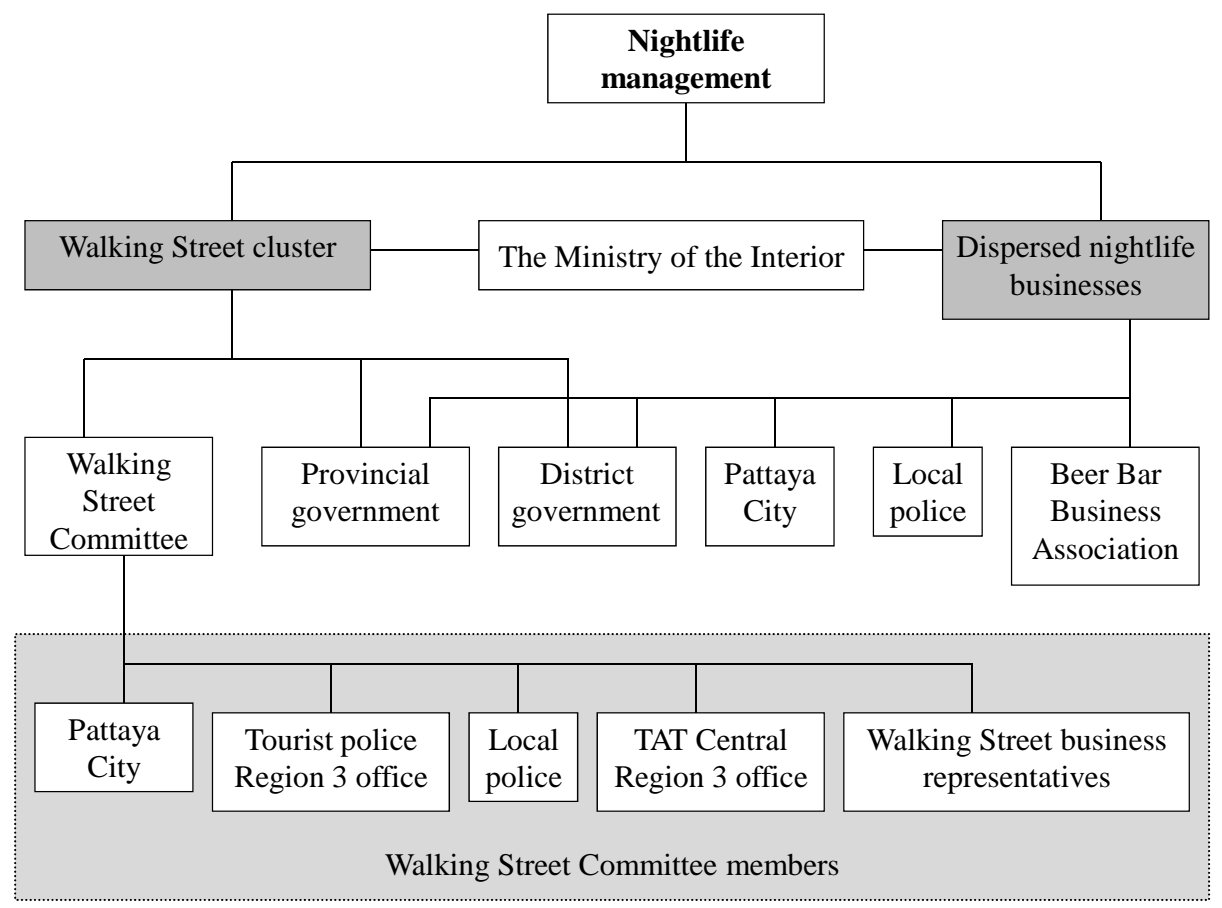

Figure 7.4 shows several agencies from the public and the private sectors that are responsible for the daily operation of nightlife businesses throughout the city area. The public agencies are from national to local levels, while the private agencies are only local. Some agencies are involved in managing both Walking Street and the dispersed nightlife businesses; some are involved in managing either Walking Street or the dispersed nightlife businesses. Some of them are members of the Walking Street Committee. The management of Walking Street is more structured.

The Walking Street Committee was formally established in 2002 to manage the cluster of businesses in the street. A review of the meeting reports of the Walking Street Committee indicated that the number of committee members is approximately 24 to 30 people. Membership varies from year to year. Typically, they include four Pattaya City congress members, three Pattaya City staff members (Mayor or Deputy Mayor, the city's chief manager, and the head of the tourism development and promotion section), the director of TAT Central Region 3 office, the chief of the 
Tourist Police Region 3 office, the chief of the traffic police Pattaya office, and more than ten Walking Street business representatives. The committee president and vice president are elected by committee members. The committee is primarily responsible for the daily operation of Walking Street. It does not oversee the operation of nightlife businesses outside of the Walking Street cluster. It also does not have a relationship with the Beer Bar Business Association.

Similar public agencies tend to oversee the operation of the dispersed nightlife businesses, but there is no formal operational committee. Even though the Beer Bar Business Association was established, it does not seem to represent all beer bar businesses in Pattaya. A representative of the Beer Bar Business Association mentioned that the association is still new and its members make up only $10 \%$ of all beer bars in Pattaya. At present, the association tries to attract more members and to increase the political clout of beer bars by providing information regarding the benefits of being a member. Its tourism promotion activities and special discounts advertised in leaflets are distributed to all beer bar businesses in Pattaya. Currently, the association does not seem to have any influence on the operation of beer bar businesses in Pattaya. Although a few beer bars in Walking Street are association members, their relationship with the association seems weak.

Different structures in managing Walking Street and the dispersed businesses were broadly reflected by the following respondent. Key management agencies and their purposes in managing Walking Street and the dispersed nightlife businesses are also illustrated in Table 7.2.

For the nightlife attractions [in general], it seems that we don't need to manage anything. It's primarily the responsibility of other public agencies. The police are responsible for maintaining order, for example. ... We [Pattaya City] cannot do anything much for nightlife management. If there are complaints, we can ask for cooperation from other agencies to find solutions or to solve relevant issues such as prostitution....

[The Walking Street Committee] consists of private and public agencies. [Walking Street Committee members] include Pattaya's administration executives such as the congress members, the department/division heads, the mayor, and the deputy. There are also the police officers such as the local police and the tourist police. And there is the Tourism Authority of Thailand Regional 3 office. The responsibilities are as their names indicate. The police are responsible for the safety of people and for managing road traffic, for example.

(Local public 13) 
Table 7.2: Management agencies and their management purposes.

\begin{tabular}{|c|c|}
\hline \multicolumn{2}{|c|}{ Pattaya's nightlife attractions } \\
\hline Walking Street & Dispersed nightlife businesses \\
\hline Ministry of the Interior & Ministry of the Interior \\
\hline $\begin{array}{l}\text { Tourist police Region } 3 \text { office } \\
\text { (represented on the Walking Street Committee) }\end{array}$ & Chonburi provincial government \\
\hline $\begin{array}{l}\text { TAT Central Region } 3 \text { office } \\
\text { (represented on the Walking Street Committee) }\end{array}$ & Banglamung district government \\
\hline Chonburi provincial government & Pattaya City \\
\hline Banglamung district government & Local police \\
\hline $\begin{array}{l}\text { Pattaya City } \\
\text { (represented on the Walking Street Committee) }\end{array}$ & Beer Bar Business Association \\
\hline $\begin{array}{l}\text { Local police } \\
\text { (represented on the Walking Street Committee) }\end{array}$ & \\
\hline $\begin{array}{l}\text { Walking Street business representatives } \\
\text { (represented on the Walking Street Committee) }\end{array}$ & \\
\hline $\begin{array}{l}\text { Management purposes } \\
\text { To achieve a common goal: Promote the area as a major tourist } \\
\text { attraction } \\
\text { Each organization seeks to achieve its own organizational goals. } \\
\text { (These goals include safety and social order.) }\end{array}$ & $\begin{array}{l}\text { Management purposes } \\
\text { Each organization seeks to achieve its own } \\
\text { organizational goals. (These goals include safety and } \\
\text { social order.) }\end{array}$ \\
\hline
\end{tabular}

Because of varied management structures, the purposes in managing Walking Street and the dispersed nightlife businesses are slightly different. Walking Street tends to be managed to achieve a common goal. Beyond social order and safety, organisations associated with managing the dispersed nightlife businesses do not have common goals. As stated in the meeting reports of the Walking Street Committee, the main purpose in developing the street was to promote the area as another major tourism attraction of the city. This purpose, since it was established by the committee members, is generally understood by them. Multiple events and festivals, for example, are undertaken in Walking Street to achieve this specific goal. Overall management practice corresponds with social order policies.

For broad goals, we aim to enhance its [Walking Street's] decorum, attractiveness, and safety. Something like this. They are broad goals. For specific goals, it depends on individual years. For example, this year, we are celebrating the king's enthronement for sixty years. We are planning what to do for the highlight of the celebration. We have had meetings to discuss the setting up and carrying out the project.

(Local public 13) 
Corresponding to the social order policies, social organization and safety seem to be broad purposes in managing Pattaya's nightlife overall. The social order policies were implemented by the Ministry of the Interior throughout the country in 2001 in order to organize society, to reduce crime and drugs, and to increase safety. In association with the operation of nightlife businesses, a set of laws was implemented. The Act of Entertainment Businesses 1966, articles 5 and 7 in particular, and the Royal Decree of Zoning Entertainment Businesses 2002 are examples (Sangsuksai, 2003). Both laws involve regulating the operation of nightlife businesses. These laws, particularly the Act of Entertainment Businesses 1966 regarding the closing time of entertainment businesses, tended to be perceived by the respondents as beneficial to society overall, but having a negative economic impact on particular nightlife businesses throughout the country. In Pattaya, a petition was lodged by Pattaya City and the nightlife businesses to the Interior Minister to reconsider the social order policy for the benefit of Pattaya's nightlife businesses. Their involvement in lodging the petition could reflect different purposes. The public sector, such as Pattaya City, tends to be involved to benefit society overall, while the private sector tends to be involved for its own commercial benefit.

According to the interviews, the primary purposes of public agencies are to achieve their organizational goals. The respondents from the public sector believed that their organizational goals were represented by their visions or missions. In a review of organizational visions of public agencies, the visions of Pattaya City and of other public agencies seem to connect to each other in terms of public administration. The line of authority is usually reflected in their vision statements. The visions of the provincial government office, the district government office, Pattaya City, and the police agencies tend to reflect the fact that their organizations are under the supervision of the Ministry of the Interior (see Table 7.3). In relation to destination management, their visions tend to reflect their responsibilities in managing Pattaya overall, particularly for safety and the quality of life of residents. In relation to nightlife management, their visions generally reflect management for social order and safety. 
Table 7.3: Visions of key public agencies involved in managing Pattaya's nightlife.

\begin{tabular}{|l|l|l|}
\hline $\begin{array}{c}\text { Operational } \\
\text { scales }\end{array}$ & \multicolumn{1}{|c|}{ Agencies } & \multicolumn{1}{c|}{ Organizational visions } \\
\hline National & $\begin{array}{l}\text { Ministry of the } \\
\text { Interior }\end{array}$ & $\begin{array}{l}\text { To be the core organization that is responsible for distress } \\
\text { mitigation, happiness enrichment, and justice facilitation of society } \\
\text { with management integration in responsible areas and to create } \\
\text { opportunity for sustaining people's wealth and stability. }\end{array}$ \\
\hline Regional & $\begin{array}{l}\text { Tourist Police, } \\
\text { Region 3 office }\end{array}$ & $\begin{array}{l}\text { Responsible in crime prevention and suppression, investigating and } \\
\text { arresting concerning about the tourist and international crimes in } \\
\text { case that may cause impact on tourism industry, help facilitating } \\
\text { and providing safety of life and belonging for the tourists and } \\
\text { working together with or giving support to other related agencies or } \\
\text { those being assigned to. }\end{array}$ \\
\hline Provincial & $\begin{array}{l}\text { Chonburi } \\
\text { government office }\end{array}$ & $\begin{array}{l}\text { To be the world's leading harbour city, a centre of international } \\
\text { tourism, a leader for industrial investment, to advance agriculture } \\
\text { and promote a liveable city. }\end{array}$ \\
\hline District & $\begin{array}{l}\text { Banglamung } \\
\text { government office }\end{array}$ & $\begin{array}{l}\text { To be a liveable town with sustainable development for people and } \\
\text { by people; to develop the quality of life for residents and } \\
\text { disadvantaged people; to increase safety in lives and assets; to } \\
\text { maintain local traditions and wisdom; and to develop the } \\
\text { environment and tourism promotion with good administration for a } \\
\text { strong economy and a community free of drugs. }\end{array}$ \\
\hline Local & $\begin{array}{l}\text { Royal Thai Police, } \\
\text { Pattaya office }\end{array}$ & $\begin{array}{l}\text { To be a modern organization; people are central; and laws and } \\
\text { regulations must be enforced with transparency, sincerity, and } \\
\text { justice. }\end{array}$ \\
\hline
\end{tabular}

Sources: Ministry of the Interior (2007), Tourist Police (2007), Chonburi Government (2007), Banglamung Government (2007), Royal Thai Police (2007)

The primary purposes of the private agencies are to maintain their businesses and to increase their influence. As mentioned previously, the idea of developing Walking Street was initiated by the businesses that operated in the cluster with the cooperation of the municipality. This pedestrian district was intentionally developed to prevent demolition and to promote commerce. It is clearly evident that the primary purpose of the business owners was to maintain their businesses.

We [businesses in Walking Street] thought to use the area for pedestrians because there was less traffic on this street at night. ... Around 10 years ago, the economy was bad. No one wanted to buy property along this street; we had to do something to maintain our businesses. So, we decided to use the street for a new tourism attraction. Now, many properties on this street are very expensive and are bought by foreigners.

(Local private 10)

Moreover, some businesses may congregate into formal clubs or associations to increase their power to lobby the government. Creating formal clubs or associations also tends to enable them to negotiate with other public or private agencies. The Beer Bar Business Association is an example, though its influence is weak. 
Our purposes are for group benefits. If we [the beer bar owners] congregate into a group, we can discuss or ask for our rights from the pubic sector and other businesses that we have to deal with. ... In the past, each business might go its own way. Nowadays, we need to work together to increase our power.

(Local private 11)

\subsection{Management activities and their responsibilities}

Four main activities are undertaken in managing Pattaya's nightlife: safety, social order, cleanliness, and tourism promotion. Since some kinds of nightlife businesses would be perceived as “dirty” businesses, which may involve drugs, prostitutes, and crime. Safety and social order seem to be crucial for nightlife management. In Pattaya, activities relevant to safety and social order are undertaken across the city but to a greater extent in Walking Street. Cleanliness and tourism promotion activities also tend to be emphasised in Walking Street. The agencies responsible for carrying out this work are presented in

Table 7.4. Particular activities may be carried out by single or multiple agencies. Responsibility for carrying out these roles tends to be different in managing Walking Street and the dispersed nightlife businesses. For Walking Street, responsibilities are shared by committee members while shared responsibilities do not exist in managing the dispersed businesses. There is no equivalent to the Walking Street Committee elsewhere in the city. Generally, public agencies are responsible for carrying out these activities. Individual private agencies tend to be involved through following the rules, regulations, or policies that are implemented by the public agencies. The responsibilities of the business representatives on the Walking Street Committee and the Beer Bar Business Association do not overlap. In managing Walking Street, these activities tend to be undertaken through the collaboration of its committee members from both public and private sectors. In contrast, there is no committee in managing the dispersed nightlife businesses. Management functions (e.g., planning, organising, monitoring, and controlling) are exercised by relevant agencies. These functions tend to be exercised by some public agencies to influence the operation of individual nightlife businesses. Different functions may be exercised by a single agency while similar functions can be exercised by different agencies. Their responsibilities in 
carrying out activities related to safety, social order, cleanliness, and tourism promotion will be discussed in turn.

Table 7.4: Management activities undertaken by particular agencies.

\begin{tabular}{|c|c|c|c|c|c|}
\hline & & Safety & Social order & Cleanliness & $\begin{array}{c}\text { Tourism } \\
\text { promotion }\end{array}$ \\
\hline \multirow{7}{*}{$\begin{array}{l}\text { Public } \\
\text { agencies }\end{array}$} & Ministry of the Interior & $\mathrm{X}$ & $\mathrm{X}$ & & \\
\hline & Tourist police Region 3 office & $\mathrm{X}$ & $\mathrm{X}$ & & \\
\hline & TAT Central Region 3 office & & & & $\mathrm{X}$ \\
\hline & Provincial government & $\mathrm{X}$ & $\mathrm{X}$ & & \\
\hline & District government & $\mathrm{X}$ & $\mathrm{X}$ & & \\
\hline & Pattaya City & $\mathrm{X}$ & $\mathrm{X}$ & $\mathrm{X}$ & $\mathrm{X}$ \\
\hline & Local police & $\mathrm{X}$ & $\mathrm{X}$ & & \\
\hline \multirow{2}{*}{$\begin{array}{l}\text { Private } \\
\text { businesses } \\
\text { and } \\
\text { organisations }\end{array}$} & $\begin{array}{l}\text { Businesses located on } \\
\text { Walking Street }\end{array}$ & $\mathrm{X}$ & $\mathrm{X}$ & $\mathrm{X}$ & $\mathrm{X}$ \\
\hline & $\begin{array}{l}\text { Beer Bar Business } \\
\text { Association }\end{array}$ & $\mathrm{X}$ & $\mathrm{X}$ & & \\
\hline
\end{tabular}

Table 7.4 presents the agencies responsible for carrying out particular activities in managing Pattaya's nightlife. The ' $\mathrm{X}$ ' marks indicate responsibility. One agency can be responsible for a single activity or multiple activities: single or multiple agencies maybe responsible for a particular activity.

\subsubsection{Safety}

Safety is the responsibility of several agencies. Generally, the local police are primarily responsible for overall safety of lives and assets in the city. They also deal with road traffic and the suppression of drugs, prostitution, and corruption. The tourist police deal with tourists' safety and cooperate with the local police when required. In relation to nightlife management, daily patrols by the tourist police in Walking Street are normally used to monitor safety in the street, while a similar approach is used by the local police to monitor safety in the city overall. The mere presence of police officers is seen as a means of deterring crime. Other public 
agencies such as the provincial and district governments and Pattaya City tend to organise, monitor, and control the operation of individual businesses in a way that corresponds to national policies, implemented by the Ministry of the Interior. Moreover, visits by government staff (such as the provincial and district governors) along with the police officers is usually a popular approach to monitor the operation of nightlife businesses in and outside the Walking Street cluster, as reported in the local newspaper and by an interview respondent:

We have a safety unit in Walking Street. Tourists can inform us about incidents. We also have official staff and volunteers patrolling along the street every night from 8 p.m. to 2 a.m. We have been doing this for approximately 5 to 6 years now. In other areas, there are patrolling staff on the main roads and sois [small streets]. ... It's routine work. ... Local police, Pattaya office is the main responsible agency. We are the supporting unit that is cooperating with them [in patrolling and suppression] when required.

(Regional public 3)

Since the street is quite small, safety activities are generally carried out to a greater extent in Walking Street than amongst the dispersed nightlife businesses. Every night, metal fences are used at the entrance of Walking Street as a gate to stop vehicles from accessing the area (see Figure 7.5). Police cars park next to the entrance and set up a temporary station to receive and provide information to tourists. Nightly patrols by tourist police officers, Pattaya's security staff, and Thai and foreign volunteers walking along Walking Street can also be seen (see Figure 7.6). An attempt to minimize safety problems in Pattaya, particularly in the Walking Street cluster is also clearly evident in the documents. The increasing numbers of patrolling officers, the suppression of prostitutes, robbers, touts, and illegal bars, and the plan to install CCTV cameras along the Walking Street area to create a safe environment in the street were reported in the meeting reports of the Walking Street Committee and the local newspapers. 
Figure 7.5: The entrance to Walking Street at night (A and B).

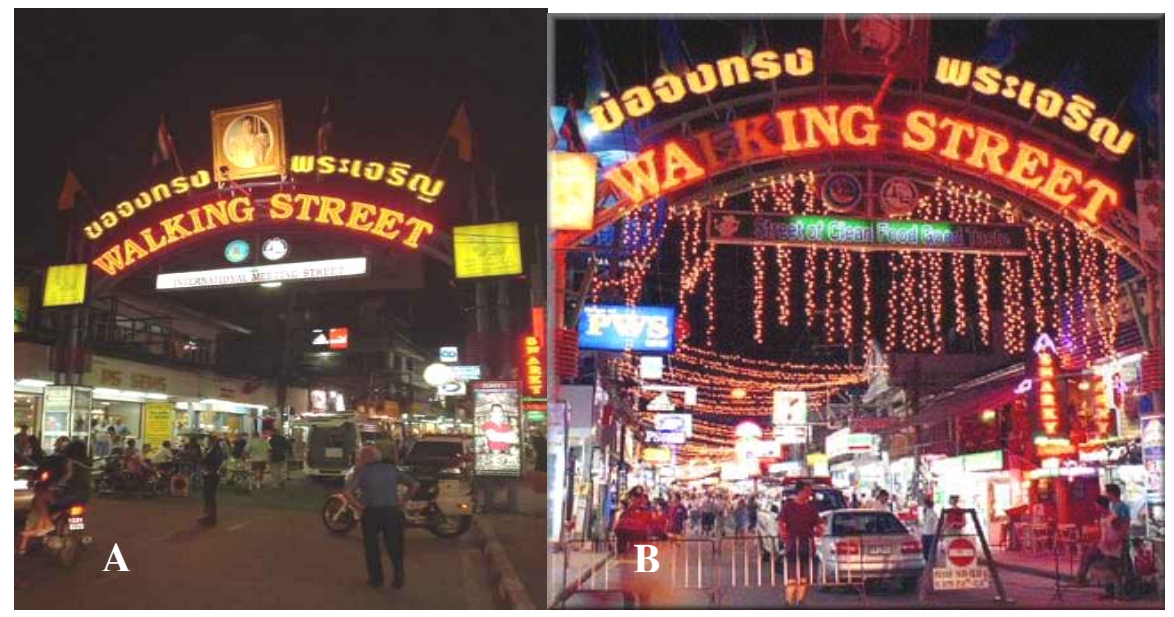

Source: pattayamail.com (2006)

Figure 7.6: Nightly patrols at Walking Street.

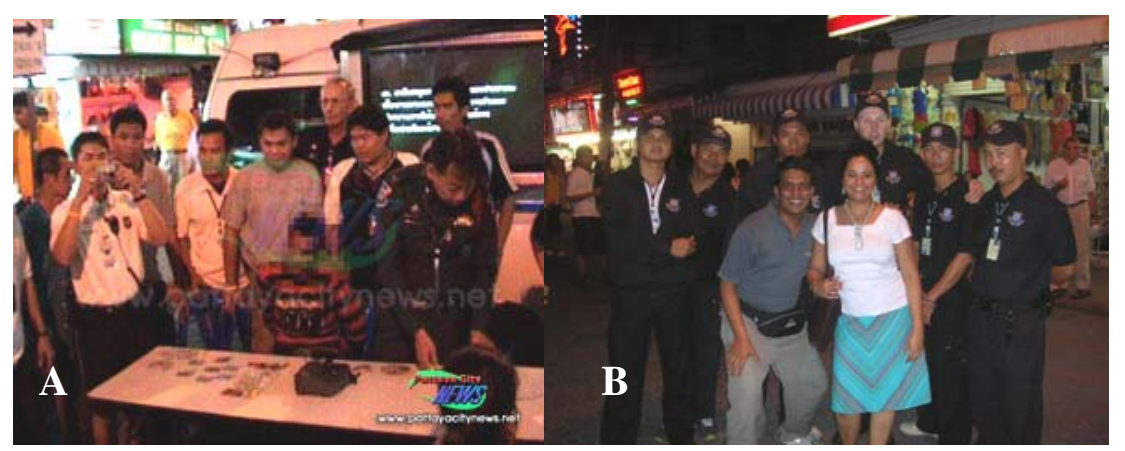

Source: pattayamail.com (2006)

Description of Illustration: Tourist police (A) and voluntary security staff (B) in Walking Street.

Meetings with nightlife business operators for safety cooperation are also carried out by Pattaya City. As mentioned in Chapter 4, the majority of Pattaya's population are short-term migrants. However, they are seen as a source of social problems by the authorities. As indicated by a respondent, Pattaya City asks for cooperation from these business operators, particularly beer bar operators, to register their staff. When this is done, the police would be able to trace the people and their place of residence. This approach may help the municipality to monitor and control the numbers of short-term migrants and enable the police to provide safety to the tourists.

We call for meetings intermittently, particularly with beer bar operators. They have many problems regarding bar girls. We ask for their cooperation by registering their staff in the 
owner's household and monitoring the freelance sex providers in their shops. If these freelance sex providers sit in their shops, the owners/managers should tell them off. This will help us to control safety at some level.

(Local public 13)

Moreover, the closing time of nightlife businesses is regulated for safety purposes. According to the local newspaper, the closing time regulation arose as a result of the social order policies implemented by the Ministry of the Interior throughout the country. Regulating closing times is designed to control late-night disorderliness. It is carried out in Pattaya for its safety and social order.

\subsubsection{Social order}

Agencies similar to those that carry out safety activities also undertake several activities to ensure social order in Pattaya. The suppression of peddlers, beggars, and endangered animal handlers and the organization of stall vendors tend to be major activities, particularly on Walking Street. According to the local newspaper, suppression of certain activities in Walking Street is carried out by the tourist police and the city's security staff. It happens to a lesser extent in the dispersed nightlife businesses. The organization of stall vendors is also clearly evident on Walking Street. After businesses on Walking Street close at approximately 2 a.m., the business operators often lease the front area of their shops to stall vendors. Based on a review of the meeting reports of the Walking Street Committee, the issue of renting space was discussed as a major issue in organizing the area from 2002 to 2006. When a meeting of the Walking Street Committee was attended on December 4, 2006, this issue was still being discussed and a solution was not arrived at. One committee member suggested drawing a line for clearer visibility for stall vendors. However, the solution was not reached at the meeting since the committee president preferred to discuss this issue with all the Walking Street business owners before making a final decision. This seemed to reflect the fact that decisions made in the committee meetings require the input of business owners on Walking Street. It also seemed to reflect the strong relationships between local politicians and business owners clustered in the Walking Street area.

The Royal Decree of Zoning Entertainment Business 2002 was implemented throughout the country. However, the practices are not clearly evident in Pattaya. 
Zoning regulation is highlighted in Pattaya, but serious enforcement does not seem to occur. According to the local newspaper, a lack of serious enforcement of the zoning regulation was indicated by the president of the Pattaya Tourism Business Association in 2003. This lack of enforcement is still an issue, as reflected in the interview responses. One member of the Walking Street Committee supported this view. She commented that beer bars should be zoned for the better organization of nightlife businesses and for the safety of tourists. A member of the Beer Bar Business Association also noted that zoning regulations have been implemented recently by the government bodies and allows nightlife businesses to operate in two different locations: zoned and unzoned areas. According to his response, the zoned areas refer to areas where beer bar owners have business licenses (such as Walking Street and the Beach Road area). Businesses in zoned areas can remain open until 2 a.m.; those in unzoned areas must close at 1 a.m. In unzoned areas, all beer bars tend to operate without permission (such as in the Jomtien area). His response indicated that the municipality or other responsible public agencies did not force businesses in unzoned areas to close down or to relocate. As long as they do not violate other regulations and cooperate with the public agencies when required, they are able to continue operating in the unzoned area. If there is evidence to show any misconduct related to drugs or law violations, the business will face consequences, as frequently reported in the local newspaper:

"If any evidence shows that those beer bars and gay bars along Jomtien road are operated in a way that contradicts the culture and morality of the country or to create a negative image of Pattaya, the City will present their names to the district governor in order to withdraw their business licences. Otherwise, many more of them will be opened in the Jomtien area, which is zoned to be a natural tourism attraction” commented Pattaya's mayor.

(Pattaya Post, Vol. 5 Issue 127, page 5, August 20 - September 1, 2003)

In addition, meetings with nightlife business operators are frequently held by Pattaya City. When new laws or policies are implemented, Pattaya City usually informs these operators to ensure that the new policies are clearly delivered and understood by them. The meeting to inform these businesses regarding the new law on smoking, to ban all smoking in pubs, bars, and other retail outlets, implemented by the Ministry of Public Health is an example. Thus, the meetings to persuade these businesses to cooperate with Pattaya City by controlling their noise levels, their staff behaviour and dress, and monitoring their staff regarding drug use are also carried out. Some 
training workshops are also provided to build knowledge and understanding of the business operators regarding relevant issues.

\subsubsection{Cleanliness}

Pattaya City is the only agency responsible for cleanliness on Walking Street. Because of the high volume of tourists, there is a desire to ensure the nightlife attractions, particularly Walking Street, are appealing. Orderliness and cleanliness are important in reinforcing Walking Street's primary goal: ensuring that it remains a popular tourist attraction. In Pattaya, garbage bins are placed throughout the city and collected four times a day by the city staff. In addition to daily garbage collection, cleaning projects also take place. The cleaning projects occur frequently and are clearly evident in Walking Street. According to the meeting report of the Walking Street Committee, the area is cleaned monthly. If there is a water shortage, the cleaning can be postponed. Thus, some cleaning projects tend to be operated by the Walking Street Committee and other agencies that are not located in the cluster, as reflected by the following news report:

\footnotetext{
Walking Street received a spring clean last Thursday morning. Business owners, city cleaners, administrators, and representatives from the international group Youth With A Mission (Y-WAM) began the arduous task of scrubbing the street clean at 7.30 a.m.
}

(On-line news, Pattaya Mail, Vol. XIII No. 9, March 4 - 10, 2005)

With respect to the dispersed nightlife businesses, the cleaning activities are normally carried out in conjunction with the overall cleaning of the city. The cleaning activities undertaken by Pattaya City and the residents throughout the city were reported in the local news.

\subsubsection{Tourism promotion}

Pattaya City and TAT Central Region 3 office are responsible for promoting Walking Street and Pattaya's nightlife overall. Based on the interview responses, Walking Street is promoted as the main nightlife attraction in Pattaya. The dispersed nightlife businesses seem to be broadly marketed and contribute to the overall picture of Pattaya’s nightlife.

The entertainment area that we promote for tourism is Walking Street. ... For other areas, we promote them in general by providing information and building the signposts for clear directions for tourists. 
Because it is a nightlife cluster, Walking Street is well suited to hosting city events. It functions well as a gathering place. There are many people already in the area who are a ready audience for a festival. To promote Walking Street, multiple festivals and events are often held in the area. Chinese New Year, the Food Festival (see Figure 7.7), Christmas, and New Year are examples.

Figure 7.7: Festivals and events held in Walking Street.

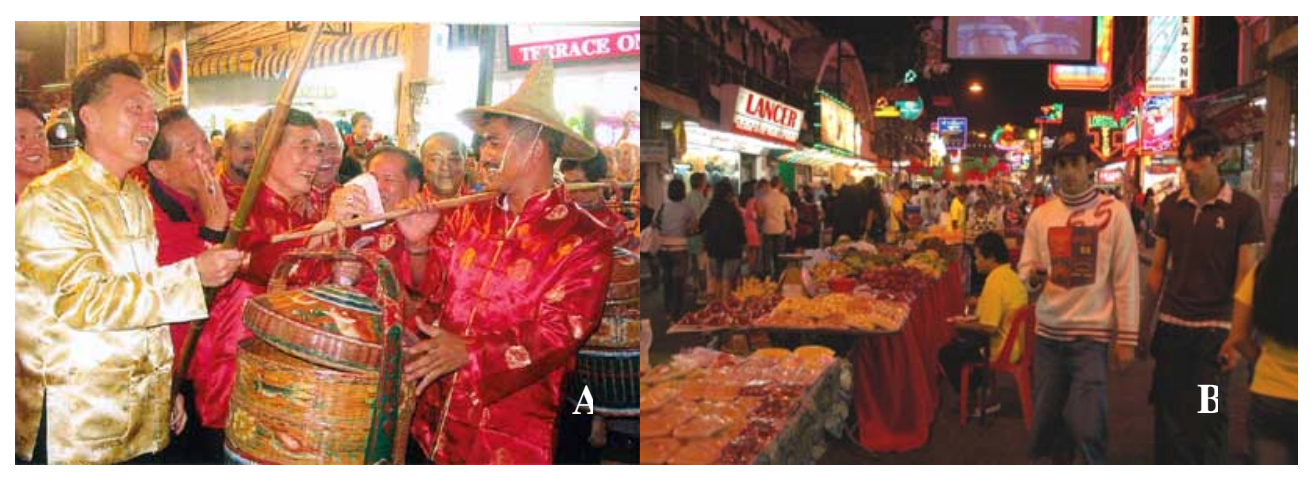

Source: pattayamail.com (2004)

Description of Illustration: Chinese New Year Festival (A) and Food Festival (B).

In carrying out festivals and events, sub-committees are formed and their responsibilities are clearly identified. The responsibilities of relevant agencies in organising Loy Krathong Festival (the cultural festival which is usually held in November of every year to thank the goddess of water) and the Beer Drinking Contest, presented below, are examples.

Six committees responsible for organising the Loy Krathong Festival are formed. They include the operational committee, area and opening ceremony committee, security and traffic committee, public relations committee, public health and cleanliness committee, and reception and general service committee. In each committee, the committee members are staff of Pattaya City, of other relevant agencies, and members of Walking Street Committee.

(Walking Street Meeting Report 5/2006 October 26, 2006)

The agencies responsible for operating the 'Beer Drinking Contest' are as followed:

1. Boonrod Trading Company Limited [the brewery] is responsible for organising the festival and providing 1,000 boxes of beers.

2. Local police, Pattaya station, is responsible for traffic and general safety.

3. The tourist police are responsible for general safety at the fair.

4. Pattaya City:

a. Division of Technical Service and Planning is responsible for stage construction and light decoration.

b. Security Division of the Office of the City's Chief Manager is responsible for traffic, parking space, and overall decorum and peace.

c. Division of Sanitary Work is responsible for cleaning a day before the festival. 
d. Public Relation Office of Division of Technical Service and Planning is responsible for printed media, press invitation, and English and Thai spokesperson arrangements.

e. Tourism Promotion and Development Section is responsible for cooperating with other divisions and agencies in operating the festival, also inviting guests and relevant operators, and sending thank-you letters.

(Walking Street Meeting Report 4/2006 August 2, 2006)

The types of festivals hosted can create positive or negative impacts on the city. The Loy Krathong Festival usually creates a positive impact since it promotes Thai culture to foreign tourists. In contrast, the Beer Drinking Contest tends to increase the number of drunken people who may create more problems and difficulties for safety and social order management. Providing "a good time” to tourists while ensuring their safety seems to be a challenge for the Walking Street Committee members. The festivals to promote nightlife tourism should be considered wisely.

This section indicates that multiple activities are carried out in managing Pattaya's nightlife. Single or multiple agencies are responsible for carrying out particular activities. Although similar activities are carried out in managing Walking Street and the dispersed businesses, they are undertaken to a greater extent on Walking Street. Since all activities are carried out by the Walking Street Committee members in managing the cluster, collective action in carrying out particular activities tends to be present. Since the responsibilities of relevant agencies tend to be independently and separately exercised in managing the dispersed businesses, collective action amongst these agencies is not evident. The management resources used in carrying out these activities in Walking Street and in the dispersed businesses are from several agencies; however, resource coordination is generally reflected in managing Walking Street only.

\subsection{Management resources}

Resources used in managing Pattaya's nightlife frequently come from several agencies. Sufficient resources used to carry out all activities, particularly relevant to safety and social order, seem crucial for nightlife management. Resource coordination is evident in managing Walking Street, but does not occur in the dispersed nightlife businesses. 
Table 7.5: Resource management in managing Pattaya's nightlife.

\begin{tabular}{|l|c|c|c|c|}
\hline \multicolumn{4}{|c|}{ Adequacy and coordination of management resources } \\
\hline & $\begin{array}{c}\text { Human } \\
\text { resources }\end{array}$ & Money & Materials & $\begin{array}{c}\text { Resource } \\
\text { coordination }\end{array}$ \\
\hline $\begin{array}{l}\text { Walking } \\
\text { Street }\end{array}$ & $\mathrm{X}$ & $\mathrm{X}$ & $\mathrm{X}$ & $\mathrm{X}$ \\
\hline $\begin{array}{l}\text { Dispersed } \\
\text { nightlife } \\
\text { businesses }\end{array}$ & $\begin{array}{c}\text { more } \\
\text { police } \\
\text { needed }\end{array}$ & $\mathrm{X}$ & $\mathrm{X}$ & $\begin{array}{c}\text { poor } \\
\text { coordination }\end{array}$ \\
\hline
\end{tabular}

Table 7.5 illustrates different resources used in managing Pattaya's nightlife. The ' $X$ ' marks indicate what resources are adequate. Although similar resources are used in managing Walking Street and the dispersed nightlife businesses, the amount of resources used tends to stand in contrast. For example, the number of staff members, particularly the police officers, are often insufficient in managing the dispersed businesses, while many security staff are present on Walking Street each night. Based on the local newspaper, crimes seem to occur frequently in Pattaya. Although many crimes generally occur at tourists' accommodations, more effort is required for safety. The volume of crime could indicate that the number of police is not enough or their work is not effective enough, particularly in managing the dispersed nightlife businesses. One respondent mentioned the limited numbers of police working in Pattaya. Based on her comment, the numbers of local police depend on the size of the city's registered residents. This criterion does not seem to suit Pattaya since the majority of its population are short-term migrants. There are approximately ten times more short-term migrants than registered residents, as discussed in Chapter 4. Also, the presence of all of the tourists adds to the workload of the police. To minimise the crime rate, more local police are necessary. One respondent from Pattaya City noted that many security staff work in Walking Street but they seem to work in a less effective fashion. His response indicated that a high number of staff may not necessarily lead to better management outcomes, but the quality of individual staff does:

Frankly, at the moment, we are trying to use fewer staff [in Walking Street]. In the past, we focused on numbers of staff. For example, we added more police when they said they didn't have enough. We added more staff when they said they didn't have enough. We added more 
vehicles and other equipment. However, all those we added did not work effectively as we expected. There might be many barriers or problems. ... At the moment, we are trying to use more technological instruments such as CCTV in our work. We will focus on the quality of staff. So, high number of staff will not be necessary.

(Local public 13)

One tourist police officer also indicated that money was important to increase the willingness of voluntary staff to participate more and to work more effectively. Money would be helpful to increase the willingness of official staff to work more effectively, but may not be necessary for volunteers. Other ways to motivate volunteers would be required. The acknowledgement or appreciation of their involvement with awards, medals, or certificates may be more helpful.

Moreover, Walking Street and the dispersed nightlife businesses are different in terms of resource coordination. According to the local newspaper, different agencies use their own resources to carry out their activities and responsibilities in managing the dispersed nightlife businesses. For example, Pattaya City uses money, human resources, and materials for the demolition of illegal buildings. These resources are used by the provincial or the district governments, or the police agencies in relation to the suppression of or closing down the illegal businesses. In contrast, in managing Walking Street, committee members cooperate in identifying issues and allocating management resources to address these issues. For example, money can come from Pattaya City's budget, individual businesses in the cluster, and sponsorship companies such as the brewery company. Human resources and materials also come from the public agencies and all businesses in the cluster. Resources are pooled and used in a way that is agreed upon by the members of the Walking Street Committee.

On a regular basis [in managing Walking Street], we do not do anything much, just cooperate with the tourist police for the area's safety and organisation. ... The Walking Street Committee is working in cooperation with the tourist police and the security staff of Pattaya City. The tourist police also train the voluntary residents, both Thais and foreigners. ... Money is provided by the City and sponsors. Human resources are from the committee members and the community.

(Local private 10)

This section illustrates the different practices used to manage resources. Resource management is more coordinated in Walking Street than amongst the more dispersed nightlife attractions. What makes Walking Street distinctive is not its access to more resources but its management of these resources. The agencies responsible are part of 
a formal group, the Walking Street Committee, that identifies and addresses priorities and issues. Some level of integration between relevant agencies is present in managing Walking Street.

\subsection{Management integration}

Relevant agencies tend to interact differently in managing the dispersed nightlife businesses and Walking Street. Their interactions can be categorised into two forms of relationships: dyadic and network. With regard to the inter-organisational relationship literature, a dyadic relationship represents an interaction between two agencies while a network relationship represents equal relationships amongst multiple agencies (R. H. Hall, 1987; Selin \& Chavez, 1995). A dyadic relationship usually occurs in managing the dispersed nightlife businesses, while a network relationship is reflected in managing Walking Street. The extent of the relationships between relevant agencies in each form of relationship tends to be different. The interactions between relevant agencies generally appear in vertical and/or horizontal directions, described in the previous chapter.

The dyadic relationships between public and private agencies and between Pattaya City and other public agencies tend to occur in managing the dispersed nightlife businesses. As discussed in beach management, sets of single dyadic relationships tend to create a low level of integration in management. Similarly, dyadic relationships normally create a low level of integration in managing the dispersed nightlife businesses. The issues relevant to Pattaya City's administrative system such as the limited authority in managing particular issues, raised in the previous chapters, were also commented on by Pattaya City's staff. These issues often cause a low level of integration in the dispersed nightlife businesses.

Frankly, we are still under the provincial governmental office. Some people understand that we are a special form of local government so we seem to be autonomous. In reality, we are not autonomous, and are still under the provincial government.

(Local public 13)

A similar issue was also reflected in the local newspaper. When an incident occurs, it can be seen that both Pattaya City and relevant public agencies do not want to admit their mistakes. They seem to put the blame on each other. Beer bar 
businesses are an example since they are a major type of nightlife businesses. Based on the review of the Building Control Act 1979 and the Entertainment Business Act 1966, beer bar businesses are not directly mentioned and it is hard to see how they fit under the business categories stated in the two acts. These two laws are implemented by different agencies. Based on the Building Control Act 1979, Pattaya City is responsible for authorising building construction in the area and issuing of building use licences after construction is completed, while the district government is responsible for authorising/issuing business licences based on the Entertainment Act 1966. The beer bar owners must be authorised by Pattaya City to construct their shops. After a construction is complete and the licence to use the building from Pattaya City is received, bar owners can apply for business licences from the district government. When there are complaints regarding particular beer bars, both agencies (Pattaya City and the district government) claim that they follow the laws. They do not seem to accept that they fail to effectively enforce the law. This issue tends to minimise the efficiency and effectiveness of management practice.

\begin{abstract}
Mr.Suraphol Tiensuwan, the district governor, said that the district office always receives complaints from the residents. For go-go bars that don't have licences, he said that he already ordered the closing down of those businesses. For beer bars, which are not in any service categories, he had already contacted Pattaya's mayor to examine whether they had permission or licences regarding building use and public health because it was the responsibility of Pattaya City. If Pattaya City finds out that these beer bars are illegal according to the building control regulations, the City has absolute authority to follow the procedure. ... Mr. Pirat Suthithamrongsawat, Pattaya's mayor, said that the City has the authority to examine building usage with respect to the Building Control Act and the Public Health and Environments Act. If there is any impeachment in relation to those acts, he will ask the district governor to withdraw the business licence immediately.
\end{abstract}

(Pattaya Post, Vol. 5 Issue 128, page 2, September 1 - 10, 2003)

Collective action between relevant agencies normally occurs in managing Walking Street. In managing Walking Street, a formal form of collective action appears in the Walking Street Committee, as described in the earlier section. Normally, there are monthly meetings to report, discuss, and follow up issues raised from the previous meetings. As evident in the meeting reports, most topics discussed in the meetings relate to marketing activities and general issues that need consideration and solutions from committee members. Issues from a meeting are usually followed up in the next meeting. The dyadic relationship between relevant agencies may occur in carrying out particular activities. Thus, sub-committees may be formed to carry out those activities, 
as mentioned in the section on management activities. Monthly meetings can be perceived as a means to monitor and control management practice. Feedback and complaints from residents, businesses, and tourists tend to be used to evaluate management outcomes. Based on meeting observation, all relevant agencies represented on the Walking Street Committee tend to have an equal voice. The committee president and vice president do not seem to have any formal authority over committee members, but are able to make decisions and monitor operational progress in order to ensure overall management outcomes. A network relationship is often reflected in their interactions (see Figure 7.8).

Figure 7.8: The network relationship of the Walking Street Committee.

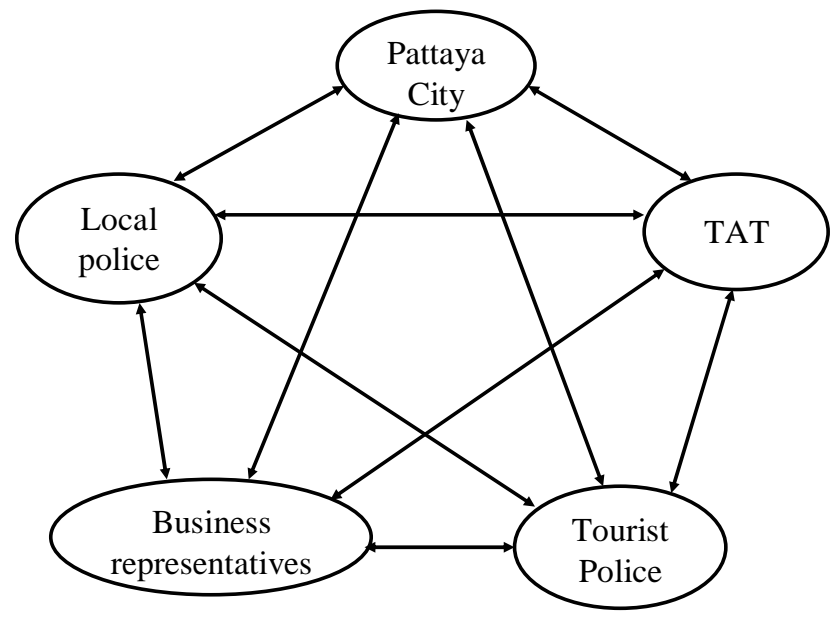

The responsibilities are shared by relevant committee members, as described in section 7.4. The issue of endangered animals and their minders is an example. Pattaya's security staff and the tourist police are responsible for arresting these animal caretakers, and taking them to the local police station to pay a fine. Pattaya City, as the municipality, has to write an official letter to inform the Ministry of Natural Resources that they will soon receive the endangered animal. Most activities undertaken in managing Walking Street generally happens throughout the city because Pattaya City has a prime responsibility in managing the city overall. Since Pattaya City has most of the resources required for management, it tends to benefit the management of Walking Street. Thus, the committee's president and vicepresident are able to manage the area more effectively if they are from Pattaya City, particularly when the committee president is the mayor. As indicated by the 
following respondent, when the mayor is elected to be committee president, things generally work faster to the satisfaction of all members. Although the mayor, as committee president, has no control over other committee members, at least s/he has the authority to directly order and control Pattaya’s staff for a quick result.

[In terms of coordination] we do it through the City. For example, if we want them to clean the area, we raise the issue in the meeting. As for the private agencies, it might be difficult for us [to get involvement from the city staff]. When the mayor is the committee president, he can directly command the city staff to do it. The operation is faster and more flexible. The activities we do are always stated in the meeting agenda. ...

(Local private 10)

In contrast to the management of dispersed nightlife businesses, a high level of integration is reflected through the network relationship in managing Walking Street. Thus, the goal to manage Walking Street is developed and commonly understood by committee members. With a common goal, although it is rather broad, activities required to manage the area can be more easily identified. The coordination of management resources from the committee members is clearly evident. Monthly meetings are used to obtain the cooperation of committee members and to monitor management progress. Although the committee president cannot control the operations of committee members, s/he is able to monitor the progress of management initiatives. The control function does not seem to be directly or bluntly used. However, willingness to participate and open discussion amongst all members in the meetings generally bring better understanding and cooperation in practice.

\subsection{Discussion and conclusion}

This chapter has discussed how Pattaya's nightlife is managed. It can be concluded that several agencies are involved in carrying out multiple activities in relation to nightlife management. However, it shows that Walking Street and the dispersed nightlife businesses are managed separately and differently. Walking Street and the dispersed nightlife businesses stand in contrast to each other in management practice and levels of integration. The management of Walking Street is structured and intensive, while the management in the dispersed nightlife businesses is the opposite. Integration, as the core concept of destination management discussed in the earlier chapters, occurs only in managing Walking Street. The practices in managing 
Walking Street and the dispersed nightlife businesses are summarised below (see Table 7.6).

Table 7.6: A summary of nightlife management in Pattaya.

\begin{tabular}{|c|c|c|}
\hline $\begin{array}{c}\text { Management } \\
\text { aspects }\end{array}$ & Walking Street & Dispersed nightlife businesses \\
\hline $\begin{array}{l}\text { Management } \\
\text { agencies }\end{array}$ & $\begin{array}{l}\text { - The Walking Street Committee } \\
\text { - Multiple public and private agencies are involved as } \\
\text { Walking Street Committee members } \\
\text { - National to local public agencies are involved, but } \\
\text { only Walking Street businesses are involved } \\
\text { - Some public agencies are involved without being } \\
\text { committee members (for example, district government) }\end{array}$ & $\begin{array}{l}\text { - No committee } \\
\text { - Multiple public agencies are involved } \\
\text { - Beer Bar Business Association is involved, but } \\
\text { has little influence }\end{array}$ \\
\hline $\begin{array}{l}\text { Management } \\
\text { purposes }\end{array}$ & $\begin{array}{l}\text { - To achieve a common goal: Promote the area as a } \\
\text { major tourist attraction } \\
\text { - To achieve organizational goals (public sector: social } \\
\text { order and safety, private sector: business goals) }\end{array}$ & $\begin{array}{l}\text { - To achieve organizational goals (public sector: } \\
\text { social order and safety, private sector: business } \\
\text { goals) }\end{array}$ \\
\hline $\begin{array}{l}\text { Management } \\
\text { activities }\end{array}$ & $\begin{array}{l}\text { - Activities relevant to safety, social order, cleanliness, and } \\
\text { tourism promotion are carried out to a greater extent in the area } \\
\text { - Multiple events/festivals are used to promote the area }\end{array}$ & $\begin{array}{l}\text { - Activities relevant to safety and social order are carried } \\
\text { out for nightlife management overall } \\
\text { - Activities relevant to cleanliness are evident as part of } \\
\text { city management overall } \\
\text { - Activities relevant to tourism promotion are undertaken } \\
\text { for marketing Pattaya overall }\end{array}$ \\
\hline $\begin{array}{l}\text { Management } \\
\text { resources }\end{array}$ & $\begin{array}{l}\text { - Resources are from different agencies responsible for } \\
\text { particular activities } \\
\text { - Resource coordination is evident }\end{array}$ & $\begin{array}{l}\text { - Resources are from different agencies responsible for } \\
\text { particular activities } \\
\text { - Resource coordination is not present }\end{array}$ \\
\hline $\begin{array}{l}\text { Management } \\
\text { integration }\end{array}$ & $\begin{array}{l}\text { - The Walking Street Committee represents a formal form of } \\
\text { coordinating relevant agencies } \\
\text { - Interaction between committee members occurs in a network } \\
\text { relationship } \\
\text { - A high level of integration is present }\end{array}$ & $\begin{array}{l}\text { - Limited coordination } \\
\text { - Interaction between relevant agencies tend to appear in } \\
\text { the form of a dyadic relationship } \\
\text { - A low level of integration is present }\end{array}$ \\
\hline
\end{tabular}

With respect to the management of Walking Street, the findings show that a high level of integration is reflected throughout the management process. Management is formally structured through the Walking Street Committee. The committee represents a formal coordinating unit that is collectively responsible for the daily operation of the area. The goal to create Walking Street as a major attraction, that was officially developed and mutually agreed upon by the committee members, tends to provide common understanding of what they are to achieve. With a common goal or goals, management activities are usually carried out in a more focused way. Responsibility for particular activities is shared by all members. Resources used in management are also provided by them. Management functions (planning, 
organising, monitoring, and controlling) are exercised by the committee members in the monthly meetings to follow up with progress and to evaluate management outcomes. These functions are also used to get coordination and cooperation from all committee members. All these practices help enable the committee members to manage Walking Street in a way to achieve its prime goal, to be a major tourism attraction. It could be seen that management is more effective when a common goal or goals exist. It could also be seen that the management practice is effective because of the small size of Walking Street; however, the management outcome would be different if there was no strong desire or willingness of its committee members to work together. Walking Street represents how a nightlife attraction should be managed but the management of Walking Street does not represent nightlife management in Pattaya overall as most nightlife businesses are outside the cluster and dispersed throughout the city.

The management of the dispersed nightlife businesses reflects a low level of integration. Although similar public agencies are involved in managing the dispersed businesses, a formal coordinating unit does not exist. There is also little cooperation between relevant agencies since no evidence of collective action can be seen. Although relevant public agencies may interact through single dyadic relationships, there is no evidence of some cooperation. Thus, their management purposes are varied since the management agencies aim to achieve their own organisational goals. These organisational goals are similar in that they emphasise safety and social order but they are not implemented in an integrated manner. Likewise, individual businesses aim to achieve their business goals which are unrelated to each others. Common goals are not formally established by individual organisations. In this regard, management activities are undertaken separately and independently. Although similar activities are undertaken by several agencies, shared responsibilities between relevant agencies do not exist. Individual agencies tend to exercise their responsibilities separately and independently. Resources used in management come from different agencies but are poorly coordinated. When compared with the management of Walking Street, the management of dispersed nightlife businesses tends to be less successful. It could be seen that lack of coordination minimises success. A lack of a coordinating unit and common goals can 
also create ineffective management practice. The management issues such as the complex nature of bureaucracy and the administrative system of Pattaya City, described in the earlier chapters, could obstruct working collaborations between relevant agencies. Thus, a lack of serious implementation of laws by the public agencies, such as Pattaya City and the district government office, can minimise management efficiency and effectiveness. As the area is rather big, dividing this area into smaller, more manageable clusters could promote more effective management. A committee, similar to that for Walking Street, could also be used in managing those clusters.

In short, a high level and a low level of integration are reflected in managing Pattaya's nightlife. The management of Walking Street reflects a high level of integration, while the management of the dispersed businesses reflects a low level. It could be seen that a high level of integration of Walking Street is a result of the cooperation between its committee members throughout the management process. As relevant agencies are working together on a committee, it seems that they can openly communicate and discuss activities required in management and the types and amount of resources required in carrying out those activities. This approach seems to help them to manage the area to achieve its main goal, to be a major tourism attraction of Pattaya. With respect to the size of Walking Street, management activities and functions can be easier to exercise in a small more focused area. Management can be more difficult and less integrated in a large dispersed area.

The research findings also show that willingness to cooperate depends on the extent of the relationship between relevant agencies. Strong relationships between relevant agencies could create a high level of cooperation, while weak ones will obstruct or minimise cooperation. It can be seen that the municipality is willing to help or cooperate with the businesses, while the businesses are not always willing to cooperate with each other. The cooperation between the municipality and the local businesses to develop Walking Street, as described earlier, occurs because of the mutual interests between both groups. Their cooperation also reflects strong relationships between local politicians and businesses in the Walking Street cluster. 
In contrast, the relationships among private agencies outside of Walking Street seem to be weak. The respondent from the Beer Bar Business Association noted that most beer bar owners may not want to get involved in the association if short-term benefits could not be seen. Willingness or the desire of relevant agencies to cooperate with each other is crucial for effective management.

With respect to overall nightlife management, issues (e.g., garbage, peddlers, and beggars) identified in an earlier section tend to reflect the way Pattaya's nightlife is managed. Based on site observation, the management of Walking Street is more effective than that of the dispersed nightlife businesses, especially regarding safety. The presence of security staff helps create a safe atmosphere, which could also be used to promote the destination. As thousands of tourists visit the areas, the ability of individual staff to work efficiently and the cooperation of relevant staff seem to be important in bringing out effective management in the area. Overall, management relies on volunteers for successful outcomes but might have to look at ways of improving volunteer motivation. Moreover, other activities such as cleanliness are necessary to improve the overall quality and physical condition of Pattaya's nightlife. At the site, some garbage, prostitutes, peddlers, beggars, and endangered animal caretakers can be seen in the Walking Street cluster and in other areas of the city. Strong waste water odours from the drains can be smelled, particularly at the end of Beach Road and along Walking Street. These issues need to be solved in order to make Pattaya’s nightlife district more appealing.

This chapter has examined the management of Pattaya's nightlife. Different aspects were identified and discussed to bring a better understanding as to how the destination is managed in the context of nightlife management. The findings of this chapter are that several agencies are involved in managing Pattaya's nightlife. However, this chapter shows that a high level of integration can occur through a formal coordinating unit such as the Walking Street Committee. Management can be more effective when a common goal or goals exist. The common goals tend to bring clear direction to management. With clear direction, all activities can be identified and carried out in an integrated and focused fashion. 
The management case studies identified and discussed in this chapter and the previous chapter help bring better understanding of how the destination is managed, particularly in the daily operation of tourism resources. In the next chapter, Chapter 8, the management of the Pattaya Music Festival will be presented and discussed. By using a similar structure, the next chapter will provide better understanding of how a tourism project is managed at the local destination, especially when compared to daily operations and to what extent it can correspond to destination management. Then, the findings regarding the operation of daily tourism resources and a tourism project will be brought together in Chapter 9. The similarities and differences in managing these three main tourism resources (the beach, the nightlife, and a festival) will be discussed and what they say about destination management practised in Pattaya will be identified. The lessons learned from these case studies will also be identified and described in the final chapter. 


\section{Chapter 8 Festival Management: the Pattaya Music Festival}

\subsection{Introduction}

In this chapter, Pattaya Music Festival, perceived as one of the major festivals in Pattaya, is used as another case study to explore destination management. The same methods, mentioned in the last two chapters, were used to collect data regarding festival management. This chapter is also structured similarly to the previous two. First, background information about the festival is provided. Second, key agencies involved in managing the festival and their management purposes are identified to provide the context for further analysis and discussion. Then, activities undertaken by them and resources used in carrying out the festival are identified. Finally, the integration of relevant agencies in managing the festival is clarified. All these aspects are brought together for a final discussion and to identify the degree of integration that occurs in managing Pattaya Music Festival.

\subsection{Characteristics of the festival}

As mentioned in Chapter 4, many events and festivals are organized in Pattaya every year. They can be categorized into two groups: those developed by Pattaya City and those by other agencies. Pattaya Music Festival is in the latter group. Pattaya Music Festival is promoted as one of the major festivals in the city. It is developed by the Tourism Authority of Thailand (TAT) under the auspices of a project called “Thailand Grand Festival”. Under this project, one grand festival is developed in each month of the year (see Table 8.1). Major towns or cities are selected as the hosts. Their main tourism resources (for example, the Fruit Festival is in Rayong, Chanthaburi, and Trat provinces where there are many orchards) correspond to the festival concepts and themes. The Music Festival is part of the broader themes seen in March: music and sport, and Pattaya is selected as the venue. 
Table 8.1: Thailand Grand Festivals organized by Tourism Authority of Thailand.

\begin{tabular}{|l|l|l|}
\hline \multicolumn{1}{|c|}{ Months } & \multicolumn{1}{|c|}{ Concepts } & \multicolumn{1}{c|}{ Themes } \\
\hline January & Art and cultural month & Legends of Kingdom \\
\hline February & Flower festival & Flower Paradise \\
\hline March & Music and sport festival & Summer Music \& Sport Festival \\
\hline April & Songkran Festival & Songkran Splendours \\
\hline May & Fruit season & Thai Fruit Festival \\
\hline June & Ecotourism & Green Adventure Festival \\
\hline July & Thailand Arts and Crafts & Timeless Thai Elegance \\
\hline August & Children take mothers for trips & Family Fun Fair \\
\hline September & Royal Barge & International Boat Races \\
\hline October & Amazing Mekong River & The Magnificent Mekong River \\
\hline November & Thai lives and rivers & Loy Krathong Festival \\
\hline December & Thailand Celebration & Thailand Extravaganza \\
\hline
\end{tabular}

Source: The Tourism Authority of Thailand (2002)

According to interviews with the TAT staff, Pattaya is chosen because of its location and its variety of tourism-related services. With its diverse tourism-related services, Pattaya is perceived as being able to cater various groups and large numbers of tourists. Since Pattaya is less popular for Thai tourists, the festival tends to be used to attract more Thai tourists, particularly teenagers. Moreover, an attempt to minimize its negative image by initiating an image of a music city was reflected in the responses of public officials.

We think that Pattaya is very close to Bangkok and it is the beach resort. Thus, it is an international city. We also want to revive its image. Since its natural environment [sea water quality] has been improved, we want to portray Pattaya as the music city. Why we don't choose other beach resorts such as Hua Hin [a beach resort in the south-west of the country which is quieter] is because we perceive that this music festival is related to pop and rock music or any similar types that are for teenagers and young people. Not like jazz, we promote only jazz music in Hua Hin. These are reasons to choose Pattaya.

(National public 1)

TAT is responsible for creating the concept of the festival which is music at the beach resort. The destination [festival site] should have beaches. We are trying to organise the festival within the area that is not far from the beaches. ... Pattaya [is selected because it] is perceived to be a fun resort city as it seems to focus on entertainment and recreation.

(Regional public 1) 
Pattaya Music Festival has been organized in Pattaya since 2002. It is usually held in the third weekend of March every year. It is a three-day free concert with various singers (both Thai and foreigner). Their music is broadly categorized into three different types. Different colours are used to symbolise different music categories, which are also used to represent the different performing stages (see Figure 8.1). In promoting the festival, brochures handed out to the public provide this information and locations of the stages (see Figure 8.1 and Figure 8.2)

Figure 8.1: An example of a brochure that provides information regarding the festival in 2004.

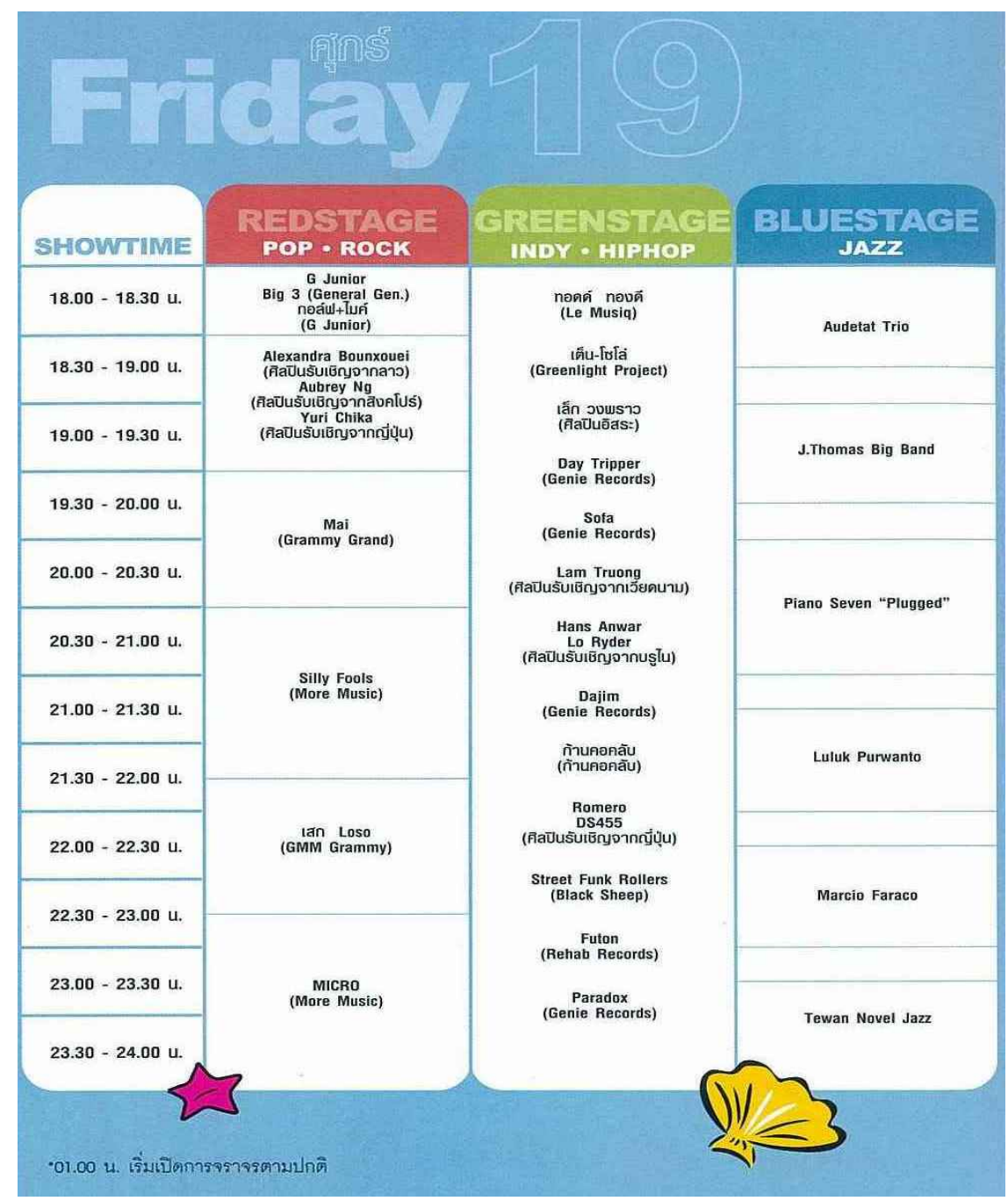

Source: The Tourism Authority of Thailand (2006)

According to reports about the Pattaya Music Festival from 2004 and 2005, approximately 300,000 tourists attend the festival each year. The evidence showed that this event requires large open spaces that can contain large numbers of people. 
Since Pattaya is filled with buildings and shops, to find a large public space becomes an issue in managing the festival, as noted by Pattaya City's staff. Although the municipality may have public spaces in other areas of the city, those areas are located far from the beaches. To correspond to the festival theme, the performing stages need to be located near the beaches. The locations of the performing stages usually change every year because suitable open space is so scarce, in part, because of urban development (see Figure 8.2). To solve this issue in the future, the performing stages may need to be located on different beaches in Pattaya.

For the music festival, we have a problem about the public area because we [Pattaya City] don't have our own land. For example, there were three performing stages last year. We had to borrow two properties from the private sector [to establish two performing stages]. One stage was on our land, the Bali Hai pier. This will also be a problem in the future. Otherwise, the stages might need to be located close to the roads or on the beaches.

(Local public 12)

For the performing areas, I suggested the central officers [from TAT Bangkok office] see the areas for themselves because there is no public space. Only Bali Hai pier is available. A hotel and a shopping mall are now established in the areas that we used last year. So, they [the staff of the TAT Bangkok] must come down here [to Pattaya] to see for themselves because the areas need to match with the festival concept. If the performing areas are far from the beaches, it will not match the festival concept.

(Regional public 1)

To find a large public space does not seem to be the only issue that the agencies must be concerned about in managing the festival. As mentioned by the interview respondents, facilities such as public toilets and parking spaces provided for tourists are also necessary for festival management. These issues must be handled by the responsible agencies to bring about a successful outcome. Good planning and preparation of the festival seems to be crucial for effective management practice and a successful outcome. Multiple agencies are involved in managing Pattaya Music Festival. 
Figure 8.2: Locations of the stages in A, 2003 and B, 2004

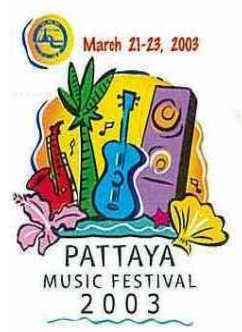

A

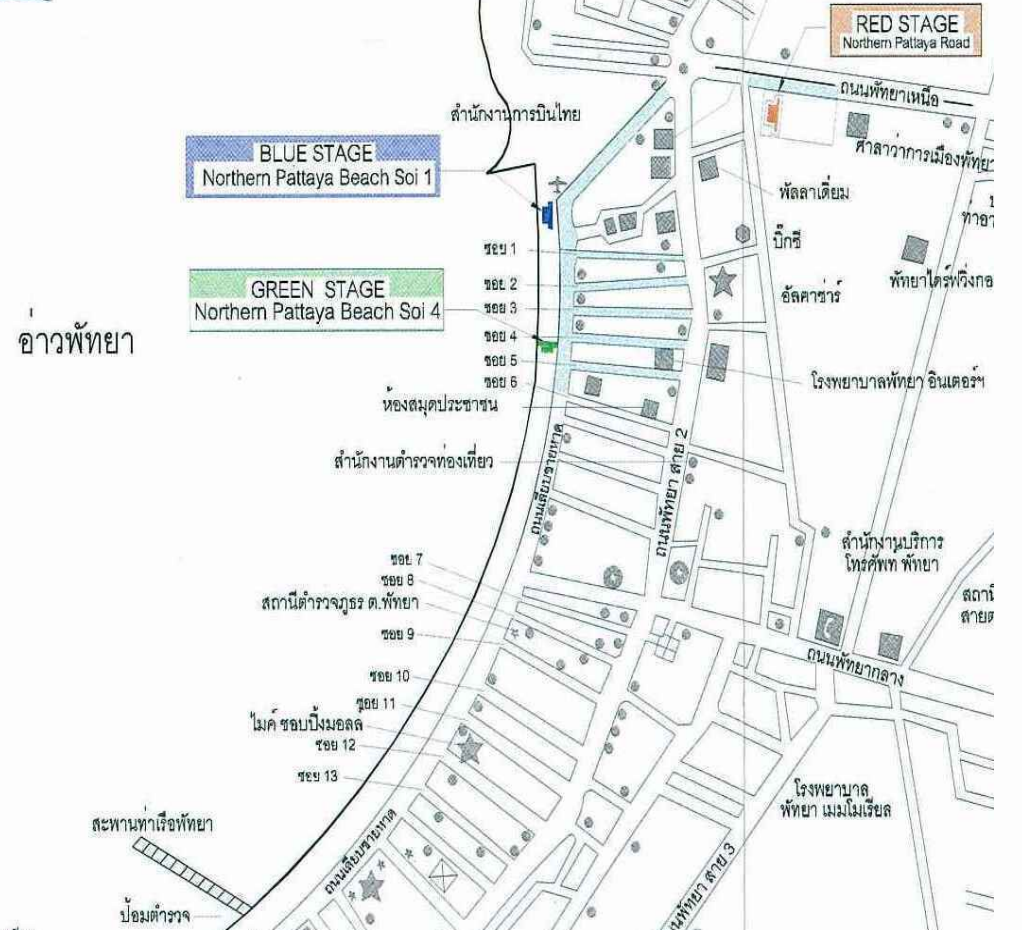

Source: The Tourism Authority of Thailand (2006)
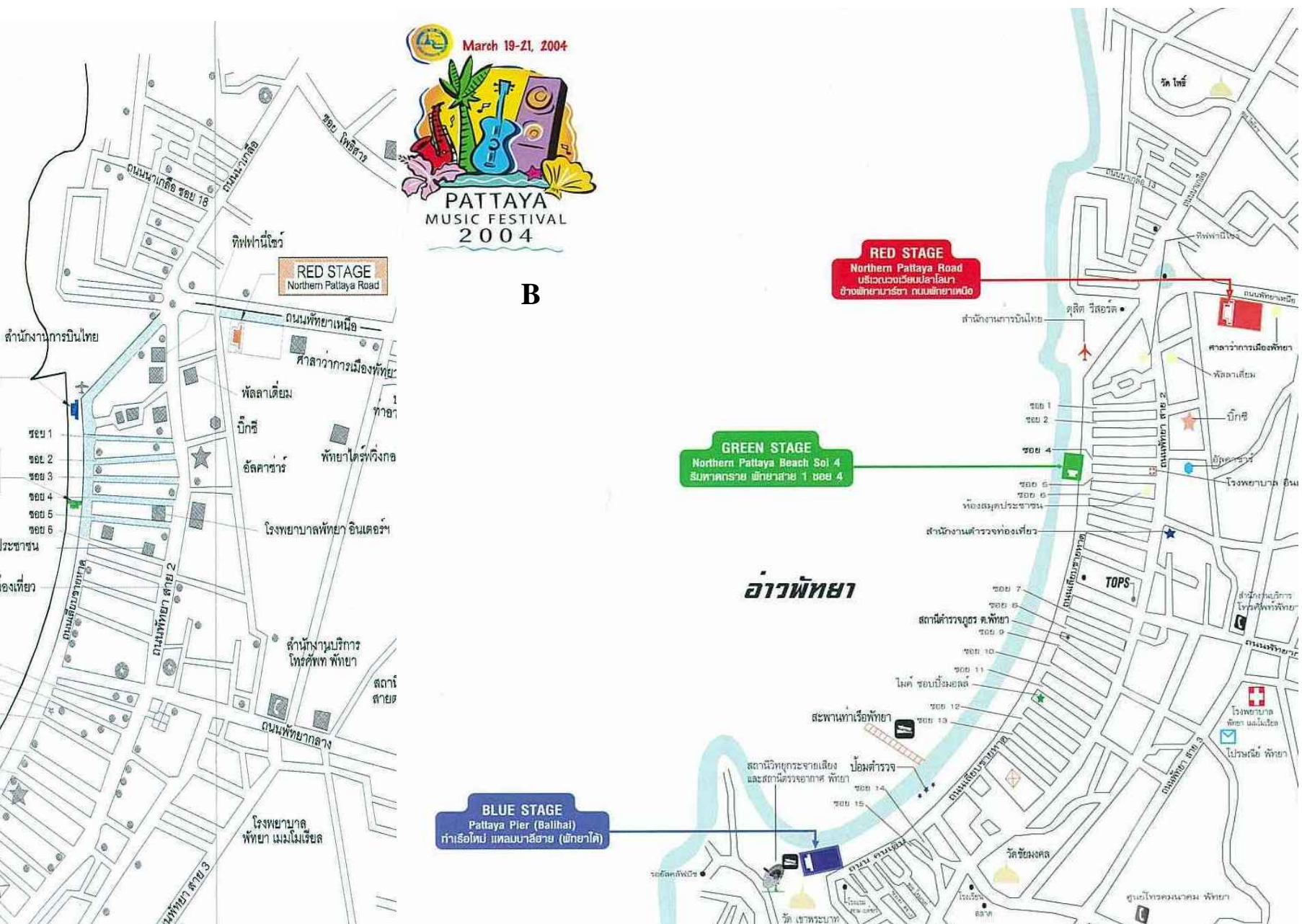


\subsection{Management agencies and their purposes}

Multiple public and private agencies from national to local scales are involved in managing Pattaya Music Festival. Several formal committees have been established. These committees generally work collectively to achieve the festival's goals. The management structure of the festival is illustrated in Figure 8.3.

Figure 8.3: Management structure for Pattaya Music Festival.

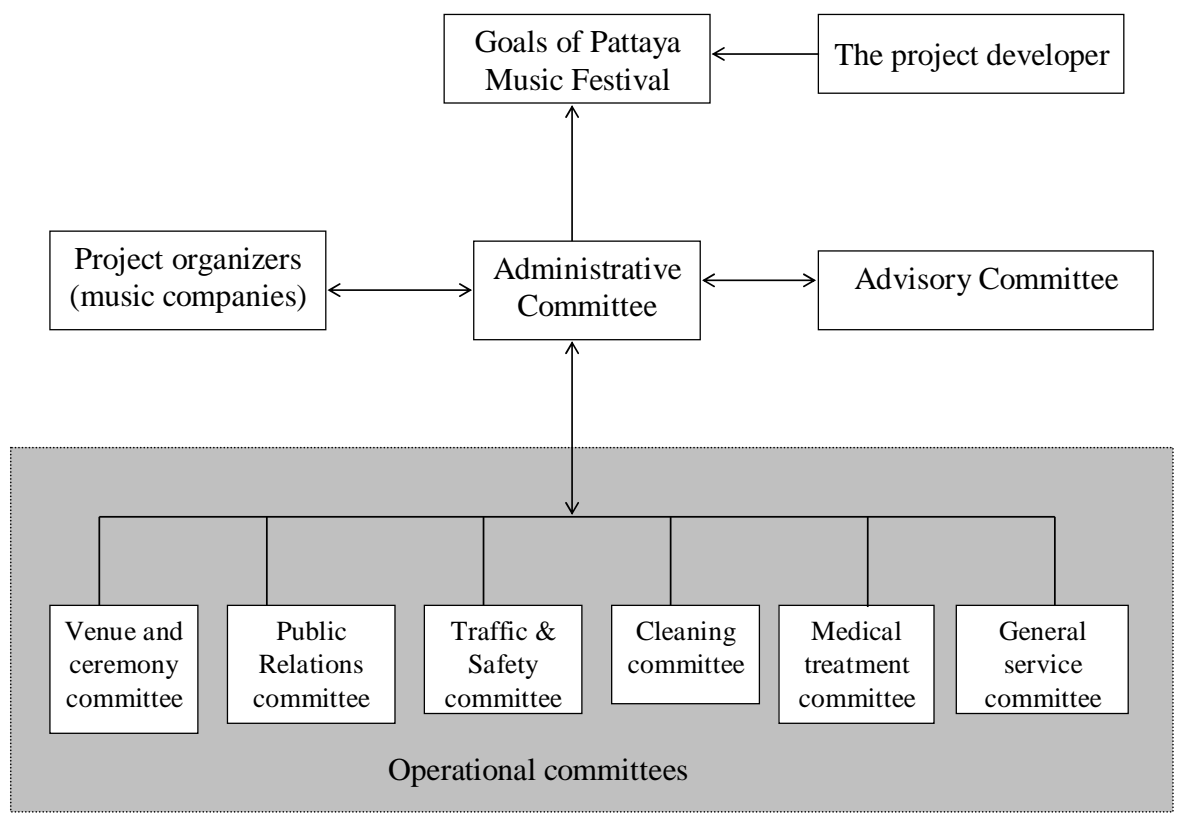

As shown in Figure 8.3, the agencies involved in managing the festival can be categorized into the project developer, the project organizers, and various committees. TAT is the project developer and responsible for initiating the festival. It is also represented on all committees. The music companies are the project organizers. Other public and private agencies are involved in different committees. Most agencies are involved in the committees related to the tasks they perform.

The main host is the TAT Bangkok office. We [TAT Central Region 3 office] represent a second host to coordinate with other agencies in the area. We have to create several operational committees. The Pattaya City and Chonburi governments must cooperate with us. Normally, the provincial governor will appoint different committees. The medical treatment committee, safety committee, and cleaning committee are examples. These committee members will discuss and plan for the operation of the festival overall.

(Regional public 1) 
According to the 429/2005 Official Announcement by the Chonburi governor regarding appointed committees for Pattaya Music Festival 2005, eight committees are officially formed by the Chonburi provincial governor. They are an advisory committee, an administrative committee, and six operational committees. The administrative committee interacts with the project organizers (which are the music companies), the advisory committee, and the operational committees. It is responsible for the overall management of the festival and made up of the executives and vice-executives of all the public agencies. The advisory committee provides guidance and support to the administrative committee. Its membership also consists of the executives and vice-executives of all the public agencies and is very similar in composition to the administrative committee. The operational committees include the venue and ceremony committee, public relations committee, traffic and safety committee, cleaning committee, medical treatment committee, and general service committee. The membership of each operational committee consists of viceexecutives and heads of divisions/departments of relevant public agencies. The presidents and vice-presidents of the private agencies are also appointed to be members of the public relations committee, safety and traffic committee, and medical treatment committee. All of these agencies seek to manage the festival to achieve its goals. The goals of the festival are developed by TAT Bangkok. Other agencies involved 'buy into' these goals. The agencies involved in managing the festival and its goals are summarized in Table 8.2.

For the music festival, TAT is the project developer. Pattaya City is like a site owner. We [Pattaya City's government] are responsible for most works operating in the area such as traffic and safety. We have to coordinate with other agencies. ... There is a name list identifying different committees, committee members, the presidents, and the secretaries. There are meetings within each committee. There are also big meetings to follow up the work of all operational committees.

(Local public 12) 
Table 8.2: A summary of management agencies involved in the different committees.

\begin{tabular}{|c|c|c|c|c|c|c|c|}
\hline \multicolumn{8}{|c|}{ Pattaya Music Festival } \\
\hline $\begin{array}{l}\text { Administrative } \\
\text { committee }\end{array}$ & $\begin{array}{l}\text { Advisory } \\
\text { committee }\end{array}$ & $\begin{array}{l}\text { Public relations } \\
\text { committee }\end{array}$ & $\begin{array}{l}\text { Traffic \& Safety } \\
\text { committee }\end{array}$ & $\begin{array}{c}\text { Procedure \& } \\
\text { Arena committee }\end{array}$ & $\begin{array}{c}\text { Medical } \\
\text { treatment } \\
\text { committee }\end{array}$ & $\begin{array}{l}\text { Cleaning } \\
\text { committee }\end{array}$ & $\begin{array}{c}\text { General } \\
\text { service } \\
\text { committee }\end{array}$ \\
\hline $\begin{array}{l}\text { Provincial } \\
\text { governor's } \\
\text { deputies }\end{array}$ & $\begin{array}{l}\text { Provincial } \\
\text { governor }\end{array}$ & $\begin{array}{l}\text { TAT, Bangkok } \\
\text { and Central } \\
\text { Region } 3 \text { offices }\end{array}$ & $\begin{array}{l}\text { Provincial to local } \\
\text { police }\end{array}$ & Pattaya City & Pattaya City & Pattaya City & Pattaya City \\
\hline Provincial police & $\begin{array}{l}\text { TAT's governor } \\
\text { and deputies, } \\
\text { Bangkok office }\end{array}$ & $\begin{array}{l}\text { Provincial public } \\
\text { relation office }\end{array}$ & Pattaya City & $\begin{array}{l}\text { TAT Central } \\
\text { Region } 3\end{array}$ & $\begin{array}{l}\text { Banglamung } \\
\text { Hospital }\end{array}$ & $\begin{array}{l}\text { TAT, Central } \\
\text { Region } 3\end{array}$ & Local police \\
\hline $\begin{array}{l}\text { Provincial } \\
\text { Administration } \\
\text { Organisation's } \\
\text { governor }\end{array}$ & $\begin{array}{l}\text { Chonburi, region } 6 \\
\text { politician } \\
\text { representatives }\end{array}$ & $\begin{array}{l}\text { Provincial radio } \\
\text { station office }\end{array}$ & $\begin{array}{l}\text { Royal Thai Army, } \\
\text { Base } 14\end{array}$ & $\begin{array}{l}\text { Electric Supply, } \\
\text { Banglamung } \\
\text { office }\end{array}$ & $\begin{array}{l}\text { Phayathai } \\
\text { Sriracha } \\
\text { Hospital }\end{array}$ & & $\begin{array}{l}\text { TAT, Central } \\
\text { Region } 3\end{array}$ \\
\hline District governor & $\begin{array}{l}\text { Royal Thai Navy, } \\
\text { Sattahip Base }\end{array}$ & Navy radio station & $\begin{array}{l}\text { Royal Thai Navy, } \\
\text { Sattahip Base }\end{array}$ & Local police & $\begin{array}{l}\text { Pattaya } \\
\text { Memorial } \\
\text { Hospital }\end{array}$ & & \\
\hline $\begin{array}{l}\text { Pattaya City's } \\
\text { government }\end{array}$ & $\begin{array}{l}\text { Royal Thai Army, } \\
\text { Base } 14\end{array}$ & $\begin{array}{l}\text { Pattaya City, } \\
\text { tourism division }\end{array}$ & $\begin{array}{l}\text { Tourist police, } \\
\text { Region } 3\end{array}$ & & $\begin{array}{l}\text { Bangkok- } \\
\text { Pattaya } \\
\text { Hospital }\end{array}$ & & \\
\hline $\begin{array}{l}\text { TAT Central } \\
\text { Region } 3\end{array}$ & $\begin{array}{l}\text { Royal Thai Police, } \\
\text { Area } 2\end{array}$ & $\begin{array}{l}\text { Pattaya Press } \\
\text { Association }\end{array}$ & $\begin{array}{l}\text { Highway police, } \\
\text { office } 3\end{array}$ & & $\begin{array}{l}\text { TAT, Central } \\
\text { Region } 3\end{array}$ & & \\
\hline \multirow[t]{5}{*}{$\begin{array}{l}\text { Provincial office, } \\
\text { Tourism and Sport } \\
\text { Dept }\end{array}$} & Pattaya’s Mayor & $\begin{array}{l}\text { Pattaya Tourism } \\
\text { Business } \\
\text { Association }\end{array}$ & $\begin{array}{l}\text { Pattaya Bus } \\
\text { Co-operative, Ltd. }\end{array}$ & & & & \\
\hline & & Pattaya Hotel Club & Volunteer groups & & & & \\
\hline & & $\begin{array}{l}\text { Pattaya Restaurant } \\
\text { Club }\end{array}$ & $\begin{array}{l}\text { TAT, Central } \\
\text { region } 3\end{array}$ & & & & \\
\hline & & $\begin{array}{l}\text { Eastern Region } \\
\text { Hotel Association }\end{array}$ & & & & & \\
\hline & & $\begin{array}{l}\text { Chonburi Tourism } \\
\text { Attraction Club }\end{array}$ & & & & & \\
\hline \multicolumn{8}{|c|}{ Management purpose: To achieve the goals of Pattaya Music Festival } \\
\hline
\end{tabular}

Table 8.2 indicates the multiple agencies involved in managing the festival with a common purpose. Some agencies, such as Pattaya City and TAT offices, are appointed to all committees, while some agencies are appointed to one or a few committees. Tourism Authority of Thailand, Bangkok office and Pattaya City are prime agencies responsible for much of the management of the festival. TAT Bangkok office as the project developer is responsible for the project overall. It provides the budget and decides the festival concept, stage themes, and opening and closing ceremonies. It also deals with the music companies and coordinates activities with other agencies through TAT Central Region 3 office. The music companies are involved as the project organizers, while other agencies are involved as project operators. Pattaya City, as the municipality, acts as a site manager that provides all required facilities and coordinates with the music companies and other agencies. 
Other agencies, those involved in managing the festival, are from public and private agencies and are from national to local scales. All agencies involved in managing the festival generally share a common purpose, to achieve the festival's goals.

The goals of Pattaya Music Festival are developed by the TAT Bangkok office. They are varied (see Figure 8.4). Its first goal is to support the Thailand Grand Festival project. According to an official document of the Thailand Grand Festival project 2002, its main objectives are: to stimulate domestic tourism, to reduce outbound tourism, and to attract foreign tourists to the country. Thus, to create an image of a fun beach resort city was clearly stated as one of the project's objectives. It was also mentioned by the interview respondents as an approach to improve Pattaya's tourism image. According to the interview respondents, these goals are commonly shared by all relevant agencies. They aim to manage the festival in a way to achieve its goals.

Figure 8.4: The project information for Pattaya Music Festival (2002).

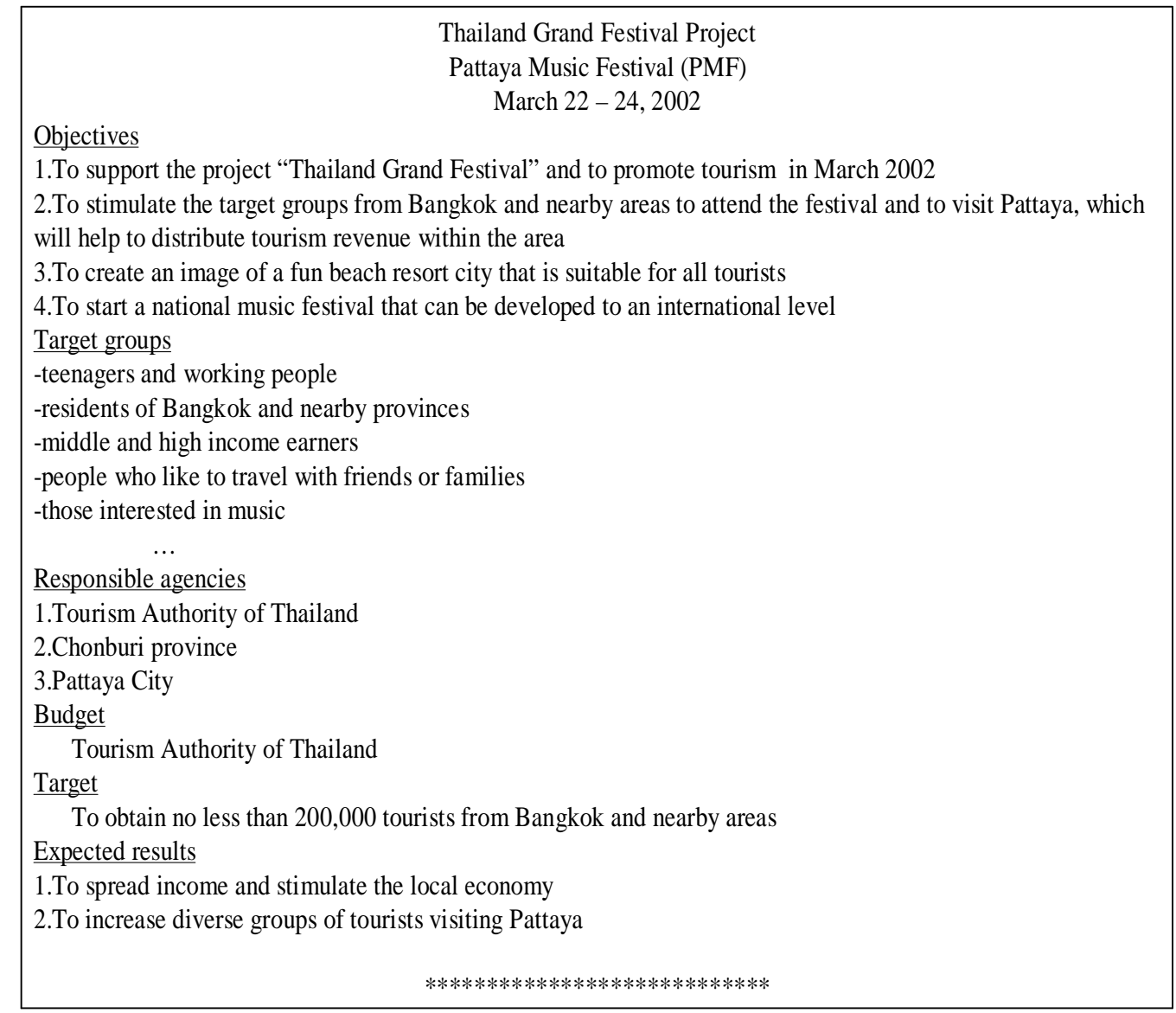

Source: Pattaya City (2006) 
This section shows that multiple public and private agencies from national to local scales are involved in managing the festival. As the project is developed by the national tourism organization (TAT Bangkok office), many agencies at lower operational levels seem to be required to get involved though they appear to do so willingly. Several committees whose members are from multiple agencies are formally formed for effective management practice. Different committees usually have different responsibilities; however, all committees are responsible for the overall management outcome.

\subsection{Management activities and their responsibilities}

The data obtained from both phases of fieldwork enabled the researcher to obtain only broad information regarding types of activities and how they are undertaken for festival management. As the festival did not occur during the fieldwork period, activities related to the management and organization of the festival were not observed. The researcher's experience was used to provide additional information to identify activities clearly evident at the site and how they were broadly carried out.

As mentioned earlier, the project developer, the project organizers, and the committees are involved in the management of the festival. The project organizers are responsible for marketing and stage management, while the committees are responsible for site management and the festival overall. The project organizers are responsible for providing and promoting the singers, advertising the festival through their media channels, and planning and operating lighting and sound on their stages. Although they are not involved in any committees, the project organizers generally work in relation to the TAT Bangkok office (the project developer) and Pattaya City (the site manager), particularly in relation to the preparation of the stages. Regarding site management, although each committee is responsible for its designated task, all committees are together responsible for the overall management outcome. All these committees tend to work collectively to bring about the successful outcome of the festival.

In the 429/2005 Official Announcement by Chonburi governor regarding appointed committees for Pattaya Music Festival 2005, the responsibilities of all committees 
are broadly identified. The advisory committee is responsible for consultancy, supporting and coordinating with other committees, and ensuring work proceeds smoothly so that the project's goals are achieved. The administrative committee is responsible for planning, managing, problem solving, monitoring, controlling, and coordinating with others for the overall operation of the festival. The venue and ceremony committee is responsible for location planning, inspecting, regulating, and coordinating with other committees regarding the performing stages and the festival overall. It is also responsible for location arrangements and decoration. The public relations committee is responsible for PR planning and coordinating and providing information to the media such as television, radio, and newspapers. The traffic and safety committee is responsible for planning, preparing, providing security for the festival, and managing traffic and organizing parking spaces. The cleaning committee is responsible for preparing public facilities such as public or mobile toilets and garbage bins. It is also responsible for collecting garbage and waste and cleaning public toilets and the area overall. The medical treatment committee is responsible for providing nursing staff, medicines, and ambulances for emergencies. The general service committee is responsible for coordinating with other operational committees, preparing the rooms for meetings, musicians, and administration, and overseeing the general decorum of the festival. In managing the site, these six operational committees (venue and ceremony, public relations, traffic and safety, cleaning, medical treatment, general service) usually work in collaboration with the administrative committee for a successful outcome.

As mentioned earlier, there are three performing stages at the festival. The members of different operational committees often plan and discuss how they can exercise their responsibilities. Responsibilities are differentiated by the stage locations. For example, each stage is the responsibility of a different hospital. When there are patients, they can be immediately treated and taken to the designated hospital. As noted above, management functions (such as planning, organising, monitoring, and controlling) tend to be exercised by particular committees and between different committees. Within each operational committee, these functions, excluding control, tend to be exercised by its committee president and vice-president. The administrative committee seeks to monitor and control the operational committees in 
order to ensure that the festival is planned and operated successfully. Thus, the TAT offices also monitor and control the overall operation of all committees in Pattaya City, as illustrated by the following respondents. We have meetings between the central TAT and the central region 3 office. Then, we have
meetings with Pattaya's mayor to discuss how we can work and cooperate and what our
responsibilities are. Then, we have a big meeting which includes all committee presidents to
plan and to discuss the responsibilities and practices of each committee. In each committee,
there are meetings to discuss how they will exercise their responsibilities. ... Pattaya City
helps us by coordinating with other agencies.

(National public 1)

Mostly, TAT is responsible for planning, organising, and controlling the overall operation. We [Pattaya City's staff] are followers. ...

(Local public 12)

In managing the festival, preparation or arrangement of all activities seems to be crucial. Multiple activities such as safety, traffic, and marketing are usually planned in advance for effective practice during the festival period. All activities are generally carried out in a collaborative fashion between all relevant agencies to bring about a successful outcome. Collective action is illustrated in the following quotation.

We [tourist police] are primarily responsible for managing the festival every year, in which
we are similar to other agencies... The City will call for meetings. We, as a member of the
safety and traffic committee, must attend the meetings. There are many agencies that are
responsible. All police agencies must send their working plans to the local police, Pattaya
office. The local police will decide which police office is responsible in which area, and how
we can coordinate.... For example, the district police, Banglamung office are responsible for
the area outside of Pattaya. The local police are responsible for traffic and safety in the area.
The tourist police are also responsible for safety. We plan for the staff, but the staff allocation
is primarily the responsibility of the local police, Pattaya office. With this approach, the
overlapping of work will not occur. (Regional public 3)

Regarding several committees mentioned above, five main activities relevant to festival management can be identified: public relations, traffic and safety, venue and ceremony, medical treatment, and cleanliness. The activities related to public relations and traffic and safety are managed to a greater extent than other activities and involve more agencies. They were frequently mentioned by the interview respondents and in the local newspaper. Agencies that are responsible for carrying out particular activities are summarised and presented in Table 8.3. In the following sections, the activities related to public relations, traffic and safety, venue and ceremony, medical treatment, and cleanliness will be discussed in turn. 
Table 8.3: Management activities and responsible agencies.

\begin{tabular}{|c|c|c|c|c|c|c|}
\hline & & $\begin{array}{c}\text { Public } \\
\text { Relations }\end{array}$ & $\begin{array}{c}\text { Traffic and } \\
\text { Safety }\end{array}$ & $\begin{array}{c}\text { Procedure } \\
\text { \& Arena }\end{array}$ & $\begin{array}{l}\text { Medical } \\
\text { Treatment }\end{array}$ & Cleanliness \\
\hline \multirow[t]{14}{*}{ Public sector } & TAT, Bangkok office & $\mathrm{X}$ & & & & \\
\hline & TAT, Central Region 3 office & $\mathrm{X}$ & $\mathrm{X}$ & $\mathrm{X}$ & $\mathrm{X}$ & $\mathrm{X}$ \\
\hline & Royal Thai Navy, Sattihip Base & & $\mathrm{X}$ & & & \\
\hline & Royal Thai Army, Base 14 & & $\mathrm{X}$ & & & \\
\hline & Royal Thai Police, Area 2 & & $\mathrm{X}$ & & & \\
\hline & Tourist police, Region 3 & & $\mathrm{X}$ & & & \\
\hline & Highway police, Region 3 & & $\mathrm{X}$ & & & \\
\hline & Radio Station, Eastern Region & & & $\mathrm{X}$ & & \\
\hline & Provincial police, Chonburi office & & $\mathrm{X}$ & & & \\
\hline & District police, Banglamung office & & $\mathrm{X}$ & & & \\
\hline & Electric Supply, Banglamung office & & & $\mathrm{X}$ & & \\
\hline & Pattaya City & $\mathrm{X}$ & $\mathrm{X}$ & $\mathrm{X}$ & $\mathrm{X}$ & $\mathrm{X}$ \\
\hline & Local police, Pattaya Office & & $\mathrm{X}$ & $\mathrm{X}$ & & \\
\hline & Navy Radio station & $\mathrm{X}$ & & & & \\
\hline \multirow{8}{*}{$\begin{array}{l}\text { Private } \\
\text { businesses and } \\
\text { organisations }\end{array}$} & Music companies & $\mathrm{X}$ & & & & \\
\hline & Thai Hotel Association, Easter Region & $\mathrm{X}$ & & & & \\
\hline & Chonburi Tourism Attraction Club & $\mathrm{X}$ & & & & \\
\hline & Hospitals & & & & $\mathrm{X}$ & \\
\hline & Pattaya Bus Co-operative, Limited & & $\mathrm{X}$ & & & \\
\hline & Pattaya Press Association & $\mathrm{X}$ & & & & \\
\hline & Local clubs & $\mathrm{X}$ & & & & \\
\hline & Volunteer groups & & $\mathrm{X}$ & & & \\
\hline
\end{tabular}

\subsubsection{Public relations}

Multiple activities to promote and advertise the festival are undertaken by the music companies and other agencies that are members of the public relations committee. Based on the interviews, it seemed that the music companies promote the festival independently and separately from the PR committee. The music companies promote the festival through their radio and television programmes. Within the PR committee, TAT Bangkok generally promotes the festival at a national scale, while other agencies tend to promote the festival at the local scale. Promotion by the music companies occurs alongside that undertaken by the PR committee. In a project information sheet, activities related to public relations were broadly identified. Some activities were carried out by the music companies, while some were undertaken by the PR committee. For example, 45 second and 15 second advertising spots were broadcast on television and radio in the music programmes produced by GMM Grammy Company (one of the music companies that bid for organising the festival). Different advertising channels/media such as radio, newspapers, television, 
magazines, and press conferences used to promote the festival were identified in the document. Based on the researcher's experience, general information regarding the festival dates, singers' names, and locations was frequently broadcast on various television and radio channels for many days in advance. Brochures and stickers were also distributed to provide similar information for tourists (see Figure 8.5). Promoting foreign singers, who perform at the festival, was also used by TAT Bangkok to attract the target groups of the festival. This strategy was also used to market Pattaya as a tourism destination to other countries. This technique was illustrated by the following respondent.

\begin{abstract}
We authorize the music companies to take responsibility for marketing and advertising. It doesn't matter how frequently or which approach they want to do. We also organise the press conferences quite frequently. In the press conferences, we give the opportunity for the fan clubs to meet their singers, especially foreign singers from Japan and Korea. We try to take the foreign singers to visit various tourism attractions in Pattaya and nearby areas that can be attractive to the foreigners. The foreign media and their fan clubs will follow them. This strategy will help to promote Pattaya in their countries....
\end{abstract}

(National public 1)

Figure 8.5: Brochures and stickers provided to the public.
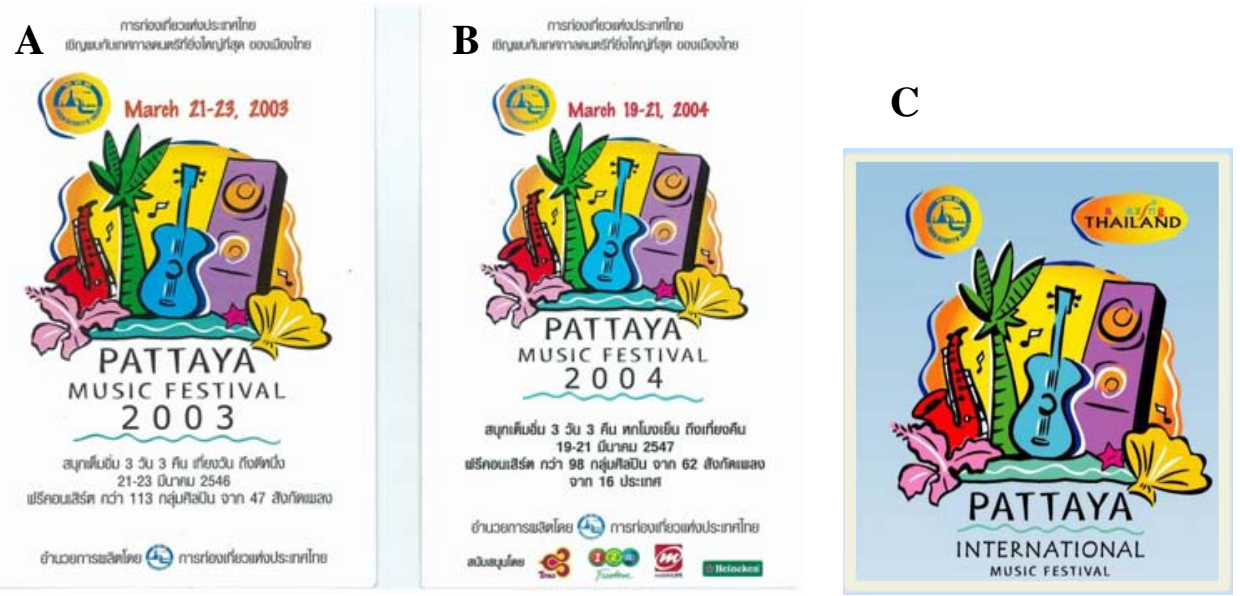

Source: The Tourism Authority of Thailand (2006)

Description of Illustration: A, brochure for 2003; B, brochure for 2004; C, general sticker.

The PR activities are seen to be effective since the festival can draw a large number of tourists to Pattaya. Based on the research reports of the festival in 2005 and 2006, more than 300,000 tourists attended the festival each year. With such a high number of tourists, the festival would seem to be successfully promoted. 


\subsubsection{Traffic and Safety}

Several activities are carried out by the traffic and safety committee. As more than a hundred thousand people attend the festival each day, traffic and safety management is crucial for festival management. The planning of the traffic system and the arrangement and allocation of traffic and security staff were frequently reported in the local newspaper. Several parking spaces provided at the site were also identified in the 2006 project information sheet. Some roads were also closed for pedestrian access only. Although the traffic system would have been well planned, traffic problems could still have occurred since thousands of cars and motorcycles enter the area per day. Frequency of bus services on the Bangkok-Pattaya route was also increased for the convenience of tourists. Moreover, hundreds of security staff and police could be seen patrolling the site. Besides the police officers, many security staff from different public agencies such as Pattaya's security staff, the military police, and the navy police were seen at the site (see Figure 8.6).

Figure 8.6: Security at Pattaya Music Festival.

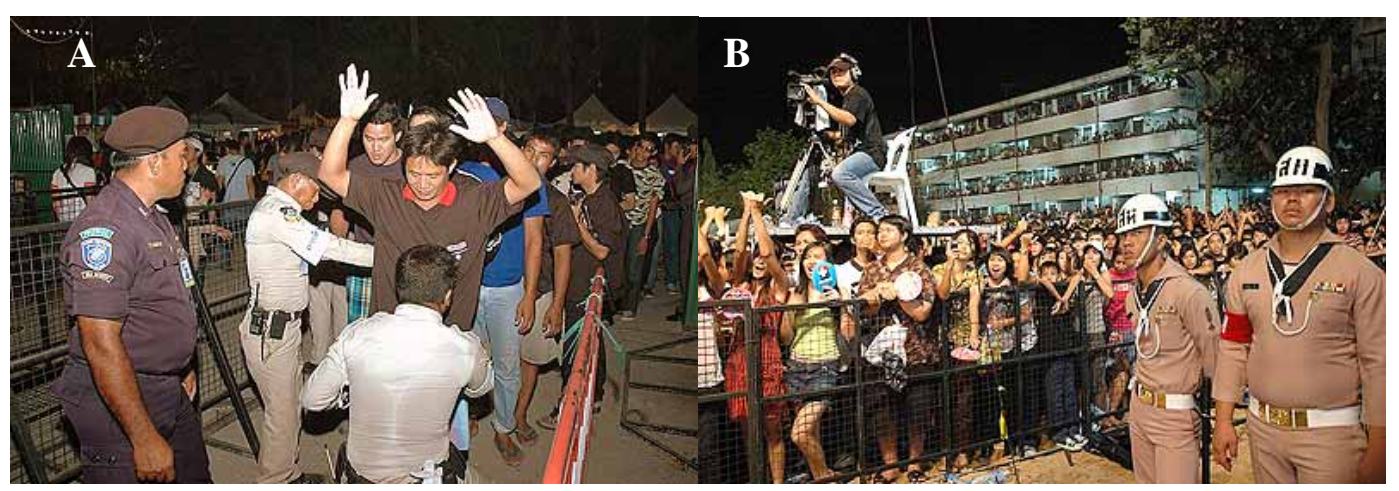

Source: pattayamail.com (2005)

Description of Illustration: A, tourist checking before entering the concert location; $\mathrm{B}$, security guards and metal fences to separate the crowd from a performing stage.

Within the areas of performing stages, metal fences were used as a physical boundary to control the crowds. Individual tourists were searched for weapons or any illegal substances before entering the area. Since most tourists are teenagers, violence and fighting between drunken youths sometimes occurs. This problem was frequently mentioned by the interview respondents and in the local newspaper. Although an attempt to provide better traffic control and more safety measures for 
tourists could be seen, traffic and safety problems seem to occur every year. As noted by the editor of Pattaya Mail in 2005, "despite the appearances of a successful music festival, with revenue in the millions and people numbering in the hundreds of thousands, safety and traffic issues are still a problem” (Tupchai, 2005).

\subsubsection{Venue and ceremony}

A number of activities are undertaken by the venue and ceremony committee for the overall organisation of the festival. Some areas in the city were divided into smaller units and rented by hundreds of stalls that sell food and other products to tourists (see Figure 8.7). Based on the interview responses, the project organizers (the music companies) and Pattaya City tend to carry out this activity separately. The project organizers are generally responsible for organising the area close to the performing stages, while Pattaya City usually deals with the areas further away from the performing stages. Vendors must contact the project organizers or Pattaya City if they want to rent space to sell their products at the fair/festival.

Figure 8.7: Hundreds of stalls crowded along Beach Road at the festival.

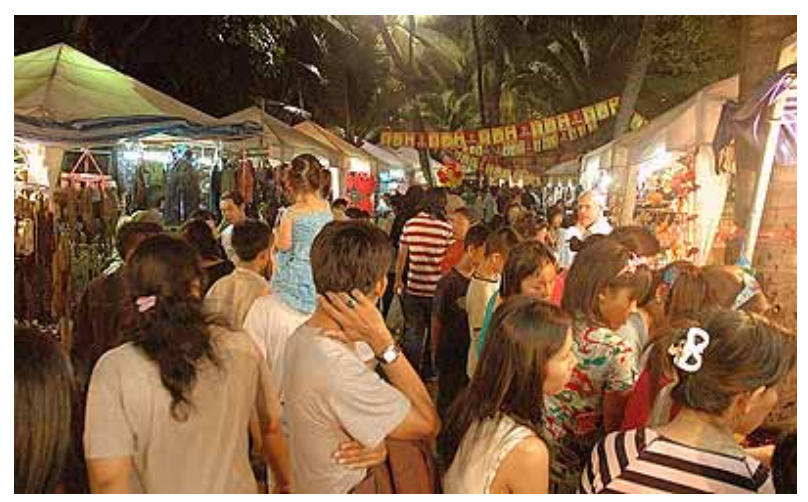

Source: pattayamail.com (2005)

The opening and closing ceremonies are also the responsibility of the venue and ceremony committee. The style of ceremonies, the selected stage, the honoured guests to participate in the ceremonies, the singers who sing the songs for the ceremonies, and the ceremony schedule are usually decided and planned by this committee, particularly by Pattaya City and TAT offices. 


\subsubsection{Medical treatment}

A few activities are undertaken by the medical treatment committee, particularly by Pattaya City and the hospitals involved. A number of nurses are provided by hospitals in Pattaya and from nearby areas. Ambulances, provided by those hospitals and the rescue foundations, work as the temporary emergency units to treat tourists and operational staff. The nurses and ambulances provided in the area can help people who require urgent treatment. As shown in Figure 8.8, the nurses can provide first aid to the tourists who faint or are injured at the festival. Tourists who are injured from the youth fights are also treated by them.

Figure 8.8: First aid and medical treatment at the festival.

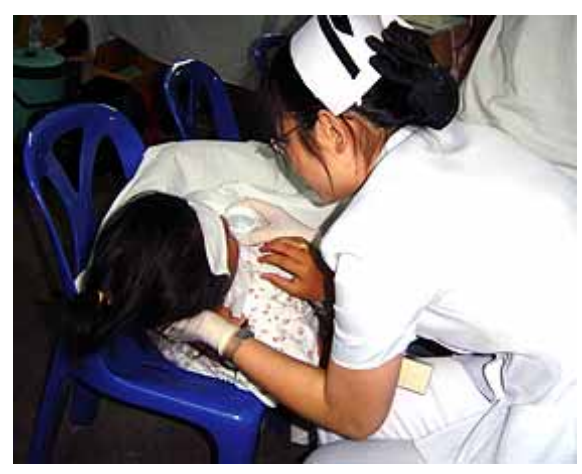

Source: pattayamail.com (2005)

\subsubsection{Cleanliness}

A few activities are undertaken by the cleaning committee although the cleaning work was not directly mentioned by the respondents and in the local newspaper. According to an official announcement by Chonburi province regarding appointed committees for Pattaya Music Festival 2005, Pattaya City appears to be the only agency responsible for cleaning the area. TAT Central Region 3 office, although appointed by the committee, does not seem to carry out cleaning activities. As mentioned before, 100,000 tourists attended the festival each day, and there was much garbage and waste from these tourists at the site. High numbers of cleaning staff are necessary to collect garbage and waste and to clean the area to be ready for the following day. 
This section has identified multiple activities that are carried out in managing the festival. Multiple activities related to public relations, traffic and safety, procedure and arena, medical treatment, and cleanliness are carried out by responsible committees. In carrying out these activities, the functions of planning, organizing, monitoring, and controlling are exercised. These management functions tend to be exercised between the administrative committee and the operational committees to ensure their success. TAT Bangkok office, as the project developer, also usually monitors and controls the overall operations of all committees through Pattaya City. This section illustrates different types of activities required and how they are broadly undertaken in managing the festival. In carrying out these activities, collaboration and cooperation between the members of all committees is demonstrated.

\subsection{Management resources}

For managing Pattaya Music Festival, funding is provided by TAT Bangkok office, while human resources and materials come from the committee members. As the project developer, TAT Bangkok office sets the annual budget for most tourism festivals organised throughout the country under the project "Thailand Grand Festival”. Other resources are from public and private agencies that are appointed to particular committees. How these resources are managed was clarified by the TAT staff;

Money is from the central TAT [TAT Bangkok office] because it is the project developer. It is also responsible for finding sponsors. The local agencies receive money from the central TAT to operate the project. If there is any additional expense, the central TAT is responsible for it. For other resources, we ask for cooperation from other agencies. We financially support them. ... The budget depends on the central policy. We follow the amount [of the budget] that we receive. For human resources, if we receive good cooperation from other agencies involved with the Pattaya Music Festival, there will be no problem because many people get involved. Safety is an example. More than a thousand staff get involved per day. Tourist police have hundreds of volunteers. The city staff and other volunteer groups are in the hundreds. It [Pattaya Music Festival] seems to be the only project that requires many human resources.

(Regional public 1)

The interview respondents agreed that management resources are sufficient to bring about successful outcomes. However, the appearance of successful outcomes does not mean that there are no management problems. The TAT officers seemed to be satisfied with the overall outcome of the festival, while other respondents tended to 
have a lesser degree of satisfaction. One respondent from Pattaya City mentioned that the management outcome would be better if a higher level of coordination occurred. According to the interviews, the limited amounts of money available can affect staff satisfaction. As indicated by the respondents, the budget received from the TAT Bangkok office is generally limited. Overtime payments paid by Pattaya City to its staff, as presented below in the first quotation, supports this view. The second quotation indicates that money to pay for individual staff is very low when compared with the responsibilities they have, particularly for the security staff. As the numbers of security staff (including volunteers, police, and staff from all relevant agencies) are quite high, the amount of money allocated to each staff member tends to be low.

We act as a coordinator to collect the operational costs estimated by all agencies. We know that TAT has a limited amount of money. Sometimes [to help TAT], we try to cut down the amount of money [estimated and proposed by other agencies through their operational costs]. ... As the municipality, we don't support other agencies with money because it's not our project. Sometimes, we have to [use the City's money to] pay for our staff who work overtime [but not for staff from other agencies].

(Local public 12)

In Pattaya Music Festival, the volunteers and security staff receive daily wages. One hundred baht [approximately US\$3] per person for eight hours work. They [security staff] have to stand and walk all night. When there is a fight, they have to stop it. Sometimes, the amount of money doesn't help much [in creating satisfaction]. ...

(Regional public 3)

Moreover, a lack of communication between TAT Bangkok office and other public agencies tends to be reflected in the practices. The municipality usually expects better cooperation from the TAT Bangkok office, particularly in providing necessary information to the public agencies at lower operational levels. A lack of information regarding site visits by senior government officers was raised by Pattaya City’s staff. Inappropriate manners of local public staff towards senior officers could be a source of embarrassment and violation of protocol. In Thai culture, appropriate manners to verbally communicate, to behave, to react, and to treat elders and people in positions of authority are crucial. People with appropriate manners will receive kindness and support from the elders and respected individuals in return. This culture is present within the public sector, particularly those agencies with a strong bureaucracy. The military organizations, the ministries, and national to local government bodies are examples. Appropriate manners to welcome and to host the senior government officers would be perceived as crucial for the staff in agencies at lower operational 
levels. Information regarding the visits by senior staff should be disseminated to staff. This cultural issue should be a concern when diverse government bodies are involved in management.

Frankly, sometimes it's difficult to work with the central agencies. Sometimes, they think that having meetings in Bangkok is enough [without informing other smaller scale public agencies]. When the provincial or the district governments do not have information, they may have problems. For example, no one informs us [the local public agencies] when senior government officers [e.g. the ministers] visit the site. The local government officers [e.g. the provincial and district governors, and the Pattaya's city chief manager] may be in trouble. It's not too bad for us [Pattaya's congress members, mayor, and deputy mayors] because we are politicians, but it might have some impact on the bureaucrats such as the provincial and district governors. There are lines of authority within and between their organizations. This kind of issue shouldn't be overlooked.

(Local public agency 12)

However, the interview responses tended to indicate that sufficient resources are not the only factor for successful management. Close relationships between relevant agencies tend to create successful management. In this case, close relationships between TAT Central Region 3 office, Pattaya City, and some agencies in the area tend to be present. Since there are many events organized by the municipality, cooperation between Pattaya City and these agencies seems to frequently occur. Since these agencies tend to work closely with each other, there is solidarity among them because they share similar responsibilities and interests. Willingness to work and cooperate with group members tends to be present, as reflected by the following respondent:

The most important factor is the relationship between agencies in the area. As our relationships with the local agencies are quite good, we do not need to say much about what we want. Sometimes, they know what we want by looking at our faces. Or sometimes, we ask them to do the work for us first, and we will pay later. This occurs quite often [laugh].

(Regional public 1)

This section has indicated that resource sufficiency is not the only factor for successful management. A desire or willingness to cooperate with each other also seems to be a key factor. A close relationship between committee members seems to create that willingness. Other factors may create cooperation between relevant agencies. To 'save face', organizations cooperate. As Pattaya Music Festival is a national tourism project, to show that the local agencies, particularly the municipality, are able to organize a national project would promote their managerial and operational abilities. The municipality might have a strong desire or willingness 
to cooperate with other agencies to manage the festival successfully in order to promote Pattaya's tourism and to benefit the city's economy overall. Collective action between relevant agencies in operating the festival is present in different forms.

\subsection{Management integration}

Collective action can occur in two forms of inter-organizational relationships: set and network. These two forms of relationships refer to the interactions between several agencies (R. H. Hall, 1987). In this case, a set relationship tends to reflect broad management, while a network relationship mainly reflects the carrying out of particular activities by different operational committees. Generally, all agencies tend to interact in a horizontal direction, to have equal authority. However, a hierarchy of command exists between the administrative committee and the operational committees. Pattaya City is seen have a crucial role in management. It acts as a project coordinator to coordinating with all agencies across a broad level of management, while it is also involved as a member of all committees in carrying out particular activities. It generally acts as an intermediary agency linking these two levels of management together.

In broad management, a set relationship tends to occur. Tourism Authority of Thailand (TAT), both Bangkok and Central Region 3 offices, are seen to act as the central agencies coordinating with all relevant agencies to successfully manage the festival overall (see Figure 8.9) 
Figure 8.9: A set relationship between Pattaya City and other agencies in broad management.

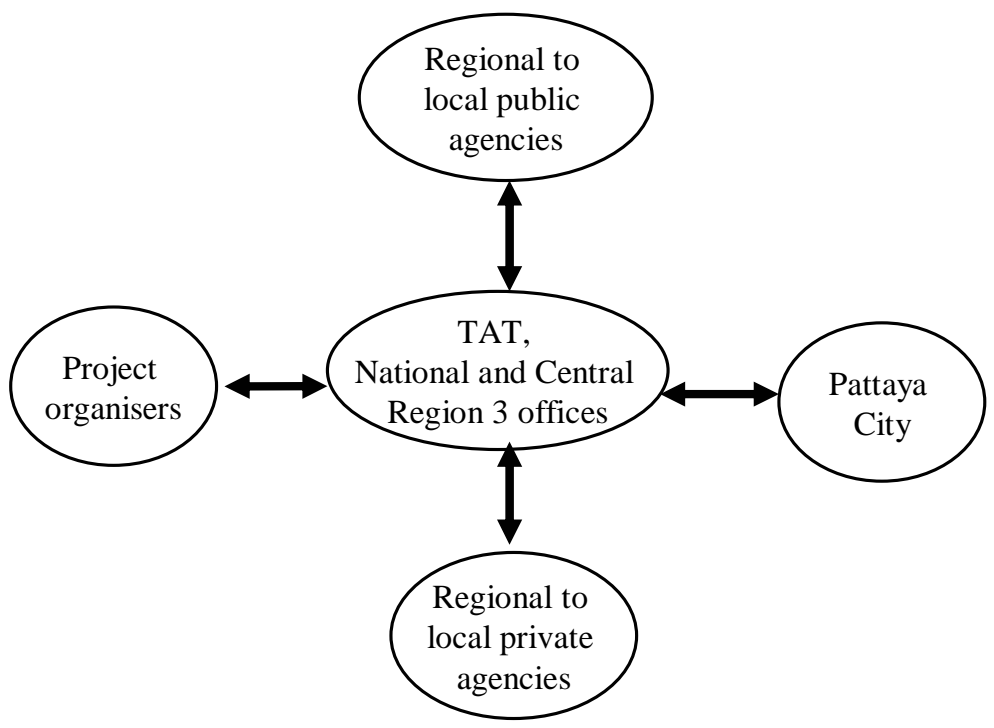

They coordinate with the festival organizers, Pattaya City, the public agencies, and the business organizations in Pattaya. As the project developer and financial provider, TAT agencies have primary authority to decide about the festival. The functions of planning, organizing, monitoring, and controlling can be used by them. Meetings between relevant agencies are often used to monitor the working progress. The solutions to solve issues or problems that emerge are also made by an agreement of all agencies.

We [TAT offices] have to work with Pattaya City, Provincial Administration Organization, District Administration Organization, business associations and clubs, and other public agencies in Pattaya. ... Pattaya City is a coordinator for us. We identify the tasks that need to be carried out in the festival. Safety, traffic, medical, and toilets are examples. Pattaya City will say which tasks it will be responsible for. ... Before starting the festival, there are meetings between TAT Central office and TAT Pattaya office [Central Region 3 office]. Then, we meet with Pattaya's mayor to discuss which agencies are responsible for which tasks. Then, we will have a big meeting, which the presidents of all committees attend, to plan and discuss about how they will perform those tasks....

(National public 1)

The main agency is TAT. It is responsible for planning, organizing, and controlling. We [Pattaya City] provide support. Sometimes, we help them to solve urgent issues or problems. ... Sometimes, we give suggestions to them but don't try too much. Otherwise, they may think that we insult their abilities.

(Local public 12)

As indicated in the above quotations, relevant agencies also seek to integrate in the form of committees. A network relationship can occur within particular committees in carrying out their responsible activities. Generally, the committee members can 
come from public and/or private agencies (see Figure 8.10). The committee presidents and vice presidents of particular committees do not seem to have any authority over the operation of committee members, but are able to make decisions and monitor their progress. Since the executives of public agencies are the members of the administrative committee, they usually have authority to monitor and control the operations of their staff, those appointed to the operational committees. According to an official announcement by the Chonburi province regarding committee appointments, the relationships between the administrative committee and the operational committees generally occurs in a vertical direction (see Figure 8.3). All members in operational committees tend to interact at an equal level. Meetings within particular committees are mainly used to monitor progress in carrying out particular activities. Thus, meetings between the administrative committee and the operational committee presidents are also used to monitor and control overall management practices. As they are involved in all committees, TAT offices are able to monitor and control the festival management in a way to achieve the festival goals.

There are several committees. We [the police offices] are members of Safety Committee. In our work, all police offices will propose the working plans to the local police. Then, the local police will allocate the police officers in different areas. It's coordinating, but other committees may work differently because there is no unity of command. There are several agencies involved and they are controlled by their executives. ...

(Regional public 3)

...Traffic management is an example. The police will draw a city map and identify which roads will be open or closed. If anyone doesn't agree, we will discuss and try to find the solutions in the meetings. ...

(National public 1) 
Figure 8.10: A network relationship of relevant agencies in a particular committee.

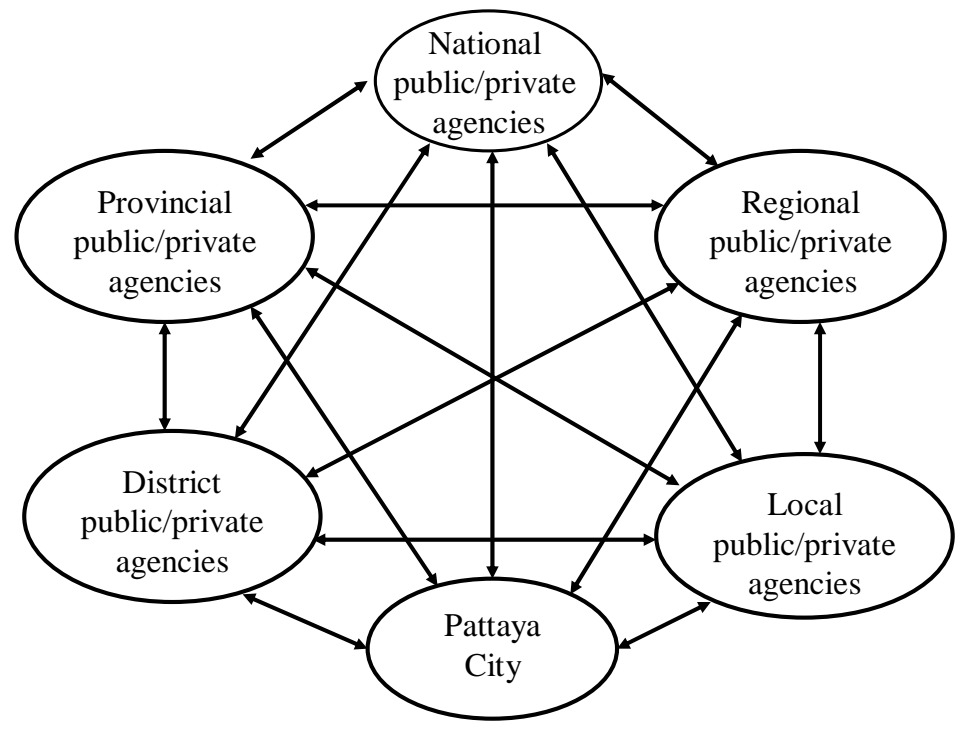

A high level of integration between relevant agencies is usually present in these two forms of inter-organizational relationships. A high level of integration tends to occur through working units, which are represented by several groups of committees. The members of particular committees and their responsibilities are identified. Pattaya City, which is involved in all committees, can monitor the overall progress of the project. This seems to strengthen its role as project coordinator when dealing with the project developer and the project organizers. Although the project's goals are developed only by the TAT Bangkok office, as mentioned earlier, all agencies seem to share these goals. There was no evidence of disagreement about the goals. With common goals, management activities can be easily identified and carried out by the committees responsible. Frequent meetings are usually used to monitor progress. The control function is mainly used by several agencies through their lines of authority. The line of authority of individual agencies tends to be used by their staff members: those appointed in the administrative committee monitor and control those appointed in the operational committees. The large number of management agencies does not seem to be a problem. Thus, the slow and complex nature of bureaucracy does not seem to exist. The requirement of the national tourism agency regarding project cooperation seems to minimize the more problematic aspects of bureaucracy. The music festival's fixed or set date serves as a deadline to which agencies work. 
As the municipality, Pattaya City has a major role as a site manager overseeing the festival management overall. It tends to act as a mediator or coordinator to help coordinate with TAT agencies and other agencies and committee members: "Pattaya City is a coordinator for us" (National Public 1). It has a major role in bridging the gap between the broad level and the specific level of management in particular committees. By being a member of all committees, Pattaya City is able to help TAT to monitor the progress of all operational committees and to report to TAT offices. However, Pattaya City has some influence in shaping the festival. The suggestion made by Pattaya City to attract higher spending tourists to the city is an example. Their suggestions seemed to be received well by the TAT since the target groups and the types of music were broadened, as identified in the project reports in 2005 and 2006. Moreover, Pattaya City is also seen to coordinate with the project organizers regarding the progress of performing stages and whether their themes and designs are matched with the types of music. With other public and private agencies, the relationships occur through related activities or issues.

Mostly, the TAT decides about the project, how they want it to be. Then, they will invite us [Pattaya's executive members] to attend the meeting to ask whether we agree or not. If we don't agree, we can make suggestions. ... We try to talk to the TAT about the project improvement. ... Now it [the project] is getting better. Before finding the project organisers, the TAT will talk to us about music trends. ... Usually, we call other agencies for meetings depending on relevant issues. We are listening to what they might comment on, the model that we have developed. Our views may not be as good as theirs because they know better in carrying out particular activities such as traffic. We also ask other agencies to do budgeting for their works. The police are an example. We ask them to send us the budget plan for their operational costs. We act like the central agency to collect all budgets from all agencies and propose them to the TAT. Wages for volunteers are examples of the expense.

(Local public 12)

\subsection{Discussions and conclusions}

This chapter has discussed how Pattaya's festival is managed. Similar to beach and nightlife management, it can be concluded that multiple agencies are involved in carrying out multiple activities in relation to festival management. Integration, as the core concept of destination management, occurs to a great extent in this case. The management practices are summarised in Table 8.4. 
Table 8.4: A summary of management practices for Pattaya Music Festival.

\begin{tabular}{|l|l|}
\hline $\begin{array}{l}\text { Management } \\
\text { aspects }\end{array}$ & \multicolumn{1}{c|}{ Pattaya Music Festival } \\
\hline $\begin{array}{l}\text { Management } \\
\text { agencies }\end{array}$ & $\begin{array}{l}\text { Several committees are formally formed to manage the festival } \\
\text { Multiple public and private agencies from national to local scales are involved } \\
\text { Some agencies are appointed to all committees, while some agencies are appointed to one or a } \\
\text { few committees }\end{array}$ \\
\hline $\begin{array}{l}\text { Management } \\
\text { purposes }\end{array}$ & $\begin{array}{l}\text { A common purpose in managing the festival is to achieve the goals of the festival } \\
\text { The primary goals of the Pattaya Music Festival project are to support the grand festival } \\
\text { project and to improve Pattaya's tourism image } \\
\text { The main goals of the project "Thailand Grand Festival” are to stimulate domestic tourism, to } \\
\text { reduce outbound tourism, and to attract foreign tourists to the country }\end{array}$ \\
\hline $\begin{array}{l}\text { Management } \\
\text { activities }\end{array}$ & $\begin{array}{l}\text { Multiple activities are carried out by several agencies in relation to PR, traffic and safety, } \\
\text { procedure and arena, medical treatment, and cleanliness } \\
\text { PR and traffic and safety require considerable management and involve a large number of } \\
\text { agencies }\end{array}$ \\
\hline $\begin{array}{l}\text { Management } \\
\text { resources }\end{array}$ & $\begin{array}{l}\text { Money is from TAT Bangkok office; human resources and materials are from committee } \\
\text { members, those carrying out particular activities } \\
\text { For some respondents, the amount of money seems to be an issue } \\
\text { Resource sufficiency does not seem to be the only factor for effective practice }\end{array}$ \\
\hline $\begin{array}{l}\text { A set relationship and a network relationship are reflected in the interactions of relevant } \\
\text { agencies } \\
\text { A set relationship tends to occur for broad management, while a network relationship tends to } \\
\text { occur within particular committees } \\
\text { A high level of integration is present }\end{array}$ \\
\hline
\end{tabular}

In Table 8.4, the major aspects in managing Pattaya Music Festival are summarized. Similar to the management of Walking Street, a high level of integration between relevant agencies occurs. Multiple agencies from different sectors and different operational scales are involved in managing the festival. Their involvement is formally structured through several committees. Different groups of committees (the administrative committee, the advisory committee, and the operational committees) tend to be designed to obtain cooperation and coordination from all relevant agencies in order to achieve the festival's goals. Although the festival's goals were developed only by the TAT Bangkok, they seem to be shared by all agencies appointed to the committees. On particular committees, relevant agencies are appointed and their responsibilities are broadly identified. All committees have a responsibility for the overall management outcome. Multiple activities are also carried out by different committees. In carrying out particular activities, the committee members usually work collectively. Materials and human resources are also coordinated by them. 
However, this case shows that resource sufficiency may not be the only factor that influences effective management practice. The close relationships between Pattaya City and some agencies in the area tend to create a desire or willingness to cooperate with each other for a successful outcome.

Thus, this case reflects that the municipality is a key agency in bridging all relevant agencies to manage the festival at the local scale. It acts as a project coordinator and destination manager. In this case, Pattaya City, as the municipality, oversees the overall management of the festival in the area. It also acts as a key coordinator to coordinating and cooperating with all agencies involved in carrying out particular activities in a way necessary to achieve the festival's goals. It usually coordinates with the TAT (as the project developer), the music companies (as the project organizers), and other agencies (as the project operators). Although it cannot control the operations of these agencies, its involvement in all committees enables Pattaya City to monitor the overall progress of the project and to oversee their progress. This strategy helps strengthen the role of Pattaya City as the municipality and the project coordinator. Although the management structure seems to be bureaucratic, its slow and complex nature does not seem to be an issue in terms of management practice. The coordination and cooperation of relevant agencies within and between different committees is seen. The controlling function tends to be used by various agencies through their staff who are appointed to the administrative committee and to the operational committees. Thus, frequent meetings are used to monitor management performance. Moreover, TAT offices also seek to monitor and control the overall operation of all agencies in a way to achieve the project's goals.

In order to measure management performance, various factors need to be considered. The physical appearance of the festival could be used to measure its management. The number of tourists could also be used if the project's aim is to attract large, or increasing, numbers of tourists. Otherwise, research to measure tourists' satisfaction regarding overall physical appearance and recommendations for better management could be used to measure the performance of festival management. The information obtained from the research could be helpful for better and more effective management practices in the future. In this case, TAT Bangkok office, as the project 
developer, is responsible for evaluating the management outcome. Research has been done to evaluate the project (CIRI, 2004, 2005). Numbers of tourists, foreign musicians and their support staff, and their satisfaction regarding the festival and its overall management were used as indicators of success. In general, tourists, foreign musicians and their support staff were satisfied with the festival; however, the research conducted was not in depth.

According to the research reports of Pattaya Music Festival 2004 and 2005 (CIRI, 2004, 2005), large numbers of tourists, particularly youths, would show that one of the project's objectives are being achieved. Issues relevant to the overall operation of the festival were also stated in the reports. Examples are problems with the project organisers, and insufficient parking spaces. These issues were also raised by the municipality and other respondents, but tended to be overlooked by the TAT officers. Thus, the research report of Pattaya Music Festival 2005 stated that the aim to improve Pattaya's image was not achieved (CIRI, 2005). The festival enhanced the image of Pattaya as 'a city of variety', but it could not change or minimise its image as 'a sex tourism destination'. This indicates that it may take more time to change an image that has long been in existence. Destination goals seem to be necessary to clarify the image that the destination wants to present to its targeted market. Consistency in terms of delivering a clear image of the destination may be required. Managing all tourism products in a way to deliver a consistent image seems to be crucial.

This chapter has addressed the management of the Pattaya Music Festival. Different aspects were identified and discussed to bring a better understanding of how the destination is managed, particularly in the context of festival management. Similar to the findings discussed in the beach and nightlife management chapters, the findings of this chapter also show that multiple agencies are involved in carrying out particular activities at the local destination. As Pattaya Music Festival is one of the major tourism projects in the country and in Pattaya, many agencies are involved in its management. However, this chapter shows that a high level of integration can occur through formal collective action and through a controlling function exercised by the executives of individual public agencies. The project's goals seem to be 
commonly shared by all relevant agencies. They can give clear direction as to what needs to be achieved. The responsibilities of different committees are clearly stated in official documents. In this regard, the activities carried out by particular committees and resources required in carrying out those activities could be identified. Several agencies generally control the operation of the festival. Authority of command within individual public agencies is necessary to ensure effective coordination and cooperation from relevant agencies.

The management issues identified and discussed in this chapter bring a better understanding of how the destination is managed, particularly in managing a tourism festival/event. In the next chapter, Chapter 9, the management of beaches, nightlife, and the music festival will be drawn together for discussion with respect to the practices of destination management overall. The next chapter will examine how destination management is practised in Pattaya. The management of daily tourism resources such as beaches and nightlife will be compared with the management of Pattaya Music Festival. How the management of these three tourism resources correspond to the concept of destination management will be clarified. Lessons learned from these case studies will also be identified and described in the chapter. 


\section{Chapter 9 Destination management in Pattaya}

\subsection{Introduction}

This chapter aims to provide an overall picture of destination management in Pattaya. By drawing together key findings from Chapters 6 to 8, the overall practices in managing tourism in Pattaya can be clarified and the extent of destination management assessed.

In this chapter, key concepts of a tourism destination and destination management discussed in Chapter 5 are summarised in section 9.2 to provide a conceptual background of destination management. Then, similarities and differences in the findings of Chapters 6 to 8 are summarised and discussed in sections 9.3 with regard to the practice of destination management in Pattaya as a whole. The implications of the findings in terms of destination management are discussed in section 9.4 to clarify whether, in what ways, and to what extent destination management is practised in Pattaya. Lessons learned from the case and recommendations for further research are described in the following sections and conclusions are drawn at the end of the chapter.

\subsection{The concepts of destination management}

As mentioned in Chapter 2, the definitions of destination management tend to vary depending on how a destination is perceived and defined. However, most concepts regarding tourism destinations and their management in the literature are those expressed by tourism scholars, not by tourism practitioners. Since the practitioners' perspectives tend to influence their practices, this thesis suggests that also taking the practitioners' views into account provides for a better understanding of the notion of destination management.

As discussed in Chapter 3, multiple approaches were taken to bring out the broad concept of 'destination management'. The practitioners in Pattaya were asked to define the terms 'tourism destination' and 'destination management' in their own 
words, to comment on the statements from the literature regarding these two terms, and to reflect on their own definitions and on Pattaya's context (Chapter 5).

\subsubsection{Defining a tourism destination (TD)}

A ‘tourism destination' was defined by Pattaya's practitioners as a place that provides multiple tourism products; has an ability to serve tourist demand; has an identity; has some level of management; and has a positive tourism atmosphere. Management is reflected as a fundamental concept underlying their views regarding a 'tourism destination'. Although it was not directly mentioned when defining the term in their own words, the necessity for some kind of management in relation to a destination was indicated in their responses. The practitioners expressed the view that facilities and services at the destination are developed and managed to serve the diverse needs and desires of tourists. Their views were further explored by reference to Ritchie \& Crouch’s (2003, p. 67) statement that:

The destination must function as a real entity. That is, it must have a sense of itself; it should have a purpose and be managed in a way that promotes the pursuit of that purpose.

In particular, the necessity for a destination to be managed was noted and the collaborative practices between relevant agencies were also highlighted. These ideas were restated when reflecting on Pattaya.

In comparing the practitioners' views with the tourism literature, similarities and differences were identified to draw out the broad concept of a tourism destination as:

A local geographical area (a village, a town, or a city) that requires management to bring out its particular tourism identity, and to provide multiple tourism products in order to attract and respond to tourists' specific needs and to create positive feelings and a tourism atmosphere for its visitors.

Four key dimensions underlie the core concept of a destination: tourism stakeholders, tourism-related activities, destination goals, and management. First, multiple tourism stakeholders at the destination (e.g., Pearce, 1989; Sautter \& Leisen, 1999; Sheehan \& Ritchie, 2005) tended to be categorised by the practitioners into two groups: 
tourism providers and tourists. Local residents, although perceived by the practitioners as an important factor for successful management practice, tended to receive less attention when defining a tourism destination. On the contrary, tourists and their satisfaction were emphasised by them. Second, multiple tourism-related activities are reflected in the concept of a destination. Tourism products are perceived as one of the primary aspects of a destination by the practitioners and in the literature (e.g., Cho, 2000; Pearce, 1989; Ritchie \& Crouch, 2003). Multiple activities are required in order to develop these tourism products, to market to the target tourists, and to serve the tourists at the destination. Third, destination goals appear to be necessary for a destination. They present an overall picture of the desired future of a destination (Terzibasoglu, 2004). As reflected in the above concept, the destination's goals can be varied. Stanford (2006), for an example, suggests a destination's goal may be to identify and target responsible tourists. The destination's goals help identify management activities required and indicate how they should be undertaken to achieve the stated goals. Management is a core concept of a tourism destination. This final dimension tends to bring all the dimensions together. The destination's goals can reflect the activities that are required to be undertaken at the destination and identify the stakeholders who are responsible for carrying out those activities. The practitioners' views regarding destination management tended to correspond to their views of a destination. Information regarding management practices was further added to define the concept of destination management.

\subsubsection{Defining destination management (DM)}

As also discussed in Chapter 5, Pattaya's practitioners defined 'destination management' as the integration of multiple tourism-related activities, of relevant agencies, and of management functions and management resources. The practitioners defined the term in their own words with respect to the management process and practice but focused more on integration after reading Anderson's (2000) statement and after reflecting on Pattaya's context. Several major points emerged from their views. 
First, the management of a destination is similar to that of an organization. As mentioned in Chapter 5, the practitioners tended to define the term based on their knowledge and experiences in organizational management. In their own words, general concepts of management such as management purposes, management functions, and management resources were initially mentioned in relation to the destination as a whole. They tended to believe that destination goals are necessary for management practices. Planning, monitoring, and controlling functions are to be exercised to manage a destination to achieve its goals. Providing quality tourism products in order to satisfy tourists seemed to be an emphasis in the practitioners' views. Practices to minimise negative tourist impacts were not mentioned. Furthermore, coordination between relevant agencies to work together and to provide management resources was stressed.

Second, integration as a core concept of destination management emerged when the practitioners commented on Anderson’s (2000a, p. 146) statement:

It is the integrated process of managing any of the three tourism destination types (urban, resort, and rural). It covers four key elements; the destination offering (visitor experience, destination image and attractiveness); the visitor mix (market research); marketing communications (awareness and promotion); and organisational responsibility (leadership and partnership).

Most respondents agreed that integration is necessary for destination management. They further added that integration throughout the management process is required and suggested that relevant agencies work together and coordinate their management resources. The practitioners believed that a high level of integration is likely to bring successful destination management. However, when reflecting on Pattaya, contradictory responses between the practitioners from the public and private sectors indicated that different levels of integration are practised in Pattaya. As discussed in Chapter 5, respondents from most public agencies, particularly the municipality, believed that their practices are carried out in an integrated fashion. They mentioned activities that were successfully managed to support their views and commonly referred to the management of marketing activities and of the Pattaya Music Festival.

On the other hand, a call for a higher level of integration between responsible agencies from the private sector practitioners suggested that a low level of integration is practised in Pattaya. More effective cooperation from Pattaya City and 
other public agencies is required (Promboot, 1995). The views of these business practitioners indicated that destination goals are crucial for destination management practice. Without destination goals that are commonly understood or shared by all relevant agencies, integration is difficult to achieve.

Drawing on the practitioners' views and the literature, the broad concept of destination management was refined as:

The collaboration of relevant agencies responsible for providing multiple tourism products at the destination in a way to achieve destination goals or common goals. These goals may include creating a positive tourism atmosphere, enhancing the destination's identity, and attracting and serving tourist demand. Broadly, destination management can be practised through the integration of management functions and resources from all relevant agencies.

As with the broad concept of a tourism destination, four key dimensions of destination management can be identified: management stakeholders, management purposes, management activities, and integration. First, multiple agencies from various sectors and operational scales are involved in destination management. Based on the practitioners' views, the public and private agencies from the local and other scales are management stakeholders. Certain groups of stakeholders appear to play a major role in managing a destination (e.g., C. M. Hall, 2000; Pearce, 1989; Selin \& Chavez, 1995). The practitioners tended to perceive local residents as followers rather than decision makers in relation to destination management. The notion commonly found in much tourism literature that local residents should be involved in the planning and decision-making process may not occur in reality. Second, a primary purpose of destination management is to pursue the destination's goals. Since destination goals can provide a picture of the overall desired future for the destination, they are perceived as a necessity for effective management (e.g., Welford \& Ytterhus, 2004; Westermann, et al., 2005). They also generally provide a clear picture of related activities required in managing a destination as a whole and provide a clear direction for management practices. This leads to the third dimension of this concept: management activities that are carried out at the destination level. 
Similar to the literature (e.g., Jamieson, 2006; Ritchie \& Crouch, 2003), the practitioners realised that multiple tourism-related activities are required to be undertaken at the local destination by related tourism providers (both public and private). They perceived that these activities need to be carried out primarily for the benefit of tourists. They believed that the tourists' satisfaction may in turn benefit the destination. Integration, a fourth dimension of destination management, is highlighted in the literature (e.g., Anderson, 2000a; Go \& Govers, 2000; Gomezelj \& Mihalic, 2008). Practitioners also suggested from their experiences that a high level of integration is required for successful management. Such a level could be achieved through collective action in establishing destination goals, implementing management functions, and providing management resources throughout the management process.

In the following section, the practices in managing Pattaya as a whole are clarified and discussed in terms of these four dimensions of destination management. The implications of the findings for the concept of destination management are also discussed at the end of this chapter.

\subsection{Practices of destination management in Pattaya}

Key findings of the study are drawn together in the matrix diagram, as presented in Table 9.1, to clarify whether, in what ways, and to what extent destination management is practised in Pattaya. The diagram summarises the management of three tourism attractions with respect to the dimensions of destination management. The summary findings of Chapters 6 to 8 are presented in the columns of beaches, nightlife attractions, and Pattaya Music Festival respectively. The four main dimensions of destination management that emerged in Chapter 5 and were used for the analytical structure in Chapters 6 to 8 are presented in the rows. Issues that occurred in managing particular tourism attractions are also presented in the last row of the diagram. 
Table 9.1: A summary of key finding of destination management in Pattaya.

\begin{tabular}{|c|c|c|c|c|c|c|c|}
\hline & & & \multicolumn{2}{|c|}{ Beaches } & \multicolumn{2}{|c|}{ Nightlife attractions } & \multirow{2}{*}{ Pattaya Music Festival } \\
\hline & & & Daily operations & Project operations & Dispersed businesses & Walking Street & \\
\hline \multirow{12}{*}{ 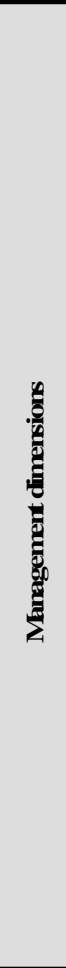 } & \multirow[t]{5}{*}{ Agencies } & $\begin{array}{l}\text { Sectors and } \\
\text { scales }\end{array}$ & $\begin{array}{l}\text { multiple national to } \\
\text { local public agencies } \\
\text { several local business } \\
\text { organizations }\end{array}$ & $\begin{array}{l}\text { public and/or private } \\
\text { agencies depending on } \\
\text { projects }\end{array}$ & $\begin{array}{l}\text { several national to local } \\
\text { public agencies } \\
\text { Beer Bar Bus iness } \\
\text { Association }\end{array}$ & $\begin{array}{l}\text { several national to local } \\
\text { public agencies } \\
\text { Walking Street businesses }\end{array}$ & $\begin{array}{l}\text { multiple national to local public } \\
\text { and private agencies }\end{array}$ \\
\hline & & Key agencies & $\begin{array}{l}\text { Pattaya City and other } \\
\text { public agencies }\end{array}$ & $\begin{array}{l}\text { Pattaya City and other } \\
\text { agencies relevant to the } \\
\text { projects }\end{array}$ & $\begin{array}{l}\text { Pattaya City and other } \\
\text { public agencies }\end{array}$ & Walking Street Committee & $\begin{array}{l}\text { Pattaya City and TAT } \\
\text { Presidents of all functional } \\
\text { committees }\end{array}$ \\
\hline & & Involvement & individual & working units & individual & Walking Street Committee & several committees \\
\hline & & $\begin{array}{l}\text { Management } \\
\text { structure }\end{array}$ & non collective structure & $\begin{array}{l}\text { formal and informal } \\
\text { collective structures } \\
\text { depending on projects }\end{array}$ & non collective structure & $\begin{array}{l}\text { a formal structure of the } \\
\text { operational committee }\end{array}$ & $\begin{array}{l}\text { a formal structure of functional } \\
\text { committees }\end{array}$ \\
\hline & & Responsibilities & separate & collective & separate & -collective & -collective \\
\hline & \multirow[t]{2}{*}{ Purposes } & Primary & $\begin{array}{l}\text { to achieve individual } \\
\text { organizational goals }\end{array}$ & $\begin{array}{l}\text { to achieve goals of } \\
\text { individual projects }\end{array}$ & $\begin{array}{l}\text { to achieve ind ividual } \\
\text { organisational goals }\end{array}$ & $\begin{array}{l}\text { to achieve the goals of } \\
\text { Walking Street }\end{array}$ & $\begin{array}{l}\text { to achieve the goals of Pattaya } \\
\text { Music Festival }\end{array}$ \\
\hline & & Secondary & $\begin{array}{l}\text { for the benefit of } \\
\text { Pattaya's tourism }\end{array}$ & $\begin{array}{l}\text { for the benefit of } \\
\text { Pattaya's tourism }\end{array}$ & $\begin{array}{l}\text { for social order and } \\
\text { safety of the city }\end{array}$ & $\begin{array}{l}\text { for social order and safety } \\
\text { of the city }\end{array}$ & for the benefit of national tourism \\
\hline & \multirow[t]{2}{*}{ Activities } & Types & $\begin{array}{l}\text { safety, general } \\
\text { organization, cleanliness, } \\
\text { physical environment }\end{array}$ & $\begin{array}{l}\text { safety, general } \\
\text { organisation, cleanliness, } \\
\text { physical environment }\end{array}$ & $\begin{array}{l}\text { safety, general } \\
\text { organisation and social } \\
\text { order, cleanliness, } \\
\text { tourism promotion }\end{array}$ & $\begin{array}{l}\text { safety, general organization } \\
\text { and social order, cleanliness, } \\
\text { tourism promotion }\end{array}$ & $\begin{array}{l}\text { safety and traffic, tourism } \\
\text { promotion and public relations, } \\
\text { venue and ceremony, cleanliness, } \\
\text { medical treatment }\end{array}$ \\
\hline & & $\begin{array}{l}\text { Levels of } \\
\text { intensity }\end{array}$ & $\begin{array}{l}\text { different levels of } \\
\text { intensity in different } \\
\text { areas of the beach zone }\end{array}$ & $\begin{array}{l}\text { high level of intens ity in } \\
\text { safety and general } \\
\text { organisation }\end{array}$ & $\begin{array}{l}\text { low level of intensity of } \\
\text { all activities }\end{array}$ & $\begin{array}{l}\text { high level of intensity of all } \\
\text { activities }\end{array}$ & $\begin{array}{l}\text { high level of intensity of safety } \\
\text { and traffic, public relations }\end{array}$ \\
\hline & \multirow[t]{3}{*}{ Integration } & $\begin{array}{l}\text { Types of inter- } \\
\text { relationships }\end{array}$ & single dyadic & $\begin{array}{l}\text { mixed dyadic } \\
\text { set }\end{array}$ & single dyadic & network & $\begin{array}{l}\text { set } \\
\text { network }\end{array}$ \\
\hline & & of resources & no & yes & no & yes & yes \\
\hline & & Levels & low & high & low & high & high \\
\hline \multicolumn{3}{|c|}{ Management issues } & $\begin{array}{l}\text { unclear and overlap of } \\
\text { responsibilities } \\
\text { negotiation of power } \\
\text { and benefits from the } \\
\text { local beach business } \\
\text { organisations }\end{array}$ & $\begin{array}{l}\text { unclear operational } \\
\text { timeframe and } \\
\text { effectiveness of some } \\
\text { projects }\end{array}$ & $\begin{array}{l}\text { unclear and overlap of } \\
\text { responsibilities } \\
\text { a lack of serious } \\
\text { implementation of laws }\end{array}$ & $\begin{array}{l}\text { the committee's president } \\
\text { cannot directly control the } \\
\text { operation of other members } \\
\text { willingness to participate } \\
\text { and open discussion } \\
\text { amongst members is } \\
\text { required }\end{array}$ & $\begin{array}{l}\text { financial resources are from a } \\
\text { single agency } \\
\text { control function is used through } \\
\text { the line of authority in ind ividual } \\
\text { agencies } \\
\text { executives of relevant agencies } \\
\text { need to be involved }\end{array}$ \\
\hline
\end{tabular}


The management dimensions of particular tourism attractions consist of management agencies, management purposes, management activities, and management integration. First, management agencies refer to agencies that are involved in managing particular tourism attractions. These agencies may come from different operational sectors and scales. They may be involved as single agencies (shown in Table 9.1 as 'individual'); or they may engage with other relevant agencies in some forms of coordination (shown as 'working units' and 'committees'). The forms of coordination may be established formally or informally depending on relevant agencies and their management objectives. The management structure of relevant agencies undertaking particular activities may be 'collective' or 'non-collective'. Their responsibilities may differ depending on their involvement and management structures. Individual management agencies may be solely responsible for carrying out their tasks (shown as 'separate') or they may share similar responsibilities with other agencies (shown as 'collective'). The management purposes, the second dimension of destination management, refer to what the agencies aim to achieve. They are categorised into primary and secondary purposes. In order to pursue their management purposes, tourism-related activities, the third dimension of destination management, is undertaken by them.

Table 9.1 shows that multiple types of activities are carried out in managing different types of tourism attractions with varying degrees of intensity. The levels of intensity can be measured in terms of frequency of undertaking, numbers of related subactivities and projects, and numbers of agencies involved. How the relevant agencies are working together to carry out particular activities is presented in the last dimension: management integration. Management integration can be measured in terms of the types of inter-relationships, the extent of coordination of resources, and the levels of the integration from low to high. Different types of inter-relationships between relevant agencies result in different levels of integration in managing particular tourism attractions.

The management of the major tourism attractions in Pattaya, used as sub-cases in this study, are presented in the three main columns. The management of the beaches, the primary tourism attraction in Pattaya, is presented in the first column. Beach 
management is separated into two components: daily operations and project operations. Daily operations refer to the practices to manage the beaches on a daily basis; while project operations refer to the practices to manage the beach related projects. Garbage collection along the beaches is an example of daily operations; the beach security project is an example of project operations (section 6.5). Likewise, the management of nightlife attractions, the second primary tourism attraction of Pattaya, consists of two components: the management of the dispersed nightlife businesses that are scattered throughout the city area and those that are clustered in Walking Street (section 7.2). In the last column, the management of Pattaya Music Festival is presented. Although the festival consists of three musical performing stages (section 8.2), there is no difference in the management of those three stages. All activities are carried out to manage the festival as a whole. The issues, presented in the last row of the diagram, are used to reflect the strengths and weaknesses of particular management patterns.

Table 9.1 enables systematic comparisons to be made between the management of different tourism attractions. First, similarities and differences in the management of the three tourism attractions are identified in terms of individual management dimensions. The broad patterns of management are clarified and compared across the sub-cases. Similar and different patterns of management can be identified.

In terms of management agencies, it can be seen that multiple agencies are involved in managing the three tourism attractions. They are from different operational sectors and levels. Key agencies are Pattaya City and other public and private agencies depending on the types of tourism attractions. The details regarding the specific management agencies are elaborated on in Table 9.2. Single agencies are involved in the daily operation of the beaches and of the dispersed nightlife businesses, but some form of coordination takes place in the management of the beach projects, Walking Street, and the festival. Two types of management agencies can be identified: single agencies and agencies that engage in some working units or committees. Their involvement, management structures, and their responsibilities are further discussed in section 9.3.1. 
Similarities and differences between the primary and secondary management purposes are shown in Table 9.1. The primary purposes of single agencies in the daily operation of the beaches and of the dispersed businesses are similar: to achieve individual organizational goals. In contrast, the agencies engaged in the projects aim to achieve the projects' goals. A working unit of Pattaya City and the police in the security project along Pattaya Beach, the Walking Street Committee to develop the street as a major tourism attraction in the city, and the establishment of several committees to manage the Pattaya Music Festival to achieve its goals are examples of this latter approach.

The secondary purposes are present only in the management of the beaches and the nightlife attractions, and they are different. Beach management aims to benefit Pattaya's tourism in general (section 6.3), while nightlife management aims for social order and to bring safety to the city (section 7.3). There is no secondary purpose in the management of Pattaya Music Festival because its management purposes are to achieve all the goals that are clearly stated as the project's objectives (see Figure 8.4). Based on Table 9.1, it can be concluded that the types of tourism attractions, the involvement, and the management structure of relevant agencies creates similarities or differences in the primary and secondary management purposes. In order to pursue their management purposes, a range of activities is carried out by relevant agencies.

In terms of management activities, Table 9.1 illustrates that multiple tourism-related activities are undertaken in Pattaya. Although similar activities are carried out in managing the three tourism attractions, particular activities may be undertaken with different levels of intensity. Project-based management activities tend to have a higher level of intensity than those involving daily operations. The activities related to the management of the beach projects, Walking Street, and the festival are undertaken at a higher level of intensity than those for the daily operation of the beaches and the dispersed nightlife businesses. The levels of intensity for daily beach operation also vary depending on the physical and geographical areas of the beach zone. The activities and levels of intensity undertaken in specific areas of the beach zone, of the dispersed businesses and Walking Street, and of the festival are 
presented in Table 9.3 and discussed further in section 9.3.2. In carrying out particular activities, relevant agencies interact in different ways reflecting different forms and levels of management integration.

In terms of management integration, it can be seen that different types of interrelationships between relevant agencies and the existence of coordination in management resources create different levels of management integration. There is a lack of coordination and a low level of management integration in terms of agencies engaged in daily operations. Single agencies are involved in managing the daily operation of the beaches and the dispersed nightlife businesses. In daily operations, Pattaya City may work in association with other public agencies because it does not have the authority to operate or to solve some issues and may need to work with some businesses or private organisations on some issues. The interaction between Pattaya City and these agencies mostly occurs in a single dyadic form (see Chapter 6 for details). The coordination between Pattaya City and other public agencies may or may not occur. Thus, there is no single organisation or working group to control the operations of all relevant agencies. Pattaya City can only inform the relevant agencies regarding emerging issues or problems that are beyond its authority. Since relevant agencies are involved as single agencies and work separately, the overlapping of tasks and responsibilities appears in the daily management, while this overlap issue does not appear in project-based management.

In contrast, the interactions of relevant agencies in project-based management create a high level of management integration. Pattaya City and other agencies from the public and private sectors and from different operational scales are collectively involved in some forms of coordination to carry out particular activities to achieve the project's goals. Working unit members, the Walking Street Committee, and several functional committees in the management of the festivals are examples. Their inter-relationships occur in several forms but a high level of integration is present. The management structure of their engagement can be formally or informally established depending on the objectives of the projects and the relevant agencies. For example, the beach cleaning project represents an informal form of coordination between Pattaya City and other public and private sectors while the beach security 
project represents a formal form of coordination between Pattaya City and the police offices (section 6.5). A committee, as represented in the management of Walking Street and of the festival, is another example of a formal form of coordination. In carrying out particular activities, planning, organising, monitoring, and controlling functions are exercised. The management of the beach's security project and of Walking Street are examples. In the case of the management of the Pattaya Music Festival, these managerial functions were directly exercised by different committee members and through the lines of authority of individual public agencies. The bureaucracy and lines of authority of the public sector, as presented in daily management, do not seem to be a major issue in managing the Pattaya Music Festival.

By looking across the sub-cases in terms of the management dimensions, three patterns of management can be identified: the management of single agencies, of some forms of coordination, and of working committees. The management of single agencies reflects a management structure where the primary purpose is to achieve individual organizational goals. It creates a low level of intensity in carrying out management activities. A lack of coordination of resources is characterised by a low level of inter-organizational relationships. Without a collective management structure, these agencies are solely responsible for carrying out their own tasks. Their primary management purposes are to achieve their individual organizational goals, which appear to be diverse and fragmented. Activities are carried out at various levels of intensity in the beach zone and at a lesser level of intensity in the dispersed nightlife businesses. The interaction between relevant agencies occurs in single dyadic relationships. There is a lack of resource coordination. In this regard, a low level of management integration occurs. Similar management issues, presented at the bottom of the daily operation and the dispersed business columns of Table 9.3, reflect the deficiency of this management pattern.

In contrast, engaging in some form of coordination reflects a collective structure of relevant agencies with the primary purpose of achieving shared goals. This pattern creates a high level of intensity in carrying out a single or a range of management activities. It also promotes a high level of management integration amongst relevant 
agencies. This pattern is evident in the management of the beach projects, Walking Street, and the Pattaya Music Festival. Within particular forms of coordination, the relevant agencies may interact through various forms of inter-relationships, but a high level of management integration occurs through their interactions. A high level of management integration tends to reflect the effectiveness or strength of this management pattern. Although management issues are present, they appear to vary depending on the physical characteristics of tourism attractions and related projects. Thus, these issues indicate that different forms of coordination may be required in the management of different projects to be effective and for successful outcomes.

Furthermore, the close commonality between the management of Walking Street and the Pattaya Music Festival also reflects another management pattern, the formation of working committees. This refers to a formal collective structure in carrying out sets of activities to achieve the goals shared by committee members. As seen in Table 9.1, this management pattern may involve single or several committees that are formally established by relevant agencies. The Walking Street Committee is formally established by the cooperation of the municipality and the local businesses (section 7.2). All related activities are collectively carried out by the committee members to achieve the goals of Walking Street (section 7.4). In the management of Pattaya Music Festival, eight committees are formally established to exercise three main functions: provide advice, administration, and operations (section 8.3). All relevant agencies are officially appointed to these different functional committees to manage the festival overall. Interaction between committee members creates a high level of management integration. Normally, a project's goals are established by committee members and all agencies work in a collaborative fashion to achieve them. This pattern is formally structured and the responsibilities are shared by all agencies that act as the committee members. Resources are coordinated. The management of the Pattaya Music Festival clearly illustrates this collective action. Although, the festival's goals are mainly established by the TAT Bangkok Office, other agencies that are committee members appeared to have a common understanding of those goals and as a result management activities tend to be carried out with more focus. The management issues, presented in Walking Street and the festival, reflect 
different characteristics of particular committees that may hinder or enhance effective management.

The management of these sub-cases reflects the management of different tourism attractions in Pattaya. Based on the information obtained in this study, the management of these sub-cases does not appear to be integrated with the management of other tourism products in Pattaya. The management of basic infrastructure, accommodation, transportation, and food service are examples. Each sector tends to be managed separately by different agencies. According to the interview respondent from the Bangkok Airport, the airports in Thailand are managed to provide services for people who are coming into or going out of the country. Tourists were perceived as one group of the airport's customers. Pattaya, although it is seen as one of the major tourism destinations, is not relevant to the airport management. The primary responsibility for road construction lies with the Ministry of Interior, Public Works Department. The provincial public works department and Pattaya City may get involved at some stage since they are local government bodies which are responsible for public administration in Pattaya.

Table 9.1 enables the commonalities and differences in the management of the three sub-cases to be identified and the broad patterns of management to be established. There are three different management patterns obtained from the study of destination management in the context of Pattaya. These management patterns tend to bring better understanding to how the agencies from different operational sectors and scales at the local destination are integrated at the destination level and to how different forms of involvement and management structure can influence the management practices and outcome. The broad patterns of management will be used to discuss the management of tourism in Pattaya as a whole destination in order to clarify whether, in what ways, and to what extent destination management is practised in Pattaya.

\subsubsection{Multiple agencies and their management involvement}

Because of its geographical scale and physical characteristics as a beach resort city and its national importance, multiple agencies are involved in managing different 
aspects of Pattaya. They are from the public and private sectors and from national to local operational levels. In daily management, these agencies are involved as single agencies. They work independently and are solely responsible for carrying out their organisational tasks. On the other hand, they may work together in carrying out particular projects.

Table 9.2 presents the agencies that are involved in managing the three attractions studied in Pattaya. They are presented according to their operational scales and sectors of involvement in particular attractions. Some agencies are involved in managing all three attractions, while some agencies are responsible for managing particular attractions. Tourist Police Region 3 Office, Tourism Authority of Thailand Central Region 3 Office, provincial government, district government, Pattaya City, and local police Pattaya Office tend to be key agencies in managing different aspects of Pattaya because they are involved in managing all three attractions. Normally, Pattaya City appears to have sufficient autonomous authority to carry out many activities across the city, while other public agencies are responsible for carrying out their organizational tasks in a specific area (Chapter 4). According to the organizational regulations or administration acts of the public sector (e.g., the Pattaya City Administration Act 1999), the public agencies may collaborate when required, but whether such collaboration occurs depending on the decision of each agency (discussed in section 6.7). Overlapping of work and responsibilities carried out by public agencies occurs in the daily management of Pattaya (Chapters 6 and 7). The private agencies are generally responsible for their own operations. Some business clubs and associations may cooperate with the government bodies and other public agencies to ensure that the rules and regulations are followed by their members. 
Table 9.2: Public and private agencies involved in managing Pattaya's attractions.

\begin{tabular}{|c|c|c|c|c|c|c|}
\hline \multirow{2}{*}{$\begin{array}{l}\text { Operational } \\
\text { scales }\end{array}$} & \multicolumn{2}{|l|}{ Beaches } & \multicolumn{2}{|c|}{ Nightlife } & \multicolumn{2}{|c|}{ Pattaya Music Festival } \\
\hline & Public sector & Private sector & Public sector & Private sector & Public sector & Private sector \\
\hline National & $\begin{array}{l}\text { Ministry of the Interior } \\
\text { Ministry of Natural Resources and } \\
\text { Environments }\end{array}$ & & $\begin{array}{l}\text { Ministry of } \\
\text { the Interior }\end{array}$ & & $\begin{array}{l}\text { Tourism Authority of Thailand } \\
\text { (TAT), Bangkok office }\end{array}$ & $\begin{array}{l}\text { The music companies such as } \\
\text { Grammy, RS, and MTV }\end{array}$ \\
\hline Regional & $\begin{array}{l}\text { Royal Thai Navy, Sattahip Naval } \\
\text { Base } \\
\text { Tourist Police, Region } 3 \\
\text { Marine Police, Regional Office } \\
\text { Marine Transportation/Harbour } \\
\text { Department, Chonburi Office } 6 \\
\text { Tourism Authority of Thailand, } \\
\text { Central Region } 3 \text { Office } \\
\text { Immigration Police, Pattaya Office }\end{array}$ & & $\begin{array}{l}\text { Tourist } \\
\text { Police, } \\
\text { Region } 3 \\
\text { Tourism } \\
\text { Authority of } \\
\text { Thailand, } \\
\text { Central } \\
\text { Region } 3 \\
\text { Office }\end{array}$ & & $\begin{array}{l}\text { Royal Thai Navy, Sattahip } \\
\text { Naval Base } \\
\text { Royal Thai Army, Base } 14 \\
\text { Royal Thai Police, Area } 2 \\
\text { Tourist Police, Region } 3 \\
\text { Tourism Authority of Thailand, } \\
\text { Central Region } 3 \text { Office } \\
\text { Highway Police, Region } 3 \\
\text { Radio station, Eastern region }\end{array}$ & $\begin{array}{l}\text { Thai Hotel Association, } \\
\text { Eastern Region }\end{array}$ \\
\hline Provincial & Provincial government & & $\begin{array}{l}\text { Provincial } \\
\text { government }\end{array}$ & & $\begin{array}{l}\text { Provincial Government } \\
\text { Provincial Administration } \\
\text { Organisation } \\
\text { Police, Chonburi office }\end{array}$ & $\begin{array}{l}\text { Chonburi Tourism Attraction } \\
\text { Club }\end{array}$ \\
\hline District & District government & & $\begin{array}{l}\text { District } \\
\text { government }\end{array}$ & & $\begin{array}{l}\text { District government } \\
\text { Police, Banglamung office } \\
\text { Electric Supply, Banglamung } \\
\text { office }\end{array}$ & $\begin{array}{l}\text { Phayathai Sriracha Hospital } \\
\text { Banglamung Hospital }\end{array}$ \\
\hline $\begin{array}{l}\text { Local/ } \\
\text { Pattaya }\end{array}$ & $\begin{array}{l}\text { Pattaya City } \\
\text { Local Police, Pattaya office }\end{array}$ & $\begin{array}{l}\text { Tourism Boat } \\
\text { Club } \\
\text { Beach Umbrella } \\
\text { Club } \\
\text { Pattaya Bus Co- } \\
\text { operative Limited }\end{array}$ & $\begin{array}{l}\text { Pattaya City } \\
\text { Local Police, } \\
\text { Pattaya office }\end{array}$ & $\begin{array}{l}\text { Business } \\
\text { representatives in } \\
\text { Walking Street } \\
\text { (the Walking } \\
\text { Street } \\
\text { Committee) } \\
\text { Beer Bar } \\
\text { Business } \\
\text { Association }\end{array}$ & $\begin{array}{l}\text { Pattaya City } \\
\text { Local police, Pattaya office } \\
\text { STR Radio station (owned by } \\
\text { Navy) }\end{array}$ & $\begin{array}{l}\text { Pattaya Press Association } \\
\text { Pattaya Tourism Business } \\
\text { Association } \\
\text { Pattaya Hotel Club } \\
\text { Pattaya Restaurant Club } \\
\text { Pattaya Bus Co-operative, } \\
\text { Limited } \\
\text { Pattaya Memorial Hospital } \\
\text { Bangkok-Pattaya Hospital } \\
\text { Volunteer Groups }\end{array}$ \\
\hline
\end{tabular}


However, individual public and private agencies are engaged in some forms of coordination in project-based management. Project-based management is more collective and structured with respect to different operational functions (as seen in Chapter 8), and urgent environmental, social, and economic issues (as reflected in the beach projects and Walking Street). Overlapping of work and responsibilities in the project-based management rarely appears. The work of the Walking Street Committee and the festival committees is an example. In project management, the coordination between relevant public agencies occurs because of the organizational regulations or acts, as mentioned earlier. The official announcement to obtain cooperation and coordination of relevant agencies in festival management (Chapter 8) is an example. Although the businesses are not regulated to collaborate, they may cooperate in the festival for their own benefit between business marketing and developing connections. A common interest also seems to promote coordination between relevant agencies, as seen with the cooperation between Pattaya City and the local businesses to develop Walking Street and the security project along Pattaya Beach. The intention to achieve a project's goals, as reflected in festival management, tends to be another factor that promotes coordination.

Various factors create different forms of involvement. The national administrative system and the differences in operational sectors and organizational cultures tend to create involvement as single agencies, while their organizational regulations, their mutual interest, and their intentions to achieve a project's goals tend to foster coordination. The number of agencies involved in daily management and projectbased management may differ depending on various factors. Physical features of tourism attractions, sizes/spaces of attractions, and degree of tourism concentration are examples. Many public agencies are involved in the daily management of the beaches because of the complex and diverse physical characteristics of the beach zone (Chapter 6). Thus, different areas of the beach zone can cover large spaces, both on land and at sea. Different public agencies that are responsible for those areas need to be involved in beach management. Likewise, a large number of public and private agencies are involved in managing the Pattaya Music Festival because it is a national tourism promotion project. In contrast, lesser numbers of agencies are involved in managing the nightlife businesses because of their specific location and service type. 


\subsubsection{Multiple management activities with different levels of intensity}

Multiple tourism-related activities are undertaken in Pattaya. Based on the findings, they can be categorised into activities related to tourism marketing, safety, general organisation, cleanliness, and natural resources and the environment. Levels of intensity in carrying out particular activities differ depending on various factors. The factors can be the physical and geographical features of tourism attractions, the scale of attractions/activities, time and space of operation, and the degree of tourism concentration. In managing particular tourism attractions, certain activities are carried out at a higher level of intensity than others. The project-based activities are also undertaken at a higher level of intensity than the daily activities.

Table 9.3 shows tourism-related activities that are carried out in managing different tourism attractions. A high level of intensity in carrying out particular activities is evident. Across the top of the diagram are the three attractions. In the first column, beach management is separated into five different geographical areas of the beach zone (section 6.2). As presented in the second column, nightlife management is separated into the dispersed nightlife businesses and Walking Street. The final column presents the management of Pattaya Music Festival. The activities that are carried out in managing particular tourism attractions are presented down the left side of the diagram. They are grouped into the activities related to tourism marketing, safety, general organization, cleanliness, and natural resource and environment. Activities related to tourism marketing are tourism promotion and public relations. The activities related to safety include general safety such as the suppression of crimes and drugs, traffic, and medical treatment. General organization of the city refers to the activities to create and organise the physical appearance of the attractions and the city overall. These activities are divided into those related to physical appearance, social order, and venue and ceremony. Cleanliness refers to garbage/waste collection and other cleaning activities. Natural resource and environment refers to waste water treatment, seawater monitoring and control, and activities that create or enhance the quality of natural resources and the environment. The symbol ' $X$ ' is used to represent the activities that are carried out in particular areas and attractions. They are undertaken by single agencies in the daily management, and by working units or committees in project-based management. The 
term 'High' is used to represent a high level of intensity to carry out particular activities in particular areas and attractions. The activities that are carried out in managing different tourism attractions and a high level of intensity to carry out particular activities are discussed below.

Table 9.3: Management activities undertaken in Pattaya.

\begin{tabular}{|c|c|c|c|c|c|c|c|c|c|}
\hline & & \multicolumn{5}{|c|}{ Beach zone } & \multicolumn{2}{|c|}{ Nightlife } & \multirow[b]{2}{*}{$\begin{array}{l}\text { Pattaya Music } \\
\text { Festival }\end{array}$} \\
\hline \multicolumn{2}{|c|}{$\begin{array}{l}\text { Management activities and } \\
\text { areas and levels of intensity }\end{array}$} & Area A & Area B & Area C & Area D & Area E & $\begin{array}{l}\text { Dispersed } \\
\text { nightlife }\end{array}$ & $\begin{array}{l}\text { Walking } \\
\text { Street }\end{array}$ & \\
\hline \multirow[t]{2}{*}{$\begin{array}{l}\text { Tourism } \\
\text { marketing }\end{array}$} & $\begin{array}{l}\text { Tourism } \\
\text { promotion }\end{array}$ & $\mathrm{X}$ & $\mathrm{X}$ & $\mathrm{X}$ & $\mathrm{X}$ & $\mathrm{X}$ & $\mathrm{X}$ & $\begin{array}{c}\mathrm{X} \\
\text { High }\end{array}$ & $\mathrm{X}$ \\
\hline & $\begin{array}{l}\text { Public } \\
\text { relations }\end{array}$ & & & & & & & & $\begin{array}{c}\text { X } \\
\text { High }\end{array}$ \\
\hline \multirow[t]{3}{*}{ Safety } & $\begin{array}{l}\text { General } \\
\text { safety }\end{array}$ & $\mathrm{X}$ & $\mathrm{X}$ & $\begin{array}{c}\mathrm{X} \\
\text { High }\end{array}$ & $\begin{array}{c}\mathrm{X} \\
\text { High }\end{array}$ & $\begin{array}{c}\text { X } \\
\text { High }\end{array}$ & $\mathrm{X}$ & $\begin{array}{c}\mathrm{X} \\
\text { High }\end{array}$ & $\begin{array}{c}\mathrm{X} \\
\text { High }\end{array}$ \\
\hline & Traffic & & $\mathrm{X}$ & & & $\mathrm{X}$ & $\mathrm{X}$ & & $\mathrm{X}$ \\
\hline & $\begin{array}{l}\text { Medical } \\
\text { treatment }\end{array}$ & & & & & & & & $\mathrm{X}$ \\
\hline \multirow[t]{3}{*}{$\begin{array}{l}\text { General } \\
\text { organization }\end{array}$} & $\begin{array}{l}\text { Physical } \\
\text { appealing }\end{array}$ & $\mathrm{X}$ & $\mathrm{X}$ & $\begin{array}{c}\mathrm{X} \\
\text { High }\end{array}$ & $\begin{array}{c}\mathrm{X} \\
\text { High }\end{array}$ & $\mathrm{X}$ & $\mathrm{X}$ & $\begin{array}{c}\mathrm{X} \\
\text { High }\end{array}$ & $\mathrm{X}$ \\
\hline & Social order & & & & & & $\mathrm{X}$ & $\begin{array}{c}\mathrm{X} \\
\text { High }\end{array}$ & \\
\hline & $\begin{array}{l}\text { Venue and } \\
\text { ceremony }\end{array}$ & & & & & & & & $\mathrm{X}$ \\
\hline \multicolumn{2}{|l|}{ Cleanliness } & $\mathrm{X}$ & $\mathrm{X}$ & $\mathrm{X}$ & $\mathrm{X}$ & $\mathrm{X}$ & $\mathrm{X}$ & $\begin{array}{c}X \\
\text { High }\end{array}$ & $\mathrm{X}$ \\
\hline \multicolumn{2}{|c|}{$\begin{array}{l}\text { Natural resource and } \\
\text { environment }\end{array}$} & & & $\mathrm{X}$ & $\mathrm{X}$ & $\mathrm{X}$ & & & \\
\hline
\end{tabular}

\subsubsection{Tourism marketing}

Multiple marketing activities are undertaken to attract tourists to Pattaya. Although the beaches are the prime tourism resource of the city, they do not seem to attract enough tourists and other tourism products are developed and promoted to draw more tourists to the city. Generally, Pattaya City, TAT Central Region 3 Office, and the business organisations such as Pattaya Tourism Business Association and the Thai Hotel Association Eastern Regional Office are the key agencies responsible for marketing Pattaya as a 'city of variety’ (Chapter 4). Moreover, individual businesses also promote their tourism products and services provided there.

Walking Street and the festival are marketed with a high level of intensity. Since Walking Street is developed to be a major tourism nightlife attraction in Pattaya, various activities are carried out to promote the street. Several fairs and festivals are 
frequently undertaken in the street (Chapter 7). To achieve the goals of attracting large numbers of tourists, the Pattaya Music Festival is advertised frequently through several media channels.

\subsubsection{Safety}

As discussed in Chapter 4, Pattaya's society consists of diverse cultural groups of people and large numbers of short-term migrants. Local news regarding crime, drugs, and theft also shows that safety is a major issue in the city. An attempt is made to solve this issue by multiple agencies. Beach management is an example. The local police and tourist police are key agencies responsible for safety in the areas A to D of the beach zone, while Pattaya City and the marine police are key agencies responsible for area $\mathrm{E}$. The local police are also primarily responsible for safety of the dispersed nightlife businesses, while the tourist police are responsible for safety in Walking Street. All police offices and other public agencies such as the army and the navy are responsible for safety at the Pattaya Music Festival.

Particular safety activities are undertaken with a higher level of intensity in some areas of the beach zone, in Walking Street, and at the festival. Due to the concentration of tourists in these areas, more safety activities are carried out in areas C to E, for example, the security project along Pattaya Beach and the implementation of laws regarding marine security. Safety activities are also carried out at a higher level of intensity in Walking Street than amongst the dispersed nightlife businesses. Because Walking Street is a major nightlife attraction that draws many tourists, safety is crucial for the quality and positive image of the attraction. Safety activities are also very important in managing the Pattaya Music Festival because it involves large numbers of tourists.

\subsubsection{General organisation of the city}

Multiple activities are also carried out for the general organization of the city. They are related to orderliness, tidiness, and positive physical appearance of the attractions and the city in general. These activities are carried out by different agencies depending on the type and location of attractions. Pattaya's security staff are responsible for carrying out activities related to the general organization of beach 
vendors and the physical appearance of the beach zone. Social order is enforced by the police. Most activities are carried out to ensure that the operation of nightlife businesses follows the social order policy and related laws. In festival management, activities related to the physical appearance of the festival venue and the ceremony are carried out by its committee members.

Similar to safety, some activities are carried out to a greater extent in the areas concentrated on tourism. As seen in Table 9.3, areas C and D of the beach zone and Walking Street are managed to a greater extent than the other areas. As described in Chapter 6, many prostitutes and mobile vendors are always present at the promenade (area C) and the beach (area D). A daily patrol to keep them away from both areas of the beach zone is undertaken by Pattaya's security staff. However, they are not always successful, as many prostitutes and mobile vendors can still be seen in those areas. Action to keep them away from the beach zone rather than to suppress them seriously might be a reason for this ineffective practice. On the other hand, the organization of the beach umbrella shops in area D of the beach zone and of stall vendors in Walking Street tends to be more successful for the general organization of the city. In relation to social organization, nightly patrols of the tourist police and security volunteers in Walking Street are undertaken to ensure that individual nightlife businesses in the street follow the social order and related laws. Similar approaches are carried out in the other areas of the city but to a lesser extent.

\subsubsection{Cleanliness}

Generally, Pattaya City is the only agency responsible for cleaning the city. Garbage/waste collection in the beach zone and throughout the city is carried out by Pattaya City. On special occasions such as public holidays, several joint cleaning projects are organized by Pattaya City and/or other public and private agencies, for example, the projects to collect garbage on the beaches and under the sea and to clean the city, mentioned in Chapters 6 and 7. Since hundreds of thousands tourists attend the Pattaya Music Festival each night, cleaning is also crucial to maintain the physical appeal of the venues. 


\subsubsection{Natural resources and physical environment}

As discussed in Chapter 4, some environmental problems are still present in Pattaya although its natural resources have been improved. An attempt to improve the overall quality of seawater is made (Chapter 6). In relation to the implementation of the Environmental Act in Pattaya, two wastewater treatment sites in the city area and one site in Larn Island have been established to help improve seawater quality. At present, the seawater in Pattaya is only of swimming standard. The disposal of unused drainage pipes into the sea to increase the presence of marine creatures, as described in Chapter 6, is an example of efforts to improve quality of tourism natural resources. Activities to improve the natural resources for the management of nightlife and Pattaya Music Festival are not evident. Strong odours of waste water in the Walking Street area suggest that there is a serious need for better management to improve the quality of the physical environment. A stronger desire and more effective management to improve the quality of its natural resource and physical environment are necessary if Pattaya is to be successfully marketed as a beach resort.

It can be concluded that similar activities are carried out in managing different tourism attractions in Pattaya. The activities related to tourism marketing, safety, general organization, and cleanliness are carried out in managing the three attractions, while the activities related to natural resource and environment are limited to beach management. Some activities are carried out at a higher level of intensity in the areas or attractions that concentrate on tourism. The findings tend to reflect the relationships between a destination life-cycle stage and types of management activities. As Pattaya has reached its maturity stage, some intense marketing activities are necessary to attract a certain number of tourists, while other activities are necessary to improve the overall quality of its tourism products. Achieving a balance between marketing activities and those related to destination resources with respect to the destination life-cycle stage appears to be crucial in terms of destination management.

\subsection{Implications of the study}

As mentioned in Chapter 1, this thesis intends to increase understanding of the notion of destination management by developing the concept of destination management 
and using it to clarify whether destination management is practised in Pattaya. By using Pattaya as a case study, the concept of destination management has been developed and the practice of destination management has been clarified. According to the concept of destination management used in this study (see Chapter 5 and section 9.2.2), destination management is 'the collaboration of relevant agencies responsible for providing multiple tourism products at the destination in a way to achieve destination goals or common goals'. Regarding this concept, collaboration of relevant agencies, provision of multiple tourism products, and destination goals/common goals are required in the practice of destination management. Collaboration refers to integration or collective action of relevant agencies in managing all tourism products and the destination as a whole, while destination goals or common goals refer to statements that illustrate an overall picture of what the destination wants to be or to achieve. With reference to this concept, it can be seen that the management in Pattaya involves multiple agencies, multiple tourism-related activities, and multiple management purposes. Collaboration is present to some extent but destination goals/common goals are not found there. The management practices in Pattaya are discussed below to clarify whether destination management is practised there.

First, the study shows that multiple public and private agencies from national to local operational levels are involved in managing multiple tourism products in Pattaya. As perceived by the practitioners, these agencies are the main tourism providers and they appear to be the key stakeholders in managing tourism-related products and services at the local destination. Since the public agencies from different operational scales are primarily responsible for public administration of the local areas, they are required to be involved in the management of these areas. For example, they are responsible for establishing and taking care of basic infrastructure such as construction of public facilities, water supply, and electricity for the quality of life of people in the destination area. On the other hand, local businesses and related business organisations at local and other scales are responsible for the operation of individual businesses to provide quality tourism-related products and services to the tourists. 
The study shows that relevant agencies can be involved at the local destination in three different forms: as single agencies, as agencies engaged in some forms of coordination, and as formal members of working committees. The levels of management integration between the three forms of involvement are different. Their roles and responsibilities may also be similar or different depending on their organisational tasks and their forms of involvement. A high level of integration practised by all relevant agencies, as suggested by the practitioners, is necessary for effective management and successful outcomes. In Pattaya, a high level of management integration is reflected only in project-based management but not in daily management. Thus, effective management and successful outcomes are clearly present only in the pattern of working committees that manage Walking Street and the Pattaya Music Festival. In other projects such as the security project of Pattaya Beach (discussed in section 6.7), the management tends to be less effective. Based on the evidence of this study, the working committee tends to be the most effective management pattern. However, it does not occur at the destination level. In terms of destination management, the collective involvement of relevant agencies as formal members of the destination working committee to oversee overall tourism-related management in Pattaya would be helpful for effective management practices. Without the coordinating unit/organisation to oversee their management practices, different directions of management occur.

Second, the study shows that multiple tourism products are managed in Pattaya. Multiple tourism-related activities are undertaken there but at varying levels of intensity. As a mature coastal destination, multiple activities are carried out to provide multiple tourism products and services in Pattaya (as described in Chapter 4). A high level of intensity of tourism marketing activities undertaken to promote multiple tourism products and services in Pattaya could reflect an attempt to draw larger numbers of tourists to the city. Likewise, safety and general organisation activities that are carried out to a greater extent in the concentrated tourism areas could reflect an attempt to provide quality tourism products in the city.

Although multiple tourism-related activities are undertaken in Pattaya, they are not integrated across the destination level. Marketing activities are undertaken to 
promote several tourism products and services within Pattaya rather than to promote Pattaya as a single product through its image, branding, and positioning. Other activities are undertaken to improve the quality of particular tourism products rather than the quality of the destination overall. Thus, there is a lack of connection in carrying out activities related to the management of tourism products. The management of the beaches and of the Pattaya Music Festival are examples. Although the beach theme is emphasised for the Pattaya Music Festival (Chapter 8), there is no evidence to show any connection between the beach management and the festival management. In this regard, the activities that are undertaken in Pattaya do not appear to deliver a clear image, brand, or market positioning of Pattaya. With diverse products and services when marketing Pattaya, an image of Pattaya might be perceived differently by different tourists. For example, they may see Pattaya as a beach resort city, a nightlife resort, a festival destination, or a city with various problems. Thus, all these activities are not integrated and undertaken in a way to strengthen the destination characteristic. The main characteristic of Pattaya as 'a city of variety' indicates this issue. This characteristic of Pattaya did not seem to be used in its early stages of development, but it appeared to be the outcome of unplanned development and unclear management directions. Since Pattaya has been developed and managed without a clear direction, multiple tourism-related activities tend to be undertaken to maintain the number of tourists and to improve the quality of some tourism products rather than to strengthen the destination's identity and enhance its tourism quality as a whole. Various goals are reflected in the management practised there.

Third, the study shows that relevant agencies that are involved in the management aim to achieve various goals. In Pattaya, these goals can be categorised into organizational goals and project goals. Daily management is practised by single agencies to achieve individual organizational goals, while project-based management is practised by a project's members or committee members to achieve the goals of particular projects. As was evident in project-based management, management with goals that are shared by relevant agencies is usually more effective, while a lack of common goals tends to lead to less effective management. Although the practitioners in Pattaya believed that destination goals are necessary for management practices, 
destination goals or common goals do not exist there. An attempt to develop common goals between key agencies was mentioned by one public agency, but the differences in organizational cultures and administration systems of relevant agencies tended to minimize its success. Thus, it could also minimize their willingness to establish destination or common goals. Since destination management must have its purposes and these goals are lacking in Pattaya, the vision statement of the municipality could be shared with other agencies to establish common understanding of what the destination wants to be or to achieve.

Although the vision statement of Pattaya City seems to illustrate the future condition of Pattaya that the city council wants to see for the destination (see Table 6.2), it does not seem to be shared by other agencies. As discussed in Chapter 6, the organizational goals of relevant agencies, particularly the public sector, are related to each other in terms of public administration in the local areas. A lack of willingness of relevant agencies to develop a common understanding regarding a vision of Pattaya City might be an issue. Although other agencies may realize that they need to work with Pattaya City in some circumstances, they may not recognize its significance in relation to their organizational operations. This may lead to a narrow focus on achieving their organizational goals (or their organizational visions as discussed in section 6.3) as their priority rather than concerning the needs of Pattaya City. Furthermore, other agencies, particularly those from other scales, may be afraid of losing their authority to Pattaya City by focusing on its visions rather than their organizational goals. Their authority, particularly in decision making, might be reduced. Physical issues existing in Pattaya indicate a low level of management integration in Pattaya. A strong desire between Pattaya City and relevant agencies to make things happen would be necessary if tourism is the priority. At some point, an attempt between key agencies to establish the destination goals of Pattaya that are commonly understood and shared by them would be necessary. These common goals could bring a clearer picture of what needs to be achieved and what activities are required to accomplish the goals. As suggested by one private agency, “[Pattaya's management] needs to decide which directions we [management agencies] want to go. Then, it should have only one blueprint [of destination's goals].” Otherwise, the vision statement of Pattaya City should be shared with other agencies to provide an 
overall picture of what the municipality wants Pattaya to be as a tourism destination. Then, Pattaya City and relevant agencies would identify which activities are required to be undertaken to achieve that vision and how the outcome could be measured.

The key management practices in Pattaya, as discussed above, illustrate that destination management is not practised there. Based on the concept of destination management used in this study, the management practices in Pattaya do not match the concept. A lack of collaboration between relevant agencies at the destination level, of integration in carrying out tourism-related activities across the destination level, and of common goals/destination goals appears as a factor that creates a lack of destination management in Pattaya. Other factors may also make it more difficult for destination management to be practised there. The multiplicity of agencies that are involved in the management might be a factor that creates a lack of collaboration between relevant agencies in developing a destination working committee, as mentioned earlier. Since these agencies are from diverse operational sectors and scales, their differences in organizational cultures, administration systems, and management purposes might be another factor. Their different roles and responsibilities in managing particular tourism aspects could also be causing difficulty in establishing a destination working committee in Pattaya. Having a wide range of tourism products in Pattaya might be complex to bring together and establish committees responsible for them. The multiplicity of agencies involved in carrying out particular activities might be another factor. All these factors could lead to a lack of willingness to establish destination goals/common goals or to form a destination-level working committee to oversee overall management there. Without clear goals that are commonly shared by relevant agencies, it would be difficult for all relevant agencies to collaborate at the destination level and to identify all tourismrelated activities required at the destination and to integrate them across the destination level. In this regard, all relevant agencies are involved in managing different aspects of Pattaya rather than managing Pattaya itself.

\subsection{Lessons learned from Pattaya}

The study shows that destination management involves collaboration of relevant agencies at the destination level, integration of tourism-related activities to be 
undertaken across the destination, and common goals or shared visions to represent destination goals. Integration of management agencies, of management activities, and of management purposes at the destination level is crucial for destination management. However, the study shows that this action may not exist at the destination scale. Several issues may hinder such management integration. Some issues appear to specifically relate to the destination context. As in the case of Pattaya, these issues include a wide range of tourism products and the multiplicity of management agencies. As described in Chapter 4, its geographical and physical characteristics of a coastal resort city create a mix of natural and urban tourism resources. This could enable a wide range of tourism products to be developed and multiplicity of agencies to be involved in managing them. As also discussed in relation to its political system (see section 4.3.1), the complexity of its organizational administration could be another reason that causes involvement of multiple single agencies, particularly from the public sector. The issues of multiple agencies and a wide range of tourism products might be found in other destinations that have similar characteristics to Pattaya. In the destinations that have a different context, the number of tourism products and management agencies may differ. For examples, the number of tourism products and management agencies would be less in ski resorts or natural parks. In smaller towns, tourism products might not be varied and only a few agencies would be involved. Different issues might be found in different destinations.

On the other hand, broad issues in Pattaya that could be found in other coastal resorts or in other developing countries are a lack of integration between relevant agencies at the destination scale and a lack of common goals or destination goals. Multiple single agencies that are involved in Pattaya seem to be a reason for this. As evident in the daily operations of the beaches and nightlife attractions (see Table 9.1), these single agencies separately and independently carry out their own tasks in order to achieve their organizational goals. There is no collective action between them. Although they may work together on some projects, they appear to carry out activities to pursue the goals of particular projects. The integration between their organizational goals and project goals is not present, which tends to create a lack of common goals for their management practices. In turn, a lack of common goals could 
create a lack of collaboration between relevant agencies in carrying out their tasks, as mentioned in the previous section. These issues could be found in a destination where tourism is managed by single agencies.

Regarding these issues, some lessons can be learned from the case of Pattaya. Collaboration or collective action of relevant agencies (Jamal \& Getz, 1995; Jamal \& Jamrozy, 2006) at the destination level is required. Thus, their collaboration throughout the management process is necessary for effective management practices (Turner, et al., 2001). Since management must pursue goals (Sisk, 1969), a tourism destination is required to have its own goals, and destination management should be practised to pursue those goals. As suggested by Sisk (1969), establishment of management purposes is required in the management process. Therefore, destination management requires management purposes to achieve destination goals. If there are no destination goals, as occurs in Pattaya, common goals or shared visions need to be established as destination goals in order to develop common understanding between relevant agencies of what they aim to achieve. With common goals, tourism-related activities can be carried out in an integrated fashion in order to accomplish them (Bramwell \& Lane, 2000; C. M. Hall, 2000; R. H. Hall, 1987; Selin \& Chavez, 1995).

As in the case of Pattaya, multiple agencies are involved in managing tourism aspects of the destination. The structures to integrate them together at the destination scale and to maximise their collaboration could vary. However, a model to maximise management integration and to scale up their management practices to the destination level is presented in Figure 9.1. It is based on the findings from Pattaya and key concepts and practices of destination management discussed in the study. Four steps to maximize the management integration at the destination scale are required: to identify management agencies and establish a coordinating unit, to establish common goals or shared visions, to identify tourism aspects and relevant activities, and to identify responsible agencies to carry out those activities. 
Figure 9.1: Maximizing management integration at the local destination.

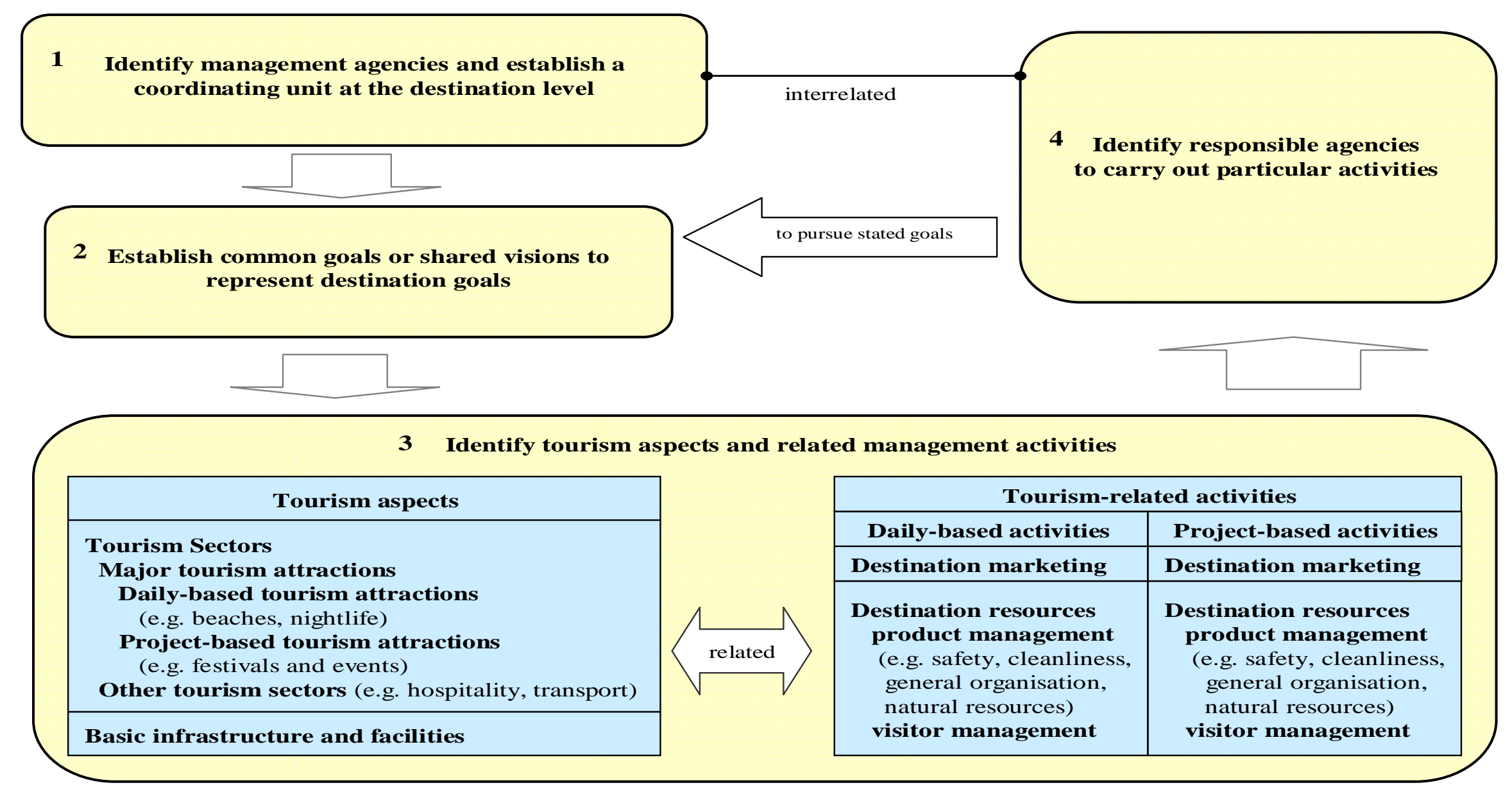


The first step is to identify management agencies that are involved in the management and to establish a coordinating unit at the destination level. As seen in Pattaya, multiple agencies are involved at the local destination but they are not integrated at the destination level. The study suggests that a coordinating unit that has broad representation from all relevant agencies could be formally established to integrate all agencies to work collectively at the local destination. This coordinating unit may be established in various forms. Examples are a destination working committee, as mentioned earlier in the thesis, or a destination management organization, also earlier discussed as DMOs in Chapter 2. Since the management agencies may come from different operational sectors and administrative levels, it is necessary to identify which agencies are involved, which operational sectors and administrative levels they are from, and what their organizational tasks are in relation to destination management. Once all agencies involved at the destination are identified, their executives or top managers could be officially appointed as members of the coordinating unit. The representatives of local residents or community leaders, which might be overlooked by the practitioners as reflected in Pattaya, should also be identified and included in the unit. With its formal structure, the collaboration of relevant agencies can be done in horizontal and vertical directions (C. M. Hall, 2000; Harvey \& Caton, 2003; Pearce, 1992; Turner, et al., 2001). The coordinating unit would enhance the collective actions through the interactions of two or more relevant agencies (R. H. Hall, 1987; Selin \& Chavez, 1995) in carrying out particular activities and managing the destination overall. Its members would be directly responsible for overseeing and coordinating relevant agencies involved in destination management and to monitor and control their organisational operations at the destination scale.

Second, the members of a coordinating unit must establish goals or visions that are commonly shared by them in order to present destination goals. The study shows that destination goals, statements that provide an overall picture of its desired future state (Terzibasoglu, 2004), may not be established or exist at the destination. The multiplicity of agencies, as reflected in the study, might raise an issue of how they can develop common goals. This task can be done through their agreement on goals in carrying out tourism-related activities (Welford \& Ytterhus, 2004) or through a 
combination of their organizational goals (Westermann, et al., 2005). Otherwise, it can be done by sharing the municipality's goals or visions in order to develop common understanding for destination management. These common goals/visions could be used as destination goals since they can broadly illustrate the future state or condition that all agencies want the destination to be or to achieve. They are defined by the agreement of the committee members and should be achievable and measurable. Deadlines, as reflected in the festival management, could be added to these goals to measure the management effectiveness and outcomes. In order to achieve their common goals, relevant tourism-related activities need to be identified and undertaken in a way that pursues those goals. For example, the prime goal of Walking Street is to be a major nightlife attraction in Pattaya. In this regard, several activities can be identified and carried out to promote intensively and manage Walking Street to pursue its goal.

Once the goals are established, tourism aspects and their relevant activities need to be identified, the third step of the model. Although multiple tourism-related activities are undertaken at the local destination (Jamieson, 2006; Ritchie \& Crouch, 2003), this study shows that they can be undertaken with different levels of intensity. A high level of intensity is present in areas of tourism concentration with lower levels of intensity in other parts of the destination. Although these activities need to be integrated for destination management (Anderson, 2000a), the study shows that overall, in practice, such integration may be very uneven and integration at the destination level may not occur. To manage the destination as a whole, the tourismrelated activities should be carried out across the destination with equal levels of intensity. At a local destination, major attractions may differ depending on the type of destination, but they can be categorised into daily and project-based attractions. Other tourism sectors such as accommodation and food services and the basic infrastructure and facilities are also provided at a destination and need to be managed. Daily and project-based activities related to destination marketing (Ritchie \& Crouch, 2003; Terzibasoglu, 2004) and destination resources (Jamieson, 2006; Ritchie \& Crouch, 2003; Terzibasoglu, 2004) should be identified in terms of the management of those tourism aspects. Specific goals and performance indicators in 
managing particular aspects might be necessary to serve the broad common goals established in the second step.

In the final step, relevant agencies and their responsibilities for carrying out particular activities need to be identified. Clarity of responsibility could minimise the issues of ambiguous and overlapping responsibilities between relevant agencies. Different managerial functions and the hierarchical structure of management (top, middle, and operational) would be exercised through the line of authority of particular agencies (Boone \& Kurtz, 1987; Hodge, et al., 2003; Wren \& Voich, 1984). As shown in the management of Walking Street and the Pattaya Music Festival, the frequency of meetings, coordination of management resources, and cooperation to carry out particular activities by its committee members appear to create a high level of management integration that can enable them to achieve their common goals. The management outcomes should be measured to monitor the effectiveness of management practices and to identify whether the stated goals are reached. Research, as evident in the management of Pattaya Music Festival, should be carried out to verify whether the management outcome can reach the stated goals. Assessment of management performance would reflect whether the broad and specific goals are achieved.

For this model to occur, a lead agency is required. The lead agency can be the municipality or other agencies depending on the destination's context. Recommendations are made in the next section on which agencies should act as a lead agency to carry out all the tasks explained in the above model.

\subsection{Recommendations for the management agencies}

In the case of Pattaya and other destinations in a similar context, the municipality should act as a lead agency. In other destinations, the lead agency may come from other agencies, such as local tourism organizations, provincial government, or business associations. Destination management organizations, commonly seen in the developed countries as DMOs, could also act as the lead agency to obtain coordination and cooperation from other agencies in managing the destination as whole rather than being responsible for marketing activities only. 
The lead agency should play an active role in managing the destination. It should coordinate with and obtain coordination and cooperation from all relevant agencies through a coordinating unit, as suggested above. The lead agency needs to be responsible for identifying management agencies and obtaining their cooperation to be involved in the establishment of a coordinating unit. Other agencies need to cooperate with the lead agency by getting involved in the unit. They should develop goals or visions that are commonly agreed by all members in order to have the same picture of what the management is aiming for. They also need to identify tourism aspects and relevant activities that must be undertaken to achieve those common goals. They also need to identify which agencies are responsible for carrying out those particular activities. Monthly meetings (as seen in the case of Walking Street) would be useful to follow up or to monitor the management progress. Research or similar approaches should also be carried out to evaluate the management outcome.

\subsection{Avenues for further research extension}

Although this research contributes to and enhances our understanding of destination management, a number of issues emerged in the study which suggest that much more work needs to be done to bring about a better understanding of the notion. The outcomes of this study will have been influenced by the characteristics of Pattaya: a mix of physical characteristics of a coastal resort city, a special form of local government, and its maturity in the destination life cycle. The characteristics of other destinations might result in different outcomes. Therefore, it would be useful to extend this research further in other areas of study to bring more insights and broaden our knowledge regarding destination management. There are several avenues where further research could help broaden our understanding of the concept and nature of destination management in different settings.

One avenue is to extend this research to other destinations. This study has shown that a lack of common goals and the absence of a coordinating unit at the destination level such as a destination working committee may occur at the local destination. It would be useful to explore whether these issues are present in other coastal destinations in other developing countries. Research in those destinations would help to identify issues relevant to destination management that might be similar or 
different to the case of Pattaya. As this issue appears to create ineffective management practices or less successful outcomes, it would also be interesting to examine destinations that have common goals or a destination-wide committee in order to compare whether they indeed produce more successful outcomes. The interrelationships or integration between relevant agencies in managing those destinations would bring further insights into the practice of destination management. Factors that may enhance successful management outcomes could also be identified. Since management practices appear to relate to the context of the destination, research in different destinations could produce issues different to those of Pattaya. For example, accessibility and transport might be a major issue in emerging destinations, and the management of ground, marine, or air transportation to access the destination might be a focus of study. Issues that may hinder or enhance effective management practices could be identified.

Another avenue that is fruitful for future research is to study the management of all tourism-related issues that exist at a destination (e.g. environmental, social, and cultural issues). As this research reveals that management activities undertaken in Pattaya are environmentally focused, studies investigating activities related to social and cultural aspects would provide a missing part of the picture and thus would enhance our current understanding in regard to this phenomenon.

Another aspect to be considered is to study a range of sectors within a destination such as attractions, accommodation, restaurants, and transport. This research has focused on the management of beaches, nightlife, and the Pattaya Music Festival because they were perceived by the respondents as crucial to Pattaya. Elsewhere respondents might identify other sectors that they believe are indicative of the way in which the destinations is, or is not, managed. Studying these could enhance understanding of how particular tourism sectors are managed and how they are integrated across the destination at the local scale.

Another avenue is to study the behaviour that underlies management practices at the destination. As evident in this research, there may be a lack of integration at the destination level and a lack of common goals. The behaviour underlying these issues 
was not the focus of this study. Future research into the factors affecting the behaviour of relevant stakeholders would be useful to bring better understanding to why destination management at particular destinations is practised in the way it is.

Finally, research to obtain the views of local residents and tourists would be useful for destination managers to monitor management performance and to evaluate management outcome. Although the local residents' needs were not perceived by the respondents as important to destination management in Pattaya, their views might reflect positive and negative impacts of destination management and offer alternative solutions. In addition, the tourists' views should also be taken into account since the destination is usually managed to serve tourists. Their satisfaction regarding the overall management of the destination could provide useful information to ensure management efficiency. A study to incorporate the views of practitioners, residents, and tourists would also be useful to refine the general concepts of a tourism destination and destination management obtained from all perspectives at the destination. Longitudinal research would be necessary to monitor the management outcomes of a destination over time.

\subsection{Conclusions}

This thesis has shown that the notion of destination management can be better understood when the practitioners' perspective is taken into account. Since there is a lack of a clear single definition of destination management in the tourism literature, the thesis has argued that it is necessary to develop a broad concept of this phenomenon and to use it to examine the management that occurs at a local destination.

Given the exploratory nature of the study, the conceptual framework of destination management (Figure 2.5) was developed from different sets of literature in order to identify key dimensions, aspects, and issues that are relevant to destination management. Given the complex nature of the phenomenon under study and the multiple and complex methodological concerns, a qualitative multi-phase case study was developed and a holistic and embedded case study was used to access broad and in-depth data that are relevant for the study (Chapter 3). By focusing on the context 
of Pattaya, a mature coastal destination in a developing country, key aspects relevant to the notion of destination management have been identified and clarified. By exploring the practitioners' views regarding destination management, developing a broad concept and using it to examine their management practices, this thesis has brought clarity and a better understanding to the notion of destination management.

The thesis has demonstrated that destination management requires integration of management agencies, management activities, and management purposes in managing the destination as a whole. Integrated practice at the destination level is necessary. However, the research has illustrated that, in reality, relevant agencies may be involved in managing aspects of the destination rather than managing the destination itself. These relevant agencies from different operational sectors and administrative scales may come together at the local destination in different patterns. Different management patterns reflect different management structures, different management purposes, different levels of management integration, and different outcomes. The pattern of the working committee tends to create the most effective management practices because of its formal management structure and common goals that are shared by all committee members. However, the thesis has shown that this management pattern may not be present at the destination level. A model to foster management integration at the local destination has been outlined. It would be helpful to formally integrate all relevant agencies together at the destination scale and to maximize their collaboration to carry out all relevant activities across the destination in a way to achieve their common goals. Recommendations for practitioners and researchers have also been provided.

From a theoretical perspective, this study has contributed in four major areas regarding the notion of destination management. First, there are relationships between the practitioners' initial views and their management practices. The practitioners' initial views tend to reflect their involvement at the local destination and to indicate their management practices. In Pattaya, the practitioners' initial views regarding a tourism destination were focused on multiple facilities and services provided to the tourists, while their initial views regarding destination management were focused on the practices to manage those facilities and services for tourists' 
satisfaction. Their initial views seemed to indicate that multiple tourism products and services are managed rather than the destination. The findings regarding their management practices supported their initial views. This suggested that the practitioners' initial views regarding a tourism destination and destination management reflect their management practices at the local destination. In addition, this research has contributed to the concepts of a tourism destination and destination management by synthesizing the views of practitioners with perspectives from the literature. Multiple approaches used to obtain the practitioners' views and drawn together with the perspectives in the tourism literature bring about a better understanding to these two concepts.

Second, multiple agencies from different operational sectors and administrative scales can be involved at the local destination in three patterns. They can be involved as single agencies, as agencies engaged in some form of coordination, and/or as committee members. These three patterns create different management structures, different levels of integration, and different outcomes. With the first pattern, a low level of integration is present and it leads to less successful outcomes. The latter two patterns tend to create a higher level of integration and more successful management outcomes. In particular, involvement as committee members presents a formal management structure and a high level of collaboration among committee members. Effective management and successful outcomes were clearly evident in the management of Pattaya Music Festival. If this form of management could be scaled up at the destination level, it could be a more effective way of managing the local destination as a whole.

Third, the destination needs to be managed in an integrated fashion at the local level. Three major factors are required for effective destination management: collaboration of relevant agencies at the local level, integration of tourism-related activities across the destination, and establishment of common goals or shared visions to represent destination goals. By incorporating these factors in management practices, the local destination would be managed more effectively and successfully. Although the destination goals are perceived as necessary for successful management (Welford \& Ytterhus, 2004; Westermann, et al., 2005), a method to get all relevant agencies 
together at the local destination seems much more challenging. The establishment of a coordinating unit was suggested in the thesis since it seems to be an effective pattern to bring all relevant agencies together at the local destination. Moreover, such a unit may help to increase solidarity among them, which would enhance their relationships and maximize their collaboration throughout the process of destination management.

Finally, the thesis has highlighted the need to move on from tourism development to concentrate more on destination management. Once a tourism destination is developed, it needs to be managed to achieve its goals. Collaboration between relevant agencies to manage the destination as a whole, as mentioned above, is required. Although this thesis has enhanced our understanding of destination management by developing the broad concept, exploring management mechanisms, and clarifying the overall practice of destination management in Pattaya, it has shown that much more work needs to be done. Given the broad and complex nature of destination management, the study has shown that a management perspective needs to be taken into account. Key aspects of destination management, obtained from this study, could be used in future research to examine other tourism sectors within a destination or to examine the overall management of other destinations. Different issues that might be found in other destinations would bring greater insight to the notion of destination management since they seem to reflect the management behaviour that contributes to the rise and fall of destinations. 


\section{References}

Agarwal, S. (1997). The resort cycle and seaside tourism: an assessment of its applicability and validity. Tourism Management, 18(2), 65-73.

Alexander, E. R. (1995). How organizations act together: Interorganizational Coordination in Theory and Practice. Luxembourg: Gordon and Breach Publishers.

Anderson, D. (2000a). Destination Management. In J. Jafari (Ed.), Encyclopedia of Tourism (pp. 720). New York: Routledge.

Anderson, D. (2000b). Destination Management Organisation. In J. Jafari (Ed.), Encyclopedia of Tourism (pp. 146-147). New York: Routledge.

Anon. (2001). TDRI Master Plan. Tourism Business Magazine, 14, 8-9.

Aramberri, J. (2000). Resort. In J. Jafari (Ed.), Encyclopedia of Tourism (pp. 720). New York: Routledge.

Augustyn, M. M., \& Knowles, T. (2000). Performance of tourism partnerships: a focus on York. Tourism Management, 21(4), 341-351.

Banglamung District Office. Retrieved June 21, 2007, from banglamung.go.th: http://www.banglamung.go.th/index.aspx?pid=vision

Biz/ed (Producer). (2005, January 20) Management Structures in Travel and Tourism. Podcast retrieved from http://www.bized.co.uk/educators/1619/tourism/business/presentation/management.ppt\#267,13,Prosandconsofdiff erentstructures.

Blaikie, N. (2000). Designing Social Research: The Logic of Anticipation. Cambridge, UK: Polity Press.

Blain, C., Levy, S. E., \& Ritchie, J. R. B. (2005). Destination Branding: Insights and Practices from Destination Management Organizations. Journal of Travel Research, 43(May), 328-338.

Boone, L. E., \& Kurtz, D. L. (1987). Management (3rd ed.). NY: Random House Business Division.

Bower, B. T., \& Turner, R. K. (2001). Characterising and analyzing benefits from integrated coastal management (ICM). In R. K. Turner \& I. J. Bateman (Eds.), Water Resources and Coastal Management (pp. 221-246). Camberley, UK: Edward Elgar Publishing.

Bramwell, B., Henry, I., Jackson, G., \& Stradten, V. (1996). A Framework for Understanding Sustainable Tourism Management. In B. Bramwell, I. Henry, G. Jackson \& V. Stradten (Eds.), Sustainable Tourism Management: Principles and Practice (pp. 23-67). Tilburg, The Netherlands: Tilburg University Press.

Bramwell, B., \& Lane, B. (2000). Collaboration and Partnerships in Tourism Planning. In B. Bramwell \& B. Lane (Eds.), Tourism Collarboration and Partnerships: Politics, Practice and Sustainability (pp. 1-11). Exeter, UK: Short Run Press.

Bramwell, B., \& Sharman, A. (1999). Collaboration in local tourism policy making. Annals of Tourism Research, 26(2), 392-415.

Brunt, P., \& Courtney, P. (1999). Host perceptions of sociocultural impacts. Annals of Tourism Research, 26(3), 493-515.

Butler, R. W. (1980). The Concept of a Tourist Area Cycle of Evolution: Implications for Management of Resources. Canadian Geographer, XXIV(1), 5-12. 
Cabrini, L. (2004, March 23). Global Tourism Trends, from www.worldtourism.org/regional/europe/PDF/SPEECHES/2004/moscow/Moscow\%20(M arch\%202004)\%20(Cabrini).pdf

Caffyn, A., \& Jobbins, G. (2003). Governance Capacity and Stakeholder Interactions in the Development and Management of Coastal Tourism: Examples from Morocco and Tunisia. Journal of Sustainable Tourism, 11(2\&3), 224-245.

Carley, M., \& Christie, I. (1993). Managing Sustainable Development. Minneapolis, USA: University of Minnesota Press.

Carlsen, J. (1999). A Systems Approach to Island Tourism Destination Management. Systems Research and Behavioral Science, 16(4), 321-327.

Carter, R., \& Fabricius, M. (2006, March 27-29). Introduction to Destination Management, from www.unwto.org/destination/ethiopia/fabricius_carter.pdf

Chaiphadung, S. (1996). The Problems and their Solutions of Managing the Municipality of Pattaya. Unpublished MA Thesis, Ramkamhaeng University, Bangkok, Thailand.

Cho, B. (2000). Destination. In J. Jafari (Ed.), Encyclopedia of Tourism (pp. 144145). NY: Routledge.

Chon, K., Singh, A., \& Mikula, J. R. (1993). Thailand's Tourism and Hotel Industry. Cornell Hotel and Restaurant Administration Quarterly 34(3), 43-49.

Chonburi108 (2005a, July 1). Lady Sudarat visited Bangpra Reservoir, from www.pattaya.com/thai/news/thainews_popup2.asp?newid=6159

Chonburi108 (2005b, May 8). Pattaya's public and private sectors plan for Japan's marketing trip on May 11-18, from www.pattaya.com/thai/news/thainews_popup2.asp?newid=5854

Chonburi Government. Retrieved June 29, 2006, from chonburi.go.th: http://www.chonburi.go.th/visai.jpg

Chulalongkorn University (1993). Pattaya Beach's road, landscape, and promenade Redevelopment Project. Bangkok: Chulalongkorn University.

CIRI (2004). Data Collection and Analysis Report: Pattaya Music Festival 2004. Bangkok: The Centre for International Research and Information.

CIRI (2005). Data Collection and Analysis Report: Pattaya International Music Festival 2005. Bangkok: The Centre for International Research and Information.

Cohen, E. (1991). Thai society in comparative perspective: Collected Essays. Bangkok: White Lotus.

Creswell, J. W. (2003). Research Design: Qualitative, Quantitative, and Mixed Methods Approaches (2nd ed.). California, USA.: Sage Publication, Inc.

Crouch, G. I. (2006). Destination Competitiveness: Insights into Attribute Importance. Paper presented at the International Conference of Trends, Impacts and Policies on Tourism Development.

d'Hauteserre, A. (2000). Lessons in managed destination competitiveness: the case of Foxwoods Casino Resort. Tourism Management, 21, 23-32.

Dana, L. P. (1999). The Social Cost of Tourism: A case study of Ios. Cornell Hotel and Restaurant Administration Quarterly, 40(4), 60-63.

Doswell, R. (1997). Tourism: How effective management makes the difference. Oxford, UK: Butterworth-Heinemann.

Dredge, D. (2006a). Networks, Conflict and Collaborative Communities. Journal of Sustainable Tourism, 14(6), 562-581.

Dredge, D. (2006b). Policy networks and the local organization of tourism. Tourism Management, 27(2), 269-280. 
Dwyer, L., \& Kim, C. (2003). Destination Competitiveness: Determinants and Indicators. Current Issues in Tourism, 6(5), 369-414.

Eccles, G., \& Costa, J. (1996). Perspectives on tourism development. International Journal of Contemporary Hospitality Management, 8(7), 44-51.

EEA (1999). Executive Summary : Environment in the European Union at the turn of the century. Copenhagen: European Environment Agency

Elliott, J. (1987). Government management of tourism - a Thai case study. Tourism Management, 8(3), 223-232.

Elliott, J. (1997). Tourism: Politics and public sector management. NY: Routledge.

Enright, M. J., \& Newton, J. (2004). Tourism destination competitiveness: a quantitative approach. Tourism Management, 25(6), 777-788.

Fall, L. T. (2004). The increasing role of public relations as a crisis management function: An empirical examination of communication restrategising efforts among destination organisation managers in the wake of 11th September, 2001. Journal of Vacation Marketing, 10(3), 238-252.

Feick, R. D., \& Hall, G. B. (2000). The Application of a Spatial Decision Support System to Tourism-Based Land Management in Small Island States. Journal of Travel Research, 39(November), 163-171.

Flagestad, A., \& Hope, C. A. (2001). Strategic success in winter sports destinations: a sustainable value creation perspective. Tourism Management, 22, 445-461.

Font, X., \& Ahjem, T. E. (1999). Searching for a balance in tourism development strategies. International Journal of Contemporary Hospitality Management, 11(2/3), 73-77.

Framke, W. (2002). The Destination as a Concept: A Discussion of the Businessrelated Perspective versus the Socio-cultural Approach in Tourism Theory. [original]. Scandinavian Journal of Hospitality and Tourism, 2(2), 92-108.

Freeman, R. E. (2005). Stakeholder Theory. In P. H. Werhane \& R. E. Freeman (Eds.), The Blackwell Encyclopedia of Management : Business Ethics (2nd ed., Vol. II). Oxford, UK: Blackwell Publishing Ltd.

Fuchs, M., \& Weiermair, K. (2004). Destination Benchmarking: An IndicatorSystem's for Exploring Guest Satisfaction. Journal of Travel Research, 42(February), 212-225.

Fyall, A., \& Garrod, B. (1997). Sustainable Tourism: Towards a Methodology for Implementing the Concept In M. J. Stabler (Ed.), Tourism and Sustainability: Principles to Practice (pp. 51-68). Oxfordshire, UK: CAB International.

Garcia, G. M., Pollard, J., \& Rodriguez, R. D. (2003). The Planning and Practice of Coastal Zone Management in Southern Spain. Journal of Sustainable Tourism, 11(2\&3), 204-223.

Go, F. M., \& Govers, R. (2000). Integrated quality management for tourist destinations: a European perspective on achieving competitiveness. Tourism Management, 21(1), 79-88.

Gomezelj, D. O., \& Mihalic, T. (2008). Destination competitiveness-Applying different models, the case of Slovenia. Tourism Management, 29(2), 294-307.

Greiner, R., Young, M. D., McDonald, A. D., \& Brooks, M. (2000). Incentive instruments for the sustainable use of marine resources. Ocean and Coastal Management 43, 29-50.

Guba, E. G., \& Lincoln, Y. S. (1994). Competing Paradigms in Qualitative Research. In N. K. Denzin \& Y. S. Lincoln (Eds.), Handbook of Qualitative Research. California, USA.: SAGE Publications. 
Hall, C. M. (2000). Rethinking Collaboration and Partnership: A Public Policy Perspective. In B. Bramwell \& B. Lane (Eds.), Tourism Collaboration and Partnerships: Politics, Practice and Sustainability (pp. 143-157). Exeter, UK: Short Run Press.

Hall, C. M. (2001). Trends in ocean and coastal tourism: the end of the last frontier? Ocean \& Coastal Management, 44, 601-618.

Hall, R. H. (1987). Organizations: Structures, Processes, and Outcomes (4 ed.). New Jersey, USA: Prentice Hall, Inc.

Hanks, L. M. (1975). The Thai Social Order as Entourage and Circle. In W. G. Skinner \& T. A. Kirch (Eds.), Change and Persistence in Thai Society (pp. 197-218). Ithaca and London: Cornell University Press.

Hardy, A. L., \& Beeton, R. J. S. (2001). Sustainable Tourism or Maintainable Tourism: Managing Resources for More Than Average Outcomes. Journal of Sustainable Tourism 9(3), 168-195.

Harvey, N., \& Caton, B. (2003). Coastal Management in Australia. Oxford, UK: Oxford University Press.

Hassan, S. S. (2000). Determinants of Market Competitiveness in an Environmentally Sustainable Tourism Industry. Journal of Travel Research 38(February), 239-245.

Hatchuel, A. (2002). Coordination and control. In M. Warner (Ed.), International Encyclopedia of Business and Management (2nd ed., Vol. 2, pp. 1059-1067). Cornwall, UK: Thompson Learning.

Haywood, M., Anderson, D., \& O'Halloran, R. (2000). Convention and visitor bureau. In J. Jafari (Ed.), Encyclopedia of Tourism (pp. 110-111). New York: Routledge.

Henderson, J. C. (2004). Healthcare Tourism in Southeast Asia. Tourism Review International, 7, 111-121.

Hodge, B. J., Anthony, W. P., \& Gales, L. M. (2003). Organization Theory: A Strategic Approach. New Jersey, USA: Pearson Education, Inc.

Hu, W., \& Wall, G. (2005). Environmental Management, Environmental Image and the Competitive Tourist Attraction. Journal of Sustainable Tourism, 13(6), 617-635.

Hussey, J., \& Hussey, R. (1997). Business Research: A practical guide for undergraduate and postgraduate students. London: Macmillan Press Ltd.

IDRC (1997). Social Development: Social Sector Decentralization: The Case of Thailand. Retrieved 16/1/2005, from International Development Research Centre (IDRC): www.idrc.ca/socdev/pub/thialand/ch1.html

Jaiyen, K. (1997). The international political economy of sex tourism in Thailand. Unpublished MA Thesis, Victoria University of Wellington, Wellington, New Zealand.

Jamal, T. B., \& Getz, D. (1995). Collaboration Theory and Community Tourism Planning. Annals of Tourism Research, 22(1), 186-204.

Jamal, T. B., \& Jamrozy, U. (2006). Collaborative Networks and Partnerships for Integrated Destination Management. In D. Buhalis \& C. Costa (Eds.), Tourism Management Dynamics: Trends, management and tools (pp. 164172). Oxford, UK: Elsevier Butterworth-Heinemann.

Jamieson, W. (Ed.). (2006). Community Destination Management in Developing Economies. New York, USA: The Haworth Hospitality Press.

Jansen-Verbeke, M. (2000). Urban tourism. In J. Jafari (Ed.), Encyclopedia of Tourism (pp. 615-617). New York: Routledge. 
Jantarat, J., \& Williams, L. (2000). Preconditions for Successful Collaborative Tourism Marketing: The Critical Role of the Convener. In K.-S. Chon (Ed.), Tourism in Southeast Asia: A New Direction. New York: The Haworth Hospitality Press.

Keane, M. J. (1997). Quality and pricing in tourism destinations. Annals of Tourism Research, 24(1), 117-130.

Knowles, T., \& Curtis, S. (1999). The market viability of European mass tourist destinations. A Post-Stagnation Life-cycle Analysis. International Journal of Tourism Research, 1(2), 87-96.

Krueathep, W. (2004). Local Government Initiatives in Thailand: Cases and Lessons Learned. The Asia Pacific Journal of Public Administration, 26(2), 217-239.

Krungthep Turakij (2006). 1.2 billions investment for entertainment complex. Krungthep Turakij, p. 20,

Kumar, R. B. (1995). Coastal Tourism and Environment. New Delhi: APH Publishing Corporation.

Ladkin, A., \& Bertramini, A. M. (2002). Collaborative Tourism Planning: A Case Study of Cusco, Peru. Current Issues in Tourism, 5(2), 71-93.

Laird, J. (2000). Money Politics, Globalisation, and Crisis: The Case of Thailand. Singapore: Graham Brash Pte Ltd.

Lamberti, A., \& Zanuttigh, B. (2005). An integrated approach to beach management in Lido di Dante, Italy. Estuarine, Coastal and Shelf Science 62, 441-451.

Laws, E. (1995). Tourist Destination Management: Issues, Analysis and Policies. London, UK: Routledge.

Leheny, D. (1995). A political economy of asian sex tourism. Annals of Tourism Research, 22(2), 367-384.

Leiper, N. (1990). Tourist attraction systems. Annals of Tourism Research, 17(3), 367-384.

Leiper, N. (1997). Tourism Management. Victoria, Australia: RMIT Press.

Leiper, N. (2000). Are Destinations 'the Heart of Tourism'? The advantages of an alternative description. Current Issues in Tourism, 3(4), 364-368.

Lew, A., \& McKercher, B. (2006). Modeling Tourist Movements: A Local Destination Analysis. Annals of Tourism Research, 33(2), 403-423.

Liu, Z. (2003). Sustainable Tourism Development: A Critique. Journal of Sustainable Tourism 11(6), 459-476.

Lovelock, B. (2001). Interorganisational Relations in the Protected Area - Tourism Policy Domain: The Influence of Macro-economic Policy. Current Issues in Tourism, 4(2-4), 253-274.

Lundin, C. G., \& Linden, O. (2001). Coastal Ecosystems: Attempts to Manage a Threatened Resource. In R. K. Turner \& I. J. Bateman (Eds.), Water Resources and Coastal Management (pp. 209-220). Camberley, UK: Edward Elgar Publishing.

Lynne, D., \& Geoffrey, I. C. (2003). Promoting destinations: An exploratory study of publicity programmes used by national tourism organisations. Journal of Vacation Marketing, 9(2), 137.

Marchant, G. (2006, October). Pattaya puts on a new face. Sawasdee, 13, 34-41.

Marine Police. Retrieved March 1, 2007, from marine_police.go.th: http://www.tnnwebdesign.com/Marine_police/content.php?Con_ID=4

Marine Transportation Department. Retrieved March 1, 2007, from md.go.th: http://www.md.go.th/eng_page/vision_mission_eng.php 
Mason, P. (2003). Tourism Impacts, Planning and Management. Oxford, UK: Elsevier Butterworth-Heinemann.

Medeiros de Araujo, L., \& Bramwell, B. (2000). Stakeholder Assessment and Collaborative Tourism Planning: The Case of Brazil's Costa Dourada Project. In B. Bramwell \& B. Lane (Eds.), Tourism Collaboration and Partnerships: Politics, Practice and Sustainability (pp. 273-294). Exeter, UK: Short Run Press.

Mihalic, T. (2000). Environmental management of a tourist destination: A factor of tourism competitiveness. Tourism Management, 21, 65-78.

Mingers, J. (2006). Realising Systems Thinking: Knowledge and Action in Management Science. USA: Springer Science+Business Media, Inc.

Ministry of Interior. Retrieved June 29, 2006, from moi.go.th: http://www.moi.go.th/portal/page?_pageid=33,120310,33_120357:33_12036

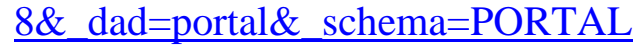

Mohammed, S. M. (2002). Pollution management in Zanzibar: the need for a new approach. Ocean and Coastal Management 45, 301-311.

Momsen, J. H. (2000). Rural tourism. In J. Jafari (Ed.), Encyclopedia of Tourism (pp. 720). New York: Routledge.

Morgan, G. (1997). Images of Organization. California, USA: SAGE Publications, Inc.

Morgan, G., \& Smircich, L. (1980). The case for qualitative research. Academy of Management. The Academy of Management Review (pre-1986), 5(4), 491500.

Mowforth, M., \& Munt, I. (2000). Tourism and Sustainability: New Tourism in the Third World. New York: Routledge.

Muqbil, I. (1995). Thailand. International Tourism Reports, 3, 66-81.

Neher, C. D. (1979). Section II: Political Culture and Environment. In C. D. Neher (Ed.), Modern Thai Politics from Village to Nation (pp. 87-93). Massachusetts: Schenkman Publishing Company.

Neher, C. D. (1990). Change in Thailand. Current History, 89(545), 101.

Neuman, M. (1999). A new approach to planning and governing: the Jersey shore. . Ocean and Coastal Management 42, 815-834.

Noronha, L. (2004). Coastal management policy: observations from an Indian case Ocean and Coastal Management 47, 63-77.

Olsen, S., Tobey, J., \& Kerr, M. (2001). A common framework for learning form ICM experience. In R. K. Turner \& I. J. Bateman (Eds.), Water Resources and Coastal Management (pp. 209-220). Camberley, UK: Edward Elgar Publishing.

Paajanen, M. (2000). Demand. In J. Jafari (Ed.), Encyclopedia of Tourism (pp. 136137). New York: Routledge.

Page, S. J. (2003). Tourism Management: Managing for change. Oxford, UK: Butterworth-Heinemann.

Page, S. J., Brunt, P., Busby, G., \& Connell, J. (2001). Tourism: A Modern Synthesis. London, UK.: Thompson Learning.

Papatheodorou, A. (2006). Introduction. In A. Papatheodorous (Ed.), Managing Tourism Destinations (pp. xv-xxvi). Cheltenham, UK: Edward Elgar Publishing.

Paraskevas, A., \& Arendell, B. (2007). A strategic framework for terrorism prevention and mitigation in tourism destinations. Tourism Management, 28(6), 1560-1573. 
Pattaya City (1980). Pattaya City: 1979 and 1980. Pattaya: Pattaya City.

Pattaya City (2004). Pattaya City Development Plan: Year 2004. Pattaya: Pattaya City.

Pattaya City (2005). Pattaya City Three Years Development Plan (2006 - 2008). Pattaya: Pattaya City.

Pattaya City (2006). Annual summary report of Pattaya City 2005. Pattaya: Pattaya City.

Pattaya City (2007). Pattaya: Tourist guide [CD]. Pattaya: Pattaya City.

Pearce, D. (1989). Tourist Development (2nd ed.). Essex, UK: Longman Group.

Pearce, D. (1992). Tourist Organizations. Essex, UK: Longman Group, Ltd.

Pearce, D. (1995). Tourism Today: A Geographical Analysis (2nd ed.). Essex, UK: Longman Scientific \& Technical.

Peleggi, M. (1996). National Heritage and Global Tourism in Thailand. Annals of Tourism Research, 23(2), 432-448.

Pizam, A. (2000). Management. In J. Jafari (Ed.), Encyclopedia of Tourism (pp. 720). NY: Routledge.

Plummer, R., Kulczycki, C., \& Stacey, C. (2006). How are we Working Together? A Framework to Assess Collaborative Arrangements in Nature-based Tourism. Current Issues in Tourism, 9(6), 499-515.

Pollnac, R. B., \& Pomeroy, R. S. (2005). Factors influencing the sustainability of integrated coastal management projects in the Philippines and Indonesia. Ocean \& Coastal Management, 48, 233-251.

Pollution Control Department. Retrieved March 1, 2007, from pcd.go.th: http://www.pcd.go.th

Pool, I. d. S. (Ed.). (1959). Trends in content analysis. Urbana: University of Illinois Press.

Poon, A. (1993). Tourism, technology and competitive strategies. Oxfordshire, UK: CAB International.

Prideaux, B. (2000). The resort development spectrum-a new approach to modeling resort development. Tourism Management, 21(3), 225-240.

Promboot, W. (1995). A study of community's element for enhancing the identity of Pattaya City. Unpublished MURP Thesis, Chularlongkorn University, Bangkok, Thailand.

Prosser, G. (1995). Tourist Destination Life Cycles: Progress, Problems and Prospects. In R. N. Shaw (Ed.), National Tourism and Hospitality Conference (pp. 318-328). Melbourne: Centre for Hospitality and Tourism Research.

Provincial Police Region 2. Retrieved March 1, 2007, from royalthaipolice.go.th: http://www.police.p2.go.th/p_1.php\#

Pyo, S. (2005). Knowledge map for tourist destinations - needs and implications. Tourism Management 26, 583-594.

Richard, W. E. (1993). Book review. Marketing tourism destinations. By Ernie Hall and Geoffrey Wall. Annals of Tourism Research, 20(2), 400-402.

Ritchie, B. J., \& Crouch, G. I. (2003). The Competitive Destination: A Sustainable Tourism Perspective. New York, USA: CABI Publishing.

Rivera-Arriaga, E., \& Villalobos, G. (2001). The coast of Mexico: approaches for its management. Ocean and Coastal Management, 44, 729-756.

Robbins, S., \& Mukerji, D. (1994). Managing Organisations: New Chllenges and Perspectives (2nd ed.). Sydney: Prentice Hall.

Royal Thai Navy. Retrieved March 1, 2007, from navi.mi.th: http://www.navy.mi.th/newwww/document/vision 
Ryan, C. (2003). Recreational Tourism: Demand and Impacts. Clevedon, UK: Channel View Publications.

Ryan, G. W., \& Bernard, H. R. (2000). Data Management and Analysis Methods. In N. K. Denzin \& Y. S. Lincoln (Eds.), Handbook of Qualitative Research (2nd ed., pp. 769-793). California, USA: Sage Publications, Inc.

Sainaghi, R. (2003). Destination Management: A process based view. Universitat St. Gallen, Bamberg.

Saksri, N. (2003). The Impact of Urban Growth upon People's Way of Life: the Case Study of Pattaya. Unpublished MA Thesis, Ramkhamhaeng University, Bangkok, Thailand.

Samson, D., \& Daft, R. L. (2003). Fundamental of Management: Pacific Rim Edition. Melbourne, Australia: Nelson Australia Pty Ltd.

Sangsuksai, W. (2003). Impacts and problems in implementing the social order policy regarding the entertainment businesses in Pattaya city. Unpublished MS Thesis, Burapha University, Chonburi, Thailand.

Sautter, E. T., \& Leisen, B. (1999). Managing Stakeholders: A Tourism Planning Model. Annals of Tourism Research 26(2), 312-328.

Selin, S., \& Chavez, D. (1995). Developing an evolutionary tourism partnership model. Annals of Tourism Research, 22(4), 844-856.

Sharpley, R. (2000). Tourism and Sustainable Development: Exploring the Theoretical Divide. Journal of Sustainable Tourism 8(1), 1-19.

Sheehan, L. R., \& Ritchie, J. R. B. (2005). Destination Stakeholders Exploring Identity and Salience. Annals of Tourism Research, 32(3), 711-734.

Shilpa Company (2006). Pattaya Food, Shopping, Entertainment \& Accommodation (Vol. 7, pp. 89). Bangkok: Shilpa Co., Ltd.

Siffin, W. J. (1979). The Essential Character of the Contemporary Bureaucracy. In C. D. Neher (Ed.), Modern Thai Politics from Village to Nation. Cambridge, Massachusetts: Schenkman Publishing Company.

Sirilerttragoon, V. (1996). The city of Pattaya as a form of local government: problems and solutions. Unpublished MA Thesis, Chularlongkorn University, Bangkok, Thailand.

Sisk, H. L. (1969). Principles of Management: A systems approach to the management process. Ohio, USA: South-western Publishing.

Slee, W., Farr, H., \& Snowdon, P. (1997). Sustainable Tourism and the Local Economy In M. J. Stabler (Ed.), Tourism and Sustainability: Principles to Practice (pp. 69-87 ). Oxfordshire, UK: CAB International.

Smith, R. A. (1992). Beach Resort Evolution: Implications for Planning. Annals of Tourism Research 19, 304-322.

Sripirom, E. (1999). Waste water management of a tourism city: the case study of Pattaya. Unpublished MURP Thesis, Chularlongkorn University, Bangkok, Thailand.

Stake, R. E. (2005). Qualitative Case Studies. In N. K. Denzin \& Y. S. Lincoln (Eds.), The SAGE Handbook of Qualitative Research (3rd ed., pp. 443-446). California, USA: SAGE Publications, Inc.

Stanford, D. (2006). Responsible tourism, responsible tourists: what makes a responsible tourist in New Zealand. Unpublished PhD Thesis, Victoria University of Wellington, Wellington, New Zealand.

Strauss, A., \& Corbin, J. (1998). Basics of Qualitative Research: Techniques and Procedures for Developing Grounded Theory (2nd ed.). California, USA.: SAGE Publications, Inc. 
Tabatchnaia-Tamirisa, N., Loke, M. K., Leung, P., \& Tucker, K. A. (1997). Energy and tourism in Hawaii. Annals of Tourism Research, 24(2), 390-401.

Tamada, Y. (1991). Itthiphon and Amnat: An Informal Aspect of Thai Politics. Southeast Asian Studies, 28(4), 455-466.

TAT (1995). Pattaya Beach's landscape and promenade and Balihai pier Redevelopment Project. Bangkok: Tourism Authority of Thailand.

TAT (2005). Marketing Plan 2005 Retrieved January 13, 2005, from www.tourismthailand.org/about_tat.php?module=tat_marketingplan

TAT (2008a). About TAT: TAT History. Retrieved 16/01/2008, from Tourism Authority of Thailand: http://www.tourismthailand.org/about-tat/

TAT (2008b). Tourism Thailand: About Thailand. Retrieved 16/01/2008, from Tourism Authority of Thailand: http://www.tourismthailand.org/aboutthailand/about-thailand-65-1.html

Terzibasoglu, E. (2004). Successful Destination Management and Marketing Fundamentals. Unpublished Presentation on Destination Marketing for the 21st Century - Moscow, 23 March. The Russian Federation.

Thanatkasidet, T. (2005). Life in the dark corner of the coconut ghosts: A case study of Pattaya Beach. Unpublished MS Thesis, Burapa University, Chonburi, Thailand.

The Nation (2006, August 20). Editorial: Tourism policy needs coherence. The Nation, from http://www.nationmultimedia.com/option/print.php?newsid=30011498

Thomas, R. J. (1993). Interviewing important people in big companies. Journal of contemporary ethnography, 22(1), 80-96.

TMI (n.d.). definition of tourism destination management Retrieved July 25, 2005, from http://www.tmi.org.uk/documents/BYELAWS\%202330-4.doc

Tosun, C., \& Timothy, D. J. (2001). Shortcoming in planning approaches to tourism development in developing countries: the case of Turkey. International Journal of Contemporary Hospitality Management 13(7), 352-359.

Tourist Police Division. Retrieved September 20, 2008, from thaitouristpolice.com: http://www.thaitouristpolice.com/main.php

Tummakird, A. W. (2003). Local Government Structure in Thailand. Retrieved 25/2/2008, from ESCAP Virtual Conference: http://www.unescap.org/DRPAD/VC/CONFERENCE/bg_th_25_lgs.htm

Tunbridge, J. (1999). Tourism management in Ottawa, Canada: nurturing in a fragile environment. In D. Tyler, Y. Guerrier \& M. Robertson (Eds.), Managing Tourism in Cities: Policy, Process and Practice [Reprinted] (pp. 91-108). Oxford, UK: John Wiley \& Sons, Ltd.

Tupchai, S. (2005, Friday March 25 - March 31). Editorial: Sounds of the Pattaya Music Festival. Pattaya Mail, from http://www.pattayamail.com/608/community.shtml\#hd5

Turner, R. K., Adgar, W. N., Crooks, S., Lorenzoni, I., \& Ledoux, L. (2001). Sustainable coastal resources management: principles and practice. In R. K. Turner \& I. J. Bateman (Eds.), Water Resources and Coastal Management (pp. 209-220). Camberley, UK: Edward Elgar Publishing.

UN (2004). The Kingdom of Thailand: Public Administration Country Profile. Unpublished Report. Division for Public Administration and Development Management (DPADM), Department of Economic and Social Affairs (DESA), United Nations. 
UNEP (2005). The definition of destination management. Retrieved July 25, 2005, from United Nations Environment Programme:

http://www.uneptie.org/pc/tourism/policy/destination-mgmt.htm

Veal, A. J. (1997). Research Methods for Leisure and Tourism: A Practical Guide (2nd ed.). London, UK: Financial Times Pitman Publishing.

Walle, A. H. (1997). Quantitative versus qualitative tourism research. Annals of Tourism Research, 24(3), 524-536.

Weaver, D., \& Lawton, L. (2002). Tourism Management (2nd ed.). Milton: John Wiley \& Sons Australia, Ltd.

Welford, R., \& Ytterhus, B. (2004). Sustainable development and tourism destination management: A case study of the Lillehammer region, Norway. International Journal of Sustainable Development and World Ecology, 11(4), 410.

Westermann, G., Pohle, B., \& Sehl, I. (2005). Strategic Management of Tourism Regions Applying Balanced Scorecards. In W. Alejziak \& R. Winiarski (Eds.), Tourism in Scientific Research (pp. 191-200): Krakow-Rzeszow.

Wren, D. A., \& Voich, D. J. (1984). Management: Process, Structure, and Behavior (3 ed.). New Jersey, USA: John Wiley \& Sons.

WTO (2008). Tourism Highlights, 2008 Edition. Madrid: World Tourism Organization (WTO).

WTO (2009). World's Top Emerging Tourism Destinations in the period 1995 2004. Madrid: World Tourism Organization (WTO).

Xue, X., Hong, H., \& Charles, A. T. (2004). Cumulative environmental impacts and integrated coastal management: the case of Xiamen, China. Journal of Environmental Management, 71, 271-283.

Yin, R. K. (2003). Case Study Research: Design and Methods (3rd ed.). California, USA: SAGE Publications.

Yu, L., \& Goulden, M. (2006). A comparative analysis of international tourists' satisfaction in Mongolia. Tourism Management, 27(6), 1331-1342. 
Appendix A:

Phase II Interview Checklist 
$\underline{\text { Respondent }}$

\section{Phase II: Checklist of questions}

1. Firstly, what is your position/title in the agency?

2. How long have you been working in this agency?

3. How long have you been working in this position?

4. Please describe your role and responsibilities in the agency/organization/department.

Organizational background

5. Please describe the type and operational scale of your agency/organization/department.

6. What is the role/responsibility of your agency/organization/department?

7. What are the goals of your agency/organization/department?

8. Are these goals written/stated in any document? (Please indicate)

9. How were these goals established?

\section{Sense of Pattaya}

10. How would you describe Pattaya?

11. What are the main characteristics of Pattaya relating to tourism?

12. What sorts of issues has the development of tourism in Pattaya created?

Meaning of "A tourism destination"

13. How would you define "a tourism destination"?

14. What do you think of this concept?

"The destination must function as a real entity. That is, it must have a sense of itself; it should have a purpose and be managed in a way that promotes the pursuit of that purpose." (Ritchie \& Crouch, 2003, p. 67)

Is Pattaya a tourism destination?

15. In what ways and to what extent does Pattaya match the definition that you defined in question 13 ?

16. In what ways and to what extent does Ritchie \& Crouch’s concept apply to Pattaya?

\section{Management of Pattaya}

17. Are you familiar with the concept of destination management?

18. If yes, what does destination management mean to you?

19. How do you think of this concept?

"Destination management is the integrated process of managing any of the three tourism destination types (urban, resort and rural). It covers four key elements; the destination offering (visitor experience, destination image and attractiveness); the visitor mix (market research); marketing communications (awareness and promotion); and organizational responsibility (leadership and partnership)." (Anderson, 2000, p. 145)

20. In what ways and to what extent is Pattaya managed as a tourism destination?

21. How would you describe the way in which tourism in Pattaya is managed?

22. What structures or organizations are in place to manage tourism in Pattaya?

23. Have common goals been established for tourism in Pattaya?

24. If yes, what are they? How were these common goals established?

25. If not, why not?

26. Are common goals needed? Why or why not?

27. How is the role/responsibility of your agency/organization/department in relation to the management of tourism in Pattaya?

28. What other organizations or people would you suggest I contact with regard to destination management in Pattaya? 
Appendix B:

Phase III Interview Checklist for attraction management 


\section{Phase III: Checklist of Questions for attraction management}

$\underline{\text { Respondent }}$

1. Firstly, what is your position/title in the agency?

2. How long have you been working in this position?

3. Please describe your role and responsibilities in the agency/department.

4. What is the role/responsibility of your agency/organization/department?

Management agencies and structure

5. Which beaches (nightlife/music festival) are responsible by your agency/department?

(Please provide geographical areas of responsibility) What are the nature or characteristics of these beaches? (public or private owned/ public leased)

6 . What are the roles and responsibilities of your agency/department in managing these beaches (nightlife/music festival)?

7. Could you outline how your agency/department is structured to carry out these roles and responsibilities? (Draw an organizational chart)

8. Are any other agencies also involved in managing these beaches (nightlife/music festival)?

9. What are their roles and responsibilities? (identify what their respective roles and responsibilities are, also explore what overlaps might occur, and whether any gap exists)

10. Which agency/department has the prime responsibility for managing these beaches (nightlife/music festival)?

11. How are the activities of the different agencies/departments coordinated?

Management goals

12. Are there any plans or projects related to the management of these beaches

(nightlife/music festival)? If yes, what are they? (Please indicate the documents) When and how were they developed/established? Who was involved? If not, why not?

13. Are there any common goals stated in these plans or projects? If yes, what are they? When and how were they developed/established? Who was involved? If not, why not?

14. Does your agency/department have specific goals in managing these beaches (nightlife/music festival)? If yes, what are they? How were they established? Who was involved? If not, why not?

15. What are the general/broad goals of your agency/department? Are these goals written/stated in any document? (Please indicate) How were these goals established? Who was involved?

Management functions

16. When referring to the beach (nightlife/music festival) management, what need to be managed?

17. What are the different functions required to manage these beaches (nightlife/music festival)? Why?

18. Which functions does your agency/department carry out? How? And why?

19. Could you outline how your agency/department is structured to carry out these functions? (Draw a map)

20. Is there any monitoring (e.g., water quality, beach cleanliness and safety)? If yes, what is a form of monitoring? Who are involved? How is the process? What kind of action is taken after the monitoring? It not, why not?

21. Is there any coordination from other agencies/departments in managing these beaches (nightlife/music festival) ? If yes, what is it? If not, why not?

22. Is the management of these beaches (nightlife/music festival) integrated with the beach (nightlife/music festival) management of Larn Islands? If so, how? If not, why not?

23. Are there challenges or barriers that prevent you from carrying out these functions more effectively? If yes, what are they? If not, why not?

24. What evaluation is there of the management functions? 


\section{Management resources}

25. What kinds of resources does your agency/department require in managing these beaches (nightlife/music festival)?

26. From where are these resources obtained?

27. Are they sufficient to perform the functions you are responsible for?

Facility and service issues

28. Which facilities and services are required at the beach (nightlife/music festival) area? Why?

29. What kinds of infrastructure and facilities need to be provided by a public sector for better management of private beaches?

30. In what ways and to what extent is the management of these beaches (nightlife/music festival) integrated with the management of other tourism services and facilities in Pattaya (e.g. infrastructure, speedboats, ferries and beach umbrella shops)? [How the public spaces are leased to the umbrella shops and chairs? How the mooring spaces for the jet boats are organized? What conditions are imposed?]

31. In what ways and to what extent do the speedboats and ferries represent the linkage between Pattaya and Larn island?

32. In what ways and to what extent can the new airport and road improvement have an impact to Pattaya?

\section{Marketing issues}

33. What is your expectation from the new airport and road improvement regarding (your business/agency and) tourism in Pattaya?

34. Which activities are practised to respond that expectation and benefit tourism marketing of Pattaya?

35. In what ways and to what extent is the management of these beaches integrated with the marketing of the destination?

36. How does the management of these beaches compare with the management of the nightlife of Pattaya and with the music festival?

37. In what ways and to what extent is the beach quality index corresponded to tourism marketing of the destination?

38. In what ways and to what extent Larn island is seen as one part of the destination of Pattaya?

General issues

39. Overall, are you satisfied with management of the beaches? Why is that?

40. Are there any aspects that might be improved?

41. Do you believe that the common goals for the management of the beaches are being met? 42. In the earlier phase of my research, I developed the following concept of destination management.

"Tourism destination management is the collaboration of relevant agencies responsible in operating multiple tourism services and facilities at the destination in a way to create positive tourism atmosphere, to enhance the destination character and to attract and serve tourism demand. Broadly, it can be practised through the integration of management functions and management resources from all relevant responsible agencies."

To what extent does the management of the beaches reflect this? Why is that? 43. Are there any other points you would like to raise with regard to the management of the beaches or of the destination? 
Appendix C:

Interview Checklist for additional private sector 
$\underline{\text { Respondent }}$

\section{A Checklist of questions for additional private sector}

1. Firstly, what is your position/title in the agency?

2. How long have you been working in this agency?

3. How long have you been working in this position?

4. Please describe your role and responsibilities in the agency/organization/department.

\section{Sense of Pattaya}

5. How would you describe Pattaya?

6. What are the main characteristics of Pattaya relating to tourism?

7. What sorts of issues has the development of tourism in Pattaya created?

8. What is your perception on the situation of hotel businesses in Pattaya for the last ten years?

(changes in price, ownership, etc.)

9. In what ways and to what extent Larn island is seen as one part of the destination of Pattaya?

Meaning of "A tourism destination"

10. How would you define "a tourism destination"?

11. What do you think of this concept?

"The destination must function as a real entity. That is, it must have a sense of itself; it should have a purpose and be managed in a way that promotes the pursuit of that purpose.” (Ritchie \& Crouch, 2003, p. 67)

Is Pattaya a tourism destination?

12. In what ways and to what extent does Pattaya match the definition that you defined in question 10 ?

13. In what ways and to what extent does Ritchie and Crouch’s concept apply to Pattaya?

\section{Management of Pattaya}

14. Are you familiar with the concept of destination management?

15. If yes, what does destination management mean to you?

16. How do you think of this concept?

"Destination management is the integrated process of managing any of the three tourism destination types (urban, resort and rural). It covers four key elements; the destination offering (visitor experience, destination image and attractiveness); the visitor mix (market research); marketing communications (awareness and promotion); and organizational responsibility (leadership and partnership).” (Anderson, 2000, p. 146)

17. In what ways and to what extent is Pattaya managed as a tourism destination?

18. How would you describe the way in which tourism in Pattaya is managed?

19. What structures or organizations are in place to manage tourism in Pattaya?

20. Have common goals been established for tourism in Pattaya?

21. If yes, what are they? How were these common goals established? If not, why not?

22. Are common goals needed? Why or why not?

23. How is the role/responsibility of your agency/organization/department in relation to the management of tourism in Pattaya? (in relation to management of the beach, nightlife, music festival) 


\section{Management issues}

24. When referring to management of the beaches (nightlife and music festival), what need to be managed?

25. What are the different functions required to manage these beaches (nightlife and music festival)? Why?

26. Is there any monitoring e.g. water quality, beach cleanliness and safety? If yes, what is a form of monitoring? Who are involved? How is the process? What kind of action is taken after the monitoring? It not, why not?

27. Is there any coordination from other agencies/departments in managing the beaches (nightlife and music festival)? If yes, what is it? If not, why not?

\section{Facility and service issues}

28. Which facilities and services are required at the beach area (nightlife and music festival)? Why?

29. What kinds of infrastructure and facilities need to be provided by a public sector for better management of private beaches?

30. In what ways and to what extent do the speedboats and ferries represent the linkage between Pattaya and Larn island?

31. In what ways and to what extent can the new airport and road improvement have an impact to Pattaya?

Marketing issues

32. What is your expectation from the new airport and road improvement regarding (your business/agency and) tourism in Pattaya?

33. Which activities are practised to respond that expectation and benefit tourism marketing of Pattaya?

34. In what ways and to what extent is the beach environmental quality index corresponded to tourism marketing of the destination?

\section{General issues}

35. Overall, are you satisfied with management of Pattaya (in relation to beaches, nightlife and music festival)? Why is that?

36. Are there any aspects that might be improved? Are there any other points you would like to raise with regard to the management of the destination?

37. In the earlier phase of my research, I developed the following concept of destination management.

"Tourism destination management is the collaboration of relevant agencies responsible in operating multiple tourism products at the destination in a way to create positive tourism atmosphere, to enhance the destination character and to attract and serve tourism demand. Broadly, it can be practised through the integration of management functions and management resources from all relevant responsible agencies."

To what extent does the management of Pattaya reflect this? Why is that? 